U.S. Department

of Transportation

National Highway

Traffic Safety

Administration

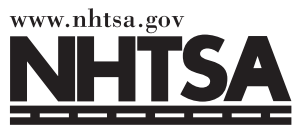

DOT HS 810648

August 2006

\title{
Pilot Test Of Heed The Speed, A Program To Reduce Speeds In Residential Neighborhoods
}

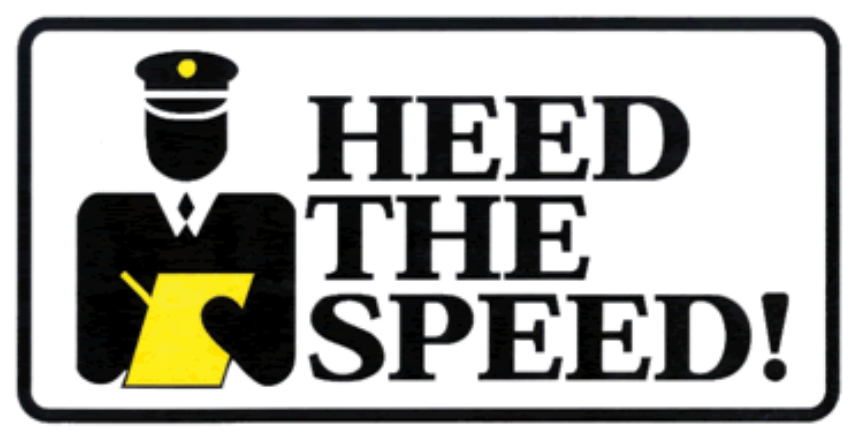

This document is available to the public from the National Technical Information Service, Springfield, Virginia 22161 
This publication is distributed by the U.S. Department of Transportation, National Highway Traffic Safety Administration, in the interest of information exchange. The opinions, findings, and conclusions expressed in this publication are those of the authors and not necessarily those of the Department of Transportation or the National Highway Traffic Safety Administration. The United States Government assumes no liability for its contents or use thereof. If trade or manufacturers' names or products are mentioned, it is because they are considered essential to the object of the publication and should not be construed as an endorsement. The United States Government does not endorse products or manufacturers. 
Technical Report Documentation Page

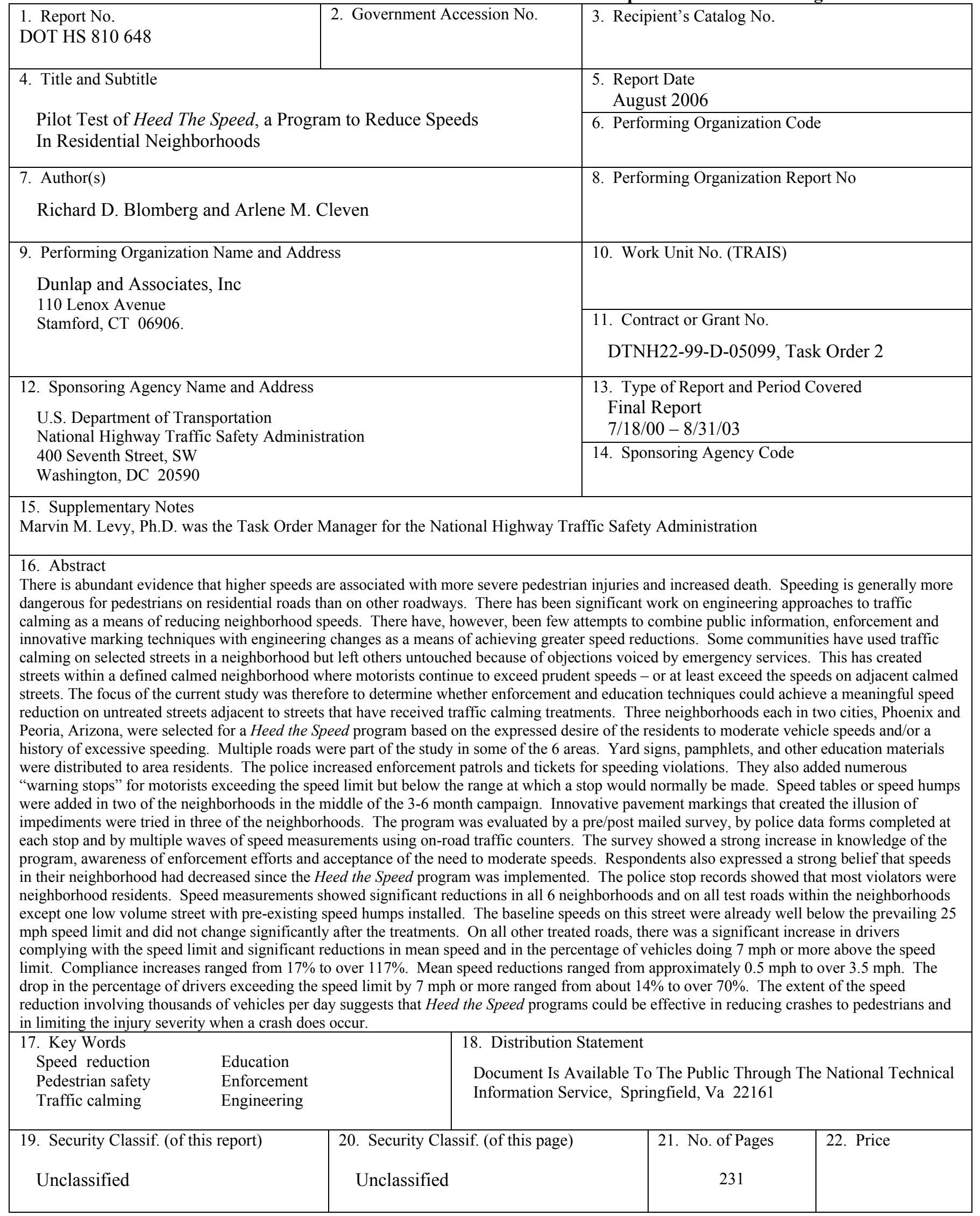

Form DOT F 1700.7 (8-72) 
This Page Intentionally Left Blank 


\section{DEPARTMENT OF TRANSPORTATION \\ NATIONAL HIGHWAY TRAFFIC SAFETY ADMINISTRATION}

TECHNICAL SUMMARY

\begin{tabular}{|c|c|}
\hline Contractor & Contract \\
\hline \multirow[t]{2}{*}{ Dunlap and Associates, Inc. } & DTNH22-99-D-05099 \\
\hline & Task Order 2 \\
\hline Report Title & Report Date \\
\hline $\begin{array}{l}\text { Pilot Test of Heed the Speed, a Program to Reduce Speeds } \\
\text { In Residential Neighborhoods }\end{array}$ & May 2006 \\
\hline
\end{tabular}

Report Author(s)

R.D. Blomberg and A.M. Cleven

There is abundant evidence that higher speeds are associated with more severe pedestrian injuries and death (Leaf and Preusser, 1999). One study has reported that 5 percent of pedestrians will die if struck by a vehicle traveling at 20 miles per hour, 45 percent will die if the striking vehicle is traveling at 30 miles per hour, 85 percent will die if the vehicle is traveling at 40 miles per hour, and almost all will die if the vehicle is traveling at 50 miles per hour (Department of Transport, 1997). In addition, a National Highway Traffic Safety Administration (NHTSA) national survey has revealed that drivers feel that speeding is more dangerous on residential roads than on other roadways, and that drivers believe that higher posted speeds will result in increased danger to neighborhood residents (Boyle, Dienstfrey, and Sothoron, 1998).

There has been significant work on engineering approaches to traffic calming as a means to reduce neighborhood speeds (c.f., Ewing, 1999; Stuster, Coffman, and Warren, 1998). NHTSA has noted, however, that there have been few attempts to combine public information and enforcement techniques with engineering changes as a means of achieving greater speed reductions. NHTSA therefore funded the current study whose objective was to develop and test a behavior-based program to reduce motorist speed in residential areas by adding education and enforcement to engineering.

It was determined that the study should focus on identifying the following types of neighborhoods/streets for this study:

- Neighborhoods/streets that have not been traffic calmed and where no traffic calming was planned - to permit a focus on the effects of education and enforcement alone on non-calmed streets.

- Neighborhoods/streets in which traffic calming already existed - to permit study of the effects of adding education and enforcement to existing traffic calming measures.

(Continued on additional pages)

"PREPARED FOR THE DEPARTMENT OF TRANSPORTATION, NATIONAL HIGHWAY TRAFFIC SAFETY ADMINISTRATION UNDER CONTRACT NO.: DTNH22-99-D-05099, TASK ORDER 2. .THE OPINIONS, FINDINGS, AND CONCLUSIONS EXPRESSED IN THIS PUBLICATION ARE THOSE OF THE AUTHORS AND NOT NECESSARILY THOSE OF THE NATIONAL HIGHWAY TRAFFIC SAFETY ADMINISTRATION." 
- Neighborhood streets that have not been traffic calmed but implementation of traffic calming measures was planned during the study period - to provide information on the effects of the concurrent implementation of education, enforcement, and engineering.

The study was conducted in two neighboring Arizona cities - Phoenix and Peoria. Three neighborhoods were selected for study in each city. In Peoria, they were the Desert Harbor/91 ${ }^{\text {st }}$ Avenue neighborhood, the Bell Park neighborhood, and $95^{\text {th }}$ Avenue. In Phoenix, they were Clarendon Avenue, Sweetwater Avenue, and the Moon Valley/Coral Gables neighborhood.

Heed the Speed was selected as the slogan for the speed reduction program and a logo was designed. Several educational materials were developed for the program including street and lawn signs that displayed the slogan and logo; print materials for homeowners, parents, and drivers (including high school drivers); press releases for the two cities; inputs for homeowner's association newsletters; and radio spots. These materials provided information on the relationship between various speeds and pedestrian injury severity in the event of a crash. Earned media included write-ups in local papers and participation in local television programs. Enforcement activities included special enforcement, training citizens to conduct neighborhood watches and deployment of speed trailers and photo speed enforcement trailers. Roadway treatments included installation of speed humps and tables and application of visual treatments to the roadway surface that gave an illusion of a roadway impediment or engineering treatment.

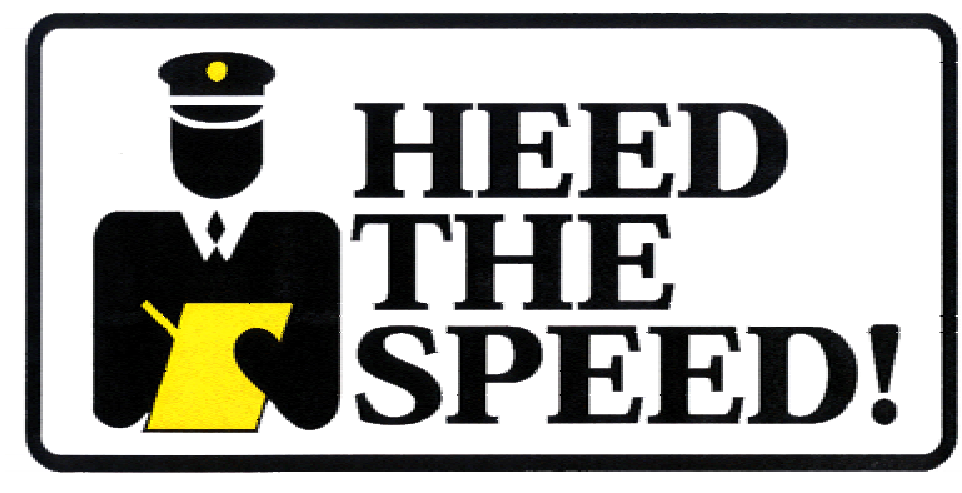

Program logo containing program slogan

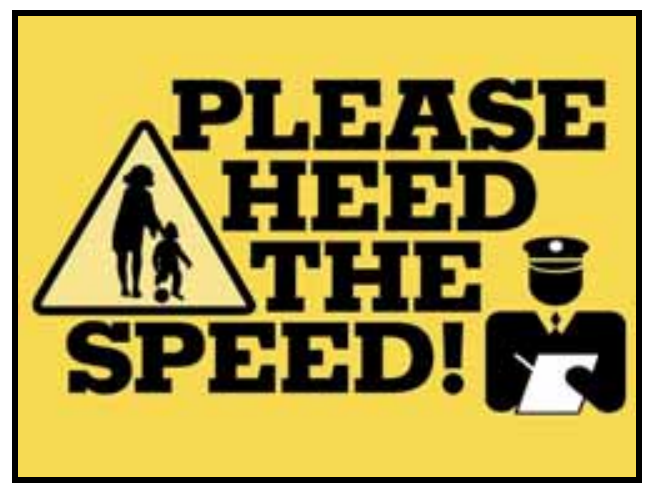

Program lawn sign

Four types of data were collected for the study - data collected by the police during routine stops made during special enforcement, information obtained from a survey of 
neighborhood residents, speed data on the various road segments, and process data obtained from project and neighborhood representatives. Each is described below.

Police Special Enforcement: Additional police patrol hours were incorporated in each neighborhood. During special enforcement, any vehicle traveling faster than the posted speed was subject to being stopped. When a stop was made, the officer approached the vehicle, announced the violation, and performed a routine check on the driver's license. For each driver stopped, the officer completed a motorist stop form that provided a profile on the drivers speeding in the various neighborhoods. The form showed that a majority of speeding drivers lived in or within a mile of the neighborhood in which they were stopped (Phoenix, 63\%; Peoria, $56 \%$ ). Most traveled on the road on which they were stopped at least once per week (Phoenix, $74 \%$; Peoria, 76\%). The average age of the drivers was 40 . Most drivers were traveling alone (Phoenix, 73\%; Peoria, 70\%). A large percentage of drivers wore their safety belts (Phoenix males, $81 \%$, and females, $89 \%$; Peoria males, $75 \%$ and females, 93\%). Tickets were given initially only to drivers who flagrantly disobeyed the law. As the study progressed, more traditional forms of ticketing were used. Five percent of the stopped Peoria drivers were given tickets for speeding; 52 percent of those stopped in Phoenix were given speeding tickets. Literature on the dangers of speeding was given to 97 percent of the drivers stopped in Peoria and 41 percent of those stopped in Phoenix.

Neighborhood Survey: A one-page survey form was designed to assess awareness of the program by neighborhood residents. Specifically, residents were asked if they noticed program components (publicity, police involvement, and roadway treatments) and if they noticed changes in vehicle speeds in the neighborhood. The survey was mailed to half of the neighborhood residents prior to the start of the program and to the other half as a follow-on after completion of the program (in Peoria) and after the installation of roadway treatments (in Phoenix). Pre-program and follow-on survey response rates in Peoria were 58 percent and 62 percent, respectively. Comparable returns in Phoenix were 60 percent and 63 percent.

All neighborhoods in both cities exhibited a significant increase in awareness of program publicity during the follow-on survey except for one neighborhood in Phoenix (Clarendon) that had no neighborhood association or vocal spokespersons and is predominately Spanish-speaking. There was a significant increase in awareness of publicity related to speeding with three neighborhoods showing a doubling or more in the percentage of people indicating they were exposed to publicity on speed control. The specific publicity item that received the largest proportion of post-program mentions in both cities consisted of the program signs (with reports ranging from $52 \%$ to $83 \%$ of the respondents), except for the Clarendon neighborhood where the percentage was 13. Flyers, bulletins, and newsletters were also mentioned, as were mail/letters, meetings, and newspapers, although the mentions for some neighborhoods were not large.

With regard to police involvement, the specific activities mentioned most frequently and considered to be definitely or probably program-related were visible enforcement (ranging from $51 \%$ to $63 \%$ ) and radar checks (ranging from $14 \%$ to $46 \%$ ). Deployment of the speed trailer was noted in all Peoria neighborhoods. The photo speed enforcement trailer was noted in the Moon Valley/Coral Gables neighborhood of Phoenix.

With regard to roadway treatments, signs again were mentioned frequently by respondents from all neighborhoods except for Clarendon. In addition, respondents in each 
neighborhood noticed the roadway visual treatments if they had been installed in the respondent's neighborhood as part of the program

Respondents were asked to rate the speeds in their neighborhoods compared to six months ago. With the exception of Clarendon, the majority of respondents in the remaining neighborhoods reported a perceived decrease in speeding.

A subjective assessment of each survey response by a project staff member led to the judgment that more than half of the survey respondents were aware of the key elements of the Heed the Speed program. This suggests that there is a basis for attributing any significant speed reductions in the test neighborhoods across the study period to the effects of Heed the Speed.

Speed Data: The six neighborhoods selected for study involved 10 studied road segments. Speed data were collected on all 10 segments by means of automated traffic counters. The devices consisted of multiple pneumatic tubes placed on the roadway to record the presence of a vehicle and its speed. Five waves of data were collected in Peoria except for $95^{\text {th }}$ Avenue where four waves were collected. Three waves were collected in Phoenix except on one segment that had five waves. The following measures were used to examine speed:

- Average speed on the road segment (mean speed)

- Mean difference in speed from the baseline value

- Average speed above the speed limit (mean above limit)

- Average speed of those exceeding the speed limit (mean of speeders)

- The percentage of drivers going the speed limit or less (complying with the limit), over the limit but less than seven miles per hour over, and seven miles per hour or more over the limit

(Speed data are reported herein to three decimal places for convenience since that is the format of the output from the statistical software employed. The presence of three decimals is not intended to imply either that the measurements were that precise or that a precision of three decimal places was required for statistical inference testing.)

Since the primary objective of the statistical analysis was to assess the relationship between the various speed countermeasures and reductions in speed, ANOVA was the indicated primary statistical technique. Chi-square tests were used to evaluate effects on certain binary and nominal transforms of the speed scale, e.g., proportion driving seven or more miles over the speed limit. The speed data were analyzed as a set of 10 case studies. Results are summarized in the table on the next page and discussed briefly below together with a description of each test road:

Peoria $-84^{\text {th }}$ Avenue: The $84^{\text {th }}$ Avenue test segment is part of the Bell Park neighborhood. It is a typical residential street with a $25 \mathrm{mph}$ speed limit. It received a moderateto-high education effort and some enforcement. Both speed tables and an innovative visual treatment known as 3-D markings were installed as part of the program. The results were quite dramatic. The initial drop in mean speed following the installation of speed tables (3.088 $\mathrm{mph})$ was almost completely sustained two months later $(2.627 \mathrm{mph})$. Also, driver compliance to the posted speed limit more than doubled, and speeds $7+$ mph over the limit decreased by about half. 
Summary of Countermeasures Implemented and Speed Reductions by Test Segment

\begin{tabular}{|c|c|c|c|c|c|c|c|c|c|}
\hline \multirow[b]{2}{*}{$\begin{array}{l}\text { TEST } \\
\text { SEGMENT }\end{array}$} & \multicolumn{9}{|c|}{ COUNTERMEASURE TYPE } \\
\hline & $\begin{array}{l}\text { Education } \\
\text { (as Reported } \\
\text { by } \\
\text { Participants) }\end{array}$ & $\begin{array}{l}\text { Special } \\
\text { Enforce- } \\
\text { ment (as } \\
\text { Reported } \\
\text { by Police) }\end{array}$ & $\begin{array}{l}\text { Pre- } \\
\text { Existing } \\
\text { Vertical } \\
\text { Treat- } \\
\text { ments } \\
\text { On Test } \\
\text { Road }\end{array}$ & $\begin{array}{l}\text { Pre- } \\
\text { Existing } \\
\text { Vertical } \\
\text { Treat- } \\
\text { ments } \\
\text { On } \\
\text { Adjacent } \\
\text { Roads }\end{array}$ & $\begin{array}{l}\text { New } \\
\text { Vertical } \\
\text { Treat- } \\
\text { ments } \\
\text { on Test } \\
\text { Road }\end{array}$ & $\begin{array}{l}\text { 3-D" } \\
\text { Marking }\end{array}$ & Tyregrip $^{\mathrm{TM}}$ & $\begin{array}{l}\% \text { Increase } \\
\text { in } \\
\text { Compliance } \\
\text { to Posted } \\
\text { Speed Limit }\end{array}$ & $\begin{array}{l}\% \\
\text { Reduction } \\
\text { in Speeds } \\
7+\text { mph } \\
\text { Over the } \\
\text { Limit* }\end{array}$ \\
\hline $\begin{array}{l}\text { Sweetwater } \\
(\text { Table } 65)^{* *}\end{array}$ & $\begin{array}{l}\text { Intensive by } \\
\text { active } \\
\text { residents }\end{array}$ & $\begin{array}{l}\text { Very high } \\
\text { prompted } \\
\text { by citizen } \\
\text { complaints }\end{array}$ & & $\sqrt{ }$ & & & $\sqrt{ }$ & $115.2 \%$ & $47.4 \%$ \\
\hline $\begin{array}{l}\text { Clarendon } \\
\text { (Table 64) }\end{array}$ & $\begin{array}{l}\text { Mostly by } \\
\text { police and } \\
\text { city personnel } \\
\text { English and } \\
\text { Spanish }\end{array}$ & High & $\sqrt{ }$ & $\sqrt{ }$ & & & & $23.9 \%$ & $\begin{array}{c}69.5 \% \\
\text { (Speed } \\
\text { between } \\
\text { existing } \\
\text { speed } \\
\text { humps) }\end{array}$ \\
\hline $\begin{array}{l}\text { Moon Valley } \\
\text { East/West } \\
\text { (Table 66) }\end{array}$ & \multirow{4}{*}{$\begin{array}{l}\text { Very active } \\
\text { and involved } \\
\text { neighborhood } \\
\text { association }\end{array}$} & \multirow{4}{*}{ High } & & & & & & $30.7 \%$ & $28.6 \%$ \\
\hline $\begin{array}{l}\text { Moon Valley } \\
\text { North/South } \\
\text { (Table 67) } \\
\end{array}$ & & & & & $\sqrt{ }$ & & & $117.8 \%$ & $59.4 \%$ \\
\hline $\begin{array}{l}\text { Coral } \\
\text { Gables } \\
\text { East/West } \\
\text { (Table 68) } \\
\end{array}$ & & & & & & $\sqrt{ }$ & & $93.8 \%$ & $61.8 \%$ \\
\hline $\begin{array}{l}\text { Coral } \\
\text { Gables } \\
\text { North/South } \\
\text { (Table 69) } \\
\end{array}$ & & & & & & & $\sqrt{ }$ & $41.4 \%$ & $44.8 \%$ \\
\hline \multicolumn{10}{|c|}{ Peoria } \\
\hline $\begin{array}{l}\text { Bell Park } \\
\text { 85 }^{\text {th }} \text { Lane } \\
(\text { Table 61) }\end{array}$ & $\begin{array}{l}\text { Moderately } \\
\text { active } \\
\text { neighborhood } \\
\text { association }\end{array}$ & $\begin{array}{l}\text { Moderate - } \\
\text { quiet side } \\
\text { street w/o } \\
\text { a speed } \\
\text { problem } \\
\end{array}$ & $\sqrt{ }$ & & & $\sqrt{ }$ & & $2.4 \% * * *$ & $\mathrm{~N} / \mathrm{A} * * * *$ \\
\hline $\begin{array}{l}\text { Desert } \\
\text { Harbor } \\
\text { 91 st Ave. } \\
\text { (Table 62) }\end{array}$ & $\begin{array}{l}\text { Very active, } \\
\text { innovative } \\
\text { and involved } \\
\text { neighborhood } \\
\text { association }\end{array}$ & $\begin{array}{l}\text { Very high } \\
\text { prompted } \\
\text { by citizen } \\
\text { complaints }\end{array}$ & & & & & & $17.1 \%$ & $14.1 \%$ \\
\hline $\begin{array}{l}\text { 95 }^{\text {th }} \text { Ave. } \\
\text { (Table 63) }\end{array}$ & $\begin{array}{l}\text { Some citizen } \\
\text { involvement } \\
\text { with direct } \\
\text { efforts of city } \\
\text { personnel }\end{array}$ & High & & & & $\sqrt{ }$ & & $23.5 \%$ & $39.7 \%$ \\
\hline
\end{tabular}

*Between initial and final measure at each site

** Location of detailed speed results within the body of the report

$* * *$ Initial compliance on $85^{\text {th }}$ Lane was $86.7 \%$

$* * * *$ A total of only 11 vehicles were going $7+$ over the limit in the first and last measurements combined (5 and 6 , respectively) 


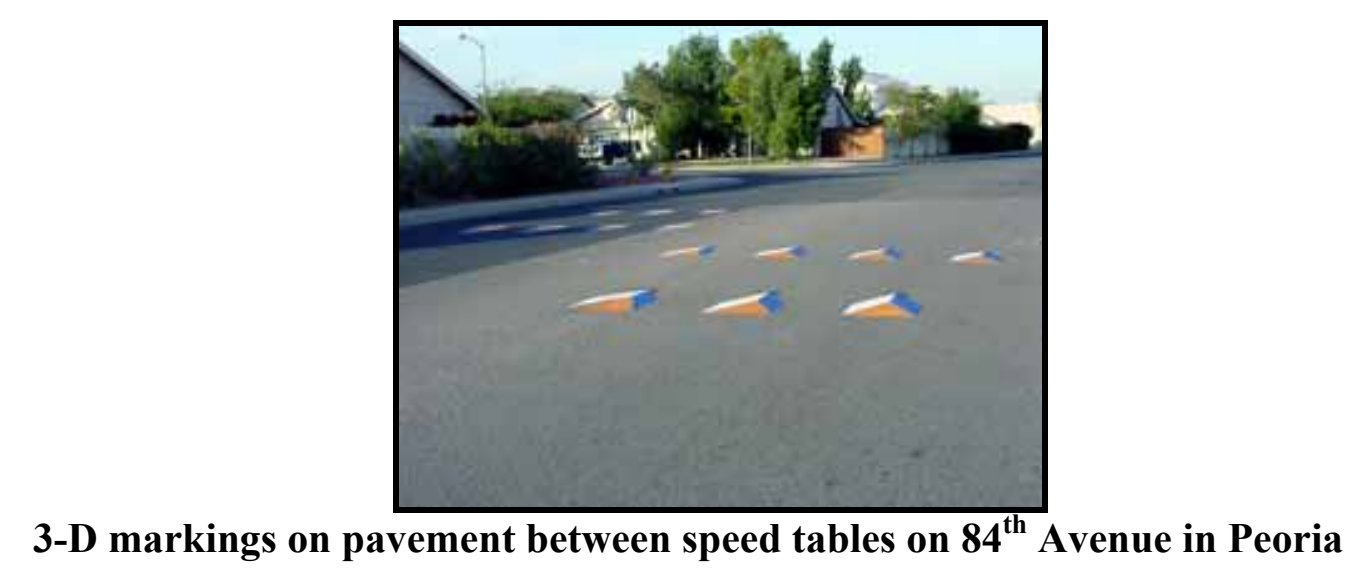

Peoria $-85^{\text {th }}$ Lane: This is a quiet side street off $84^{\text {th }}$ Avenue in Bell Park with a $25 \mathrm{mph}$ speed limit. It had three speed humps installed well before the study began, but the residents wanted another hump because they thought the existing installations were too far apart. There was some education on this street from the yard and fixed signs, but little enforcement because of the low traffic volumes and benign speed profile. The 3-D markings were installed during the program. There was no meaningful change on $85^{\text {th }}$ Lane, which is not surprising given the low baseline speed (19.675 $\mathrm{mph}$ ) and the extremely small number of drivers going seven or more miles over the limit (5 and 6 in the first and last measurements, respectively).

Peoria-91st Avenue: The $91^{\text {st }}$ Avenue test segment is a 78 foot wide street containing four travel lanes and a 28 foot wide landscaped center median. The street is conducive to high speeds and has a $30 \mathrm{mph}$ speed limit. No roadway treatments, either physical traffic calming or visual treatment, were applied. The education program was intensive and sustained because of the high degree of interest of the neighborhood association. Enforcement was also applied because of the known propensity for speeding and the pressure on the police from the residents. The initial education and enforcement efforts produced a significant reduction in mean speed of $1.283 \mathrm{mph}$. After a return toward baseline, the renewed efforts of the neighborhood association and police revived the initial impact. Although the effect was relatively small compared with the streets that had physical changes, it appears to have come almost entirely from drivers in the highest speed class. The proportion of vehicles going over the limit but less than seven miles per hour over stayed virtually constant while the percentage at or under the limit increased and those going seven or more miles per hour over the limit decreased. The mean speed above the speed limit was also down significantly in all post waves.

Peoria $-95^{\text {th }}$ Avenue: This is a straight roadway with a $30 \mathrm{mph}$ speed limit. In addition to a moderate-to-high level of education and moderate enforcement, five sets of 3-D markings were placed on the roadway during the study. The initial education and enforcement produced a noteworthy effect with a drop in mean speed of $1.369 \mathrm{mph}$ and a particularly large drop in the number of high-speed drivers and the mean of their speeds. This effect increased to $1.933 \mathrm{mph}$ with the addition of the 3-D markings and was still evident, although somewhat diminished (1.029 $\mathrm{mph})$, at the end of the data collection period.

Phoenix - Clarendon: Clarendon is a street with a $25 \mathrm{mph}$ speed limit that had existing speed humps. Residents were complaining that the existing vertical treatments were spaced too far apart thereby allowing motorists to speed between the humps. There is no neighborhood association for Clarendon, and a large proportion of the population is Spanish-speaking. As a 
result, the education campaign likely had moderate intensity even though many of the materials were translated into Spanish. Police enforcement was applied, but at a lower level than at other sites since the baseline speeds were well below the posted limit. The mean speeds at the two measurement locations between the humps showed a significant drop $(2.506 \mathrm{mph})$ that was sustained through two post data collection waves. The reduction in drivers going seven mph or more over the prevailing $25 \mathrm{mph}$ limit (from $16.7 \%$ to $5.1 \%$ ) was particularly noteworthy.

Phoenix-Sweetwater: Sweetwater Avenue received intensive education and enforcement spurred by the efforts of a vocal and active neighborhood association. In addition, Tyregrip $^{\mathrm{TM}}$ material (a pavement surface visual treatment) was installed during the study period. The results showed almost a 50-percent reduction in the number of drivers going seven mph or more over the posted limit. The reduction was largest in the last data collection wave. The mean speed of the speeders also was reduced markedly in the last two data collection waves when compared with the baseline (3.610 $\mathrm{mph}$ and $3.213 \mathrm{mph}$, respectively). The reduction in the mean speed above the limit of speeders from $8.017 \mathrm{mph}$ in the next-to-last wave to $7.634 \mathrm{mph}$ in the last wave was also statistically significant $(\mathrm{p}<.001)$. It should be noted that across the three waves of measurement the shift in speeds was largest to the lowest category (under the speed limit). This category more than doubled. At the same time, the intermediate category of people going less than seven mph above the limit went from 28.8 percent to 42.3 percent, an increase of 46.9 percent. The mean of speeders also showed continued improvement. This suggests that the Tyregrip $^{\mathrm{TM}}$ installation may have yielded a further moderation in the most aberrant speeds even though the mean speed rose slightly. Since there was only a single wave of measurement after the appearance of the Tyregrip ${ }^{\mathrm{TM}}$, no inference can be drawn concerning its long-term effectiveness.

Phoenix - Moon Valley Drive East/West Segment: Moon Valley Drive is a $25 \mathrm{mph}$ speed limit road with a segment that runs east and west on which only education and enforcement were applied. Significant mean speed reductions $(1.578 \mathrm{mph})$ were achieved without the use of any physical measures - a reduction in average speed and a shift to the lower class intervals from the seven or more mph over the limit category. A particularly interesting aspect of the results at this site was that the effect was maintained and even increased significantly between the last two waves of data collection. This suggests the possibility of some persistence of the education plus enforcement approach.

Phoenix - Moon Valley Drive North/South Segment: This segment of Moon Valley Drive running north and south received essentially the same education and enforcement as the east/west segment but also had two speed humps installed during the study program. The speed limit on this segment is also $25 \mathrm{mph}$. The results indicated that the effect of education and enforcement alone on speed on this roadway, although significant $(0.693 \mathrm{mph})$, was somewhat less than that on the east/west segment of Moon Valley Drive. The influence of the addition of a speed hump before the last data collection wave was large $(3.233 \mathrm{mph})$ and consistent with what was seen on $84^{\text {th }}$ Avenue in Peoria.

Phoenix - Coral Gables Drive East/West Segment: The east/west segment of Coral Gables Drive was treated with 3-D and Tyregrip ${ }^{\mathrm{TM}}$ materials. There were also education and enforcement countermeasures. Overall speed was below the baseline in excess of two mph in all post waves. The last two waves show markedly lower speeds by speeders. The addition of Tyregrip $^{\mathrm{TM}}$ was associated with a significant increase of $0.489 \mathrm{mph}$ in overall speed but a significant decrease of $0.434 \mathrm{mph}$ in the mean speed of speeders between the last two data collection waves. 
Phoenix - Coral Gables Drive North/South Segment: The north/south portion of Coral Gables Drive is wide and lined with expensive single-family homes. This segment received enforcement and education as well as a Tyregrip ${ }^{\mathrm{TM}}$ installation between the last two data collection waves. Results showed a reduction in mean speed of as much as $1.470 \mathrm{mph}$ and a decrease in the percentage of speeders traveling seven mph or more over the speed limit of 44.8 percent.

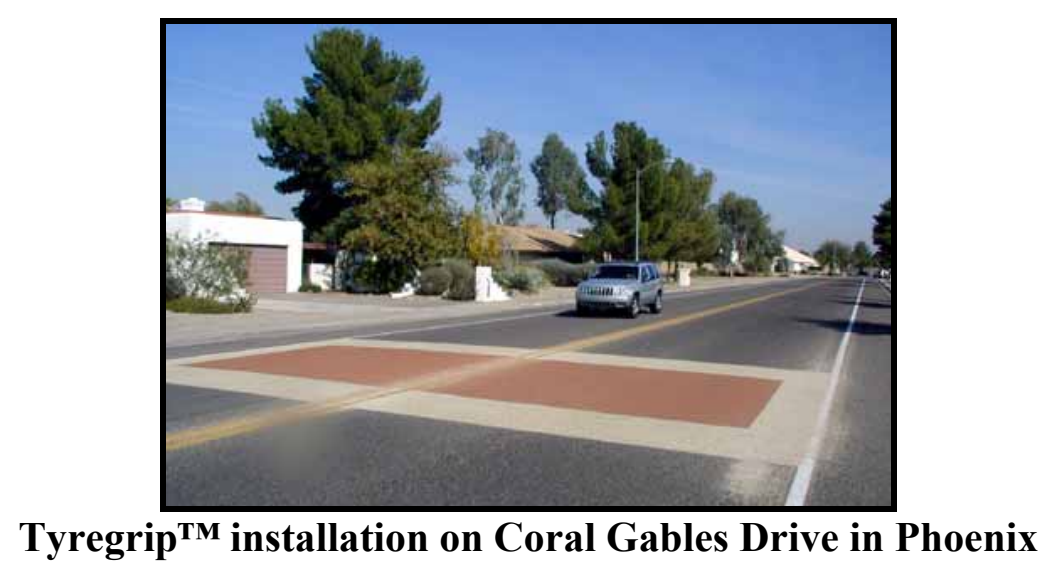

Summary of Speed Results: The large samples of speed data indicated a consistent and operationally meaningful pattern of reductions in all neighborhoods and on all test segments except $85^{\text {th }}$ Lane in Peoria. It is particularly noteworthy that the changes in the desired direction represent thousands of vehicles per day at each site. Clearly, the physical changes such as speed tables and speed humps produced the largest drops in speed. This was expected from previous research findings (e.g., Ewing, 1999). The general pattern of results across all of the test roads consisted of a decrease in mean speed accompanied by a moderate-to-large reduction of drivers exceeding the speed limit by seven mph or more and a concomitant increase in drivers proceeding at or below the speed limit. The mean speed above the speed limit and the mean speed of speeders also declined significantly at all sites except $85^{\text {th }}$ Lane in Peoria, the site with low traffic volumes and preexisting speed humps.

Summary of Traffic Volume Results: Traffic volumes varied across the various study measurements without a consistent pattern. Increases, decreases, and static volumes were noted. There is nothing in the traffic volume results, however, that suggests that the observed speed reduction effects were the result of diverting higher speed drivers to other, non-studied streets where they would continue to be a hazard. On $84^{\text {th }}$ Avenue, volume dropped 29.7 percent from the first (baseline) wave to the last measurement. Over the same time period, the number of vehicles traveling $7+$ mph over the speed limit decreased by 80.3 percent. On Sweetwater, the number of vehicles counted declined by 4,862 from the baseline to the last measurement while the number of vehicles measured at $7+$ mph over the limit dropped by 8,606 .

Process Data: Discussions on the program were held with project representatives and with representatives from the neighborhoods under study. The Heed the Speed program elicited mostly positive and constructive comments for improvement from both those who helped mount it and the citizens it affected. Together with the survey data, these follow-up commentaries on the process suggest that the concept of a multi-disciplinary, multi-faceted neighborhood speed reduction program was well accepted and could even be improved in future implementations based on the lessons learned. 
Discussion: The results show conclusively that Heed the Speed produced significant changes in speeding behavior in the six test neighborhoods. Nine of the 10 individual road segment analyses showed statistically significant and operationally meaningful reductions in speed after the application of the Heed the Speed countermeasures. The one segment that did not show a reduction, $85^{\text {th }}$ Lane in Peoria, had baseline mean speeds almost 5 mph below the speed limit.

On all nine segments that showed speed reductions, speeds were still statistically lower than prior to the Heed the Speed countermeasures at the final measurement wave, almost five months after the program began. In some cases, speeds seemed to be sliding back towards baseline. In several others, however, the speed reductions appeared to be holding or even improving as the program progressed.

The design of this study was not intended to isolate the effects of the individual countermeasures employed. Rather, the objective was to mount a multi-pronged effort focused on achieving speed reductions in the test neighborhoods. The realities of the implementation of the Heed the Speed program, however, afforded some insights into the effects of some of the individual interventions:

- Enforcement alone: Although not in total isolation because Spanish language educational materials were distributed, enforcement was a primary countermeasure in operation at the Clarendon Avenue test site in Phoenix. Thus, the reduction of approximately $2.5 \mathrm{mph}$ in mean speed between the speed humps on Clarendon can be largely attributed to the special police enforcement and its deterrent effect.

- Education alone: As with enforcement, there was no "pure" application of education in the test. The closest situation was likely the change between Wave 1 and Wave 2 at both 91st Avenue and 95th Avenue in Peoria. During this period, the Peoria police were focusing their enforcement primarily on 84th Avenue in Bell Park. Taking this view, the education efforts on 91st and 95th Avenues can be credited with the observed reductions of $1.283 \mathrm{mph}$ and $1.369 \mathrm{mph}$, respectively, in mean speeds. It is therefore reasonable to conclude that the Heed the Speed education materials contributed positively to the overall program effectiveness.

- Enforcement and education together: The data provide many replications of wave-towave speed measurements in which the operative countermeasures applied over the transition were education and enforcement in combination. The combination of education and enforcement only failed to yield a significant speed reduction in one instance - between Waves 1 and 2 at $84^{\text {th }}$ Avenue in Peoria. This may have been a result of the almost single-minded focus of the neighborhood leaders on getting speed tables installed as soon as possible. In all of the other cases in which education and enforcement operated alone, a significant mean speed reduction was achieved.

- Vertical treatments: The study included two new installations of vertical roadway treatments. Both were highly effective in reducing speeds, particularly the more significant speed infractions. It is not surprising to find that vertical engineering treatments are effective in achieving traffic calming. This has been reported before (e.g., Ewing, 1999). Their application within this study, however, provides both a replication 
of the effects reported in the literature and a benchmark against which to compare the other countermeasures used.

- Innovative Pavement Markings: The study employed two types of innovative pavement markings - 3-D markings and Tyregrip ${ }^{\mathrm{TM}}$ surfacing. Based on the findings and limitations of this study, it is reasonable to conclude that innovative pavement markings such as the ones tested are a viable addition to the speed reduction techniques available to program managers and merit serious consideration, particularly when used in combination with other types of speed reduction countermeasures. It might have been even more effective to integrate the innovative markings more closely with the remainder of the program, particularly the education materials by installing them earlier in the program timeline. This could help give the innovative markings a dual purpose as both the illusion of an impediment in the roadway and as a symbolic reminder to slow down.

Countermeasure Persistence: The present study was only able to examine very shortterm persistence of the countermeasures. Even over this limited period there were conflicting findings. In four of the nine successful tests mean speed reductions were higher in the last measurement wave than in any of the preceding waves. In the remaining five tests, the last measurement represented some increase in speed from the lowest mean value obtained. In one of these five, although the last wave was not the slowest, it was significantly slower than the immediately preceding wave. This pattern of results suggests that the present study simply did not have a good view of countermeasure persistence - short, intermediate or long term. Additional research would be needed to yield a definitive resolution of how long Heed the Speed continued to be successful.

Program Costs: Exclusive of the evaluation and associated research, Heed the Speed was implemented in all six neighborhoods and 10 road segments for approximately $\$ 55,000$ in out-of-pocket expenditures. These costs covered police overtime, acquiring lawn signs and stakes and printing education materials. Program participants in Peoria and Phoenix believe that subsequent Heed the Speed neighborhood programs can be mounted for $\$ 5,000$ per neighborhood or less.

Safety Implications of the Findings: There is no simple formula to relate speed reduction results to either reduced crashes or decreased injury severity. The clear finding from the literature review is that distributional shifts in the speeds of vehicles on residential streets such as those obtained in this study should provide for both a lower crash incidence and greater survivability if a crash does occur. When these shifts are applied to thousands of vehicles per day, as was the case on these test roads, a safety benefit is highly likely. Further, the success of Heed the Speed on nine of 10 test road segments suggests that the widespread implementation of the program would have a significant societal benefit. The low cost of the program means that achieving the potential safety benefits of Heed the Speed should be highly cost effective.

Lessons Learned: The answer to the basic research question addressed by this study is that education and enforcement can add to the effectiveness of physical traffic calming. It was also shown that at least in the short term a program such as Heed the Speed can produce speed reductions of a significant and meaningful magnitude on through streets and other roads within traffic calmed areas that were not candidates for physical treatments. 


\section{ACKNOWLEDGMENTS}

The authors wish to express their appreciation to the many individuals who supported the conduct of this study. They include people who aided in project planning as well as in the design, implementation, and evaluation of the countermeasure program.

The contributions of the following Phoenix representatives are acknowledged:

- Michael Cynecki, Street Transportation Department

- Sara Elco, Street Transportation Department

- Leticia Vargas, Street Transportation Department

- Lt. Emilien Sapon, Police Department

- Sgt. Rich Maiocco, Police Department

- Officer Sandor Rogoff, Police Department

The contributions of the following Peoria representatives are acknowledged:

- Scott Nodes, Engineering Department

- Kelly LaRosa, Engineering Department

- Sgt. Clark Collier, Police Department

The authors also wish to express their appreciation for the support of Sonny Yamamoto of SJS America who arranged for and provided most of the 3-D pavement markings for the project.

Although a study of this type would not have been possible without the support of those named above and many others who provided guidance, assistance, and resources, the findings and conclusions contained herein are solely those of the authors. 
This Page Intentionally Left Blank 


\section{TABLE OF CONTENTS}

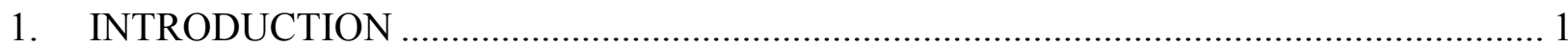

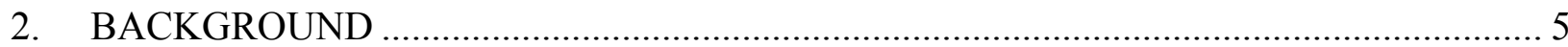

2.1 Literature Review Approach and Relevant Findings ................................................... 5

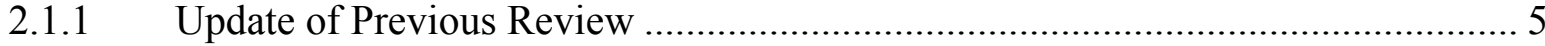

2.1.2 Pedestrian Safety Benefits of Speed Reduction.................................................... 7

$2.2 \quad$ Workshop on Speed-Reducing Countermeasures..................................................... 8

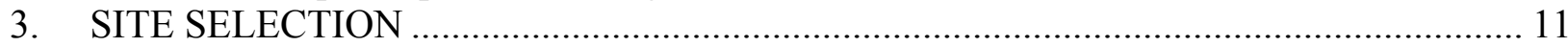

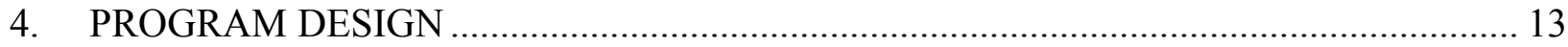

$4.1 \quad$ Approach

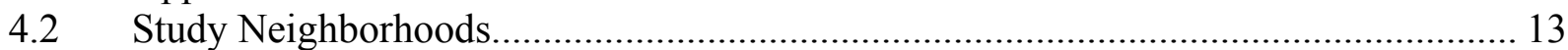

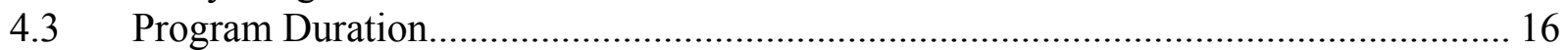

4.4 Program Organization, Slogan, and Logo.............................................................. 16

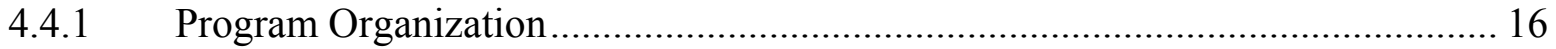

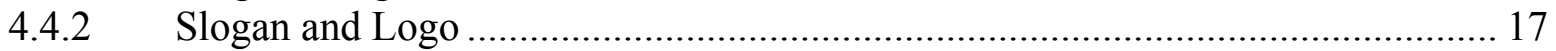

4.4.3 Homeowner's Association Meetings ................................................................. 17

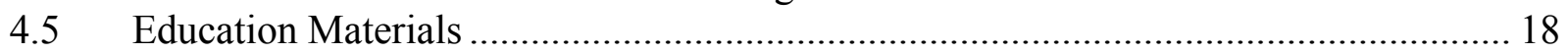

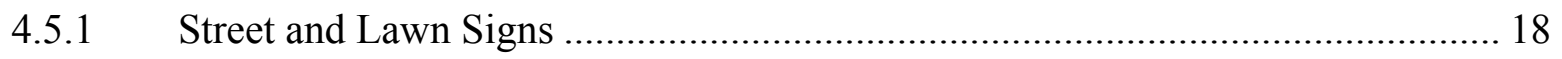

4.5.2 Printed Materials and Radio Spots................................................................ 19

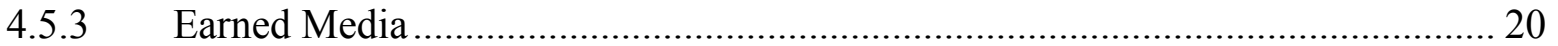

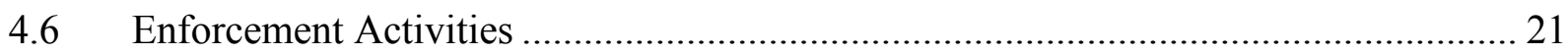

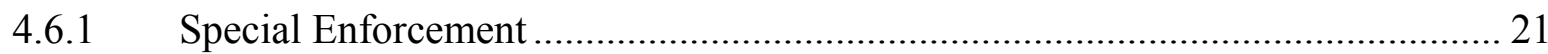

4.6.2 Neighborhood Speed Watches ......................................................................... 22

4.6.3 Deployment of Speed and Photo Speed Enforcement Trailers............................. 22

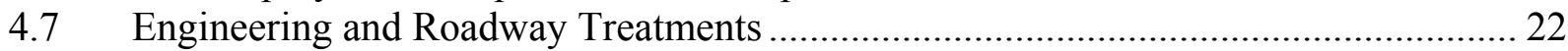

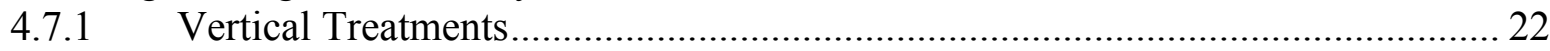

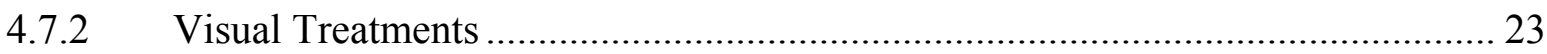

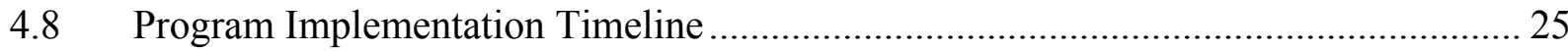

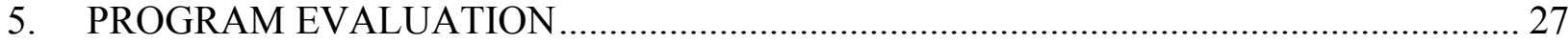

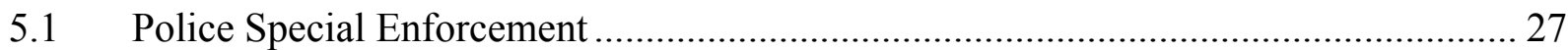

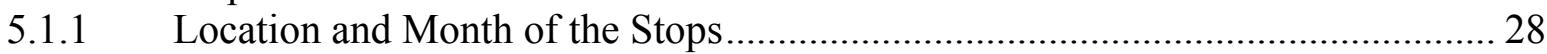

5.1.2 Proximity of Driver Address to Neighborhood ................................................... 30

5.1.3 Frequency of Travel on Road Stopped .............................................................. 31

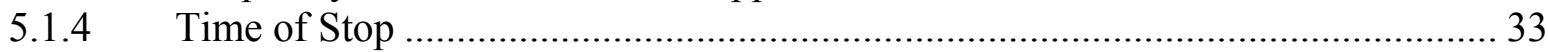

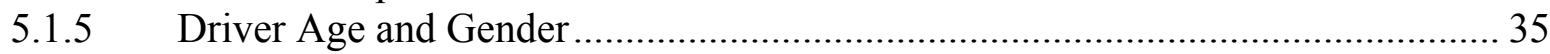

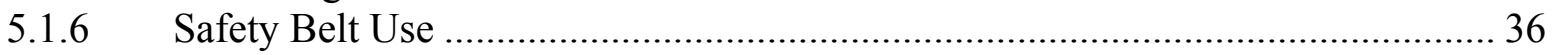

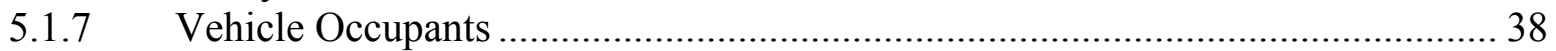

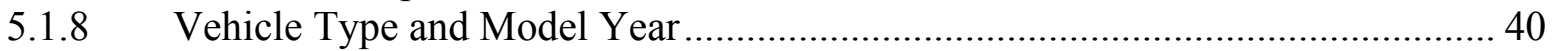

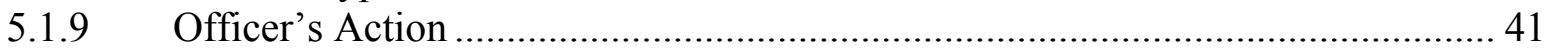

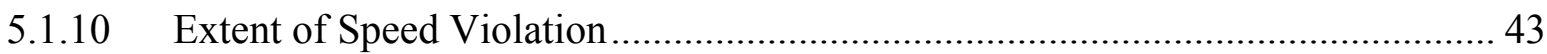

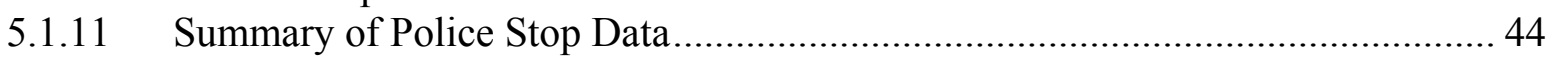

5.2 Knowledge and Exposure Survey …………….................................................. 46

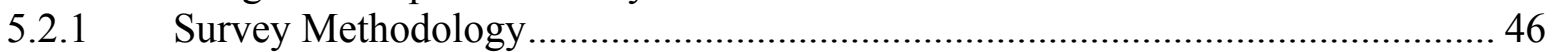

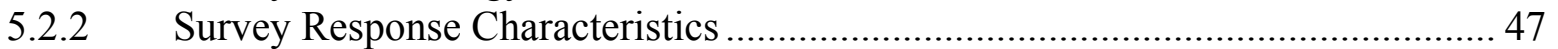

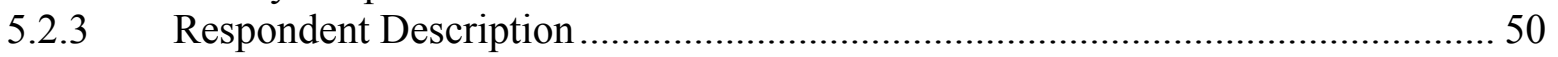

5.2.4 Awareness of Activities to Control Speeds ....................................................... 55

5.2.5 Awareness of Program Activity Categories........................................................ 56 
5.2.6 Awareness of Specific Publicity Activities........................................................ 59

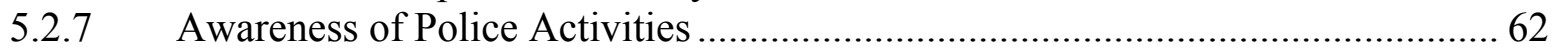

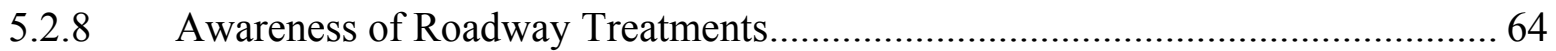

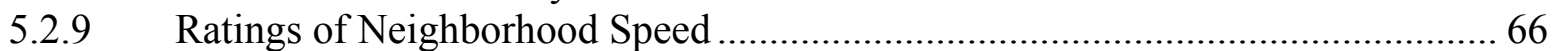

5.2.10 Respondent Exposure to the Heed the Speed Program .............................................. 69

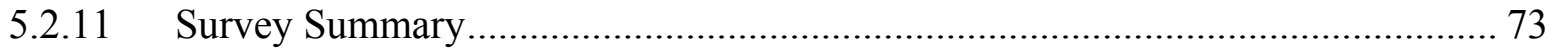

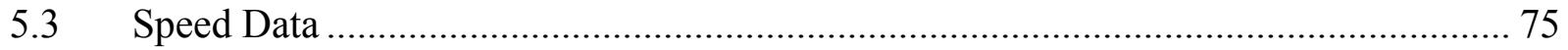

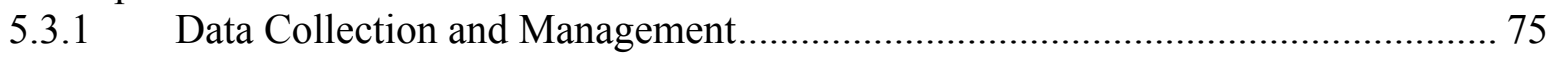

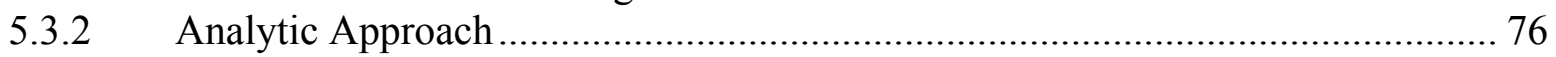

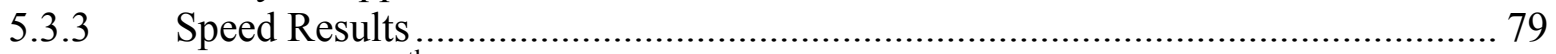

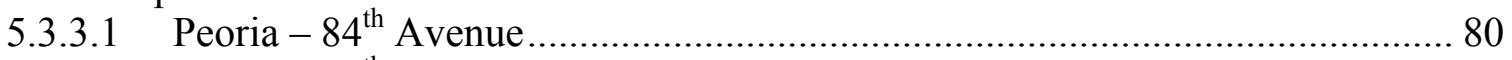

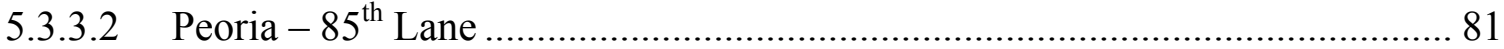

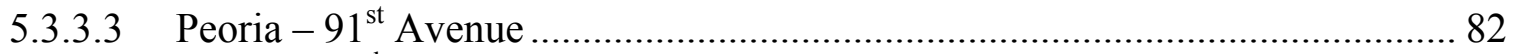

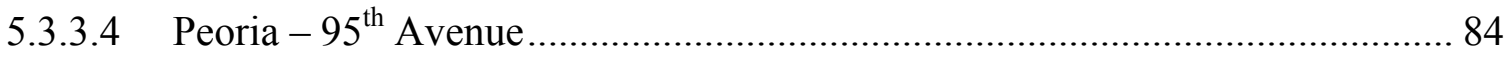

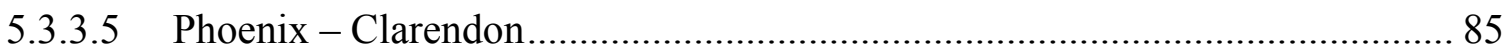

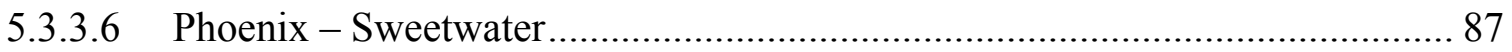

5.3.3.7 Phoenix - Moon Valley Drive East/West Segment........................................... 89

5.3.3.8 Phoenix - Moon Valley Drive North/South Segment ..................................... 90

5.3.3.9 Phoenix - Coral Gables Drive East/West Segment ............................................ 91

5.3.3.10 Phoenix - Coral Gables Drive North/South Segment.................................... 93

5.3.3.11 Summary of Speed Results ……………….............................................. 94

5.3.3.12 Summary of Traffic Volume Results ......................................................... 94

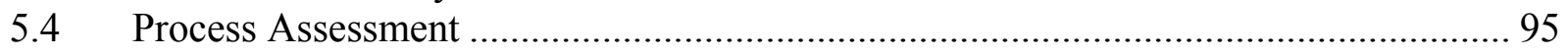

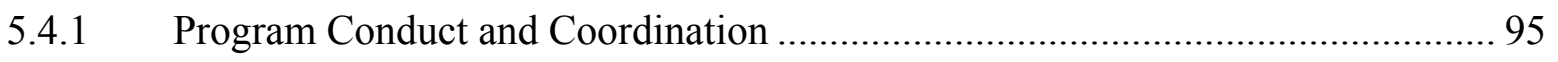

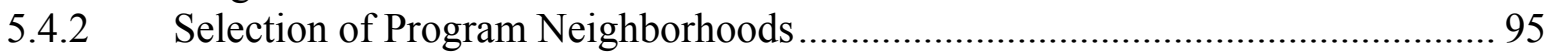

5.4.3 Neighborhood Speed Watch …………………................................................ 96

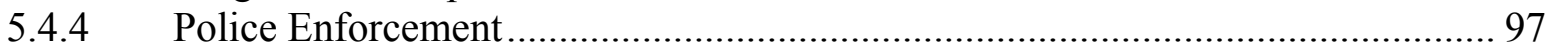

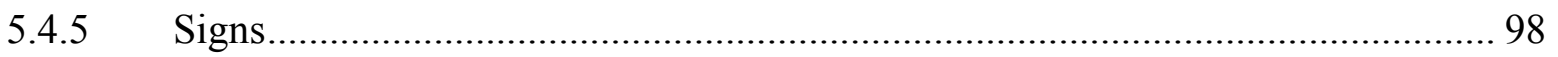

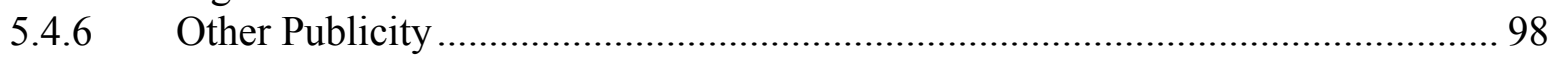

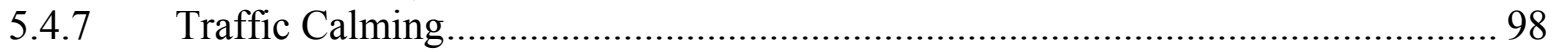

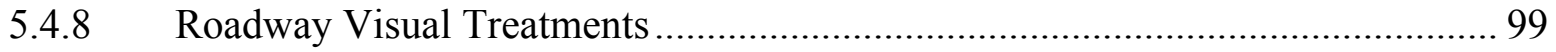

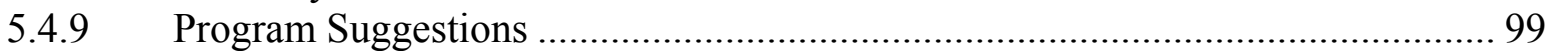

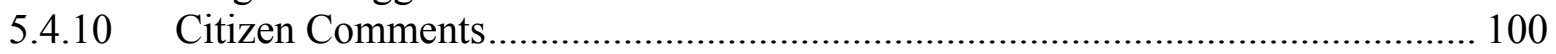

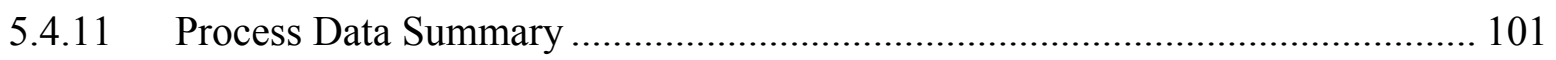

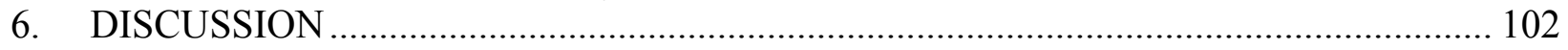

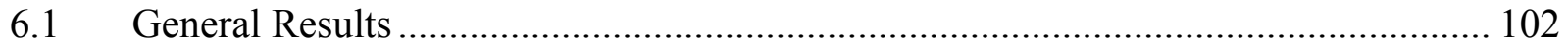

6.2 Effect of the Heed the Speed Program.................................................................... 103

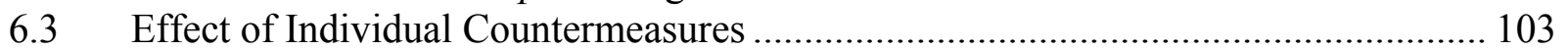

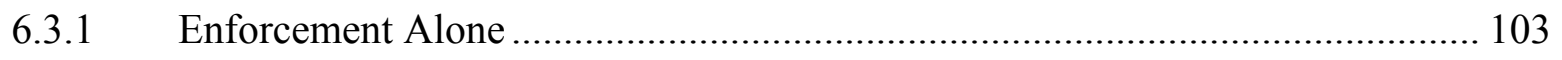

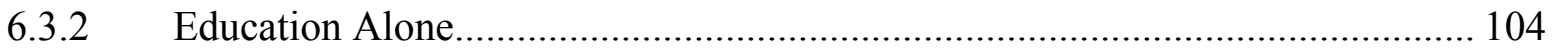

6.3.3 Education and Enforcement Together .............................................................. 104

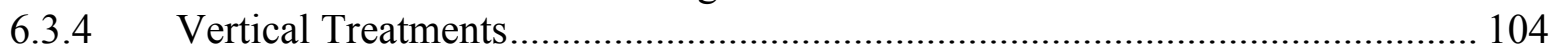

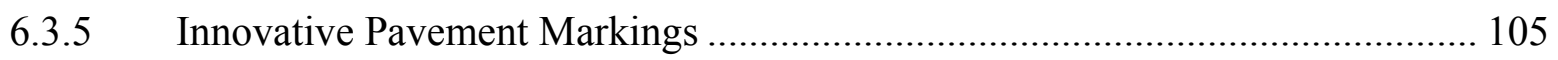

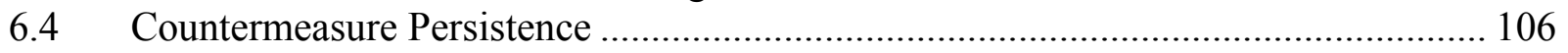

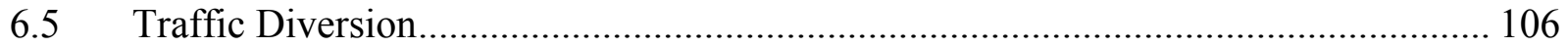

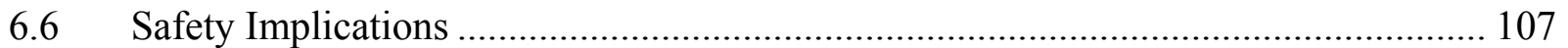

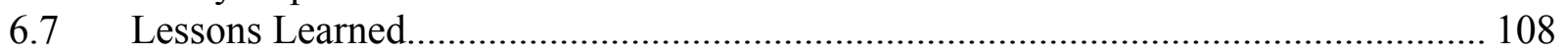

6.8 Guide for Future Heed the Speed Programs ........................................................... 109

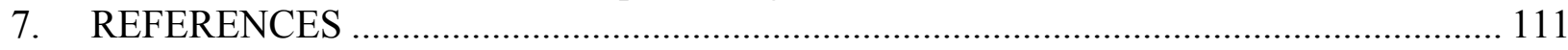




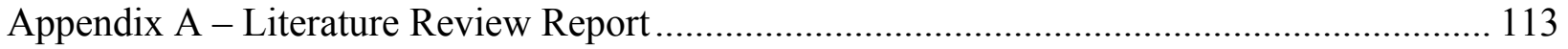

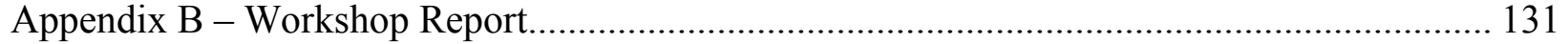

Appendix C - Program Countermeasure Materials .................................................................. 149

Appendix D - Program Data Collection Forms.................................................................... 178

Appendix E - Maps Of Phoenix And Peoria Study Areas ................................................. 186

Appendix F - Draft Heed The Speed Guide ........................................................................... 196 


\section{LIST OF TABLES}

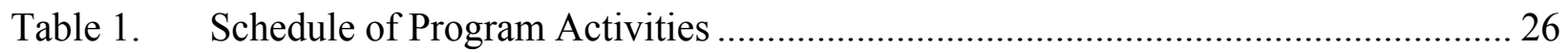

Table 2. $\quad$ Police Stops by Neighborhood and Study Month (Peoria)........................................ 29

Table 3. Police Stops by Neighborhood and Study Month (Phoenix) .................................... 29

Table 4. Proximity of Driver Address to Neighborhood (Peoria)............................................ 31

Table 5. Proximity of Driver Address to Neighborhood (Phoenix)........................................ 32

Table 6. Proximity of Driver Address to Neighborhood versus Frequency of Driver Travel

on Road Stopped (Peoria) .................................................................................... 32

Table 7. Proximity of Driver Address to Neighborhood versus Frequency of Driver Travel on Road Stopped (Phoenix) …………………………........................................... 33

Table 8. Time of Stop (Peoria and Phoenix) ............................................................................ 34

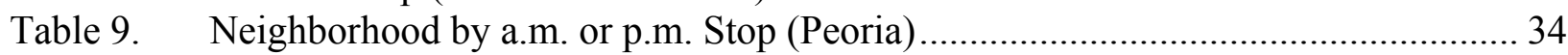

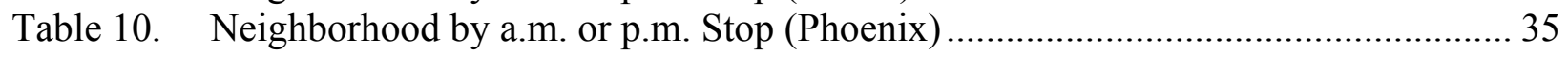

Table 11. Age Range and Gender of Drivers Stopped (Peoria)................................................ 36

Table 12. Age Range and Gender of Drivers Stopped (Phoenix) ……………………................ 36

Table 13. Driver Safety Belt Use versus Gender (Peoria) ........................................................ 37

Table 14. Driver Safety Belt Use versus Gender (Phoenix) ……….......................................... 37

Table 15. Driver Safety Belt Use versus Gender and Age Range (Peoria) ............................... 38

Table 16. Driver Safety Belt Use versus Gender and Age Range (Phoenix)........................... 39

Table 17. Number of People in the Stopped Vehicles (Peoria and Phoenix) ........................... 39

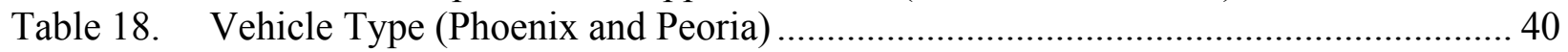

Table 19. Vehicle Model Year (Peoria and Phoenix) ……...................................................... 41

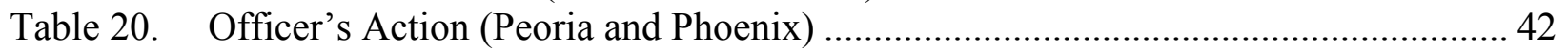

Table 21. Amounts that Stopped Vehicles Traveled Over Posted Speeds (Phoenix)............... 43

Table 22. Summary of Police Stop Form Data Collection (Peoria and Phoenix)...................... 44

Table 23. Profile of Stopped Peoria and Phoenix Speeders........................................................ 45

Table 24. Survey Returns as a Percentage of Surveys Delivered (All Neighborhoods)............ 47

Table 25. Survey Returns From Each City by Wave (All Neighborhoods) ………................... 48

Table 26. Awareness of Activities to Control Speeds in Neighborhoods.................................. 49

Table 27. Respondent Exposure to the Heed the Speed Program (Phoenix and Peoria) ........... 50

Table 28. How Long Respondents Have Lived in Their Current Neighborhoods

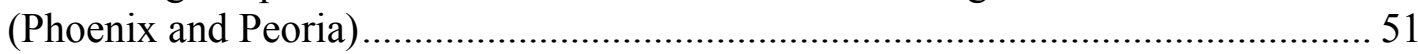

Table 29. How Long Respondents Have Lived in Their Current Neighborhoods (Peoria)...... 52

Table 30. How Long Respondents Have Lived in Their Current Neighborhoods (Phoenix)... 52

Table 31. Age of Respondents (Phoenix and Peoria) ………………………………….......... 53

Table 32. Age of Respondents by Neighborhood (Peoria) ..........................................................5 53

Table 33. Age of Respondents by Neighborhood (Phoenix) ..................................................... 54

Table 34. Gender of Respondents (Phoenix and Peoria) ........................................................... 54

Table 35. Gender of Respondents by Neighborhood (Peoria) ....................................................... 55

Table 36. Gender of Respondents by Neighborhood (Phoenix) .................................................. 55

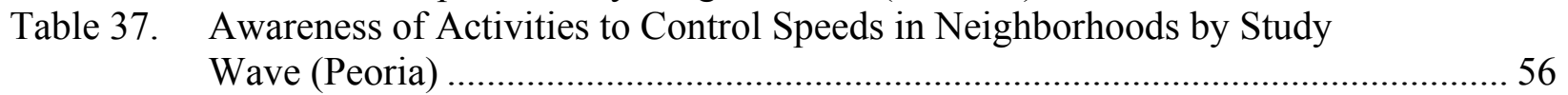

Table 38. Awareness of Activities to Control Speeds in Neighborhoods by Study

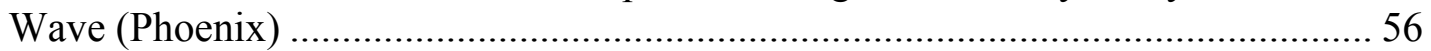

Table 39. Category of Awareness by Neighborhood (Peoria) .................................................. 57

Table 40. Category of Awareness by Neighborhood (Phoenix) ...............................................5 58 
Table 41. Comments on Publicity Made by Follow-On Survey Respondents

(Phoenix and Peoria).

Table 42. Comments on Publicity Made by Follow-On Survey Respondents by

Neighborhood (Peoria).

Table 43. Comments on Publicity Made by Follow-On Survey Respondents by

Neighborhood (Phoenix)....

Table 44. Comments on Police Involvement Made by Follow-On Survey Respondents (Phoenix and Peoria).

Table 45. Comments on Police Involvement Made by Follow-On Survey Respondents by Neighborhood (Peoria).

Table 46. Comments on Police Involvement Made by Follow-On Survey Respondents by Neighborhood (Phoenix).

Table 47. Comments on Roadway Changes Made by Follow-On Survey Respondents (Phoenix and Peoria).... 66

Table 48. Comments on Roadway Changes Made by Follow-On Survey Respondents by Neighborhood (Peoria).

Table 49. Comments on Roadway Changes Made by Follow-On Survey Respondents by Neighborhood (Phoenix). 68

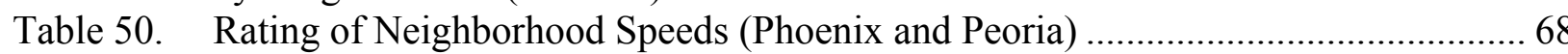

Table 51. Rating of Neighborhood Speeds by Neighborhood (Peoria) ................................. 69

Table 52. Rating of Neighborhood Speeds by Neighborhood (Phoenix) .............................. 70

Table 53. Respondent Follow-On Mention of Heed the Speed (Phoenix and Peoria).............. 70

Table 54. Respondent Follow-On Mention of Heed the Speed (Peoria) ................................. 71

Table 55. Respondent Follow-On Mention of Heed the Speed (Phoenix).............................. 71

Table 56. Respondent Follow-On Exposure to the Heed the Speed Program (Phoenix and Peoria)... .71

Table 57. Respondent Follow-On Exposure to the Heed the Speed Program by Neighborhood (Peoria).................................................................................... 73

Table 58. Respondent Follow-On Exposure to the Heed the Speed Program

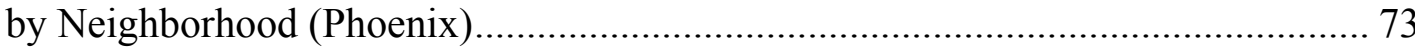

Table 59. Summary of Countermeasures Implemented on Each Test Segment ..................... 78

Table 60. Peoria 84 $4^{\text {th }}$ Avenue Speed Results ..................................................................... 80

Table 61. Peoria $-85^{\text {th }}$ Lane Speed Results................................................................... 82

Table 62. Peoria - 91 $1^{\text {st }}$ Avenue Speed Results................................................................. 83

Table 63. Peoria - 95 ${ }^{\text {th }}$ Avenue Speed Results ................................................................ 85

Table 64. Phoenix - Clarendon Speed Results (Only Sensors Between the Existing Speed Humps)............................................................................. 86

Table 65. Phoenix - Sweetwater Speed Results ............................................................. 87

Table 66. Phoenix - Moon Valley Drive East/West Segment Speed Results ....................... 89

Table 67. Phoenix - Moon Valley Drive North/South Segment Speed Results..................... 91

Table 68. Phoenix - Coral Gables Drive East/West Segment Speed Results........................ 92

Table 69. Phoenix - Coral Gables Drive North/South Segment Speed Results ..................... 93 


\section{LIST OF FIGURES}

Figure 1. Program Logo Containing Program Slogan...................................................... 17

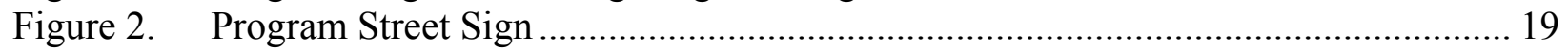

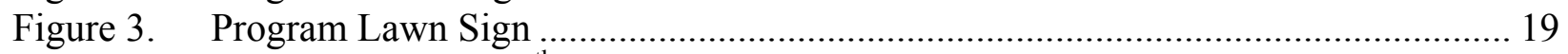

Figure 4. $\quad 3$-D Markings on $85^{\text {th }}$ Lane in Peoria.................................................................. 24

Figure 5. 3-D Markings on Top of Speed Table on $84^{\text {th }}$ Avenue in Peoria ........................... 24

Figure 6. 3-D Markings on Pavement Between Speed Tables on $84^{\text {th }}$ Avenue in Peoria........ 24

Figure 7. Tyregrip ${ }^{\text {TM }}$ Installation on Coral Gables Drive in Phoenix .................................. 25

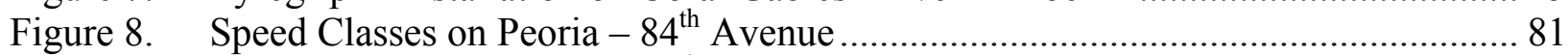

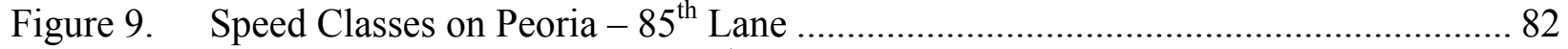

Figure 10. Speed Classes on Peoria $-91^{\text {st }}$ Avenue ......................................................... 84

Figure 11. Speed Classes on Peoria $-95^{\text {th }}$ Avenue ....................................................... 85

Figure 12. Speed Classes on Phoenix - Clarendon Between the Speed Humps.................. 87

Figure 13. Speed Classes on Phoenix - Sweetwater ......................................................... 88

Figure 14. Speed Classes on Phoenix - Moon Valley Drive East/West Segment ................ 90

Figure 15. Speed Classes on Phoenix - Moon Valley Drive North/South Segment............. 91

Figure 16. Speed Classes on Phoenix - Coral Gables East/West Segment ........................ 93

Figure 17. Speed Classes on Phoenix - Coral Gables North/South Segment...................... 94 


\section{INTRODUCTION}

This final report describes a research study that implemented and evaluated a program named Heed the Speed designed to reduce vehicle speeds in residential neighborhoods. The study was sponsored by the National Highway Traffic Safety Administration (NHTSA).

There is abundant evidence that higher speeds are associated with more severe pedestrian injuries and death (Leaf and Preusser, 1999). One study has reported that 5 percent of pedestrians will die if a vehicle traveling at 20 miles per hour strikes them (Department of Transport, 1997). The study further reported that 45 percent will die if the striking vehicle is traveling at 30 miles per hour, 85 percent will die if the vehicle is traveling at 40 miles per hour, and almost all will die if the vehicle is traveling at 50 miles per hour. In addition, a NHTSA national survey revealed that drivers feel that speeding is more dangerous on residential streets than on other roadways, and that drivers believe that higher posted speeds will result in increased danger to neighborhood residents (Boyle, Dienstfrey and Sothoron, 1998).

There has been significant work on engineering approaches to traffic calming as a means to reduce neighborhood speeds (c.f., Ewing, 1999, Stuster, Coffman, and Warren, 1998). There has also been research on the effects of enforcement and education on speeding behavior that suggests that the effects they achieve may be more transitory than those produced by the physical changes associated with traffic calming. NHTSA noted, however, that there have been few attempts to combine public information and enforcement techniques with engineering changes as a means of achieving greater speed reductions. NHTSA therefore funded the current study whose objective was to:

\section{Develop and test a behavior-based program to reduce motorist speed in residential areas by adding education and enforcement to engineering.}

Preliminary project discussions with professionals from areas with active traffic calming programs revealed that some communities have used traffic calming on selected streets in a neighborhood but left others untouched because of objections voiced by emergency services and others. This procedure has created streets within a defined calmed neighborhood where motorists can (and probably do) exceed prudent speeds - or at least exceed the speeds on adjacent streets. Other communities have used traffic calming on a street-by-street basis. This process typically has resulted in traffic calming on side streets, but collector/arterial streets have remained unchanged, again largely because of emergency services concerns. It therefore seemed reasonable to utilize enforcement and education to attempt to achieve on these untreated streets a level of calming consistent with that on the adjacent streets that have received physical calming treatments.

As a result of these discussions, it was determined that the study should focus on identifying the following types of streets/neighborhoods for this study:

- Neighborhoods/streets that have not been traffic calmed and where no traffic calming is planned. This focused on the effects of education and enforcement alone on non-calmed streets. 
- Neighborhoods/streets in which traffic calming has been in place for some time. This studied the effects of adding education and enforcement to existing traffic calming measures.

- Neighborhood streets that have not been traffic calmed but implementation of traffic calming measures is planned during the study period. This provided information on the effects of the concurrent implementation of education, enforcement, and engineering.

To achieve the objective of the study, the following tasks were conducted:

- Literature search. The identification and review of speed-related studies that have been completed since NHTSA produced its literature review on vehicle travel speeds (Leaf and Preusser, 1999).

- Expert workshop. A meeting of a panel of experts to explore the problem of speeding in neighborhoods, to identify promising countermeasures and to identify appropriate measures for use in assessing program success.

- Selection of test sites. Development of site selection criteria, personal contact with eligible cities to determine their interest in supporting the program, and final site selection. The availability and interest of two contiguous cities - one large and one small - resulted in the selection of two Arizona cities (Phoenix and Peoria) as test sites.

- Development of the countermeasure implementation and evaluation program.

Development of education countermeasures to be implemented in the test sites plus plans for implementing the education, enforcement, and engineering countermeasures. For this task, the police departments of both test cities agreed to complete a form on all drivers stopped for speeding in the neighborhoods during the study. In addition, the engineering departments of both cities sponsored surveys to assess community awareness of program activities and accomplishments and provided traffic volume and speed measurements.

- Evaluation of program results. Analysis of the police forms completed on drivers stopped for speeding, the survey returns, the speed data collected on all study streets, and the process data.

- Preparation of a community guide. Preparation of a guide to assist other communities in implementing speed reduction programs.

The subsequent sections of this final report describe the study approach and present the results and conclusions derived from the study:

- Section II provides background information regarding the literature reviewed and persons contacted and the expert workshop.

- Section III describes the site selection process for the two Arizona cities of Phoenix and Peoria. 
- Section IV describes the countermeasure program implemented in the two cities.

- Section $\mathrm{V}$ describes program evaluation procedures and results.

- Section VI provides a discussion of the results obtained from the study.

- Appendix A is a letter report of the results of the literature review conducted as part of the development of the study design.

- Appendix B contains a letter report documenting the activities and results of an expert panel session to generate ideas and provide guidance to the study design and evaluation.

- Appendix C contains black and white copies of program education countermeasures and supporting materials that were used in Peoria and Phoenix.

- Appendix D contains program data collection forms.

- Appendix E contains diagrams of the Phoenix and Peoria streets/neighborhoods that were studied.

- Appendix F contains a draft guide for communities to use when developing Heed the Speed programs. 


\section{This Page Intentionally Left Blank}




\section{BACKGROUND}

Two activities provided background information for the study. One consisted of a literature review on vehicle speeds to update an earlier review performed for NHTSA by Leaf and Preusser (1999). The second involved the selection of a panel of experts in traffic calming and speed management and conduct of a workshop to explore the speed problem, possible countermeasures, and possible evaluation measures. Each of these activities is described below.

\subsection{Literature Review Approach and Relevant Findings}

A review of the relevant literature was performed to help guide the study effort. There were two separate areas of focus. The first was an update of an extensive review previously performed for NHTSA (Leaf and Preusser, 1999). The second was a search for references that could relate speed reductions to specific pedestrian safety benefits.

\subsubsection{Update of Previous Review}

The purpose of this effort was to identify relevant materials that had been produced since NHTSA's previous report on the effects of speeding (Leaf and Preusser, 1999) was compiled. Searches were made of the Transportation Research Board Transportation Research Information Services (TRIS) database to identify studies published after 1998 on the topics of traffic calming, speed, enforcement, education, and pedestrian safety. In addition, contact was made with selected NHTSA and Federal Highway Administration (FHWA) representatives, with bicycle and pedestrian professionals, and with contributors to the vehicle speed report to request additional references and materials. Finally, Web sites of cities with known traffic calming programs were accessed to obtain additional reports and information. Appendix A contains the entire letter report of the literature review. Its highlights are presented below.

In all, over 175 documents were identified, and abstracts of each were read. Based on the abstracts, hard copies of 60 of these documents were obtained and reviewed. The subject matter of the reviewed documents ranged widely and included descriptions of specific traffic calming techniques, legal aspects of traffic calming, crime issues, property value issues, and others. Although all hard-copy documents that were received were read, the major interest was in identifying evaluative studies of methods of traffic calming, especially those that might have combined education and enforcement with engineering. Very few evaluative studies were located. However, reports that summarized and quoted results of evaluative studies were found and proved useful (see Appendix A).

Two major documents were produced since the publication of NHTSA's speed report (Leaf and Preusser, 1999). One was an Institute of Transportation Engineers (ITE) report on the state of the practice of traffic calming (Ewing, 1999). Among other topics, it provides a brief history of traffic calming, a toolbox of traffic calming measures, engineering and aesthetic issues, impacts of traffic management measures, legal authority and liability issues, warrants, project selection procedures, public involvement, traffic calming on other than neighborhood and collector streets, and traffic calming in new developments. Twenty United States traffic calming 
programs are featured in the document. Specifications proposed by certain jurisdictions or professional groups for selected measures are included.

A second major document of specific interest to the present effort was a synthesis of safety research related to speed and speed management sponsored by the Federal Highway Administration (FHWA) (Stuster, Coffman, and Warren, 1998). This report covers speed-safety relationships, factors influencing speed, speed limits and speeds, speed limits and safety, enforcement and engineering measures.

The supplementary literature review revealed very little new information germane to the present study beyond what was contained in NHTSA's vehicle speed report (Leaf and Preusser, 1999). However, much of the new information served to confirm or amplify information contained in the NHTSA report. Across all of the literature examined, the following points of relevance to the current study were culled or inferred:

- Although some professional groups and jurisdictions have proposed standards, there are no national standards for design and use of traffic calming measures.

- The most effective traffic calming methods involve vertical treatments to the roadway. Humps have been proven to be very effective, and the public believes they are effective in reducing speeding. This was confirmed by the fact that the test sites for the present study chose vertical treatments for all of the physical calming measures employed.

- Traffic circles such as those employed in Seattle have been proven not to induce vehicleto-vehicle crashes. They are, however, quite expensive and therefore are not widely used. Neither test site in the present study employed traffic circles in the studied neighborhoods.

- There are rubber humps that can be used as a temporary traffic calming measure. Other measures can be created for temporary use, for example, permitting parking on opposite sides of the street for each block to create a chicane and using planters as bulbouts. The expert panel and officials at the chosen test sites, however, were opposed to using these temporary approaches because they could mar the aesthetics of the test neighborhoods.

- Data on the effectiveness of roadway perceptual devices are inconclusive. Although street narrowing decreases speeding, there are data that suggest that it increases crashes. Some data show that street width must be reduced to 20 feet or less before speed reductions are noted. As it turned out, street narrowing was not an option in any of the test neighborhoods.

- No studies were found in which education alone was used as a traffic calming measure. Typically, education programs consist of citizen watches combined with enforcement. Success in reducing speeding has been reported anecdotally, but no rigorous evaluation studies were found.

- Enforcement is effective but may be impractical on low volume streets. Compliance is greatest in the vicinity of the police vehicle. This is also true of speed display boards. The public finds enforcement effective in reducing speeding. Again, although these 
concepts were promulgated by several authors, no definitive evaluation study was uncovered.

- Anecdotal reports and limited scale studies indicate that photo radar has been successful in reducing speeds when deployed in neighborhoods in Europe. Some success has also been reported in the United States but the technique still has problems with political acceptability. The public apparently believes that photo radar is effective in reducing speeds. Photo radar was not permitted to be used at either of the test sites. As discussed below, however, speed trailers, that tell drivers the speed at which they are traveling without taking any automated enforcement actions, were used.

- Measures of effectiveness for traffic calming are typically $85^{\text {th }}$ percentile speed, average speed, percent exceeding posted speed, percent " $x$ " miles per hour above posted speed and volume. Crashes are included sometimes. Only one study (Cambridge, 2000) was located that used pedestrian-related measures - it used number of drivers yielding to pedestrians.

- Some jurisdictions use "hidden" measures for traffic calming, e.g., changes in traffic lights, prohibiting turns, making a "maze-like" path by creating a series of one-way streets. The two test communities chose not to employ these in the present study.

\subsubsection{Pedestrian Safety Benefits of Speed Reduction}

Relatively few references were located that provided a quantitative link between speed reduction and pedestrian safety benefits. Many of the references cited in Appendix A allude to the presumed benefits in terms of both injury reduction and crash avoidance, but there is a paucity of specific studies that confirm these links.

The case for the injury reduction benefits of lower speeds is perhaps more fully documented because both biomechanical analyses and epidemiological studies are relevant. For example, Leaf and Preusser (1999) report on the effects of vehicle speed on pedestrian fatalities and cite several studies that show that the risk of a fatality increases exponentially with striking vehicle speed. One study reported from England shows that 5 percent of pedestrians struck at 20 mph will die, compared with 45 percent at $30 \mathrm{mph}$, and 85 percent at $40 \mathrm{mph}$ (Department of Transport, 1997).

Other methodological development studies have proposed complex formulas for calculating the crash reduction potential of diminished travel speeds (cf., Navin, Chow, and Kwan, 2001; Davis, 1998). While these studies clearly support the general notion that lower speeds are associated with reduced crash risk, they do not provide a specific method in the context of the present study to translate any speed reduction obtained into an estimate of crashes avoided.

Perhaps the most direct evidence for the pedestrian crash reduction potential of reduced speeds comes from a study by Tester et al. (2004). The study examined the protective effectiveness of speed humps in reducing child pedestrian injuries in residential neighborhoods. This case-control study showed that children living on streets where speed humps had been installed had lower odds of being injured within their neighborhoods and being struck by a motor vehicle in front of their homes. While this study provides excellent support for the crash- 
reducing potential of successful speed countermeasures, it does not provide a direct formula for estimating the benefits of any particular application.

A recent article (Lindenmann, 2004) examines crash quantification tools and aids in the context of all highway crashes, not just pedestrians. The overwhelming evidence reported is that lowering speed produces a reduction in crashes. Lindenmann (2004) cites a study from Finland (Kallberg, 1997) that concluded that an increase in the average speed of traffic by $1 \mathrm{~km} / \mathrm{h}(0.62$ $\mathrm{mph}$ ) increases the number of injury crashes by approximately 3 percent. This equates to an increase of about 4.8 percent for a speed increase of $1 \mathrm{mph}$. The study also points out that crash costs increase by about twice as much since the higher speeds increase severity. Obviously, pedestrians are included in this overall estimate, although no way is reported to separate out the specific pedestrian crash or injury risks.

Thus, there is a widely held and partially proven theory that lowering speeds in residential neighborhoods will produce safety benefits both in terms of crashes avoided and by lessening injury severity when a crash does occur. This suggests that measures of both the mean or average speed and of those traveling at the highest speeds are needed in order to assess countermeasure programs such as those mounted in the current project.

\subsection{Workshop on Speed-Reducing Countermeasures}

A panel of experts was assembled for a workshop to discuss existing speed reduction approaches and brainstorm new ideas. In addition to the authors and the NHTSA task order manager, the panel included practitioners from a cross-section of jurisdictions and specialists on speed countermeasures, pedestrian safety, the state-of-the-practice of traffic calming, traffic enforcement, and education. The workshop was held on May 10-11, 2001, at the FHWA Learning Center in Arlington, Virginia. The complete letter report of the workshop is included as Appendix B to this report. A summary of the key results follows.

The workshop participants were challenged to enumerate candidate test conditions, evaluation paradigms, and possible test locations for the study. The aim was to identify a reasonable (in terms of cost and time) and sufficiently general test or tests that could answer the question posed by the main objective of the study, i.e., to determine if a speed-reduction benefit is obtained by adding education and/or enforcement to more traditional traffic calming approaches.

The workshop was initiated by asking participants to identify speed-reducing countermeasures in the three E's-engineering, enforcement, and education. Constraints and positive aspects were then noted for each. In an exercise in which participants attempted to identify a desirable set of countermeasures from those identified, no consensus was reached. However, the following principles, guidelines, and considerations that could be applicable to any project that attempts to reduce neighborhood speeds emerged from this activity:

- A countermeasure can trick the senses but it can't be deceitful (e.g., an artificial construction zone).

- A countermeasure cannot devalue the neighborhood; it should improve the neighborhood.

- Neighbors might not like to be the "bad guys" (e.g., participate in a trial by peers). 
- There should be a valid punitive value in any sanctions employed (e.g., a trial by peers may not be a deterrent if there is no meaningful punishment possible).

- There must be places in the area to mount the countermeasure (e.g., there are few red lights in residential areas).

- A countermeasure must not be annoying or contribute to neighborhood litter (e.g., windshield wiper flyers).

- A countermeasure must be legal (e.g., mounting flyers on utility poles is illegal in many jurisdictions).

- A countermeasure must be easily targeted (e.g., in-car cameras are tough to target).

- The implementation and maintenance costs must be reasonable (e.g., cameras are expensive).

- A countermeasure should not generate any privacy issues (e.g., people don't want to feel watched).

- Providing a good model for children is desirable (e.g., sending materials home from school).

- Crime reduction can be an added benefit to some of the countermeasures used (e.g., added police patrols, increased lighting).

- Sufficient space must be available (e.g., a street must be sufficiently wide to install a median).

- It is preferable that residential countermeasures not limit access to homes and driveways (as would a median; however, short medians could be installed).

- Appropriate data must be available or collectible to evaluate the actions.

- Neighborhood involvement is advisable (e.g., a neighborhood speed watch program).

The guidance represented by these principles was helpful in selecting and implementing countermeasures in Peoria and Phoenix. All of them were considered and applied to the extent applicable in each of the participating test neighborhoods. This list can also be helpful to anyone attempting any type of neighborhood-based programs.

Although there was no consensus on specific countermeasure approaches, the workshop participants did agree that the project should work with permanent installations of engineering treatments whenever possible. It was noted that temporary installations, e.g., rubber speed humps, are often not aesthetically pleasing and can therefore engender negative reactions based on appearances alone. This can cause a backlash and make it difficult to generalize from temporary to permanent installations. 
With regard to process, it was considered desirable that the project start from the beginning and look at transition from a non-calmed to a calmed neighborhood. Since it was acknowledged that this might not be possible under the constraints of the study, it was agreed that using an already calmed location with available "before" data was a viable alternative.

In a discussion of meaningful speed reduction, it was agreed that $85^{\text {th }}$ percentile and average are not the most representative measures of what people are concerned about. People want the excessive speeders eliminated. It was proposed that the project focus on overall comfort level and unacceptably high speeds. The primary aim would be to eliminate speed outliers. Thus, the project should focus on the high tail of the speed distribution as well as the mean. To follow this recommendation, the study would require accurate speed data on each vehicle, not class interval or "bin" data.

A brief discussion was held on possible test sites for the program. The sites mentioned included those where pre- and post-studies have not had optimum results as well as those that have good process and treatments pending. Although participants mentioned several possible test sites, there was no consensus on an ideal test site for the study. Therefore, an independent site selection effort was mounted to find an appropriate test location.

The literature review and the expert panel session suggested that the study needed test sites that have implemented (or are in the process of implementing) traffic calming in the form of permanent rather than temporary physical changes. It was also considered desirable to select locales that would be willing to attempt some innovative treatments that might provide compelling visual stimuli without constituting an impediment to the transit of emergency vehicles. As discussed in the next section, the study was fortunate in finding two contiguous sites that met these basic criteria and were interested in helping to develop and test the Heed the Speed program. 


\section{SITE SELECTION}

As stated previously (see Section 1), it was determined that the study site should contain neighborhoods/streets in which:

- There has been no traffic calming and none is planned.

- Traffic calming has been in place for some time.

- There has been no traffic calming but implementation of traffic calming is planned during the study period.

In addition, it was determined that the following site selection criteria were desirable:

- Cooperation of key officials including the police and engineering personnel

- Existence of adequate "before" data or a willingness to collect sufficient baseline data prior to implementing any countermeasures

- Reasonable accessibility to the Dunlap offices

- A concern for pedestrians among the involved city officials. It was considered beneficial to work in locales in which pedestrian safety was an established priority.

Telephone contacts were made with representatives from selected communities that were recommended as possible test sites by participants in the NHTSA speed workshop. With the exception of Phoenix, Arizona, contacts were limited to communities on the East Coast because of their relative proximity to the Dunlap offices. Phoenix was included because of previous working relationships with the city's traffic engineering department in the conduct of other NHTSA field studies (Blomberg and Cleven, 1998). In all, contacts were made with eight communities/jurisdictions to solicit possible participation in the study.

As a result of the telephone contacts, two communities were identified as prime candidates to participate as study sites: Boca Raton, Florida, and Phoenix, Arizona. Both cities had active traffic calming programs and several neighborhoods that met the study criteria. In addition, traffic engineers in both cities were eager to participate in the study and had excellent working relationships with the local police departments to secure their support. The balance of the eight candidates either did not express an interest in participating or did not offer the same level of engineering/police cooperation that appeared to be available in Boca Raton and Phoenix.

During the selection process, the study's contact in Boca Raton left and accepted a position in Peoria, Arizona, a neighboring city to Phoenix. Since Peoria also had several neighborhoods that met study criteria and it was contiguous to Phoenix, it was decided to use the two cities as one "mega site." Both cities met all site selection criteria, and liaison with both could be accomplished simultaneously because the traffic engineering representatives in the two cities knew each other and were eager to work together on a steering committee for the study. The Peoria and Phoenix police departments were also interested in the study and in forging a collaborative effort. 
Using both Phoenix and Peoria as test sites provided the following benefits:

- Replication of the countermeasure tests in a variety of neighborhoods

- More test sites so that testing of education and enforcement alone and in conjunction with engineering traffic calming efforts would be possible

- Larger sample sizes

- Greater variety in types of roadways included in the program

Once Phoenix and Peoria were identified as study sites, a subcontract arrangement was established with each. The cities were provided with approximately $\$ 25,000$ each to cover the cost of additional police patrols and the acquisition of study-related equipment. These funds were only a small percentage of the value of police and city staff time provided by each site. The remaining effort was paid for by the sites themselves. 


\section{PROGRAM DESIGN}

This section describes the design of the program, the specific neighborhoods selected for study in each city, and the countermeasures that were implemented in each neighborhood. The neighborhoods were selected by traffic engineering and police representatives in each city. Countermeasures were proposed and designed by members of a study working group consisting of project staff and local traffic engineering and police personnel. Selections of countermeasures to be implemented in the various neighborhoods were made by city representatives. All print countermeasures were distributed on a CD-ROM so that city representatives could select the items of interest and adapt them as desired for each neighborhood.

\subsection{Approach}

The study involved the use of two cities and three neighborhoods within each. The goal was to implement a variety of countermeasures in three different environments - streets with preexisting physical traffic calming; streets not scheduled for physical changes; and streets on which education and enforcement would be mounted along with roadway changes, such as speed humps, during the study period.

The adopted approach was not amenable to an experimental/comparison design because there would have been no reasonable way to select six comparison neighborhoods that were suitably matched with the selected experimental neighborhoods. In fact, as discussed below, the test areas were selected in part because they were unique or at least different from the norm with respect to interest in achieving speed reductions. Therefore, a longitudinal, pre/post study design was adopted. Baseline speed and knowledge/attitude measures were collected in each neighborhood before any countermeasures were started. One additional attitude/knowledge survey was conducted after countermeasure implementation. At least two additional postinitiation speed measurements were collected. On those test streets on which treatments were phased, up to two supplemental speed measurements were collected in order to assess the incremental effects of the added countermeasures.

\subsection{Study Neighborhoods}

As indicated previously, three neighborhoods/streets were selected for study in each city. The rationale for selection was fourfold. First, the location had to meet the requirements of the study, i.e., a road or neighborhood with existing traffic calming, planned calming during the study period or no planned engineering treatments for the foreseeable future. Second, the location had to be of interest to the cooperating city either because of a history of complaints or because of known speeding violations and previous unsuccessful efforts to curtail them. Third, the neighborhood had to have an active association or one or more vocal residents who would agree to spearhead the countermeasure efforts. Fourth, the neighborhood had to have pedestrian activity that could potentially be made safer by a reduction in vehicle speeds. Pedestrian crash counts were not used in the selection of neighborhoods because the expected numbers in any given neighborhood are quite small. 
The areas selected for study in Phoenix were:

- $\quad$ Clarendon Avenue - Clarendon Avenue is an east/west 32-foot wide local street north of the downtown area of Phoenix. The Clarendon Avenue study segment runs from $24^{\text {th }}$ Street to $28^{\text {th }}$ Street, which is east of Central Avenue, the centerpoint of the city. It is approximately one-fourth of a mile in length and includes three existing speed humps. The posted speed is $25 \mathrm{mph}$, and there are $20 \mathrm{mph}$ advisory signs posted with the speed hump warning signs. This segment is improved with rolled curbing and gutter. ${ }^{1}$ This is an older neighborhood with sporadic placement of sidewalks. Forty-two percent of the surrounding neighborhood population is Hispanic. The area residents are predominantly household renters $(86 \%)$ in contrast to owners $(14 \%)$. The neighborhood appears to be made up of low- to middle-income wage earners. The major concern among the residents was high speeds between the recently installed speed humps. They had requested that the city install additional humps on the assumption that the existing three were too far apart. Since Phoenix will not place humps closer than 500 feet apart in consideration of fire department response times, the city was interested in finding an alternative way to reduce speeds and placate the residents.

- $\quad$ Sweetwater Avenue - Sweetwater Avenue is an east/west 40-foot wide collector street in northeast Phoenix. The Sweetwater Avenue study segment encompasses the segment from $64^{\text {th }}$ Street to Scottsdale Road (the eastern extremity of Phoenix on its border with Scottsdale) and is one mile in length. The posted speed limit is $30 \mathrm{mph}$. This segment is improved with vertical curbing and gutter, and there are striped on-street bike lanes which narrow each travel lane to a width of about 14 feet. Sidewalks are randomly placed in the one-mile segment. The area residents are predominantly household owners $(93 \%)$ in contrast to renters $(7 \%)$. The neighborhood appears to be made up of middle- to high-income wage earners. The study area contains an active homeowner's group that had been vociferously requesting traffic calming from the city to counter excessive speeding. The city could not install conventional engineering treatments on Sweetwater since it is a collector street and the treatments could have too much of a negative impact on fire department response times. The combined use of enforcement, education, and innovative markings was therefore an attractive alternative.

- Moon Valley/Coral Gables Area - The Moon Valley/Coral Gables neighborhood is on the northwest side of Phoenix. It is characterized by upscale homes and broad roadways that invite high speeds. The Coral Gables Drive study segment runs from Thunderbird Road to $7^{\text {th }}$ Street and is approximately $2-1 / 2$ miles in length. The westernmost part runs essentially north and south and then turns due east to reach $7^{\text {th }}$ Street. Coral Gables is a 40-foot wide collector street with painted on-street bike lanes that narrow travel lanes to about 14 feet in each direction. The only stopping point is a three-way stop sign about midway at $7^{\text {th }}$ Avenue. The north/south and east/west segments of Coral Gables Drive were treated as separate segments for countermeasures and analysis. The posted speed limit is $30 \mathrm{mph}$ except for a $15 \mathrm{mph}$ zone at the eastern end that is in effect on school days on each approach to a school crosswalk. This segment is improved with vertical curbing, sidewalk, and gutter. The Moon Valley Drive study segment meanders north and east from Coral Gables Drive to Gleneagles Drive and is approximately 1-1/2 miles in length. As with Coral Gables Drive, the north/south and east/west portions of Moon

\footnotetext{
${ }^{1}$ All improvements referenced within these site descriptions were pre-existing when the study began.
} 
Valley Drive were treated separately in the study. The posted speed is $25 \mathrm{mph}$. The street improvements on this segment include a mixture of vertical curbing or rolled curbing, sidewalk, and gutter. The area residents are predominantly household owners $(95 \%)$ in contrast to renters $(5 \%)$. This neighborhood has a highly organized homeowner's association.

The neighborhoods/roadways selected for study in Peoria were:

- $95^{\text {th }}$ Avenue $-95^{\text {th }}$ Avenue is a north/south thoroughfare. The $95^{\text {th }}$ Avenue study segment runs from Olive Avenue to Peoria Avenue and is one mile long. It is a straight two-lane, undivided roadway with a striped double-yellow centerline and marked bike lanes. The posted speed limit is $30 \mathrm{mph}$. The road width measures 28 feet from bike lane to bike lane. It is bordered on the east side by the Springer Ranch neighborhood with an organized homeowner's association. There are no houses directly fronting the east side of the avenue. Most of the subdivision is separated from the roadway by a wall, except at the southern end. The test segment is bordered on the west side by two developments. On the northern half of the west side, single-family homes in a retirement community back directly up to $95^{\text {th }}$ Avenue with unfenced yards. There is no wall separating the roadway from the back yards. On the southern half of the west side, there is a community with a mixture of duplex and single family homes. The area is middle class with generally retirees on the western side of $95^{\text {th }}$ Avenue and younger families on the eastern side. The straight, open vista provided by $95^{\text {th }}$ Avenue is conducive to speeding. Several vocal residents had requested action from the city and agreed to assist the project. This segment of $95^{\text {th }}$ Avenue is classified by the City of Peoria as a collector street.

- Desert Harbor $/ 91^{\text {st }}$ Avenue - Desert Harbor derives its name from the lake contained within the neighborhood. $91^{\text {st }}$ Avenue runs north/south alongside the lake and residential and semi-commercial areas. The $91^{\text {st }}$ Avenue study segment runs from Thunderbird Road to Greenway Road and is one mile long. The posted speed is $30 \mathrm{mph}$. It is a 78foot wide, four-lane divided roadway (with a 28 -foot landscaped center median) that runs through the Desert Harbor community. Desert Harbor has two layers of homeowner's associations. There are sub-associations for each cluster development and a larger homeowner's association that oversees the subdivisions in the entire community. Desert Harbor is a higher-end upper-class community with a combination of single-family homes and gated waterfront estates. No homes directly front on $91^{\text {st }}$ Avenue. There is an elementary school immediately north of the study area. The Desert Harbor associations are active and vocal and had been requesting actions against speeders for some time. This segment of $91^{\text {st }}$ Avenue is classified by the City of Peoria as an arterial roadway.

- Bell Park $/ 84^{\text {th }}$ Avenue and $85^{\text {th }}$ Lane - Bell Park is an upper-middle class neighborhood in northern Peoria. The main roadway within the neighborhood is $84^{\text {th }}$ Avenue which connects to Bell Road, a major commercial arterial thoroughfare. The $84^{\text {th }}$ Avenue study segment runs from Bell Road to Grovers Road/Country Club Parkway and is approximately $2 / 3$ mile long. Several homes and cul de sacs front on $84^{\text {th }}$ Avenue. There is an elementary school at the northern end. The avenue is very wide and experiences cut-through traffic and traffic from vehicle dealerships on Bell Road that use $84^{\text {th }}$ Avenue for test drives. The residents wanted vertical traffic calming treatments installed and were willing to execute all of the necessary petitions in time for an installation coincident with the study period. One of the side roads, $85^{\text {th }}$ Lane, running from Grovers Avenue to 
$84^{\text {th }}$ Avenue was also a test segment. It received three speed humps approximately one year before the Heed the Speed program began. Nevertheless, residents on $85^{\text {th }}$ Lane perceived that speeds were still too high and requested additional countermeasures.

Since additional speed humps were not warranted, other study countermeasures had to be employed. The 84th Avenue segment is a two-lane, undivided facility with no centerline striping. From curb to curb, $84^{\text {th }}$ Avenue measures 48 feet and $85^{\text {th }}$ lane measures 38 feet. The posted speed on both roads is $25 \mathrm{mph}$. Both roadways are classified by the City of Peoria as local roadways. $84^{\text {th }}$ Avenue serves as a local collector.

Thus, there were actually 10 road segments addressed by the study as shown by the maps in Appendix E. ${ }^{2}$ Across these 10 road segments, all of the desired study conditions were present and replicated at least once:

- No physical traffic calming and none planned - Sweetwater Avenue, Coral Gables Drive (north/south segment), Coral Gables Drive (east/west segment), Moon Valley Drive (east/west segment), $91^{\text {st }}$ Avenue and $95^{\text {th }}$ Avenue.

- $\quad$ Traffic calming in place $-85^{\text {th }}$ Lane and Clarendon Avenue.

- No traffic calming but traffic calming planned during the study period - Moon Valley Drive (north/south segment) and $84^{\text {th }}$ Avenue.

\subsection{Program Duration}

The planning and preparation for the program began in early 2002 with the formation of a steering group and the development of materials as described below. A baseline set of evaluation measures was collected during October 2002. Countermeasure implementation commenced at the end of October. The planned active period for the countermeasures was three months. In actuality, the education and engineering efforts had no fixed end dates. The special enforcement program took place over a three-month period in Peoria. The enforcement effort in Phoenix was extended to six months because of the high local interest in the effort. The final evaluation measures were collected in February 2003. A detailed time phasing of the countermeasure implementation is presented below.

\subsection{Program Organization, Slogan, and Logo}

The countermeasures used during this study were not discrete efforts by the project staff. Rather, they were part of a coherent campaign mounted by Phoenix and Peoria working together. The organization of the program and its developed identity were an important part of its operation.

\subsubsection{Program Organization}

By design, the countermeasure program to be tested included a representation of all three E's - education, enforcement, and engineering. In both Phoenix and Peoria, both engineering and traffic safety education are within the purview of the cognizant traffic engineering agencies. ${ }^{3}$

\footnotetext{
${ }^{2}$ There were four in Moon Valley/Coral Gables, two in Bell Park, and one each in the other four neighborhoods.

${ }^{3}$ Street Transportation Department in Phoenix and Engineering Department in Peoria
} 
Enforcement responsibilities obviously rest within the police departments in both jurisdictions. A planning and steering committee was therefore established that included these four agencies as well as the Dunlap and Associates project staff. This group met approximately every six weeks from the outset through the end of the data collection period.

One of the first decisions made by the steering group was to develop a slogan and logo around which activities could coalesce. The group also agreed that a single unifying theme was desirable as opposed to separate identities for Phoenix and Peoria. The logic in this decision was that both cities share media, and many commuters to Phoenix live in Peoria. There was also a desire to have a single program identity going forward if the test project proved successful.

\subsubsection{Slogan and Logo}

Heed the Speed was selected as the slogan for the speed reduction activities. The name had been used previously by the Phoenix Police Department for a small pilot program that used a variety of education and enforcement techniques to produce a reduction in speeds in one neighborhood of Phoenix. That program has continued at a reduce level of police involvement. Since the goals of the current effort were largely the same as those in this pilot program, the Phoenix Police Department suggested that the same name be employed, and the Peoria participants concurred.

A stylized version of a police officer writing a ticket was designed for the program logo. The slogan and logo appeared on most of the educational materials used in the study. They also appeared on street and lawn signs that were displayed throughout the duration of the program. The slogan and logo for the study are shown in Figure 1. The sign is black on white except that the emblem on the police officer's hat and the pad and pencil in the officer's hand are bright yellow.

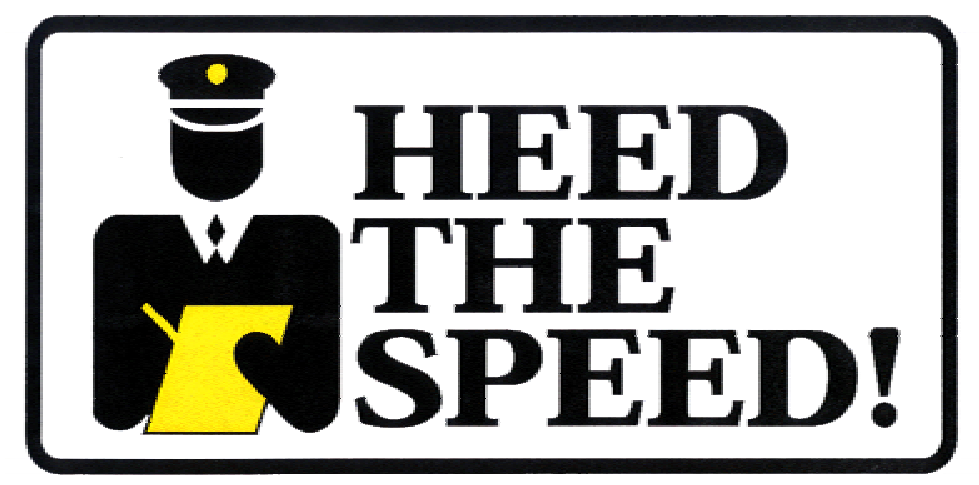

Figure 1. Program Logo Containing Program Slogan

\subsubsection{Homeowner's Association Meetings}

As discussed earlier, one of the selection criteria for the test neighborhoods was the existence of an active homeowner's association or at least a vocal and cooperative group of residents. Therefore, when possible, the program started in each neighborhood with a homeowner's association meeting. At these meetings, representatives from their cities apprised residents of the purpose of the program and the various planned activities. In addition, 
volunteers were solicited for some program activities (e.g., distributing education flyers, displaying lawn signs, and monitoring vehicle speeds).

Two of the Peoria meetings took place before the formal start of the program - the Desert Harbor $/ 91^{\text {st }}$ Avenue meeting took place on September 4, 2002, and the Bell Park $/ 84^{\text {th }}$ Avenue meeting took place on October 10, 2002. Therefore, these meetings may have slightly contaminated the baseline in these communities by unveiling program objectives and the impending enforcement and education activities before the initial speed measurements were collected. The effect, if any, is likely small. The $95^{\text {th }}$ Avenue meeting occurred on October 21, 2002 - the day the program started in Peoria. A further meeting was held on November 14, 2002, with the Spinnaker Cove subdivision of the Desert Harbor community.

In Phoenix, a combined meeting of the Moon Valley/Coral Gables and Sweetwater residents took place on October 22, 2002, the day the program officially started. There was no meeting with Clarendon residents since they had no homeowner's association.

\subsection{Education Materials}

The project developed all of the education materials used in the test. The general approach was to discuss media forms and themes at the planning committee meeting. Once there was agreement on an approach, a draft was produced and reviewed at the next meeting. After including any desired changes, a final version was produced. In addition to initial print runs, all of the materials were supplied to each city in electronic form so that they could be customized as needed for specific audiences. Each of the major education items is discussed below.

\subsubsection{Street and Lawn Signs}

Retroreflective metal street signs with the program slogan and logo were displayed at the entrance to each of the test roads in the neighborhoods under study. Measuring $24 \times 12$ inches, the signs were designed to meet the specifications for street signs in both cities and were produced by the City of Phoenix sign shop for both cities without cost to the project. They matched the width of a speed limit sign and were mounted below the first speed limit sign on the street. The program street sign is shown in Figure 2. As with the basic logo, the sign is black on white except that the emblem on the police officer's hat and the pad and pencil in the officer's hand are bright yellow.

Overall in Peoria, four signs were mounted on each road segment - two in each direction. In Phoenix, the longer road segments received four signs while the shorter got only two. Thus, four signs were mounted on Sweetwater Avenue and Coral Gables Drive, two on Clarendon and one on Moon Valley. 


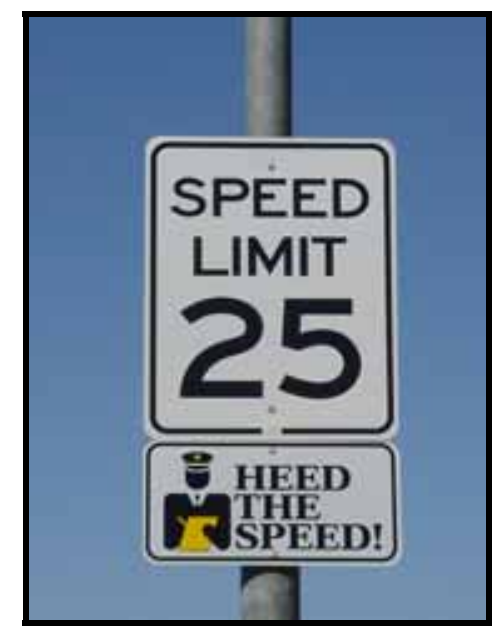

Figure 2. Program Street Sign

Lawn signs were designed for the program, and homeowners were encouraged to display them on their property. These signs were reproduced in black on a bright yellow background on both sides of a piece of $24 \times 16$ Coroplast $^{\mathrm{TM}}$, a corrugated plastic material supported on the lawn by an H-shaped wire stake. The triangle with the pedestrians is a halftone of the yellow color, and the police officer's cap and pad are white. A place on the sign was reserved for the name of the applicable homeowner's association, as desired; however none of the neighborhoods chose to personalize the signs. The program lawn sign is shown in Figure 3. Initially, 600 signs were produced and distributed evenly between the two test cities. After the initial distribution and some attrition of signs on Halloween, an additional 400 signs were printed and split between the cities. The total cost for the signs and stakes for mounting them was less than $\$ 3,000$.

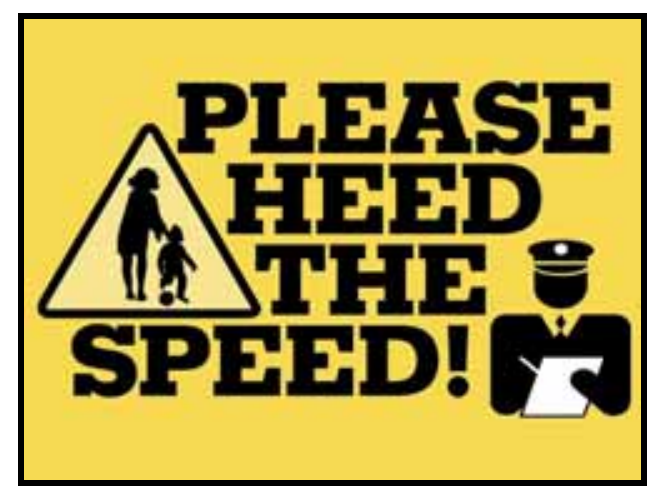

Figure 3. Program Lawn Sign

\subsubsection{Printed Materials and Radio Spots}

Several flyers and other types of printed materials were produced for the program. A black and white copy of each is contained in Appendix C. The specific flyers that were reproduced typically in black on either white or on variously colored paper included:

- A message for homeowners indicating the program activities that might be incorporated in their neighborhood and what they could do to support the program - in both English 
and Spanish. In Peoria, the flyer was delivered to each neighborhood residence by the local homeowner's associations and resident volunteers or was handed out at meetings by city personnel. In Phoenix, the flyer was mailed to residents in all three neighborhoods. Both English and Spanish language versions of the flyer were mailed to residents in the Clarendon neighborhood because of its large Hispanic population.

- A message for parents distributed through schools indicating the program activities that might be incorporated in their neighborhood and what they can do to support the program - in both English and Spanish.

- A message for drivers indicating the dangers of speeding - printed on the reverse side of replicas of both a Phoenix and Peoria traffic ticket. These $8 \frac{1}{2}$ by 11 inch replicas were handed out by police officers when they made warning or enforcement stops in the neighborhoods (see Section 4.6.1 below).

- A slim version of the message for drivers, excluding the traffic ticket, for distribution wherever drivers congregated (e.g., gas stations) and for distribution as door hangers.

- A message for car dealers requesting them to ask their customers to drive slowly, to drive slowly themselves, and to avoid test drives on neighborhood streets. One neighborhood in each of the test cities experienced this problem.

- A message for high school drivers for distribution at schools on the dangers of speeding reproduced in both English and Spanish.

- A press release announcing the program.

- Write-ups on the program for homeowner's associations to use in neighborhood newsletters.

In addition to the printed materials, five live copy radio spots on the dangers of speeding were prepared for distribution to local radio stations. These were short and suitable for use as either a public service announcement or as part of a station break/promo.

All print materials were reproduced on a CD-ROM and provided to local transportation representatives in both cities. Thus, the materials could be customized for individual neighborhoods as desired.

\subsubsection{Earned Media}

The existence of the program also generated its own education countermeasures. One was an article in the local newspaper describing the program. Another was a taped interview on the Phoenix Channel 11 television program called Leading Edge. In that program, local Phoenix transportation and police personnel described the many program components. Another was a news spot on Phoenix Channel 5 in which a reporter did a live story from $95^{\text {th }}$ Avenue in Peoria. Heed the Speed generated additional earned media through the Phoenix cable channel, city council sessions, caller-on-hold messages and a radio spot in Peoria. Valley-wide radio spots were sent out by the City of Phoenix. In addition, Peoria representatives developed a variety of print materials that were specific to its neighborhoods under study. These materials were 
mentioned quite frequently in the mail survey responses that were part of the evaluation (see Section 5).

\subsection{Enforcement Activities}

In addition to being active participants in program planning and neighborhood meetings, police in each city assumed responsibility for the following activities:

- Performing special enforcement

- Training citizens to conduct neighborhood speed watches and use radar guns

- Deploying radar speed and photo speed enforcement trailers

\subsubsection{Special Enforcement}

It was agreed among the steering committee, Dunlap project representatives, and NHTSA sponsors that special enforcement activities were needed in addition to routine neighborhood patrols. In this context, special enforcement meant both increased patrols and more stringent criteria for making stops whether as a warning or to issue a citation. To accomplish the desired special enforcement activities, the project gave each jurisdiction a small subcontract to fund some police overtime. The funding covered only a portion of the total supervisory and patrol time that was involved in the heightened enforcement effort.

In Peoria, officers of the traffic squad implemented special enforcement for three months. Their strategy was to get the attention of the neighborhoods scheduled for subsequent engineering changes at the outset and then to focus on the remaining neighborhoods that were not receiving physical alterations.

Phoenix implemented a six-month enforcement campaign that focused on all three neighborhoods. Rather than "blitz" an area and then leave, the Phoenix police strategy involved rotating officers through all of the areas on a regular basis. In addition to the regular patrol, the Phoenix Police Department employed officers in radar speed unit training for many of the special patrols. Through this approach, they were able to support the program and provide valuable training experience to new officers in the proper procedures for traffic stops.

During the special enforcement time periods, virtually all vehicles that were traveling faster than the posted speed limit were subject to being stopped. The typical allowance of five to seven miles per hour over the limit was largely ignored as a criterion for making a stop. After the stop, the officer approached the vehicle, announced the violation, and performed a routine check on the driver's license. With regard to the speed violation, initially only drivers who were flagrantly disobeying the law or who were uncooperative or belligerent were ticketed. The remainder who were not ticketed received a verbal warning and the facsimile of a speeding ticket with the education material on its reverse side. Officers either discussed the literature with the driver or waited while the driver read it. As shown in Appendix C, the message for drivers pointed out the dangers and penalties of speeding. The idea was to make the violator think he or she was about to receive a citation and then make it clear that it was just a warning. 
Also, for each stop, the officer filled out a motorist stop form, a copy of which is included in Appendix D. This form was designed to obtain information on the drivers who were speeding in the neighborhood. It provided data on the location of the stop, the proximity of the driver's address to the neighborhood, the driver's age and gender, whether or not the driver was wearing a safety belt, how often the driver traveled on the road, the number of people in the vehicle, the vehicle type and model year, and the outcome of the stop (that is, if the officer gave the driver a ticket and/or literature). Information obtained from this form is described in Section 5 of this final report.

\subsubsection{Neighborhood Speed Watches}

Neighborhood speed watches are groups of citizen volunteers who use speed radar units provided by the police department to monitor speeds near their homes. Police train the volunteers on how to use the radar guns, what information to collect and how to collect the information. When speeders are clocked, they can report the license plate, speed, time and place of the observation to the police. Follow-up typically consists of a warning or educational letter to the registered owner of the vehicle.

The police departments in both Peoria and Phoenix acquired additional radar units and trained volunteers to use them to measure the speeds of vehicles at various points in their neighborhoods. Although there was much enthusiasm among the trainees, this obviously did not carry over into the actual use of the radars as the Phoenix Police received no citizen reports on the watches, and the Peoria Police received only a few.

\subsubsection{Deployment of Speed and Photo Speed Enforcement Trailers}

A trailer or speed van that displayed a vehicle's speed as it passed was deployed in both cities. In Peoria, it was deployed on 17 different days during the three-month study period - six days in Bell Park, eight days on $95^{\text {th }}$ Avenue, and three days in Desert Harbor. In Phoenix the photo speed enforcement trailer was deployed in the Moon Valley/Coral Gables neighborhood approximately once per week during the first two months of the program. It was deployed at the $15 \mathrm{mph}$ zone on Coral Gables at Moon Valley Elementary School. No speed data were collected during these deployments but photo enforcement was conducted. The Phoenix City Council only allows automated speed enforcement in school zones, which limited the use of this enforcement tool.

\subsection{Engineering and Roadway Treatments}

The countermeasure program included two types of roadway treatments. The first were standard vertical treatments that were permanently affixed to the roadway. The second were surface treatments intended to create the illusion of an impediment or simulate an engineering treatment.

\subsubsection{Vertical Treatments}

Two of the test road segments had vertical treatments added during the test. The north/south segment of Moon Valley Drive in Phoenix had two speed humps added early in 2003 prior to the final wave of speed measurements. Four speed tables were added to $84^{\text {th }}$ Avenue in 
Peoria prior to the third wave of measurements there in December 2002. These speed tables were combined with one of the innovative pavement markings as described below.

In addition to the vertical treatments on Moon Valley and $84^{\text {th }}$ Avenue, there were existing speed humps on Clarendon Avenue in Phoenix and on $85^{\text {th }}$ Lane in the Peoria Bell Park neighborhood.

\subsubsection{Visual Treatments}

One of the countermeasure ideas initiated from the expert panel and more fully discussed during Phoenix/Peoria steering committee meetings consisted of innovative pavement markings that would not present an actual barrier to travel but would appear to be an impediment. During the process of defining specific countermeasures, two commercially available products were identified - Solidsheet 3-Dimensional Road Marking and Tyregrip ${ }^{\mathrm{TM}}$ surfacing.

Solidsheet 3-Dimensional Road Marking (“3-D marking”) is a product of Sekisui Jushi Corporation in Japan. ${ }^{4}$ This patented material is a geometrically shaped, multi-colored thermoplastic flat sheet that creates an optical illusion of a three-dimensional object in the roadway. Retroreflective glass beads are incorporated into the sheets for increased nighttime visibility. The 3-D marking material has been used for a variety of road marking tasks such as crosswalks and edge lines. Previous research on the 3-D marking showed encouraging results (Organization for Traffic Safety, 2001).

The 3-D markings come in a variety of shapes and sizes. For this project's applications, the "Large Mountain" shapes were used as shown in Figure 4. The markings are installed by first applying a primer to the road surface. Then the sheets are placed on the ground in the predetermined pattern and heated with a torch until they adhere to the pavement.

In Peoria, 3-D markings were applied on $85^{\text {th }}$ Lane between two of the existing speed humps and at seven locations on $84^{\text {th }}$ Avenue - four on the four newly installed speed tables (see Figure 5) and three in the spaces between the new speed tables (see Figure 6). The material was also applied alone without vertical treatments at five locations on $95^{\text {th }}$ Avenue. In Phoenix, it was applied at three locations on Coral Gables Drive.

Tyregrip $^{\mathrm{TM}}$ is a combination of a two-part resin binder with a drop-on aggregate. ${ }^{5}$ Although primarily designed for skid resistance, the appearance of the material can be structured so that it resembles a speed table, crosswalk or neighborhood entry treatment. Tyregrip ${ }^{\mathrm{TM}}$ was not used in Peoria. In Phoenix, it was applied at five locations on Coral Gables Drive and six locations on Sweetwater Avenue. A Tyregrip ${ }^{\mathrm{TM}}$ installation on Coral Gables Drive in Phoenix is shown in Figure 7.

\footnotetext{
${ }^{4}$ Much of the 3-D marking product used in the test was provided to the project for test purposes by the SJS (America), Inc., Cartersville, Georgia.

${ }^{5}$ Tyregrip $^{\mathrm{TM}}$ is sold in the US by Traffic Safety Systems, Inc. of Roswell, Georgia.
} 


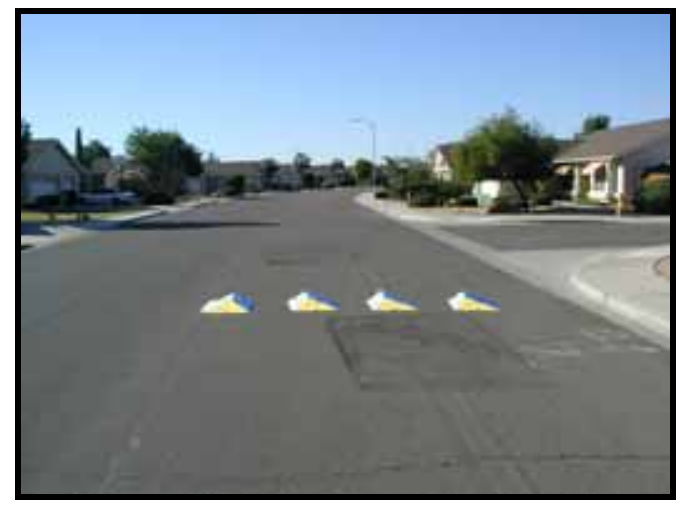

Figure 4. 3-D Markings on $85^{\text {th }}$ Lane in Peoria

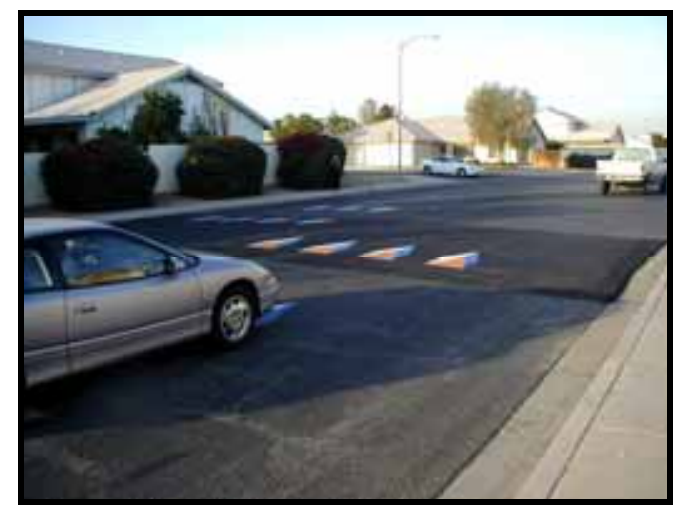

Figure 5. 3-D Markings on Top of Speed Table on $84^{\text {th }}$ Avenue in Peoria

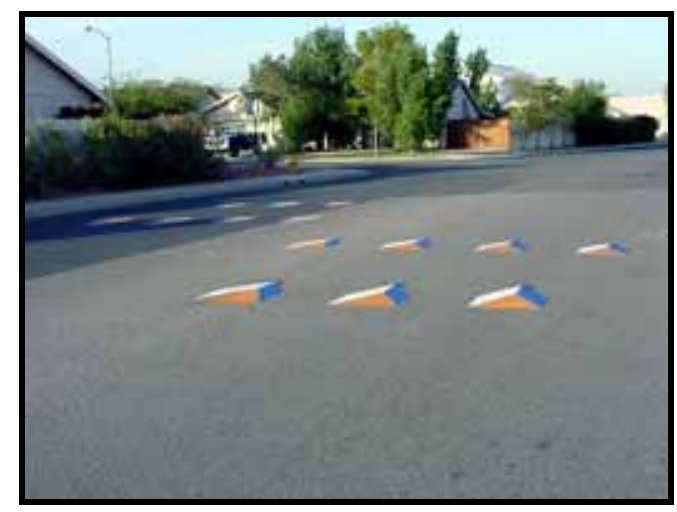

Figure 6. 3-D Markings on Pavement Between Speed Tables on $84^{\text {th }}$ Avenue in Peoria 


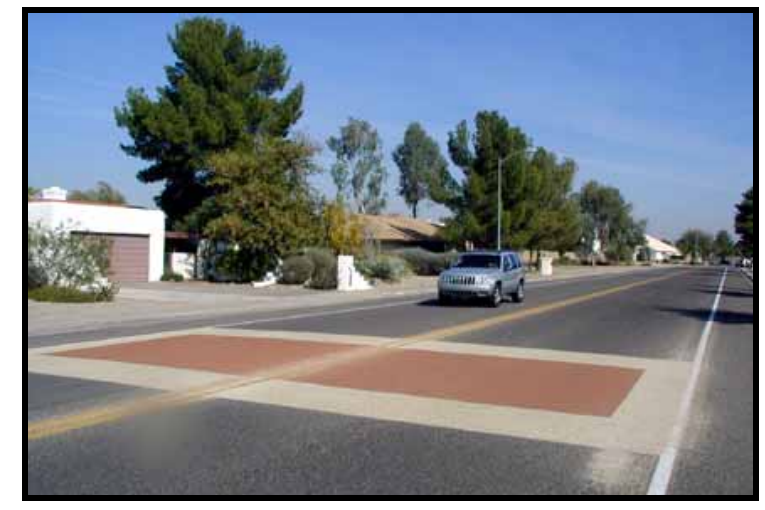

Figure 7. Tyregrip ${ }^{\mathrm{TM}}$ Installation on Coral Gables Drive in Phoenix

\subsection{Program Implementation Timeline}

Table 1 summarizes the timeline of the implementation of program activities in each of the two cities. A more detailed description of the specific activities on each road segment within each neighborhood can be found later in the report in Table 59. 
Table 1. Schedule of Program Activities*

\begin{tabular}{|c|c|c|}
\hline Month & Phoenix & Peoria \\
\hline $\begin{array}{l}\text { September } \\
2002\end{array}$ & & $\begin{array}{l}\text { Desert Harbor - Meeting with homeowner's } \\
\text { association }\end{array}$ \\
\hline October 2002 & $\begin{array}{l}\text { All sites - press release issued } \\
\text { All sites - news article in Arizona Republic } \\
\text { Moon Valley and Sweetwater - meeting } \\
\text { with homeowner's associations } \\
\text { All sites - Heed the Speed traffic signs } \\
\text { posted } \\
\text { All sites - Heed the Speed lawn signs } \\
\text { distributed } \\
\text { All sites - special enforcement initiated } \\
\text { All sites - program materials distributed } \\
\text { All sites - press release issued } \\
\text { Coral Gables - photo speed van deployed }\end{array}$ & $\begin{array}{l}\text { All sites - press release issued } \\
\text { All sites - news article in Arizona Republic } \\
95^{\text {th }} \text { Ave and Bell Park-open house } \\
\text { meetings with residents } \\
\text { All sites - police training on radar guns } \\
\text { All sites - Heed the Speed traffic signs posted } \\
\text { All sites - Heed the Speed lawn signs } \\
\text { distributed } \\
\text { All sites - special enforcement initiated } \\
\text { All sites - program materials distributed } \\
\text { Bell Park - speed trailer deployed }\end{array}$ \\
\hline $\begin{array}{l}\text { November } \\
2002\end{array}$ & $\begin{array}{l}\text { All sites - Channel } 11 \text { interview with police } \\
\text { and transportation personnel on Leading } \\
\text { Edge program } \\
\text { All sites - special enforcement continued } \\
\text { All sites - additional program materials } \\
\text { distributed as needed } \\
\text { Coral Gables - photo speed van deployed }\end{array}$ & $\begin{array}{l}\text { All sites - special enforcement continued } \\
\text { Desert Harbor - presentation to Spinnaker } \\
\text { Cove subdivision } \\
\text { All sites - additional program materials } \\
\text { distributed as needed } \\
9^{\text {th }} \text { Ave - Speed trailer deployed }\end{array}$ \\
\hline $\begin{array}{l}\text { December } \\
2002\end{array}$ & $\begin{array}{l}\text { All sites - special enforcement continued } \\
\text { All sites - additional program materials } \\
\text { distributed as needed } \\
\text { Coral Gables - 3-D materials applied }\end{array}$ & 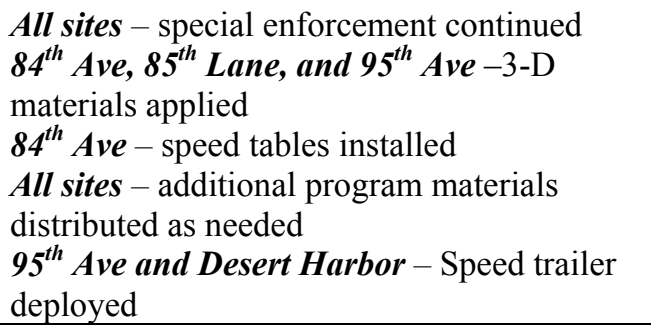 \\
\hline January 2003 & $\begin{array}{l}\text { All sites }- \text { special enforcement continued } \\
\text { Coral Gables - Tyregrip }{ }^{\mathrm{TM}} \text { applied }\end{array}$ & $\begin{array}{l}\text { All sites - special enforcement continued } \\
\text { 95 }{ }^{\text {th }} \text { Ave - installation of 3-D material } \\
\text { completed }^{\text {95 }}{ }^{\text {th }} \text { Ave - speed trailer deployed } \\
\text { All sites - enforcement program ended } \\
(1 / 21 / 03)\end{array}$ \\
\hline February 2003 & $\begin{array}{l}\text { All sites - special enforcement continued } \\
\text { Sweetwater Ave - Tyregrip }{ }^{\mathrm{TM}} \text { applied } \\
\text { Moon Valley - speed humps installed }\end{array}$ & \\
\hline $\begin{array}{l}\text { March to April } \\
2003\end{array}$ & $\begin{array}{l}\text { All sites - special enforcement continued } \\
\text { All sites - enforcement program ended } \\
(4 / 15 / 03)\end{array}$ & \\
\hline
\end{tabular}

*Program started October 21, 2002. No new activities were initiated and special enforcement ceased after January 21, 2003, in Peoria and April 15, 2003, in Phoenix. 


\section{PROGRAM EVALUATION}

This section describes program evaluation procedures and results. It includes information obtained from the police special enforcement stop form, the neighborhood mailed opinion and knowledge survey, and speed data collected during the conduct of the study. It also contains process data that were obtained from focus groups/discussions with the engineering and police representatives from both cities as well as with representatives from the various study neighborhoods.

The focus of the evaluation was on obtaining information that could be linked to both the actual speed response in the studied neighborhoods and the extent to which any change towards lower speeds was the result of deterrence produced by Heed the Speed activities. Since it is not reasonable to presume that police will always be present to witness speeding violations and available to take enforcement action, the deterrence of the unsafe behavior is crucial to a reduction in pedestrian crash risk. The operative theory is that increased enforcement will generate specific deterrence among those stopped and warned or cited for speeding. In addition, a general deterrence of speeding should result among those who witness the increased enforcement activity as well as among those whose attitudes and values are altered by the messages in the Heed the Speed educational materials.

When viewing these data, the reader should keep in mind that the project essentially consisted of 10 separate case studies as described earlier. Only the speed data, however, were sufficiently differentiated to permit a separate assessment of each of the 10 test segments. The police data did include an indication of where each speeding stop was made which permitted this information to be disaggregated by neighborhood. It was not possible, however, to determine what proportion of the special police patrol time was allotted to each road segment. The mail survey was sent out anonymously and precoded by neighborhood but not specific address and therefore could not be broken down by road segment.

\subsection{Police Special Enforcement}

Additional hours of police patrols were incorporated in each neighborhood for the project enforcement activities. This special enforcement was performed in addition to routine neighborhood patrols.

During the special enforcement time periods, any vehicle traveling faster than the posted speed limit by any amount was subject to being stopped. This represented a change from normal practice in which motorists could exceed the speed limit by five to seven miles per hour with virtual impunity as long as their driving behavior was not erratic.

When a stop was made during the program, the officer approached the vehicle, announced the violation, and performed a routine check on the driver's license. With regard to the speeding violation, only drivers who were flagrantly disobeying the law, who were stopped multiple times, or who were rude were ticketed initially. As the study period progressed, however, a higher percentage of speeding tickets were issued as the tolerance of the participating officers diminished. 
Drivers who were not ticketed received a verbal warning and a facsimile of a police ticket. The back of the facsimile ticket contained a message for drivers that pointed out the dangers and penalties of speeding. A copy of the speeding message is included in the countermeasures reproduced in Appendix C.

For each driver stopped, the officer filled out a motorist stop form, a copy of which is included in Appendix D. This form was designed to obtain a profile on the drivers who were speeding in the various neighborhoods. In addition to the date and time of the stop, it consisted of 11 items that provided the following information:

- The test neighborhood in which the stop was made

- Specific street on which the stop was made

- Proximity of the driver's address to the neighborhood in which the stop was made

- Gender of the driver

- Date of driver's birth

- Driver's safety belt use

- How often driver travels on the street on which stopped

- Number of people in the vehicle

- Vehicle type

- Vehicle model year

- Officer's action, (i.e., if the officer gave the driver a ticket and/or literature that provided information on the dangers of speeding)

Unless otherwise noted, when data were missing for a particular item, the record for that stop has been excluded from the summary tables that follow pertaining to the missing item. The second item (street on which the stop was made) was only used to confirm the neighborhood identification as necessary and was not analyzed separately.

\subsubsection{Location and Month of the Stops}

The police stop form data from Peoria were collected over a three-month period starting on October 23, 2002, and ending on January 17, 2003. Collection of the stop form data in Phoenix also started on October 23, 2002. However, data in Phoenix were collected over a sixmonth period ending on April 15, 2003. The returns obtained from each Peoria neighborhood during the three study months are shown in Table 2. Those obtained from Phoenix are shown in Table 3. It should be noted that these data are only a profile of those people stopped during the program and not an estimate of the incidence of speeding in the test neighborhoods.

Table 2 shows that 283 stops were made in Peoria during the three-month study period an average of 94 stops per month. The largest percentage of stops were made in the 95 th Avenue neighborhood (45.9\%), and the smallest in Bell Park (19.4\%). In addition, the largest percentage of stops were made in the first study month $(47.3 \%)$, followed by the second $(28.6 \%)$, and the third (24\%). Given the demonstrated reduction in speeding (see below), there were likely fewer violators for the police to stop. It is also possible that there was some waning of police interest that also contributed to the decline in stops over time. 
Table 2. Police Stops by Neighborhood and Study Month (Peoria)

\begin{tabular}{|c|c|c|c|c|c|}
\hline \multirow{2}{*}{\multicolumn{2}{|c|}{ Study Month }} & \multicolumn{4}{|c|}{ Neighborhood } \\
\hline & & 95th Avenue & $\begin{array}{c}\text { Desert } \\
\text { Harbor/91st } \\
\text { Avenue }\end{array}$ & $\begin{array}{c}\text { Bell Park/84th } \\
\text { Avenue }\end{array}$ & Total \\
\hline \multirow{3}{*}{$\begin{array}{l}1-\text { Oct } 23 \\
\text { to Nov } 16\end{array}$} & Count & 56 & 29 & 49 & 134 \\
\hline & Row \% & $41.8 \%$ & $21.6 \%$ & $36.6 \%$ & $100 \%$ \\
\hline & Column $\%$ & $43.1 \%$ & $29.6 \%$ & $89.1 \%$ & $47.3 \%$ \\
\hline \multirow{3}{*}{$\begin{array}{l}\text { 2-Nov } 17 \\
\text { to Dec } 14\end{array}$} & Count & 48 & 33 & 0 & 81 \\
\hline & Row \% & $59.3 \%$ & $40.7 \%$ & $0 \%$ & $0 \%$ \\
\hline & Column \% & $36.9 \%$ & $33.7 \%$ & $0 \%$ & $28.6 \%$ \\
\hline \multirow{3}{*}{$\begin{array}{l}3-\operatorname{Dec} 15 \\
\text { to Jan } 18\end{array}$} & Count & 26 & 36 & 6 & 68 \\
\hline & Row \% & $38.2 \%$ & $52.9 \%$ & $8.8 \%$ & $100 \%$ \\
\hline & Column \% & $20 \%$ & $36.7 \%$ & $10.9 \%$ & $24 \%$ \\
\hline \multirow{3}{*}{ Total } & Count & 130 & 98 & 55 & 283 \\
\hline & Row \% & $45.9 \%$ & $34.6 \%$ & $19.4 \%$ & $100 \%$ \\
\hline & Column \% & $100 \%$ & $100 \%$ & $100 \%$ & $100 \%$ \\
\hline
\end{tabular}

Table 3. Police Stops by Neighborhood and Study Month (Phoenix)

\begin{tabular}{|c|c|c|c|c|c|}
\hline \multirow{3}{*}{\multicolumn{2}{|c|}{ Study Month }} & \multirow{2}{*}{\multicolumn{4}{|c|}{ Neighborhood }} \\
\hline & & & & & \\
\hline & & \multirow{2}{*}{$\frac{\text { Sweetwater }}{23}$} & \multirow{2}{*}{$\begin{array}{c}\text { Moon } \\
\begin{array}{c}\text { Molley/Coral } \\
\text { Gables }\end{array} \\
135 \\
\end{array}$} & \multirow{2}{*}{$\begin{array}{r}\text { Clarendon } \\
29\end{array}$} & \multirow{2}{*}{$\begin{array}{r}\text { Total } \\
187\end{array}$} \\
\hline \multirow{3}{*}{$\begin{array}{l}1-\text { Oct } 23 \\
\text { to Nov } 16\end{array}$} & Count & & & & \\
\hline & Row \% & $12.3 \%$ & $72.2 \%$ & $15.5 \%$ & $100 \%$ \\
\hline & Column \% & $7.2 \%$ & $32.5 \%$ & $50.9 \%$ & $23.6 \%$ \\
\hline \multirow{3}{*}{$\begin{array}{l}\text { 2-Nov } 17 \\
\text { to Dec } 14\end{array}$} & Count & 47 & 51 & 13 & 111 \\
\hline & Row \% & $42.3 \%$ & $45.9 \%$ & $11.7 \%$ & $100 \%$ \\
\hline & Column \% & $14.6 \%$ & $12.3 \%$ & $22.8 \%$ & $14 \%$ \\
\hline \multirow{3}{*}{$\begin{array}{l}3-\text { Dec } 15 \\
\text { to Jan } 18\end{array}$} & Count & 16 & 10 & 7 & 33 \\
\hline & Row \% & $48.5 \%$ & $30.3 \%$ & $21.2 \%$ & $100 \%$ \\
\hline & Column \% & $5 \%$ & $2.4 \%$ & $12.3 \%$ & $4.2 \%$ \\
\hline \multirow{3}{*}{$\begin{array}{l}\text { 4-Jan } 19 \\
\text { to Feb } 15\end{array}$} & Count & 149 & 145 & 1 & 295 \\
\hline & Row \% & $50.5 \%$ & $49.2 \%$ & $.3 \%$ & $100 \%$ \\
\hline & Column \% & $46.4 \%$ & $34.9 \%$ & $1.8 \%$ & $37.1 \%$ \\
\hline \multirow{3}{*}{$\begin{array}{l}\text { 5-Feb } 16 \\
\text { to Mar } 15\end{array}$} & Count & 55 & 60 & 7 & 122 \\
\hline & Row \% & $45.1 \%$ & $49.2 \%$ & $5.7 \%$ & $100 \%$ \\
\hline & Column \% & $17.1 \%$ & $14.4 \%$ & $12.3 \%$ & $15.4 \%$ \\
\hline \multirow{3}{*}{$\begin{array}{l}\text { 6-Mar } 16 \\
\text { to Apr } 15\end{array}$} & Count & 31 & 15 & 0 & 46 \\
\hline & Row \% & $67.4 \%$ & $32.6 \%$ & $.0 \%$ & $100 \%$ \\
\hline & Column \% & $9.7 \%$ & $3.6 \%$ & $.0 \%$ & $5.8 \%$ \\
\hline \multirow{3}{*}{ Total } & Count & 321 & 416 & 57 & 794 \\
\hline & Row \% & $40.4 \%$ & $52.4 \%$ & $7.2 \%$ & $100 \%$ \\
\hline & Column \% & $100 \%$ & $100 \%$ & $100 \%$ & $100 \%$ \\
\hline
\end{tabular}


In Bell Park, 89.1 percent of the stops were made in the first study month, none in the second, and 10.9 percent in the third. In the 95th Avenue neighborhood, 43.1 percent of the stops were made during the first month, followed by 36.9 percent in the second, and 20 percent in the third. The stops made in the Desert Harbor neighborhood were distributed reasonably evenly over the three-month period. This was the pattern of enforcement activity that the police in Peoria chose to execute. In particular, the intent was to concentrate enforcement in the Bell Park area during the first two weeks and then stop when the speed tables were installed on $84^{\text {th }}$ Avenue. In practice, the installation of the speed tables was delayed. However, the original plan for heavy enforcement in Bell Park in the first two weeks was carried out. It was then stopped and not started again until near the end of the program in Peoria.

Table 3 shows that 794 police stops were made in Phoenix during the six-month period an average of 132 stops per month. The largest percentage of stops in Phoenix took place in the Moon Valley/Coral Gables neighborhood (52.4\%), followed by the Sweetwater neighborhood $(40.4 \%)$, and the Clarendon neighborhood $(7.2 \%)$. There was a great deal of variability in percentage of stops per month ranging from 37.1 percent for month 4 (January 19 to February 15) to 4.2 percent for month 3 (the month in which the Christmas/New Year holidays occurred). In general, there was a spurt for the first study month followed by two months of gradual decline. There was then another spurt in the fourth month followed by another two months of gradual decline.

With regard to Phoenix neighborhoods, half of the police stops made in the Clarendon neighborhood $(50.9 \%)$ were made in the first study month. Almost one-quarter $(22.8 \%)$ were made in the second study month. No stops were made during the last study month. For Sweetwater, the largest percentage of stops were made in month 4 (46.4\% for January 19 to February 15) followed by 17.1 percent in month 5 (February 16 to March 15). For the Moon Valley/Coral Gables neighborhood, the largest percentage of stops were made in month 4 (34.9\% for January 19 to February 15), followed by month 1 (32.5\% for October 23 to November 16).

\subsubsection{Proximity of Driver Address to Neighborhood}

Included on the police stop form was a question asking how close the driver's address was to the neighborhood in which the driver was stopped. The intent here was to determine how many of the speeders lived in (or very near) the neighborhood in which they were stopped. The police officer could check one of three categories: "in the neighborhood," "near the neighborhood" (within one mile) or "outside the neighborhood" (more than one mile). The results for Peoria are given in Table 4 and those for Phoenix are given in Table 5.

Table 4 shows that 37.9 percent of the drivers who were stopped in Peoria lived in the neighborhood in which they were stopped, and an additional 18.1 percent lived within a mile of that neighborhood. Thus, over half $(56.0 \%)$ of the drivers stopped in Peoria lived in or within a mile of the neighborhood in which they were stopped. Forty-four percent of the drivers lived more than one mile from the neighborhood in which they were stopped.

With regard to individual Peoria neighborhoods, 95th Avenue had the largest number of stops for residents residing in the neighborhood (52.3\%). In fact, 60.8 percent of the drivers stopped in the 95th Avenue neighborhood lived in or within one mile of the neighborhood in which they were stopped. Comparable data for the Bell Park and Desert Harbor neighborhoods 
were 52.7 percent and 51.5 percent, respectively, but these neighborhoods had lower proportions of in-neighborhood violators and higher percentages of near-neighborhood speeders.

Table 4. Proximity of Driver Address to Neighborhood (Peoria)

\begin{tabular}{|c|c|c|c|c|c|}
\hline & & & Neighb & rhood & \\
\hline $\begin{array}{r}\text { Proximity o } \\
\text { to Nei }\end{array}$ & $\begin{array}{l}\text { river Address } \\
\text { borhood }\end{array}$ & & $\begin{array}{c}\text { Desert } \\
\text { Harbor/91st }\end{array}$ & Bell Park/84th & \\
\hline & Count & 68 & 21 & 18 & 107 \\
\hline Neighborhood & Row \% & $63.6 \%$ & $19.6 \%$ & $16.8 \%$ & $100 \%$ \\
\hline & Column \% & $52.3 \%$ & $21.6 \%$ & $32.7 \%$ & $37.9 \%$ \\
\hline & Count & 11 & 29 & 11 & 51 \\
\hline $\begin{array}{l}\text { Near } \\
\text { Neighborhood }\end{array}$ & Row \% & $21.6 \%$ & $56.9 \%$ & $21.6 \%$ & $100 \%$ \\
\hline & Column \% & $8.5 \%$ & $29.9 \%$ & $20 \%$ & $18.1 \%$ \\
\hline & Count & 51 & 47 & 26 & 124 \\
\hline Neighborhood & Row \% & $41.1 \%$ & $37.9 \%$ & $21 \%$ & $100 \%$ \\
\hline & Column \% & $39.2 \%$ & $48.5 \%$ & $47.3 \%$ & $44 \%$ \\
\hline & Count & 130 & 97 & 55 & 282 \\
\hline Total & Row \% & $46.1 \%$ & $34.4 \%$ & $19.5 \%$ & $100 \%$ \\
\hline & Column \% & $100 \%$ & $100 \%$ & $100 \%$ & $100 \%$ \\
\hline
\end{tabular}

Table 5 shows that 51.4 percent of the drivers stopped in Phoenix lived in the neighborhood in which they were stopped, and an additional 12.0 percent lived within one mile of the neighborhood. Thus 63.4 percent of the stopped drivers lived in or within one mile of the neighborhood in which they were stopped. Only about a third of the drivers $(36.6 \%)$ lived outside the neighborhood. With regard to individual neighborhoods, the Moon Valley/Coral Gables neighborhood (57.4\%) had the largest percentage of drivers who lived in the neighborhood followed by Sweetwater $(46.5 \%)$ and Clarendon $(34.5 \%)$. This is not surprising since Moon Valley was the largest of the studied neighborhoods, and Clarendon was the smallest. For the Moon Valley neighborhood, 67.1 percent of the drivers lived in or within one mile of the neighborhood in which they were stopped. These data for the Clarendon and Sweetwater neighborhoods were 60 percent and 59.2 percent, respectively.

\subsubsection{Frequency of Travel on Road Stopped}

Tables 6 and 7 compare the proximity of driver address with frequency of travel on the road on which the driver was stopped, for Peoria and Phoenix, respectively. Table 6 shows that, of those drivers stopped in Peoria who lived "in the neighborhood," 92.5 percent traveled on the road daily and an additional 4.7 percent traveled on the road weekly. Of those who lived within a mile of the neighborhood, 70.6 percent traveled on the road daily and an additional 19.6 percent traveled on the road weekly. Of those who lived "outside the neighborhood," 21 percent traveled on the road daily, and an additional 30.6 percent traveled on the road weekly. In fact, 75.9 percent of all of the drivers stopped for speeding in Peoria traveled on the road on which they were stopped at least once a week. Only 10.3 percent had never used the road before. Thus, they were frequent users of the roads on which they were stopped. 
Table 5. Proximity of Driver Address to Neighborhood (Phoenix)

\begin{tabular}{|c|c|c|c|c|c|}
\hline \multirow{2}{*}{\multicolumn{2}{|c|}{$\begin{array}{c}\text { Proximity of Driver Address to } \\
\text { Neighborhood }\end{array}$}} & \multicolumn{4}{|c|}{ Neighborhood } \\
\hline & & \multirow{2}{*}{$\frac{\text { Sweetwater }}{147}$} & \multirow{2}{*}{$\begin{array}{l}\begin{array}{c}\text { Moon } \\
\text { Valley/Coral } \\
\text { Gables }\end{array} \\
237\end{array}$} & \multirow{2}{*}{$\frac{\text { Clarendon }}{19}$} & \multirow{2}{*}{$\frac{\text { Total }}{403}$} \\
\hline \multirow{3}{*}{ In Neighborhood } & Count & & & & \\
\hline & Row \% & $36.5 \%$ & $58.8 \%$ & $4.7 \%$ & $100 \%$ \\
\hline & Column \% & $46.5 \%$ & $57.4 \%$ & $34.5 \%$ & $51.4 \%$ \\
\hline \multirow{3}{*}{$\begin{array}{l}\text { Near } \\
\text { Neighborhood }\end{array}$} & Count & 40 & 40 & 14 & 94 \\
\hline & Row \% & $42.6 \%$ & $42.6 \%$ & $14.9 \%$ & $100 \%$ \\
\hline & Column \% & $12.7 \%$ & $9.7 \%$ & $25.5 \%$ & $12 \%$ \\
\hline \multirow{3}{*}{$\begin{array}{l}\text { Outside } \\
\text { Neighborhood }\end{array}$} & Count & 129 & 136 & 22 & 287 \\
\hline & Row \% & $44.9 \%$ & $47.4 \%$ & $7.7 \%$ & $100 \%$ \\
\hline & Column \% & $40.8 \%$ & $32.9 \%$ & $40.0 \%$ & $36.6 \%$ \\
\hline \multirow{3}{*}{ Total } & Count & 316 & 413 & 55 & 784 \\
\hline & Row \% & $40.3 \%$ & $52.7 \%$ & $7.0 \%$ & $100 \%$ \\
\hline & Column \% & $100 \%$ & $100 \%$ & $100 \%$ & $100 \%$ \\
\hline
\end{tabular}

Table 6. Proximity of Driver Address to Neighborhood versus Frequency of Driver Travel on Road Stopped (Peoria)

\begin{tabular}{|c|c|c|c|c|c|}
\hline \multirow{2}{*}{\multicolumn{2}{|c|}{$\begin{array}{c}\text { Frequency of Travel } \\
\text { on Road Where } \\
\text { Stop Was Made }\end{array}$}} & \multicolumn{4}{|c|}{ Proximity } \\
\hline & & $\begin{array}{c}\text { In } \\
\text { Neighborhood }\end{array}$ & $\begin{array}{c}\text { Near } \\
\text { Neighborhood }\end{array}$ & $\begin{array}{c}\text { Outside } \\
\text { Neighborhood }\end{array}$ & Total \\
\hline \multirow{3}{*}{ Daily } & Count & 99 & 36 & 26 & 161 \\
\hline & Row \% & $61.5 \%$ & $22.4 \%$ & $16.1 \%$ & $100 \%$ \\
\hline & Column \% & $92.5 \%$ & $70.6 \%$ & $21.0 \%$ & $57.1 \%$ \\
\hline \multirow{3}{*}{ Weekly } & Count & 5 & 10 & 38 & 53 \\
\hline & Row \% & $9.4 \%$ & $18.9 \%$ & $71.7 \%$ & $100 \%$ \\
\hline & Column \% & $4.7 \%$ & $19.6 \%$ & $30.6 \%$ & $18.8 \%$ \\
\hline \multirow{3}{*}{ Monthly } & Count & 1 & 2 & 25 & 28 \\
\hline & Row \% & $3.6 \%$ & $7.1 \%$ & $89.3 \%$ & $100 \%$ \\
\hline & Column \% & $.9 \%$ & $3.9 \%$ & $20.2 \%$ & $9.9 \%$ \\
\hline \multirow{3}{*}{$\begin{array}{l}\text { Never } \\
\text { Before }\end{array}$} & Count & 0 & 2 & 27 & 29 \\
\hline & Row \% & $0 \%$ & $6.9 \%$ & $93.1 \%$ & $100 \%$ \\
\hline & Column \% & $0 \%$ & $3.9 \%$ & $21.8 \%$ & $10.3 \%$ \\
\hline \multirow{3}{*}{ Other } & Count & 2 & 1 & 8 & 11 \\
\hline & Row \% & $18.2 \%$ & $9.1 \%$ & $72.7 \%$ & $100 \%$ \\
\hline & Column \% & $1.9 \%$ & $2 \%$ & $6.5 \%$ & $3.9 \%$ \\
\hline \multirow{3}{*}{ Total } & Count & 107 & 51 & 124 & 282 \\
\hline & Row \% & $37.9 \%$ & $18.1 \%$ & $44 \%$ & $100 \%$ \\
\hline & Column \% & $100 \%$ & $100 \%$ & $100 \%$ & $100 \%$ \\
\hline
\end{tabular}

Table 7 shows that, of those drivers stopped in Phoenix who lived "in the neighborhood," 87 percent traveled on the road daily and an additional 8.2 percent traveled on the road weekly. Of those who lived within a mile of the neighborhood, 58.7 percent traveled on the road daily and an additional 30.4 percent traveled on the road weekly. Of those who lived "outside the 
neighborhood," 12.1 percent traveled on the road daily and an additional 25.9 percent traveled on the road weekly. Overall, 73.7 percent of the drivers stopped for speeding in Phoenix traveled on the road on which they were stopped at least once a week. Only 13.2 percent had never used the road before. Thus, as was true of the stopped Peoria speeders, the stopped Phoenix speeders were frequent users of the roads on which they were stopped.

Table 7. Proximity of Driver Address to Neighborhood versus Frequency of Driver Travel on Road Stopped (Phoenix)

\begin{tabular}{|c|c|c|c|c|c|}
\hline \multirow{2}{*}{\multicolumn{2}{|c|}{$\begin{array}{c}\text { Frequency of Travel } \\
\text { on Road Where } \\
\text { Stop Was Made }\end{array}$}} & \multicolumn{4}{|c|}{ Proximity } \\
\hline & & \multirow{2}{*}{$\begin{array}{r}\begin{array}{c}\text { In } \\
\text { Neighborhood }\end{array} \\
349\end{array}$} & \multirow{2}{*}{$\begin{array}{r}\begin{array}{c}\text { Near } \\
\text { Neighborhood }\end{array} \\
54\end{array}$} & \multirow{2}{*}{$\begin{array}{r}\begin{array}{c}\text { Outside } \\
\text { Neighborhood }\end{array} \\
34\end{array}$} & \multirow{2}{*}{$\frac{\text { Total }}{437}$} \\
\hline \multirow{3}{*}{ Daily } & Count & & & & \\
\hline & Row \% & $79.9 \%$ & $12.4 \%$ & $7.8 \%$ & $100 \%$ \\
\hline & Column \% & $87 \%$ & $58.7 \%$ & $12.1 \%$ & $56.4 \%$ \\
\hline \multirow{3}{*}{ Weekly } & Count & 33 & 28 & 73 & 134 \\
\hline & Row \% & $24.6 \%$ & $20.9 \%$ & $54.5 \%$ & $100 \%$ \\
\hline & Column \% & $8.2 \%$ & $30.4 \%$ & $25.9 \%$ & $17.3 \%$ \\
\hline \multirow{3}{*}{ Monthly } & Count & 7 & 7 & 66 & 80 \\
\hline & Row \% & $8.8 \%$ & $8.8 \%$ & $82.5 \%$ & $100 \%$ \\
\hline & Column \% & $1.7 \%$ & $7.6 \%$ & $23.4 \%$ & $10.3 \%$ \\
\hline \multirow{3}{*}{$\begin{array}{l}\text { Never } \\
\text { Before }\end{array}$} & Count & 10 & 3 & 89 & 102 \\
\hline & Row \% & $9.8 \%$ & $2.9 \%$ & $87.3 \%$ & $100 \%$ \\
\hline & Column \% & $2.5 \%$ & $3.3 \%$ & $31.6 \%$ & $13.2 \%$ \\
\hline \multirow{3}{*}{ Other } & Count & 2 & 0 & 20 & 22 \\
\hline & Row \% & $9.1 \%$ & $0 \%$ & $90.9 \%$ & $100 \%$ \\
\hline & Column \% & $.5 \%$ & $0 \%$ & $7.1 \%$ & $2.8 \%$ \\
\hline \multirow{3}{*}{ Total } & Count & 401 & 92 & 282 & 775 \\
\hline & Row \% & $51.7 \%$ & $11.9 \%$ & $36.4 \%$ & $100 \%$ \\
\hline & Column \% & $100 \%$ & $100 \%$ & $100 \%$ & $100 \%$ \\
\hline
\end{tabular}

\subsubsection{Time of Stop}

Table 8 shows the times that the special enforcement speeding stops were made in both Peoria and Phoenix. The table shows that all Peoria stops were made in two time periods: 6 a.m. to $8: 59$ a.m. (40.8\%) and 2 p.m. to 6:59 p.m. (59.2\%). These times appear to be selected to cover rush hour traffic, and therefore the drivers are likely typical of those who speed during rush hours in the three neighborhoods.

In contrast, the Phoenix police spread their special enforcement activities throughout the day (omitting the "graveyard shift" 11 p.m. to 5:59 a.m. time period). The majority of their stops $(55.5 \%)$ were made in the 2 p.m. to $6: 59$ p.m. time period. However, they also stopped 14.6 percent of their speeders in the morning rush hour (6 a.m. to 8:59 p.m.) and 25.7 percent of their speeders in the period from 9 a.m. to 1:59 p.m. A few stops were also made after 7 p.m. 
Table 8. Time of Stop (Peoria and Phoenix)

\begin{tabular}{|l|l|r|r|r|}
\hline \multicolumn{2}{|c|}{ Time of Stop } & \multicolumn{3}{c|}{ City } \\
\cline { 2 - 5 } & \multicolumn{1}{|c|}{ Phoenix } & \multicolumn{1}{c|}{ Peoria } & \multicolumn{1}{c|}{ Total } \\
\hline \multirow{4}{*}{ 6 a.m. to 8:59 am } & Count & 113 & 115 & 228 \\
\cline { 2 - 5 } & Row \% & $49.6 \%$ & $50.4 \%$ & $100 \%$ \\
\cline { 2 - 5 } & Column \% & $14.6 \%$ & $40.8 \%$ & $21.6 \%$ \\
\hline \multirow{4}{*}{ a.m. to 1:59 pm } & Count & 199 & 0 & 199 \\
\cline { 2 - 5 } & Row \% & $100 \%$ & $0 \%$ & $100 \%$ \\
\cline { 2 - 5 } & Column \% & $25.7 \%$ & $0 \%$ & $18.9 \%$ \\
\hline \multirow{3}{*}{ p.m. to 6:59 pm } & Count & 429 & 167 & 596 \\
\cline { 2 - 5 } & Row \% & $72 \%$ & $28 \%$ & $100 \%$ \\
\cline { 2 - 5 } & Column \% & $55.5 \%$ & $59.2 \%$ & $56.5 \%$ \\
\hline \multirow{3}{*}{$\begin{array}{l}\text { p.m. to } \\
\text { 10:59 p.m. }\end{array}$} & Count & 32 & 0 & 32 \\
\cline { 2 - 5 } & Row \% & $100 \%$ & $0 \%$ & $100 \%$ \\
\cline { 2 - 5 } & Column \% & $4.1 \%$ & $0 \%$ & $3 \%$ \\
\hline \multirow{3}{*}{ Total } & Count & 773 & 282 & 1055 \\
\cline { 2 - 5 } & Row \% & $73.3 \%$ & $26.7 \%$ & $100 \%$ \\
\cline { 2 - 5 } & Column \% & $100 \%$ & $100 \%$ & $100 \%$ \\
\hline
\end{tabular}

Table 9 shows the stops made by Peoria police broken down by time and the three neighborhoods under study. It shows that afternoon stops were made more often in the 95th Avenue neighborhood (71.5\%) and the Bell Park neighborhood (56.4\%). Morning stops were made more frequently in the Desert Harbor neighborhood (55.7\%).

Table 9. Neighborhood by a.m. or p.m. Stop (Peoria)

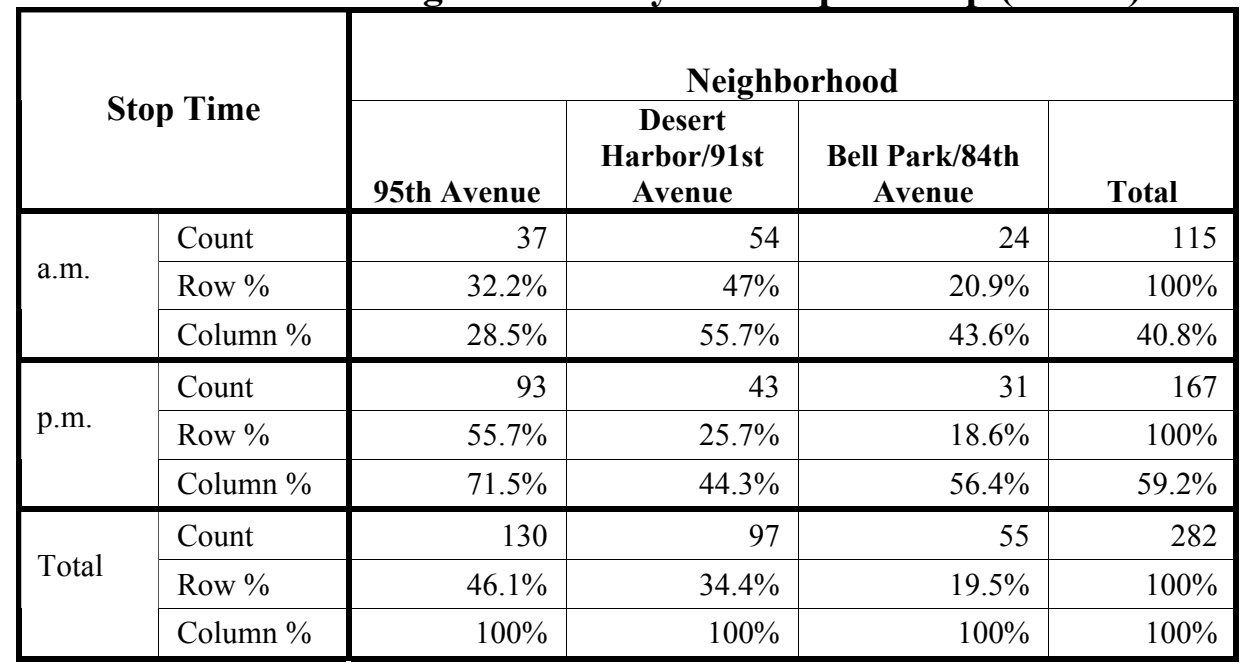

Similar data for Phoenix are shown in Table 10. That table shows that most stops (71.1\%) were made after the noon hour. This was true for all Phoenix neighborhoods, particularly the Clarendon neighborhood where 89.1 percent of the stops were made after the noon hour and Moon Valley/Coral Gables where 79.9 percent of the stops were made after the noon hour. 
Table 10. Neighborhood by a.m. or p.m. Stop (Phoenix)

\begin{tabular}{|c|c|c|c|c|c|}
\hline \multirow{2}{*}{\multicolumn{2}{|c|}{ Stop Time }} & \multicolumn{4}{|c|}{ Neighborhood } \\
\hline & & \multirow{2}{*}{$\frac{\text { Sweetwater }}{136}$} & \multirow{2}{*}{$\begin{array}{c}\begin{array}{c}\text { Moon } \\
\text { Valley/Coral } \\
\text { Gables }\end{array} \\
81\end{array}$} & \multirow{2}{*}{$\begin{array}{r}\text { Clarendon } \\
6\end{array}$} & \multirow{2}{*}{$\frac{\text { Total }}{223}$} \\
\hline \multirow{3}{*}{ a.m. } & Count & & & & \\
\hline & Row \% & $61 \%$ & $36.3 \%$ & $2.7 \%$ & $100 \%$ \\
\hline & Column \% & $43.3 \%$ & $20.1 \%$ & $10.9 \%$ & $28.9 \%$ \\
\hline \multirow{3}{*}{ p.m. } & Count & 178 & 322 & 49 & 549 \\
\hline & Row \% & $32.4 \%$ & $58.7 \%$ & $8.9 \%$ & $100 \%$ \\
\hline & Column \% & $56.7 \%$ & $79.9 \%$ & $89.1 \%$ & $71.1 \%$ \\
\hline \multirow{3}{*}{ Total } & Count & 314 & 403 & 55 & 772 \\
\hline & Row \% & $40.7 \%$ & $52.2 \%$ & $7.1 \%$ & $100 \%$ \\
\hline & Column \% & $100 \%$ & $100 \%$ & $100 \%$ & $100 \%$ \\
\hline
\end{tabular}

\subsubsection{Driver Age and Gender}

The next results address the demographics of the stopped drivers. These are presented simply to describe the stopped individuals rather than to suggest any overrepresentation since the underlying populations of all drivers on the road at the time of the stops is not known. Table 11 gives the gender of the Peoria drivers stopped for speeding as a function of their ages. Similar data for Phoenix are shown in Table 12. In terms of gender, Table 11 shows that the total Peoria sample of drivers stopped for speeding included more females $(53.4 \%)$ than males $(46.6 \%)$. In terms of age, the largest sample consisted of individuals who were in the range of 25 to 39 years $(37.6 \%)$. This age range was followed by those who were 40 to 64 years old $(33.7 \%)$, those who were under $25(20.8 \%)$, and those who were 65 or older $(7.9 \%)$. Males under $25(27.7 \%)$ were stopped more often than females $(14.8 \%)$ in the same age group, and females in the age range of 25 to $39(42.3 \%)$ were stopped more often than males $(32.3 \%)$ in that age group. For other age categories, the proportion of males and females was approximately the same.

Table 12 shows that the Phoenix sample of speeding drivers also included slightly more females $(52.4 \%)$ than males $(47.6 \%)$. In terms of age, the largest Phoenix sample consisted of individuals in the range of 40 to $64(42.6 \%)$. It was followed by those who were 25 to 39 (33.8\%), those who were under $25(19 \%)$, and those who are 65 and older $(4.6 \%)$. Males under 25 years of age $(23.3 \%)$ were stopped more often than females $(15.1 \%)$ in the same age group, and females in both age groups 25 to 39 and 40 to 64 were stopped more often than males in those age groups.

The mean age and age range of the stopped drivers from the two cities were similar. The mean age for Peoria drivers was 39 and the ages ranged from 16 to 82 . The mean age for Phoenix drivers was 39.1 and the ages ranged from 15 to 85 . 
Table 11. Age Range and Gender of Drivers Stopped (Peoria)

\begin{tabular}{|l|l|r|r|r|}
\hline \multicolumn{2}{|c|}{ Age Range } & \multicolumn{3}{c|}{ Gender } \\
\cline { 3 - 5 } \multicolumn{2}{|c|}{} & \multicolumn{1}{c|}{ Male } & \multicolumn{1}{c|}{ Female } & \multicolumn{1}{c|}{ Total } \\
\hline \multirow{3}{*}{$<25$} & Count & 36 & 22 & 58 \\
\cline { 2 - 5 } & Row $\%$ & $62.1 \%$ & $37.9 \%$ & $100 \%$ \\
\cline { 2 - 5 } & Column \% & $27.7 \%$ & $14.8 \%$ & $20.8 \%$ \\
\hline \multirow{3}{*}{$25-39$} & Count & 42 & 63 & 105 \\
\cline { 2 - 5 } & Row $\%$ & $40 \%$ & $60 \%$ & $100 \%$ \\
\cline { 2 - 5 } & Column \% & $32.3 \%$ & $42.3 \%$ & $37.6 \%$ \\
\hline \multirow{3}{*}{$65-64$} & Count & 41 & 53 & 94 \\
\cline { 2 - 5 } & Row $\%$ & $43.6 \%$ & $56.4 \%$ & $100 \%$ \\
\cline { 2 - 5 } & Column \% & $31.5 \%$ & $35.6 \%$ & $33.7 \%$ \\
\hline \multirow{3}{*}{ Total } & Count & 11 & 11 & 22 \\
\cline { 2 - 5 } & Row $\%$ & $50 \%$ & $50 \%$ & $100 \%$ \\
\cline { 2 - 5 } & Column $\%$ & $8.5 \%$ & $7.4 \%$ & $7.9 \%$ \\
\hline & Count & 130 & 149 & 279 \\
\cline { 2 - 5 } & Row $\%$ & $46.6 \%$ & $53.4 \%$ & $100 \%$ \\
\cline { 2 - 5 } & Column \% & $100 \%$ & $100 \%$ & $100 \%$ \\
\hline
\end{tabular}

Table 12. Age Range and Gender of Drivers Stopped (Phoenix)

\begin{tabular}{|l|l|r|r|r|}
\hline \multicolumn{2}{|c|}{ Age Range } & \multicolumn{3}{c|}{ Gender } \\
\cline { 3 - 5 } \multicolumn{2}{|c|}{} & \multicolumn{1}{c|}{ Male } & \multicolumn{1}{c|}{ Female } & \multicolumn{1}{c|}{ Total } \\
\hline \multirow{2}{*}{$<25$} & Count & 87 & 62 & 149 \\
\cline { 2 - 5 } & Row $\%$ & $58.4 \%$ & $41.6 \%$ & $100 \%$ \\
\cline { 2 - 5 } & Column \% & $23.3 \%$ & $15.1 \%$ & $19 \%$ \\
\hline \multirow{2}{*}{$25-39$} & Count & 113 & 152 & 265 \\
\cline { 2 - 5 } & Row $\%$ & $42.6 \%$ & $57.4 \%$ & $100 \%$ \\
\cline { 2 - 5 } & Column \% & $30.3 \%$ & $37 \%$ & $33.8 \%$ \\
\hline \multirow{3}{*}{$40-64$} & Count & 152 & 182 & 334 \\
\cline { 2 - 5 } & Row $\%$ & $45.5 \%$ & $54.5 \%$ & $100 \%$ \\
\cline { 2 - 5 } & Column \% & $40.8 \%$ & $44.3 \%$ & $42.6 \%$ \\
\hline \multirow{2}{*}{$65+$} & Count & 21 & 15 & 36 \\
\cline { 2 - 5 } & Row $\%$ & $58.3 \%$ & $41.7 \%$ & $100 \%$ \\
\cline { 2 - 5 } & Column \% & $5.6 \%$ & $3.6 \%$ & $4.6 \%$ \\
\hline \multirow{2}{*}{ Total } & Count & 373 & 411 & 784 \\
\cline { 2 - 5 } & Row $\%$ & $47.6 \%$ & $52.4 \%$ & $100 \%$ \\
\cline { 2 - 5 } & Column \% & $100 \%$ & $100 \%$ & $100 \%$ \\
\hline
\end{tabular}

\subsubsection{Safety Belt Use}

Table 13 shows whether or not the drivers stopped in Peoria were wearing safety belts as a function of their gender. Similar data for Phoenix drivers are shown in Table 14. Arizona has only a secondary safety belt law but has shown extremely high safety belt use rates in national surveys. The measured Arizona safety belt use rates for 2002 and 2003, respectively, were 73.7 percent and 86.2 percent (NHTSA, 2004). 
Overall, Table 13 shows that 84.6 percent of the drivers stopped for speeding in Peoria were belted. By gender, the table shows that 93.3 percent of the stopped females were belted in contrast to only 74.8 percent of the stopped males.

Table 14 shows that the belt use data for Phoenix are similar to those for Peoria. Overall, 85.1 percent of the drivers stopped for speeding in Phoenix were belted. However, the difference in belt use between males and females was not as pronounced as it was in Peoria. A smaller proportion of females (88.8\%) were belted in Phoenix than in Peoria. Also, a larger proportion of males $(80.9 \%)$ were belted in Phoenix than in Peoria. Across both cities, it is noteworthy that belt use appears unusually high for a population of drivers caught speeding. Perhaps drivers even those who are speeding - in the residential neighborhood settings studied in this project are simply conscientious safety belt users.

Table 13. Driver Safety Belt Use versus Gender (Peoria)

\begin{tabular}{|l|l|r|r|r|}
\hline \multirow{2}{*}{ Was Driver Belted? } & \multicolumn{3}{|c|}{ Gender } \\
\cline { 3 - 5 } & \multicolumn{1}{|c|}{ Male } & \multicolumn{1}{c|}{ Female } & \multicolumn{1}{c|}{ Total } \\
\hline \multirow{3}{*}{ Yes } & Count & 98 & 139 & 237 \\
\cline { 2 - 5 } & Row $\%$ & $41.4 \%$ & $58.6 \%$ & $100 \%$ \\
\cline { 2 - 5 } & Column $\%$ & $74.8 \%$ & $93.3 \%$ & $84.6 \%$ \\
\hline \multirow{3}{*}{ No } & Count & 33 & 10 & 43 \\
\cline { 2 - 5 } & Row $\%$ & $76.7 \%$ & $23.3 \%$ & $100 \%$ \\
\cline { 2 - 5 } & Column $\%$ & $25.2 \%$ & $6.7 \%$ & $15.4 \%$ \\
\hline \multirow{3}{*}{ Total } & Count & 131 & 149 & 280 \\
\cline { 2 - 5 } & Row $\%$ & $46.8 \%$ & $53.2 \%$ & $100 \%$ \\
\cline { 2 - 5 } & Column $\%$ & $100 \%$ & $100 \%$ & $100 \%$ \\
\hline
\end{tabular}

Table 14. Driver Safety Belt Use versus Gender (Phoenix)

\begin{tabular}{|c|c|c|c|c|}
\hline \multirow{2}{*}{\multicolumn{2}{|c|}{ Was Driver Belted? }} & \multicolumn{3}{|c|}{ Gender } \\
\hline & & \multirow{2}{*}{$\frac{\text { Male }}{301}$} & \multirow{2}{*}{$\frac{\text { Female }}{365}$} & \multirow{2}{*}{$\frac{\text { Total }}{666}$} \\
\hline Yes & Count & & & \\
\hline & Row \% & $45.2 \%$ & $54.8 \%$ & $100 \%$ \\
\hline & Column \% & $80.9 \%$ & $88.8 \%$ & $85.1 \%$ \\
\hline \multirow[t]{3}{*}{ No } & Count & 71 & 46 & 117 \\
\hline & Row \% & $60.7 \%$ & $39.3 \%$ & $100 \%$ \\
\hline & Column \% & $19.1 \%$ & $11.2 \%$ & $14.9 \%$ \\
\hline \multirow{3}{*}{ Total } & Count & 372 & 411 & 783 \\
\hline & Row \% & $47.5 \%$ & $52.5 \%$ & $100 \%$ \\
\hline & Column \% & $100 \%$ & $100 \%$ & $100 \%$ \\
\hline
\end{tabular}

Table 15 shows driver safety belt use by age and gender for Peoria stopped drivers. Similar data for Phoenix stopped drivers are shown in Table 16.

Table 15 shows that 25 percent of stopped males in Peoria who were under age 25 were unbelted in contrast to 9.1 percent of the females. For stopped drivers between 25 and 39 years of age, 32.5 percent of males were unbelted in contrast to 9.5 percent of females. For stopped 
drivers between 40 and 64 years of age, 19.5 percent of males were unbelted in contrast to 1.9 percent of the females. Finally, for stopped drivers who are 65 years of age and older, 9.1 percent of both males and females were unbelted.

It is interesting that the largest nonuse of safety belts among males was observed for the 25 to 39 age range followed by the under 25 age group. Use of safety belts by males increased at age 40 and above. For females, nonuse of belts was reasonably constant at around 9 percent, except for the age range of 40 to 64 where it dropped to 1.9 percent. However, the number of unbelted females was extremely small in each age range (ranging from one to six).

Table 15. Driver Safety Belt Use versus Gender and Age Range (Peoria)

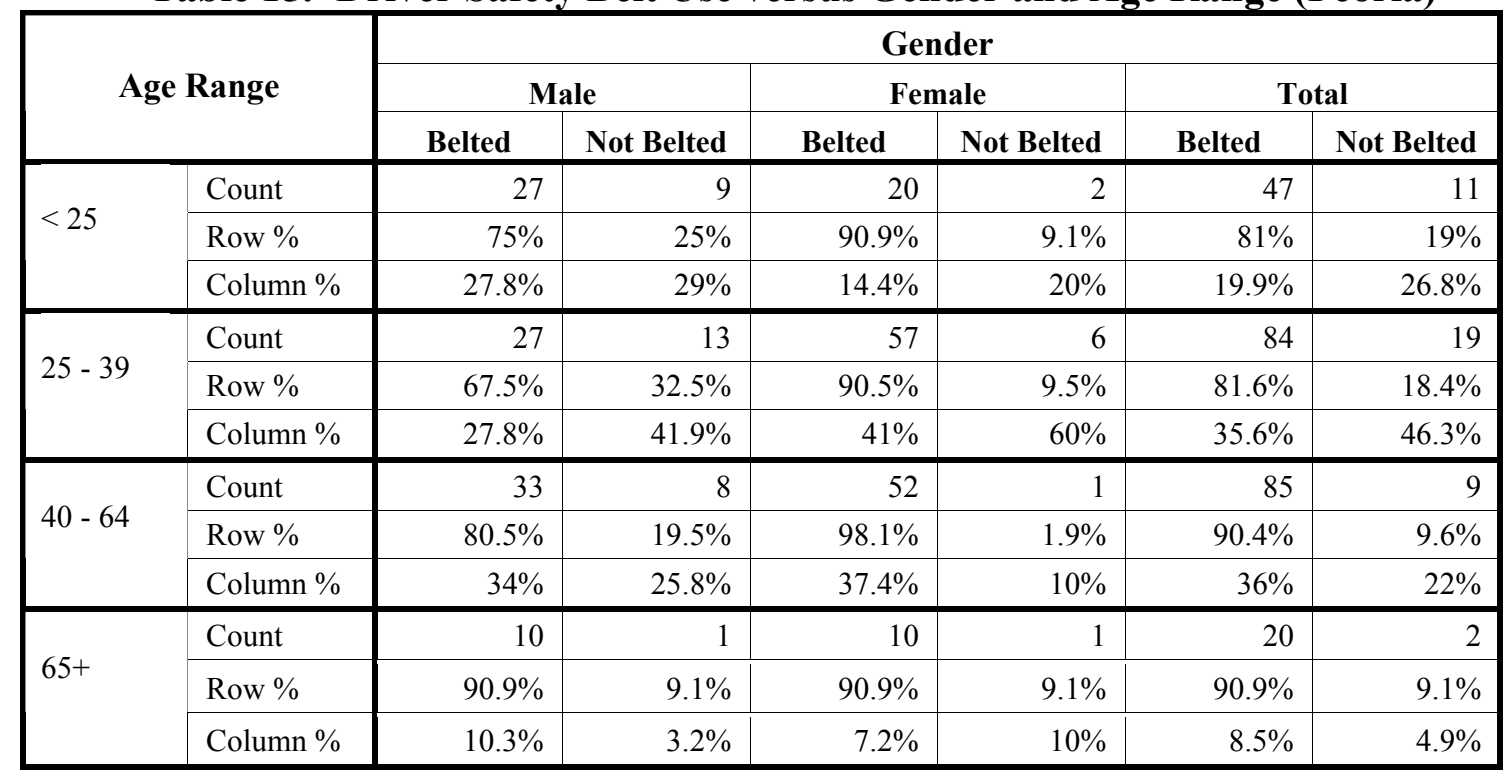

Table 16 shows that 21.8 percent of the stopped Phoenix males under 25 were unbelted in contrast to 30.6 percent of the females. For males between 25 and 39 years of age, 23 percent were unbelted in comparison to 10 percent of the females. Belt use increased for males aged 40 and above as it did for females. There were no unbelted females aged 65 and above. As was the case with Peoria speeders, the number of unbelted females in each age range category was small.

\subsubsection{Vehicle Occupants}

The number of people (including the driver) in the speeders' vehicles is shown in Table 17. Data in this table are combined for both Peoria and Phoenix. As might be expected (since many of the stops were made during rush hours), the majority of vehicles stopped in both cities contained a driver only (73\% for Phoenix and $70.1 \%$ for Peoria). There was a driver only or a driver with one passenger in 90.2 percent of the vehicles. The maximum number of occupants in any one vehicle was six. 
Table 16. Driver Safety Belt Use versus Gender and Age Range (Phoenix)

\begin{tabular}{|c|c|c|c|c|c|c|c|}
\hline \multirow{2}{*}{\multicolumn{2}{|c|}{ Age Range }} & \multicolumn{6}{|c|}{ Gender } \\
\hline & & Belted & Not Belted & Belted & Not Belted & Belted & Not Belted \\
\hline \multirow{3}{*}{$<25$} & Count & 68 & 19 & 43 & 19 & 111 & 38 \\
\hline & Row \% & $78.2 \%$ & $21.8 \%$ & $69.4 \%$ & $30.6 \%$ & $74.5 \%$ & $25.5 \%$ \\
\hline & Column \% & $22.7 \%$ & $27.5 \%$ & $11.9 \%$ & $41.3 \%$ & $16.8 \%$ & $33 \%$ \\
\hline \multirow{3}{*}{$25-39$} & Count & 87 & 26 & 135 & 15 & 222 & 41 \\
\hline & Row \% & $77 \%$ & $23 \%$ & $90 \%$ & $10 \%$ & $84.4 \%$ & $15.6 \%$ \\
\hline & Column \% & $29 \%$ & $37.7 \%$ & $37.3 \%$ & $32.6 \%$ & $33.5 \%$ & $35.7 \%$ \\
\hline \multirow{3}{*}{$40-64$} & Count & 128 & 20 & 169 & 12 & 297 & 32 \\
\hline & Row \% & $86.5 \%$ & $13.5 \%$ & $93.4 \%$ & $6.6 \%$ & $90.3 \%$ & $9.7 \%$ \\
\hline & Column \% & $42.7 \%$ & $29 \%$ & $46.7 \%$ & $26.1 \%$ & $44.9 \%$ & $27.8 \%$ \\
\hline \multirow{3}{*}{$65+$} & Count & 17 & 4 & 15 & 0 & 32 & 4 \\
\hline & Row \% & $81 \%$ & $19 \%$ & $100 \%$ & $0 \%$ & $88.9 \%$ & $11.1 \%$ \\
\hline & Column \% & $5.7 \%$ & $5.8 \%$ & $4.1 \%$ & $0 \%$ & $4.8 \%$ & $3.5 \%$ \\
\hline
\end{tabular}

Table 17. Number of People in the Stopped Vehicles (Peoria and Phoenix)

\begin{tabular}{|c|c|c|c|c|}
\hline \multirow{2}{*}{\multicolumn{2}{|c|}{$\begin{array}{c}\text { Number of People in } \\
\text { Vehicle }\end{array}$}} & \multicolumn{3}{|c|}{ City } \\
\hline & & \multirow{2}{*}{$\frac{\text { Phoenix }}{574}$} & \multirow{2}{*}{$\frac{\text { Peoria }}{197}$} & \multirow{2}{*}{$\frac{\text { Total }}{771}$} \\
\hline \multirow{3}{*}{1} & Count & & & \\
\hline & Row \% & $74.4 \%$ & $25.6 \%$ & $100 \%$ \\
\hline & Column \% & $73 \%$ & $70.1 \%$ & $72.3 \%$ \\
\hline \multirow{3}{*}{2} & Count & 136 & 55 & 191 \\
\hline & Row \% & $71.2 \%$ & $28.8 \%$ & $100 \%$ \\
\hline & Column \% & $17.3 \%$ & $19.6 \%$ & $17.9 \%$ \\
\hline \multirow{3}{*}{3} & Count & 45 & 14 & 59 \\
\hline & Row \% & $76.3 \%$ & $23.7 \%$ & $100 \%$ \\
\hline & Column \% & $5.7 \%$ & $5 \%$ & $5.5 \%$ \\
\hline \multirow{3}{*}{4} & Count & 24 & 13 & 37 \\
\hline & Row \% & $64.9 \%$ & $35.1 \%$ & $100 \%$ \\
\hline & Column \% & $3.1 \%$ & $4.6 \%$ & $3.5 \%$ \\
\hline \multirow{3}{*}{5} & Count & 5 & 1 & 6 \\
\hline & Row \% & $83.3 \%$ & $16.7 \%$ & $100 \%$ \\
\hline & Column \% & $.6 \%$ & $.4 \%$ & $.6 \%$ \\
\hline \multirow{3}{*}{6} & Count & 2 & 1 & 3 \\
\hline & Row \% & $66.7 \%$ & $33.3 \%$ & $100 \%$ \\
\hline & Column \% & $.3 \%$ & $.4 \%$ & $.3 \%$ \\
\hline \multirow{3}{*}{ Total } & Count & 786 & 281 & 1067 \\
\hline & Row \% & $73.7 \%$ & $26.3 \%$ & $100 \%$ \\
\hline & Column \% & $100 \%$ & $100 \%$ & $100 \%$ \\
\hline
\end{tabular}




\subsubsection{Vehicle Type and Model Year}

Table 18 shows that just over half $(53.5 \%)$ of the stopped vehicles in the two cities combined were cars. This was true for both Peoria (53.4\%) and Phoenix (53.5\%). The next largest categories consisted of SUVs (17.9\%), pickup trucks $(17.4 \%)$, and minivans $(8.5 \%)$. The data for Peoria and Phoenix were similar except that the second most-used vehicle in Peoria was the pickup truck (24.4\% versus $14.9 \%$ in Phoenix). The third most-used vehicle in Peoria was the SUV (11.3\% versus $20.3 \%$ for Phoenix).

The vehicle model years ranged from 1966 to 2003. A grouping by vehicle model year is presented in Table 19. That table shows that the model year of 92.8 percent of the vehicles was 1990 or newer, and the model year of 41.2 percent of the vehicles was 2000 or newer. The data were similar for both cities.

Table 18. Vehicle Type (Phoenix and Peoria)

\begin{tabular}{|c|c|c|c|c|}
\hline \multirow{2}{*}{\multicolumn{2}{|c|}{ Vehicle type }} & \multicolumn{3}{|c|}{ City } \\
\hline & & Phoenix & Peoria & Total \\
\hline \multirow{3}{*}{ Car } & Count & 425 & 151 & 576 \\
\hline & Row \% & $73.8 \%$ & $26.2 \%$ & $100 \%$ \\
\hline & Column \% & $53.5 \%$ & $53.4 \%$ & $53.5 \%$ \\
\hline \multirow{3}{*}{ Minivan } & Count & 68 & 24 & 92 \\
\hline & Row \% & $73.9 \%$ & $26.1 \%$ & $100 \%$ \\
\hline & Column \% & $8.6 \%$ & $8.5 \%$ & $8.5 \%$ \\
\hline \multirow{3}{*}{ SUV } & Count & 161 & 32 & 193 \\
\hline & Row \% & $83.4 \%$ & $16.6 \%$ & $100 \%$ \\
\hline & Column \% & $20.3 \%$ & $11.3 \%$ & $17.9 \%$ \\
\hline \multirow{3}{*}{ Pickup } & Count & 118 & 69 & 187 \\
\hline & Row \% & $63.1 \%$ & $36.9 \%$ & $100 \%$ \\
\hline & Column \% & $14.9 \%$ & $24.4 \%$ & $17.4 \%$ \\
\hline \multirow{3}{*}{ Other truck } & Count & 7 & 0 & 7 \\
\hline & Row \% & $100 \%$ & $0 \%$ & $100 \%$ \\
\hline & Column \% & $.9 \%$ & $0 \%$ & $.6 \%$ \\
\hline \multirow{3}{*}{ Motorcycle } & Count & 5 & 2 & 7 \\
\hline & Row \% & $71.4 \%$ & $28.6 \%$ & $100 \%$ \\
\hline & Column \% & $.6 \%$ & $.7 \%$ & $.6 \%$ \\
\hline \multirow{3}{*}{ Other } & Count & 10 & 5 & 15 \\
\hline & Row \% & $66.7 \%$ & $33.3 \%$ & $100 \%$ \\
\hline & Column \% & $1.3 \%$ & $1.8 \%$ & $1.4 \%$ \\
\hline \multirow{3}{*}{ Total } & Count & 794 & 283 & 1,077 \\
\hline & Row \% & $73.7 \%$ & $26.3 \%$ & $100 \%$ \\
\hline & Column \% & $100 \%$ & $100 \%$ & $100 \%$ \\
\hline
\end{tabular}


Table 19. Vehicle Model Year (Peoria and Phoenix)

\begin{tabular}{|l|l|c|c|c|}
\hline \multicolumn{2}{|c|}{ Model Year } & \multicolumn{3}{|c|}{ City } \\
\cline { 3 - 5 } & Phoenix & Peoria & Total \\
\hline \multirow{2}{*}{$<1980$} & Count & 13 & 6 & 19 \\
\cline { 2 - 5 } & Row \% & $68.4 \%$ & $31.6 \%$ & $100 \%$ \\
\cline { 2 - 5 } & Column \% & $1.6 \%$ & $2.1 \%$ & $1.8 \%$ \\
\hline \multirow{3}{*}{$1980-1989$} & Count & 39 & 19 & 58 \\
\cline { 2 - 5 } & Row \% & $67.2 \%$ & $32.8 \%$ & $100 \%$ \\
\cline { 2 - 5 } & Column \% & $4.9 \%$ & $6.7 \%$ & $5.4 \%$ \\
\hline \multirow{3}{*}{$1990-1999$} & Count & 412 & 142 & 554 \\
\cline { 2 - 5 } & Row \% & $74.4 \%$ & $25.6 \%$ & $100 \%$ \\
\cline { 2 - 5 } & Column \% & $52.2 \%$ & $50.2 \%$ & $51.6 \%$ \\
\hline \multirow{2}{*}{$2000-2003$} & Count & 326 & 116 & 442 \\
\cline { 2 - 5 } & Row \% & $73.8 \%$ & $26.2 \%$ & $100 \%$ \\
\cline { 2 - 5 } & Column \% & $41.3 \%$ & $41 \%$ & $41.2 \%$ \\
\hline \multirow{2}{*}{ Total } & Count & 790 & 283 & 1073 \\
\cline { 2 - 5 } & Row \% & $73.6 \%$ & $26.4 \%$ & $100 \%$ \\
\cline { 2 - 5 } & Column \% & $100 \%$ & $100 \%$ & $100 \%$ \\
\hline
\end{tabular}

\subsubsection{Officer's Action}

Finally, each officer was asked to indicate the action taken as a result of the stop. Specifically, the officer was asked to indicate if a ticket was issued, if the ticket facsimile that contained literature on the dangers of speeding was given to the driver, or if both a ticket and the literature were given. Officers from the two cities handled the question somewhat differently. The results are given in Table 20.

Table 20 shows that officers in Peoria ticketed 5 percent of the stopped speeders -3.2 percent of all those stopped received a ticket only, and 1.8 percent received both a ticket and the project speeding literature (the ticket facsimile). No request was made on the police stop form for the officer to indicate the type of ticket issued. Since the stop was made for a speeding offense, it was assumed that any ticket issued was also for a speeding offense.

In all, 96.8 percent of the stopped Peoria speeders received the project literature. As indicated previously, the primary intent of this activity was to have the police officer provide information on the dangers of speeding - at least initially. Peoria officers issued tickets only in exceptional cases when the driver was unusually flagrant in disobeying the law.

The officers in Phoenix used a more traditional method of ticketing. In addition, several officers included on the form not only tickets issued for speeding but also tickets issued for other offenses. The "other" category in Table 20 includes all of these "other" ticketing situations (i.e., those that did not involve speeding). These other offenses included license irregularities, lack of safety belts, etc. As in Peoria, if no specific offense was listed, speeding was assumed since that was the focus of the study. The following listing provides a summary of all known ticketing by the Phoenix police during their special enforcement program: 
Ticket Type

Speeding

Speeding warning

Insurance

Safety belt

License

Stop sign

Registration

Drugs

\section{Count}

460

10

29

28

18

2

2

1
$\%$ of Total Police Actions

$59.1 \%$

$1.3 \%$

$3.7 \%$

$3.6 \%$

$2.3 \%$

$0.2 \%$

$0.2 \%$

$0.1 \%$

In addition, 342 individuals (43.9\% of the drivers stopped in Phoenix) were given project literature. Of the Phoenix drivers who were stopped, 298 (38.3\%) received literature alone.

Table 20. Officer's Action (Peoria and Phoenix)

\begin{tabular}{|c|c|c|c|c|}
\hline \multirow{2}{*}{\multicolumn{2}{|c|}{ Officer's Action }} & \multicolumn{3}{|c|}{ City } \\
\hline & & \multirow{2}{*}{$\frac{\text { Phoenix }}{384}$} & \multirow{2}{*}{$\begin{array}{r}\text { Peoria } \\
9\end{array}$} & \multirow{2}{*}{$\frac{\text { Total }}{393}$} \\
\hline \multirow{3}{*}{$\begin{array}{l}\text { Gave Ticket (Speed) } \\
\text { Only }\end{array}$} & Count & & & \\
\hline & Row \% & $97.7 \%$ & $2.3 \%$ & $100 \%$ \\
\hline & Column \% & $49.3 \%$ & $3.2 \%$ & $37.1 \%$ \\
\hline \multirow{3}{*}{ Gave Literature Only } & Count & 298 & 265 & 563 \\
\hline & Row \% & $52.9 \%$ & $47.1 \%$ & $100 \%$ \\
\hline & Column \% & $38.3 \%$ & $95 \%$ & $53.2 \%$ \\
\hline \multirow{3}{*}{$\begin{array}{l}\text { Gave Ticket (Speed) } \\
\text { and Literature }\end{array}$} & Count & 24 & 5 & 29 \\
\hline & Row \% & $82.8 \%$ & $17.2 \%$ & $100 \%$ \\
\hline & Column \% & $3.1 \%$ & $1.8 \%$ & $2.7 \%$ \\
\hline \multirow{3}{*}{$\begin{array}{l}\text { Gave Tickets (Speed } \\
\text { and Other) }\end{array}$} & Count & 47 & 0 & 47 \\
\hline & Row \% & $100 \%$ & $0 \%$ & $100 \%$ \\
\hline & Column \% & $6.0 \%$ & $0 \%$ & $4.4 \%$ \\
\hline \multirow{3}{*}{$\begin{array}{l}\text { Gave Tickets (Speed } \\
\text { and Other) and } \\
\text { Literature }\end{array}$} & Count & 5 & 0 & 5 \\
\hline & Row \% & $100 \%$ & $0 \%$ & $100 \%$ \\
\hline & Column \% & $.6 \%$ & $0 \%$ & $.5 \%$ \\
\hline \multirow{3}{*}{$\begin{array}{l}\text { Gave Warning } \\
\text { (Speed) and } \\
\text { Literature }\end{array}$} & Count & 8 & 0 & 8 \\
\hline & Row \% & $100 \%$ & $0 \%$ & $100 \%$ \\
\hline & Column \% & $1 \%$ & $0 \%$ & $.8 \%$ \\
\hline \multirow{3}{*}{$\begin{array}{l}\text { Gave Warning } \\
\text { (Speed), Ticket } \\
\text { (Other), and } \\
\text { Literature }\end{array}$} & Count & 2 & 0 & 2 \\
\hline & Row \% & $100 \%$ & $0 \%$ & $100 \%$ \\
\hline & Column \% & $.3 \%$ & $0 \%$ & $.2 \%$ \\
\hline \multirow{3}{*}{ Gave Ticket (Other) } & Count & 6 & 0 & 6 \\
\hline & Row \% & $100.0 \%$ & $.0 \%$ & $100.0 \%$ \\
\hline & Column \% & $.8 \%$ & $.0 \%$ & $.6 \%$ \\
\hline \multirow{3}{*}{$\begin{array}{l}\text { Gave Ticket (Other) } \\
\text { and Literature }\end{array}$} & Count & 5 & 0 & 5 \\
\hline & Row \% & $100 \%$ & $0 \%$ & $100 \%$ \\
\hline & Column \% & $.6 \%$ & $0 \%$ & $.5 \%$ \\
\hline \multirow{3}{*}{ Total } & Count & 779 & 279 & 1,058 \\
\hline & Row \% & $73.6 \%$ & $26.4 \%$ & $100 \%$ \\
\hline & Column \% & $100 \%$ & $100 \%$ & $100 \%$ \\
\hline
\end{tabular}




\subsubsection{Extent of Speed Violation}

Although there was no space allocated on the police stop form for recording the speed that prompted the stop ${ }^{6}$, some officers wrote one or more of the following items of information on the form - posted speed, actual speed or amount the vehicle was moving over the posted speed. In Phoenix, 552 forms (69.5\%) contained data that indicated the amount that vehicles were traveling over posted speeds. The data for those 552 forms are shown in Table 21.

Table 21 shows that vehicles stopped in Phoenix for which the police wrote in data exceeded posted speeds by a range of 6 to 31 miles. In $88 \%$ of the cases, the vehicles exceeded the posted speeds by $10 \mathrm{mph}$ or more. The roads on which these vehicles were traveling had speed limits of either 25 or $30 \mathrm{mph}$.

Table 21. Amounts That Stopped Vehicles Traveled Over Posted Speeds (Phoenix)

\begin{tabular}{|c|c|c|c|}
\hline $\begin{array}{c}\text { Speed Over } \\
\text { Posted Speed } \\
(\text { mph })\end{array}$ & Count & Percent & $\begin{array}{c}\text { Cumulative } \\
\text { Percent }\end{array}$ \\
\hline 6 & 1 & $.2 \%$ & $.2 \%$ \\
\hline 7 & 11 & $2 \%$ & $2.2 \%$ \\
\hline 8 & 27 & $4.9 \%$ & $7.1 \%$ \\
\hline 9 & 27 & $4.9 \%$ & $12 \%$ \\
\hline 10 & 65 & $11.8 \%$ & $23.7 \%$ \\
\hline 11 & 93 & $16.8 \%$ & $40.6 \%$ \\
\hline 12 & 81 & $14.7 \%$ & $55.3 \%$ \\
\hline 13 & 76 & $13.8 \%$ & $69 \%$ \\
\hline 14 & 46 & $8.3 \%$ & $77.4 \%$ \\
\hline 15 & 34 & $6.2 \%$ & $83.5 \%$ \\
\hline 16 & 22 & $4 \%$ & $87.5 \%$ \\
\hline 17 & 15 & $2.7 \%$ & $90.2 \%$ \\
\hline 18 & 18 & $3.3 \%$ & $93.5 \%$ \\
\hline 19 & 13 & $2.4 \%$ & $95.8 \%$ \\
\hline 20 & 6 & $1.1 \%$ & $96.9 \%$ \\
\hline 21 & 3 & $.5 \%$ & $97.5 \%$ \\
\hline 22 & 4 & $.7 \%$ & $98.2 \%$ \\
\hline 23 & 3 & $.5 \%$ & $98.7 \%$ \\
\hline 24 & 4 & $.7 \%$ & $99.5 \%$ \\
\hline 30 & 1 & $.2 \%$ & $99.6 \%$ \\
\hline 31 & 2 & $.4 \%$ & $100 \%$ \\
\hline Total & 552 & $100 \%$ & \\
\hline
\end{tabular}

\footnotetext{
${ }^{6}$ In retrospect, this was probably a poor decision on the part of this project. It was assumed that the police would not want to publicize their decision-making and so no data category was included. As data collection progressed, it became clear that the participating police would have been willing to record the information. At that point, the Phoenix police participants agreed to ask all involved officers to write in the information.
} 
The Phoenix data on extent of speed violation were not obtained from all neighborhoods. No speed data were available for any stops made in the Clarendon neighborhood. This is not surprising since, as will be discussed later, prevailing speeds on Clarendon were quite low because of the speed humps that had been installed prior to the commencement of this study. Even the higher speeds between the humps were not sufficient to prompt the officers to make a note. In terms of the other neighborhoods, 58.7 percent of the speed data came from stops made in the Moon Valley/Coral Gables neighborhood, and 41.3 percent came from stops made in the Sweetwater neighborhood.

Only 38 of the police stop Peoria forms (13.4\% of the sample) contained speed data. The data came primarily from the Bell Park neighborhood and showed actual speeds over the posted limit ranging from $7 \mathrm{mph}$ to $18 \mathrm{mph}$.

\subsubsection{Summary of Police Stop Data}

Tables 22 and 23 summarize the information obtained from the police stop form. Table 22 provides information on data collection. Table 23 provides a profile of individuals stopped for speeding during the Heed the Speed program in Peoria and Phoenix.

Table 22. Summary of Police Stop Form Data Collection (Peoria and Phoenix)

\begin{tabular}{|c|c|c|}
\hline Activity/Information & Peoria & Phoenix \\
\hline Duration of Data Collection & 3 months & 6 months \\
\hline Forms Completed & 283 & 794 \\
\hline Stops Made per Month & $\begin{array}{l}\text { Month } 1-47.3 \% \\
\text { Month } 2-28.6 \% \\
\text { Month } 3-24 \%\end{array}$ & $\begin{array}{ll}\text { Month 1 - 23.6\% } & \text { Month 4-37.1\% } \\
\text { Month 2-14\% } & \text { Month 5 - 15.4\% } \\
\text { Month 3- 4.2\% } & \text { Month 6 - 5.8\% }\end{array}$ \\
\hline Unusual Stop Coverage & $\begin{array}{l}89.1 \% \text { of Bell Park stops were made } \\
\text { in the first month }\end{array}$ & None \\
\hline Time of Stops & Rush hour & All day \\
\hline $\begin{array}{l}\text { Stops Made per } \\
\text { Neighborhood }\end{array}$ & $\begin{array}{l}95 \text { th Avenue }-45.9 \% \\
\text { Desert Harbor }-34.6 \% \\
\text { Bell Park } \quad-19.4 \%\end{array}$ & $\begin{array}{lr}\text { Moon Valley }-52.4 \% \\
\text { Sweetwater } \quad-40.4 \% \\
\text { Clarendon } \quad-7.2 \%\end{array}$ \\
\hline Speed Data & $\begin{array}{l}\text { Forms for } 13.4 \% \text { of the stops included } \\
\text { speed data }\end{array}$ & $\begin{array}{l}\text { Forms for } 69.5 \% \text { of the stops included } \\
\text { speed data }\end{array}$ \\
\hline
\end{tabular}


Table 23. Profile of Stopped Peoria and Phoenix Speeders

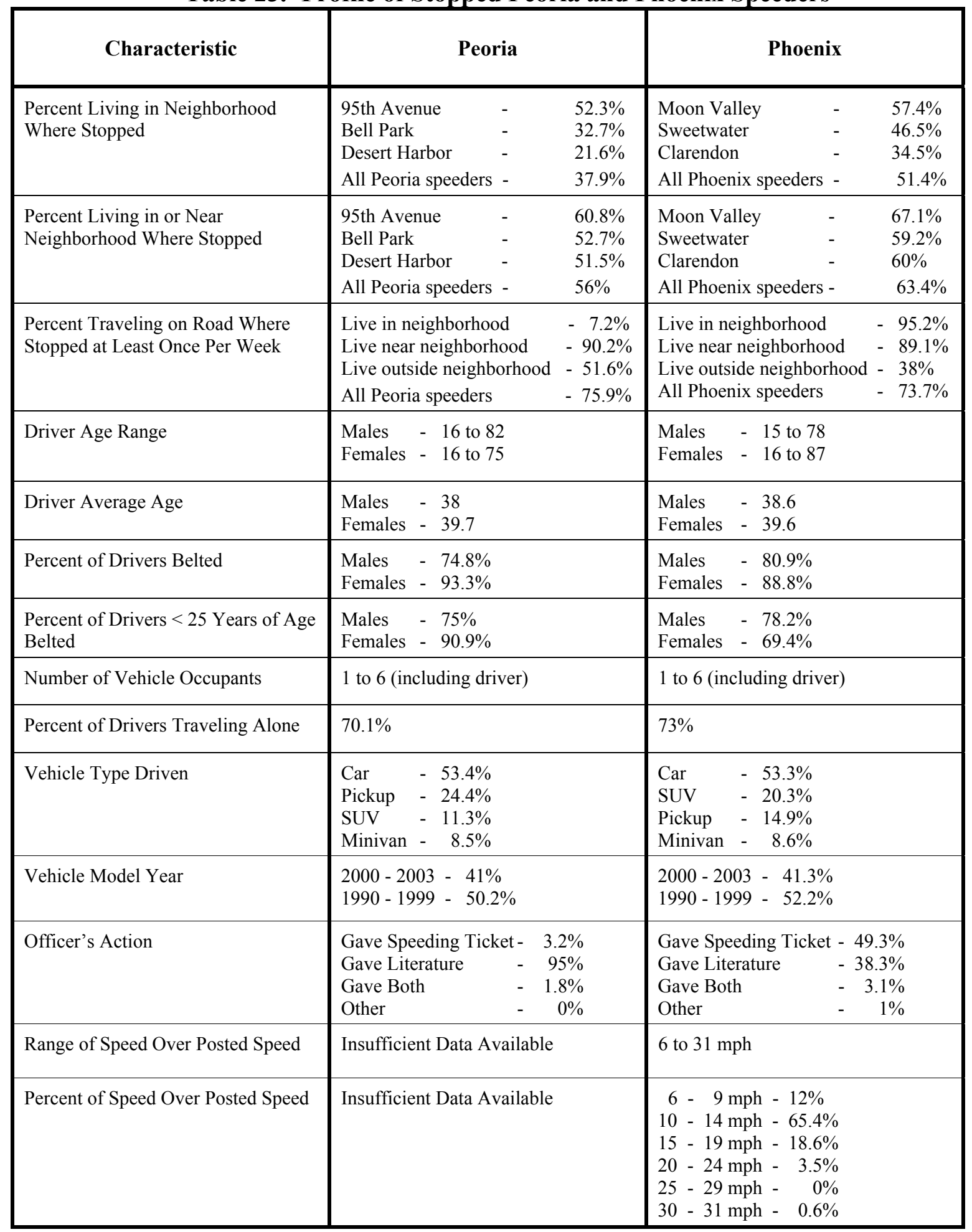




\subsection{Knowledge and Exposure Survey}

Both the Phoenix Street Transportation Department and the City of Peoria Engineering Department sponsored a mail survey to assess awareness of the program by residents of each of the study neighborhoods. Specifically, answers were sought to the following research questions:

- What program activities did the residents notice?

- What activities were noticed most?

- Did they notice a change in vehicle speeds in their neighborhoods compared to six months ago?

- Who noticed the activities or changes in vehicle speeds?

\subsubsection{Survey Methodology}

The identical one-page survey was mailed to all residents of the six study neighborhoods in two waves - pre-program and follow-on. The survey was printed on the back of a letter from a city official requesting cooperation (see Appendix D). A reply envelope with a postage stamp was included.

The survey sample was drawn from the available city mailing lists. Approximately 500 households were selected in each neighborhood by choosing the addresses closest to the test segment roads. ${ }^{7}$ Thus, for example, households in the Bell Park neighborhood of Peoria were selected along the $84^{\text {th }}$ Avenue test segment first. Then, if needed, additional households closest to the test segments were added until the sample needs were fulfilled. The available databases only contained addresses, not the names of the owners or tenants. Thus, the envelopes with the questionnaires were addressed to "Resident." The return envelope was addressed by name to the city official signing the letter.

One month prior to the start of program activities, the pre-program survey was sent to half of the residents in each of the Peoria and Phoenix neighborhoods. This was accomplished by selecting every other label on the sheets of labels containing the names for each neighborhood. For Peoria, the follow-on survey was sent to the remaining residents of each of its neighborhoods in the week following the completion of program activities in that city. Therefore, for Peoria, the time span that the residents had for observing program activities was three months. For Phoenix, the follow-on survey was mailed to the remaining sample of residents of each of its neighborhoods four months after the program started in that city. The differential timing was occasioned by the delay in the implementation of roadway treatments in Phoenix. The extra month ensured that all planned roadway treatments were in place. The special enforcement program in Phoenix continued for almost an additional two months after mailing of the follow-on survey. Therefore the follow-on survey was actually sent out while the program in Phoenix was still in process.

\footnotetext{
${ }^{7}$ As of July 1, 2004, there were slightly over 500,000 households in Phoenix and approximately 40,000 in Peoria.
} 


\subsubsection{Survey Response Characteristics}

Overall, 60.9 percent of the mailed surveys that were delivered as addressed were completed and returned. A slightly higher percentage of follow-on surveys $(62.7 \%)$ were returned than of pre-program surveys (59.1\%). Approximately the same proportion of returns was received from Phoenix (61.9\%) as from Peoria (60.1\%). Table 24 shows the number of returns for both waves and both cities as well as the percentage of delivered survey forms that were completed and returned.

Table 24. Survey Returns as a Percentage of Surveys Delivered (All Neighborhoods)

\begin{tabular}{|l|l|c|c|c|}
\hline \multirow{2}{*}{ Survey wave } & Sent/Received & Phoenix & Peoria & Total \\
\hline \multirow{3}{*}{ Pre-Program } & Surveys Sent & 686 & 783 & 1469 \\
\cline { 2 - 5 } & Surveys Received & 413 & 455 & 868 \\
\cline { 2 - 5 } & Percent Received & $60.2 \%$ & $58.1 \%$ & $59.1 \%$ \\
\hline \multirow{3}{*}{ Follow-On } & Surveys Sent & 733 & 779 & 1512 \\
\cline { 2 - 5 } & Surveys Received & 465 & 483 & 948 \\
\cline { 2 - 5 } & Percent Received & $63.4 \%$ & $62 \%$ & $62.7 \%$ \\
\hline \multirow{3}{*}{ Total } & Surveys Sent & 1419 & 1562 & 2981 \\
\cline { 2 - 5 } & Surveys Received & 878 & 938 & $60.9 \%$ \\
\cline { 2 - 5 } & Percent Received & $61.9 \%$ & $60.1 \%$ & 1816 \\
\hline
\end{tabular}

Of the first wave of survey returns, 96 (50 from Phoenix and 46 from Peoria) were received after the publicity and enforcement programs had started in the two cities. They were separated from the pre-program returns and identified in the database as "late returns" in order to be able to examine this small group of returns for possible changes in exposure to program activities.

The resultant study samples by survey wave are shown in Table 25. This table shows a remarkable consistency in returns for each wave for each city, that is, pre-program returns were 41.3 percent of returns in Phoenix and 43.6 percent in Peoria, late returns were 5.7 percent of the returns in Phoenix and 4.9 percent in Peoria, and follow-on returns were 53 percent of returns in Phoenix and 51.5 percent of returns in Peoria.

The survey form used in both cities is shown in Appendix D. It consisted of eight questions that asked the following of neighborhood residents:

1. Are you aware of any recent activities to control speeds in your neighborhood?

2. Did any of these activities include any publicity? If yes, what publicity?

3. Were the police involved in any of these activities? If yes, what activities?

4. Did any of these activities include any physical changes to the road or the physical environment? If yes, what changes?

5. Compared to 6 months ago, how would you rate the speeds in your neighborhood - much slower, a bit slower, the same, a bit faster, much faster?

6. How long have you lived in your current neighborhood - less than 1 year, 1 to 5 years, more than 5 years?

7. What is your age?

8. What is your gender? 
Table 25. Survey Returns From Each City by Wave (All Neighborhoods Combined)

\begin{tabular}{|c|c|c|c|c|}
\hline \multicolumn{2}{|c|}{ Survey Wave } & \multicolumn{3}{|c|}{ City } \\
\hline & & Phoenix & Peoria & Total \\
\hline \multirow{3}{*}{ Pre-Program } & Count & 363 & 409 & 772 \\
\hline & Row \% & $47 \%$ & $53 \%$ & $100 \%$ \\
\hline & Column \% & $41.3 \%$ & $43.6 \%$ & $42.5 \%$ \\
\hline \multirow{3}{*}{ Late Return } & Count & 50 & 46 & 96 \\
\hline & Row \% & $52.1 \%$ & $47.9 \%$ & $100 \%$ \\
\hline & Column \% & $5.7 \%$ & $4.9 \%$ & $5.3 \%$ \\
\hline \multirow{3}{*}{ Follow-On } & Count & 465 & 483 & 948 \\
\hline & Row \% & $49.1 \%$ & $50.9 \%$ & $100 \%$ \\
\hline & Column \% & $53 \%$ & $51.5 \%$ & $52.2 \%$ \\
\hline \multirow{3}{*}{ Total } & Count & 878 & 938 & 1816 \\
\hline & Row \% & $48.3 \%$ & $51.7 \%$ & $100 \%$ \\
\hline & Column \% & $100 \%$ & $100 \%$ & $100 \%$ \\
\hline
\end{tabular}

Thus, the survey provided information on the following:

- Awareness of activities to control speeds in the six neighborhoods

- Specific awareness of:

- Publicity activities

- Police activities

- Roadway treatments

- Perceived changes in vehicle speeds in the neighborhoods

- Description of the responders

- Time lived in the neighborhood

- Age

- Gender

A database was created that documented the answers of each survey respondent. Each publicity/police/roadway event or activity that was specified by the respondent was post-coded to indicate whether the activity was perceived to be "definitely program-related," "probably program-related," or "not program-related (or program relation was unknown)." Assignment of these codes and the resulting analysis were therefore conservative because they were based on unaided recall of the Heed the Speed program and a high threshold for assuming a program relationship when post coding. As an example, comments that the respondent had seen police ticketing or general mentions of hearing messages were coded as "probably program-related," although it is likely that most of the police enforcement and media efforts during the program period were program-related. Likewise, a mention of 3-D paint on the road or yellow signs was judged to be "definitely program related."

Two additional subjective post codes were entered in the database. One provided an indication of whether or not the respondent had referred to the Heed the Speed program by name. 
For the second, each respondent was assigned one of three codes depending on whether the survey form as a whole indicated that the respondent had definitely been exposed to the program, had probably been exposed to the program or had not been exposed to the program.

An initial examination was made of the returns to determine if the late returns should be maintained as a separate file, combined with the pre-program or follow-on returns, or eliminated from the analysis. For this examination, responses to two survey questions were explored respondent awareness of speed control activities and exposure to the Heed the Speed program.

The first survey question asked respondents if they were aware of any recent activities to control speeds in their neighborhoods. The responses for both cities are given in Table 26, which shows significant differences between survey waves for both cities.

In both Phoenix and Peoria, the table shows a significant increase in awareness of activities from pre-program data to late returns to follow-on data. It is interesting to note that approximately two-fifths of the respondents in both cities reported being aware of activities to control speeds in their neighborhoods before the program started. In Phoenix, 44.1 percent of the pre-program returns indicated awareness of activities, 74 percent of late returns, and 84.5 percent of follow-on returns. In Peoria, these data were 41.6 percent, 58.7 percent, and 82 percent, respectively. The data for late returns likely indicate a building exposure to program activities in the two cities.

Table 26. Awareness of Activities to Control Speeds in Neighborhoods by Study Wave and City (Phoenix and Peoria)

\begin{tabular}{|c|c|c|c|c|c|c|c|}
\hline \multirow{2}{*}{\multicolumn{2}{|c|}{$\begin{array}{c}\text { Awareness of } \\
\text { Activities to Control } \\
\text { Speeds }\end{array}$}} & \multicolumn{3}{|c|}{ Phoenix* } & \multicolumn{3}{|c|}{ Peoria** } \\
\hline & & $\begin{array}{c}\text { Pre- } \\
\text { Program }\end{array}$ & $\begin{array}{c}\text { Late } \\
\text { Return }\end{array}$ & Follow_On & $\begin{array}{c}\text { Pre- } \\
\text { Prooram }\end{array}$ & $\begin{array}{c}\text { Late } \\
\text { Return }\end{array}$ & Follow_On \\
\hline \multirow{3}{*}{ Yes } & Count & 160 & 37 & 393 & 170 & 27 & 395 \\
\hline & Row \% & $27.1 \%$ & $6.3 \%$ & $66.6 \%$ & $28.7 \%$ & $4.6 \%$ & $66.7 \%$ \\
\hline & Column \% & $44.1 \%$ & $74 \%$ & $84.5 \%$ & $41.6 \%$ & $58.7 \%$ & $82 \%$ \\
\hline \multirow{3}{*}{ No } & Count & 203 & 13 & 72 & 239 & 19 & 87 \\
\hline & Row \% & $70.5 \%$ & $4.5 \%$ & $25 \%$ & $69.3 \%$ & $5.5 \%$ & $25.2 \%$ \\
\hline & Column \% & $55.9 \%$ & $26 \%$ & $15.5 \%$ & $58.4 \%$ & $41.3 \%$ & $18 \%$ \\
\hline \multirow{3}{*}{ Total } & Count & 363 & 50 & 465 & 409 & 46 & 482 \\
\hline & Row \% & $41.3 \%$ & $5.7 \%$ & $53 \%$ & $43.6 \%$ & $4.9 \%$ & $51.4 \%$ \\
\hline & Column \% & $100 \%$ & $100 \%$ & $100 \%$ & $100 \%$ & $100 \%$ & $100 \%$ \\
\hline
\end{tabular}

*Phoenix chi square significance $=.000$

**Peoria chi square significance $=.000$

Table 27 shows whether or not the respondent was judged to have been exposed to the Heed the Speed program. The table shows that only one of the pre-program respondents had probably been exposed to the program. However, 22 percent of the respondents who sent in late returns from Phoenix had probably or definitely been exposed to the program as had 19.6 percent of the late returns from Peoria. These data, though small in number, appear to indicate that awareness of the program was already present in the late return data. By the time of the followon survey, 69.5 percent of the Phoenix residents had probably or definitely been exposed to the program as had 70.8 percent of the Peoria respondents. 
Table 27. Respondent Exposure to the Heed the Speed Program (Phoenix and Peoria)

\begin{tabular}{|c|c|c|c|c|c|c|c|}
\hline \multirow{2}{*}{\multicolumn{2}{|c|}{$\begin{array}{l}\text { Was Respondent } \\
\text { Exposed to the } \\
\text { Heed the Speed } \\
\text { Program? }\end{array}$}} & \multicolumn{3}{|c|}{ Phoenix* } & \multicolumn{3}{|c|}{ Peoria** } \\
\hline & & \multirow{2}{*}{$\begin{array}{c}\begin{array}{c}\text { Pre- } \\
\text { program }\end{array} \\
0\end{array}$} & \multirow{2}{*}{ Late return } & \multirow{2}{*}{$\frac{\text { Follow-on }}{261}$} & \multirow{2}{*}{$\begin{array}{c}\begin{array}{c}\text { Pre- } \\
\text { program }\end{array} \\
0\end{array}$} & \multirow{2}{*}{$\frac{\text { Late return }}{4}$} & \multirow{2}{*}{$\frac{\text { Follow-on }}{210}$} \\
\hline \multirow{3}{*}{$\begin{array}{l}\text { Yes, } \\
\text { Definite- } \\
\text { ly }\end{array}$} & Count & & & & & & \\
\hline & Row \% & $0 \%$ & $1.9 \%$ & $98.1 \%$ & $0 \%$ & $1.9 \%$ & $98.1 \%$ \\
\hline & Column \% & $0 \%$ & $10 \%$ & $57.2 \%$ & $0 \%$ & $8.7 \%$ & $43.5 \%$ \\
\hline \multirow{3}{*}{$\begin{array}{l}\text { Yes, } \\
\text { Probably }\end{array}$} & Count & 1 & 6 & 56 & 0 & 5 & 132 \\
\hline & Row \% & $1.6 \%$ & $9.5 \%$ & $88.9 \%$ & $0 \%$ & $3.6 \%$ & $96.4 \%$ \\
\hline & Column \% & $.3 \%$ & $12 \%$ & $12.3 \%$ & $0 \%$ & $10.9 \%$ & $27.3 \%$ \\
\hline \multirow{3}{*}{ No } & Count & 362 & 39 & 139 & 409 & 37 & 141 \\
\hline & Row \% & $66.9 \%$ & $7.2 \%$ & $25.7 \%$ & $69.7 \%$ & $6.3 \%$ & $24 \%$ \\
\hline & Column \% & $99.7 \%$ & $78 \%$ & $30.5 \%$ & $100 \%$ & $80.4 \%$ & $29.2 \%$ \\
\hline \multirow{3}{*}{ Total } & Count & 363 & 50 & $456 * * *$ & 409 & 46 & 483 \\
\hline & Row \% & $41.8 \%$ & $5.8 \%$ & $52.5 \%$ & $43.6 \%$ & $4.9 \%$ & $51.5 \%$ \\
\hline & Column \% & $100 \%$ & $100 \%$ & $100 \%$ & $100 \%$ & $100 \%$ & $100 \%$ \\
\hline
\end{tabular}

*Phoenix chi square significance $=.000$

$* *$ Peoria chi square significance $=.000$

***Nine follow-on period surveys in Phoenix had insufficient information to determine program exposure and were therefore deleted from the original sample of 465.

As indicated previously, the number of late returns was quite small. The foregoing tables, however, suggest that the late returns were somewhat different from both the pre-program and program samples. Since there was an insufficient number of late program returns to support analyses of meaningful subsets (e.g., gender, neighborhood) and it was inappropriate to combine them with either the pre-program or program data, they were omitted from further analyses. Subsequent tables therefore include only pre-program and follow-on data.

The information obtained from the surveys is presented in the following paragraphs. Unless otherwise noted, when no data were provided for a given item, the record for that item has been excluded from the summary tables. Significant associations were tested for selected survey results by means of the chi-square test. Differences reaching the 0.05 level of significance or less are noted.

\subsubsection{Respondent Description}

Three questions on the survey form provided descriptive information on the respondents. One question asked how long they had lived in the neighborhood, another asked their age, and a third inquired about their gender.

The length of time respondents lived in their current neighborhoods is given in Table 28 . The table shows that approximately 72 percent of both the pre-program and follow-on Phoenix respondents have lived in their neighborhoods for over five years. For Peoria, more than 50 percent have lived in their neighborhoods more than five years. Very few in both cities have lived in their neighborhoods one year or less. There are no meaningful differences between preand follow-on respondents as would be expected since the survey waves were only months apart. 
Table 28. How Long Respondents Have Lived in Their Current Neighborhoods (Phoenix and Peoria)

\begin{tabular}{|c|c|c|c|c|c|}
\hline \multirow{2}{*}{\multicolumn{2}{|c|}{$\begin{array}{c}\text { How Long Have You } \\
\text { Lived in Your Current } \\
\text { Neighborhood? }\end{array}$}} & \multicolumn{2}{|c|}{ Phoenix } & \multicolumn{2}{|c|}{ Peoria } \\
\hline & & \multirow{2}{*}{$\begin{array}{r}\begin{array}{c}\text { Pre- } \\
\text { Program }\end{array} \\
13 \\
\end{array}$} & \multirow{2}{*}{$\begin{array}{r}\text { Follow-On } \\
23\end{array}$} & \multirow{2}{*}{$\begin{array}{r}\begin{array}{c}\text { Pre- } \\
\text { Program }\end{array} \\
30 \\
\end{array}$} & \multirow{2}{*}{$\frac{\text { Follow-On }}{40}$} \\
\hline \multirow{3}{*}{$\begin{array}{l}\text { Less Than } 1 \\
\text { Year }\end{array}$} & Count & & & & \\
\hline & Row \% & $36.1 \%$ & $63.9 \%$ & $42.9 \%$ & $57.1 \%$ \\
\hline & Column \% & $3.6 \%$ & $4.9 \%$ & $7.4 \%$ & $8.3 \%$ \\
\hline \multirow{3}{*}{1 to 5 Years } & Count & 87 & 103 & 150 & 186 \\
\hline & Row \% & $45.8 \%$ & $54.2 \%$ & $44.6 \%$ & $55.4 \%$ \\
\hline & Column \% & $24 \%$ & $22.2 \%$ & $36.9 \%$ & $38.5 \%$ \\
\hline \multirow{3}{*}{$\begin{array}{l}\text { More Than } \\
5 \text { Years }\end{array}$} & Count & 263 & 339 & 226 & 257 \\
\hline & Row \% & $43.7 \%$ & $56.3 \%$ & $46.8 \%$ & $53.2 \%$ \\
\hline & Column \% & $72.5 \%$ & $72.9 \%$ & $55.7 \%$ & $53.2 \%$ \\
\hline
\end{tabular}

The length of time respondents of each Peoria neighborhood reported living in their neighborhoods is given in Table 29. The table shows that respondents from $95^{\text {th }}$ Avenue (where approximately one-third have lived in their neighborhoods more than five years) have not lived in their neighborhoods as long as have those from Desert Harbor and Bell Park (where close to two-thirds have lived in their neighborhoods more than five years). Fewer than 10 percent of the respondents from all neighborhoods have lived in their neighborhoods less than one year. There are essentially no differences between pre-program and follow-on respondents.

Similar data for Phoenix neighborhoods are given in Table 30 which shows a more uniform pattern. Almost three-quarters of respondents, regardless of neighborhood, have lived in their neighborhoods more than five years. Again, fewer than 10 percent of the respondents from all neighborhoods have lived in their neighborhoods less than one year. There are no notable differences between pre- and follow-on respondents.

The age range of respondents from the two cities is shown in Table 31. The table shows that nearly three-fifths (ranging from $54.8 \%$ to $59.5 \%$ ) of the respondents in each city were in the age range of 40 to 64 . In fact, approximately four-fifths (ranging from $78.5 \%$ to $86.1 \%$ ) of the respondents in each group were over age 39 . Very few respondents were under 25 years old. The ages of pre-program and follow-on respondents are essentially the same. These data are not inconsistent with the descriptions of the areas in which the test was conducted as provided by the participating Peoria and Phoenix personnel and described earlier. 
Table 29. How Long Respondents Have Lived in Their Current Neighborhoods (Peoria)

\begin{tabular}{|c|c|c|c|c|c|c|c|}
\hline \multirow{2}{*}{\multicolumn{2}{|c|}{$\begin{array}{l}\text { How Long Have You } \\
\text { Lived in Your Current } \\
\text { Neighborhood? }\end{array}$}} & \multicolumn{4}{|c|}{ 95th Ave } & \multicolumn{2}{|c|}{ Bell Park/84th Ave } \\
\hline & & \multirow{2}{*}{$\begin{array}{r}\begin{array}{c}\text { Pre- } \\
\text { Program }\end{array} \\
13\end{array}$} & \multirow{2}{*}{$\frac{\text { Follow-On }}{13}$} & \multirow{2}{*}{$\begin{array}{c}\begin{array}{c}\text { Pre- } \\
\text { Program }\end{array} \\
6\end{array}$} & \multirow{2}{*}{$\frac{\text { Follow-On }}{14}$} & \multirow{2}{*}{$\begin{array}{r}\begin{array}{c}\text { Pre- } \\
\text { Program }\end{array} \\
11\end{array}$} & \multirow{2}{*}{$\frac{\text { Follow-On }}{13}$} \\
\hline \multirow{3}{*}{$\begin{array}{l}\text { Less Than } 1 \\
\text { Year }\end{array}$} & Count & & & & & & \\
\hline & Row \% & $50 \%$ & $50 \%$ & $30 \%$ & $70 \%$ & $45.8 \%$ & $54.2 \%$ \\
\hline & Column \% & $9.9 \%$ & $8.1 \%$ & $5.5 \%$ & $8.6 \%$ & $6.7 \%$ & $8.2 \%$ \\
\hline \multirow{3}{*}{1 to 5 Years } & Count & 72 & 93 & 36 & 45 & 41 & 47 \\
\hline & Row \% & $43.6 \%$ & $56.4 \%$ & $44.4 \%$ & $55.6 \%$ & $46.6 \%$ & $53.4 \%$ \\
\hline & Column \% & $55 \%$ & $58.1 \%$ & $33 \%$ & $27.8 \%$ & $25 \%$ & $29.6 \%$ \\
\hline \multirow{3}{*}{$\begin{array}{l}\text { More Than } \\
5 \text { Years }\end{array}$} & Count & 46 & 54 & 67 & 103 & 112 & 99 \\
\hline & Row \% & $46 \%$ & $54 \%$ & $39.4 \%$ & $60.6 \%$ & $53.1 \%$ & $46.9 \%$ \\
\hline & Column \% & $35.1 \%$ & $33.8 \%$ & $61.5 \%$ & $63.6 \%$ & $68.3 \%$ & $62.3 \%$ \\
\hline
\end{tabular}

Table 30. How Long Respondents Have Lived in Their Current Neighborhoods (Phoenix)

\begin{tabular}{|c|c|c|c|c|c|c|c|}
\hline \multirow{3}{*}{\multicolumn{2}{|c|}{$\begin{array}{l}\text { How Long Have You } \\
\text { Lived in Your Current } \\
\text { Neighborhood? }\end{array}$}} & \multicolumn{6}{|c|}{ Phoenix Neighborhoods } \\
\hline & & \multicolumn{2}{|c|}{ Sweetwater } & \multicolumn{2}{|c|}{ Moon Valley/Coral Gables } & \multicolumn{2}{|c|}{ Clarendon } \\
\hline & & $\begin{array}{c}\text { Pre- } \\
\text { Program }\end{array}$ & Follow-On & $\begin{array}{c}\text { Pre- } \\
\text { Program }\end{array}$ & Follow-On & $\begin{array}{c}\text { Pre- } \\
\text { Program }\end{array}$ & Follow-On \\
\hline \multirow{3}{*}{$\begin{array}{l}\text { Less Than } 1 \\
\text { Year }\end{array}$} & Count & 4 & 9 & 3 & 8 & 6 & 6 \\
\hline & Row \% & $30.8 \%$ & $69.2 \%$ & $27.3 \%$ & $72.7 \%$ & $50 \%$ & $50 \%$ \\
\hline & Column \% & $3.2 \%$ & $5.2 \%$ & $2.2 \%$ & $4.6 \%$ & $6.1 \%$ & $5 \%$ \\
\hline \multirow{3}{*}{1 to 5 Years } & Count & 31 & 46 & 31 & 31 & 25 & 26 \\
\hline & Row \% & $40.3 \%$ & $59.7 \%$ & $50 \%$ & $50 \%$ & $49 \%$ & $51 \%$ \\
\hline & Column \% & $24.6 \%$ & $26.6 \%$ & $22.5 \%$ & $17.9 \%$ & $25.3 \%$ & $21.8 \%$ \\
\hline \multirow{3}{*}{$\begin{array}{l}\text { More Than } \\
5 \text { Years }\end{array}$} & Count & 91 & 118 & 104 & 134 & 68 & 87 \\
\hline & Row $\%$ & $43.5 \%$ & $56.5 \%$ & $43.7 \%$ & $56.3 \%$ & $43.9 \%$ & $56.1 \%$ \\
\hline & Column \% & $72.2 \%$ & $68.2 \%$ & $75.4 \%$ & $77.5 \%$ & $68.7 \%$ & $73.1 \%$ \\
\hline
\end{tabular}

The age ranges of respondents from each Peoria neighborhood are shown in Table 32. The table shows that the $95^{\text {th }}$ Avenue neighborhood had the highest proportion of respondents 65 and over. Desert Harbor and Bell Park had less than half the representation of respondents 65+ as did $95^{\text {th }}$ Avenue, which had the highest mean ages of the Peoria respondents (56 and 55 years for the pre-program and follow-on surveys, respectively). The pre-program and follow-on means for Desert Harbor respondents were 52 years and 51 years, and the average Bell Park respondent was 48 years old in both survey waves. 
Table 31. Age of Respondents (Phoenix and Peoria)

\begin{tabular}{|c|c|c|c|c|c|}
\hline \multirow{2}{*}{\multicolumn{2}{|c|}{ Age Range }} & \multicolumn{2}{|c|}{ Phoenix } & \multicolumn{2}{|c|}{ Peoria } \\
\hline & & \multirow{2}{*}{$\begin{array}{c}\begin{array}{c}\text { Pre- } \\
\text { Program }\end{array} \\
1\end{array}$} & \multirow{2}{*}{$\frac{\text { Follow-On }}{6}$} & \multirow{2}{*}{$\begin{array}{c}\begin{array}{c}\text { Pre- } \\
\text { Program }\end{array} \\
1\end{array}$} & \multirow{2}{*}{$\frac{\text { Follow-On }}{5}$} \\
\hline$<25$ & Count & & & & \\
\hline & Row \% & $14.3 \%$ & $85.7 \%$ & $16.7 \%$ & $83.3 \%$ \\
\hline & Column \% & $.3 \%$ & $1.4 \%$ & $.2 \%$ & $1.1 \%$ \\
\hline \multirow{3}{*}{$25-39$} & Count & 48 & 81 & 86 & 96 \\
\hline & Row \% & $37.2 \%$ & $62.8 \%$ & $47.3 \%$ & $52.7 \%$ \\
\hline & Column \% & $13.6 \%$ & $18.3 \%$ & $21.3 \%$ & $20.3 \%$ \\
\hline \multirow{3}{*}{$40-64$} & Count & 207 & 242 & 233 & 281 \\
\hline & Row \% & $46.1 \%$ & $53.9 \%$ & $45.3 \%$ & $54.7 \%$ \\
\hline & Column \% & $58.6 \%$ & $54.8 \%$ & $57.7 \%$ & $59.5 \%$ \\
\hline \multirow{3}{*}{$65+$} & Count & 97 & 113 & 84 & 90 \\
\hline & Row \% & $46.2 \%$ & $53.8 \%$ & $48.3 \%$ & $51.7 \%$ \\
\hline & Column \% & $27.5 \%$ & $25.6 \%$ & $20.8 \%$ & $19.1 \%$ \\
\hline
\end{tabular}

The age ranges of respondents from each Phoenix neighborhood are shown in Table 33. Approximately 30 percent of the respondents from Moon Valley were 65 or older as were approximately 18 percent of those from Sweetwater. For Clarendon, pre-program 65+ respondents represented 34.4 percent of the pre-program respondents in contrast to 27.8 percent of the follow-on respondents. Clarendon showed a significant difference in pre-program and follow-on ages of the respondents. Since the measures were close together, this is likely just chance and should have no meaningful bearing on the results. Mean pre-program and follow-on ages for Sweetwater respondents were 52 and 51 years, respectively. For Moon Valley respondents, mean pre-program and follow-on ages were both 57 years. The mean age for Clarendon pre-program respondents was 58 years and that for follow-on respondents was 53 years.

Table 32. Age of Respondents by Neighborhood (Peoria)

\begin{tabular}{|c|c|c|c|c|c|c|c|}
\hline \multirow{3}{*}{\multicolumn{2}{|c|}{ Age range }} & \multicolumn{6}{|c|}{ Peoria Neighborhoods } \\
\hline & & \multicolumn{2}{|c|}{ 95th Ave } & \multicolumn{2}{|c|}{ Desert Harbor/91st Ave } & \multicolumn{2}{|c|}{ Bell Park/84th Ave } \\
\hline & & $\begin{array}{c}\text { Pre- } \\
\text { Program }\end{array}$ & Follow-On & $\begin{array}{c}\text { Pre- } \\
\text { Program }\end{array}$ & Follow-On & $\begin{array}{c}\text { Pre- } \\
\text { Program }\end{array}$ & Follow-On \\
\hline \multirow[t]{3}{*}{$<25$} & Count & 1 & 2 & 0 & 0 & 0 & 3 \\
\hline & Row \% & $33.3 \%$ & $66.7 \%$ & $0 \%$ & $0 \%$ & $0 \%$ & $100 \%$ \\
\hline & Column \% & $.8 \%$ & $1.3 \%$ & $0 \%$ & $.10 \%$ & $0 \%$ & $1.9 \%$ \\
\hline \multirow[t]{3}{*}{$25-39$} & Count & 31 & 35 & 17 & 27 & 36 & 33 \\
\hline & Row \% & $47.0 \%$ & $53 \%$ & $38.6 \%$ & $61.4 \%$ & $52.2 \%$ & $47.8 \%$ \\
\hline & Column \% & $23.7 \%$ & $22.6 \%$ & $15.5 \%$ & $17 \%$ & $22.4 \%$ & $21.2 \%$ \\
\hline \multirow{3}{*}{$40-64$} & Count & 51 & 67 & 76 & 108 & 106 & 105 \\
\hline & Row \% & $43.2 \%$ & $56.8 \%$ & $41.3 \%$ & $58.7 \%$ & $50.2 \%$ & $49.8 \%$ \\
\hline & Column \% & $38.9 \%$ & $43.2 \%$ & $69.1 \%$ & $67.9 \%$ & $65.8 \%$ & $67.3 \%$ \\
\hline \multirow[t]{3}{*}{$65+$} & Count & 48 & 51 & 17 & 24 & 19 & 15 \\
\hline & Row \% & $48.5 \%$ & $51.5 \%$ & $41.5 \%$ & $58.5 \%$ & $55.9 \%$ & $44.1 \%$ \\
\hline & Column \% & $36.6 \%$ & $32.9 \%$ & $15.5 \%$ & $15.1 \%$ & $11.8 \%$ & $9.6 \%$ \\
\hline
\end{tabular}


Table 33. Age of Respondents by Neighborhood (Phoenix)

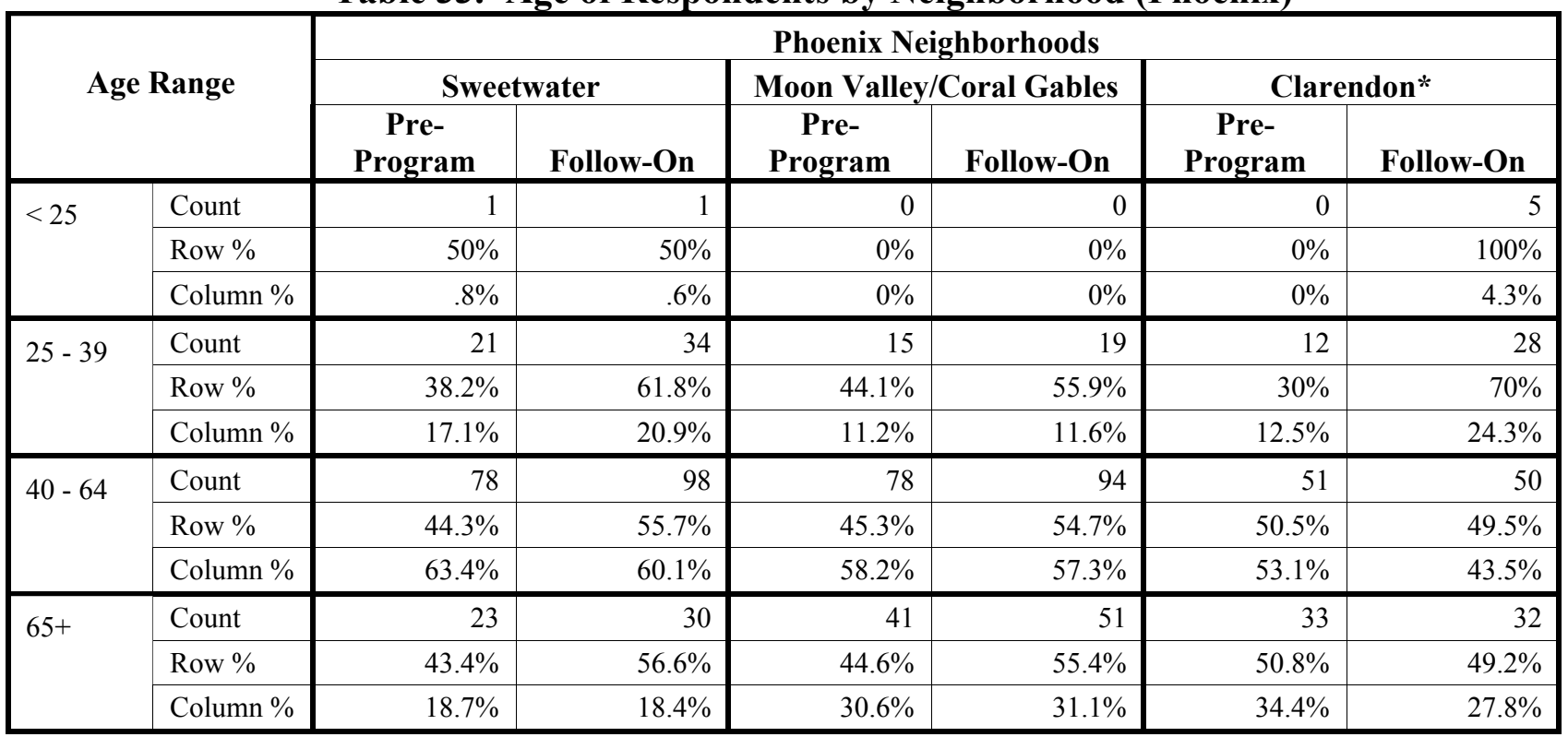

${ }^{*}$ Clarendon chi square significance $=.020$

The gender of respondents from the two cities is shown in Table 34. The table shows that there were slightly more females than males in the survey samples with the largest difference being the follow-on measurement in Phoenix.

The gender of respondents from each Peoria neighborhood is given in Table 35. Similar data for Phoenix neighborhoods are provided in Table 36. Although there is variability across neighborhoods and between the two cities, the magnitude of the differences is not particularly noteworthy. When viewing the gender and age data, it is important to remember that the surveys were addressed to "Respondent." Therefore, anyone within a household could therefore complete the questionnaire.

Table 34. Gender of Respondents (Phoenix and Peoria)

\begin{tabular}{|l|l|r|r|r|r|}
\hline \multirow{2}{*}{ Respondent Gender } & \multicolumn{2}{|c|}{ Phoenix } & \multicolumn{2}{c|}{ Peoria } \\
\cline { 3 - 6 } & \multicolumn{2}{|c|}{$\begin{array}{c}\text { Pre- } \\
\text { Program }\end{array}$} & Follow-On & \multicolumn{1}{c|}{$\begin{array}{c}\text { Program } \\
\text { Prollow-On }\end{array}$} & Follow \\
\hline \multirow{2}{*}{ Male } & Count & 177 & 200 & 197 & 235 \\
\cline { 2 - 6 } & Row $\%$ & $46.8 \%$ & $53.1 \%$ & $45.6 \%$ & $54.4 \%$ \\
\cline { 2 - 6 } & Column $\%$ & $49.2 \%$ & $44.1 \%$ & $48.2 \%$ & $49 \%$ \\
\hline \multirow{2}{*}{ Female } & Count & 183 & 254 & 212 & 245 \\
\cline { 2 - 6 } & Row $\%$ & $42 \%$ & $58.1 \%$ & $46.4 \%$ & $53.6 \%$ \\
\cline { 2 - 6 } & Column $\%$ & $50.8 \%$ & $55.9 \%$ & $51.8 \%$ & $51 \%$ \\
\hline
\end{tabular}


Table 35. Gender of Respondents by Neighborhood (Peoria)

\begin{tabular}{|c|c|c|c|c|c|c|c|}
\hline \multirow{3}{*}{\multicolumn{2}{|c|}{ Respondent Gender }} & \multicolumn{6}{|c|}{ Peoria Neighborhoods } \\
\hline & & \multicolumn{2}{|c|}{ 95th Ave } & \multicolumn{2}{|c|}{ Desert Harbor/91st Ave } & \multicolumn{2}{|c|}{ Bell Park/84th Ave } \\
\hline & & $\begin{array}{c}\text { Pre- } \\
\text { Program }\end{array}$ & Follow-On & $\begin{array}{c}\text { Pre- } \\
\text { Program }\end{array}$ & Follow-On & $\begin{array}{c}\text { Pre- } \\
\text { Program }\end{array}$ & Follow-On \\
\hline \multirow{3}{*}{ Male } & Count & 52 & 75 & 56 & 87 & 88 & 72 \\
\hline & Row \% & $40.9 \%$ & $59.1 \%$ & $39.2 \%$ & $60.8 \%$ & $55 \%$ & $45 \%$ \\
\hline & Column \% & $39.7 \%$ & $47.2 \%$ & $50.9 \%$ & $53.7 \%$ & $53 \%$ & $45.9 \%$ \\
\hline \multirow{3}{*}{ Female } & Count & 79 & 84 & 54 & 75 & 78 & 85 \\
\hline & Row \% & $48.5 \%$ & $51.5 \%$ & $41.9 \%$ & $58.1 \%$ & $47.9 \%$ & $52.1 \%$ \\
\hline & Column \% & $60.3 \%$ & $52.8 \%$ & $49.1 \%$ & $46.3 \%$ & $47 \%$ & $54.1 \%$ \\
\hline
\end{tabular}

Table 36. Gender of Respondents by Neighborhood (Phoenix)

\begin{tabular}{|c|c|c|c|c|c|c|c|}
\hline \multirow{3}{*}{\multicolumn{2}{|c|}{ Respondent Gender }} & \multicolumn{6}{|c|}{ Phoenix Neighborhoods } \\
\hline & & \multicolumn{2}{|c|}{ Sweetwater } & \multicolumn{2}{|c|}{ Moon Valley/Coral Gables } & \multicolumn{2}{|c|}{ Clarendon } \\
\hline & & $\begin{array}{c}\text { Pre- } \\
\text { Program }\end{array}$ & Follow-On & $\begin{array}{c}\text { Pre- } \\
\text { Program }\end{array}$ & Follow-On & $\begin{array}{c}\text { Pre- } \\
\text { Program }\end{array}$ & Follow-On \\
\hline \multirow[t]{3}{*}{ Male } & Count & 67 & 79 & 67 & 68 & 43 & 53 \\
\hline & Row \% & $45.9 \%$ & $54.1 \%$ & $49.6 \%$ & $50.4 \%$ & $44.8 \%$ & $55.2 \%$ \\
\hline & Column \% & $53.2 \%$ & $47.6 \%$ & $48.9 \%$ & $39.8 \%$ & $44.3 \%$ & $45.3 \%$ \\
\hline \multirow{3}{*}{ Female } & Count & 59 & 87 & 70 & 103 & 54 & 64 \\
\hline & Row \% & $40.4 \%$ & $59.6 \%$ & $40.5 \%$ & $59.5 \%$ & $45.8 \%$ & $54.2 \%$ \\
\hline & Column \% & $46.8 \%$ & $52.4 \%$ & $51.1 \%$ & $60.2 \%$ & $55.7 \%$ & $54.7 \%$ \\
\hline
\end{tabular}

\subsubsection{Awareness of Activities to Control Speeds}

Table 37 shows respondent awareness of activities to control speeds disaggregated by Peoria neighborhoods. It shows significant differences in the rate of survey returns and substantial increases in awareness for all three neighborhoods. The lowest pre-program awareness (29\%) was reported for the $95^{\text {th }}$ Avenue neighborhood, where the follow-on awareness was 86.3 percent. The data for Desert Harbor were 46.4 percent and 71.4 percent, respectively, and those for Bell Park were 47.6 percent and 88.1 percent, respectively.

Table 38 shows respondent awareness of activities to control speeds by Phoenix neighborhoods. It indicates significant differences in the rate of survey returns for both the Sweetwater and Moon Valley/Coral Gables neighborhoods. Both of these neighborhoods show substantial changes in the percentage of pre-program and follow-on awareness. In the Sweetwater neighborhood, for example, 34.1 percent of the pre-program respondents reported awareness of activities to control speeds in contrast to 92.5 percent of the follow-on respondents. These data for the Moon Valley/Coral Gables neighborhood were 42.8 percent and 96.5 percent, respectively. In contrast, almost three-fifths (58.6 percent) of the respondents from the Clarendon neighborhood reported a pre-program awareness of activities to control speeds. This large percentage of pre-program awareness may have been due to the existing speed humps on this road. The Clarendon resident follow-on awareness decreased slightly to 55.5 percent. This 
is likely the result of a combination of the high baseline rate of awareness and the absence of an organized neighborhood group in the Clarendon area to distribute the Heed the Speed literature.

Table 37. Awareness of Activities to Control Speeds in Neighborhoods by Study Wave (Peoria)

\begin{tabular}{|c|c|c|c|c|c|c|c|}
\hline \multirow{3}{*}{\multicolumn{2}{|c|}{$\begin{array}{c}\text { Awareness of } \\
\text { Activities to Control } \\
\text { Speeds }\end{array}$}} & \multicolumn{6}{|c|}{ Peoria Neighborhoods } \\
\hline & & \multicolumn{2}{|c|}{ 95th Ave* } & \multicolumn{2}{|c|}{ Desert Harbor/91st Ave** } & \multicolumn{2}{|c|}{ Bell Park/84th Ave*** } \\
\hline & & $\begin{array}{c}\text { Pre- } \\
\text { Program }\end{array}$ & Follow-On & $\begin{array}{c}\text { Pre- } \\
\text { Program }\end{array}$ & Follow-On & $\begin{array}{c}\text { Pre- } \\
\text { Program }\end{array}$ & Follow-On \\
\hline \multirow{3}{*}{ Yes } & Count & 38 & 138 & 51 & 115 & 79 & 140 \\
\hline & Row \% & $21.6 \%$ & $78.4 \%$ & $30.7 \%$ & $69.3 \%$ & $36.1 \%$ & $63.9 \%$ \\
\hline & Column \% & $29 \%$ & $86.3 \%$ & $46.4 \%$ & $71.4 \%$ & $47.6 \%$ & $88.1 \%$ \\
\hline \multirow{3}{*}{ No } & Count & 93 & 22 & 59 & 46 & 87 & 19 \\
\hline & Row \% & $80.9 \%$ & $19.1 \%$ & $56.2 \%$ & $43.8 \%$ & $82.1 \%$ & $17.9 \%$ \\
\hline & Column \% & $71 \%$ & $13.8 \%$ & $53.6 \%$ & $28.6 \%$ & $52.4 \%$ & $11.9 \%$ \\
\hline \multirow{3}{*}{ Total } & Count & 131 & 160 & 110 & 161 & 166 & 159 \\
\hline & Row \% & $45 \%$ & $55 \%$ & $40.6 \%$ & $59.4 \%$ & $51.1 \%$ & $48.9 \%$ \\
\hline & Column \% & $100 \%$ & $100 \%$ & $100 \%$ & $100 \%$ & $100 \%$ & $100 \%$ \\
\hline
\end{tabular}

$* 95^{\text {th }}$ Avenue chi square significance $=.000$

$* *$ Desert Harbor chi square significance $=.000$

$* * *$ Bell Park chi square significance $\quad=.000$

Table 38. Awareness of Activities to Control Speeds in Neighborhoods by Study Wave (Phoenix)

\begin{tabular}{|c|c|c|c|c|c|c|c|}
\hline \multirow{3}{*}{\multicolumn{2}{|c|}{$\begin{array}{c}\text { Awareness of } \\
\text { Activities to Control } \\
\text { Speeds }\end{array}$}} & \multicolumn{6}{|c|}{ Phoenix Neighborhoods } \\
\hline & & \multicolumn{2}{|c|}{ Sweetwater* } & \multicolumn{2}{|c|}{$\begin{array}{c}\text { Moon Valley/Coral } \\
\text { Gables** }\end{array}$} & \multicolumn{2}{|c|}{ Clarendon } \\
\hline & & \multirow{2}{*}{$\begin{array}{r}\begin{array}{c}\text { Pre- } \\
\text { Program }\end{array} \\
43\end{array}$} & \multirow{2}{*}{$\frac{\text { Follow-On }}{160}$} & \multirow{2}{*}{$\begin{array}{r}\begin{array}{c}\text { Pre- } \\
\text { Program }\end{array} \\
59 \\
\end{array}$} & \multirow{2}{*}{$\frac{\text { Follow-On }}{167}$} & \multirow{2}{*}{$\begin{aligned} & \begin{array}{c}\text { Pre- } \\
\text { Program }\end{array} \\
& 58\end{aligned}$} & \multirow{2}{*}{$\frac{\text { Follow-On }}{66}$} \\
\hline \multirow{3}{*}{ Yes } & Count & & & & & & \\
\hline & Row \% & $21.2 \%$ & $78.8 \%$ & $26.1 \%$ & $73.9 \%$ & $46.8 \%$ & $53.2 \%$ \\
\hline & Column \% & $34.1 \%$ & $92.5 \%$ & $42.8 \%$ & $96.5 \%$ & $58.6 \%$ & $55.5 \%$ \\
\hline \multirow{3}{*}{ No } & Count & 83 & 13 & 79 & 6 & 41 & 53 \\
\hline & Row \% & $86.5 \%$ & $13.5 \%$ & $92.9 \%$ & $7.1 \%$ & $43.6 \%$ & $56.4 \%$ \\
\hline & Column \% & $65.9 \%$ & $7.5 \%$ & $57.2 \%$ & $3.5 \%$ & $41.4 \%$ & $44.5 \%$ \\
\hline \multirow{3}{*}{ Total } & Count & 126 & 173 & 138 & 173 & 99 & 119 \\
\hline & Row \% & $42.1 \%$ & $57.9 \%$ & $44.4 \%$ & $55.6 \%$ & $45.4 \%$ & $54.6 \%$ \\
\hline & Column \% & $100 \%$ & $100 \%$ & $100 \%$ & $100 \%$ & $100 \%$ & $100 \%$ \\
\hline
\end{tabular}

*Sweetwater chi square significance $=.000$

$* *$ Moon Valley chi square significance $=.000$

\subsubsection{Awareness of Program Activity Categories}

Table 39 shows the category or type of awareness by Peoria neighborhood and survey wave, that is, awareness of program publicity, police involvement and roadway treatments. Significant increases in awareness of publicity from pre-program to follow-on respondents were obtained in all three Peoria neighborhoods. Publicity awareness increased from 10.5 percent to 51.4 percent in the $95^{\text {th }}$ Avenue neighborhood, from 33.3 percent to 66.7 percent in Desert Harbor, and from 40.5 percent to 68.1 percent in Bell Park. 
Table 39. Category of Awareness by Neighborhood (Peoria)

\begin{tabular}{|c|c|c|c|c|c|c|c|c|}
\hline \multirow{3}{*}{\multicolumn{3}{|c|}{$\begin{array}{c}\text { Category of Awareness - Publicity, } \\
\text { Police Involvement, and Roadway } \\
\text { Treatment }\end{array}$}} & \multicolumn{6}{|c|}{ Peoria Neighborhoods } \\
\hline & & & \multicolumn{2}{|c|}{ 95th Ave } & \multicolumn{2}{|c|}{$\begin{array}{c}\text { Desert Harbor/ } \\
\text { 91st Ave }\end{array}$} & \multicolumn{2}{|c|}{ Bell Park/84th Ave } \\
\hline & & & $\begin{array}{c}\text { Pre- } \\
\text { Program }\end{array}$ & $\begin{array}{c}\text { Follow- } \\
\text { On }\end{array}$ & $\begin{array}{c}\text { Pre- } \\
\text { Program }\end{array}$ & $\begin{array}{l}\text { Follow- } \\
\text { On }\end{array}$ & $\begin{array}{c}\text { Pre- } \\
\text { Program }\end{array}$ & $\begin{array}{l}\text { Follow- } \\
\text { On }\end{array}$ \\
\hline \multirow{6}{*}{$\begin{array}{l}\text { Did Any of } \\
\text { These } \\
\text { Activities } \\
\text { Include Any } \\
\text { Publicity?* }\end{array}$} & \multirow[t]{2}{*}{ Yes } & Count & 4 & 71 & 17 & 76 & 32 & 94 \\
\hline & & Column \% & $10.5 \%$ & $51.4 \%$ & $33.3 \%$ & $66.7 \%$ & $40.5 \%$ & $68.1 \%$ \\
\hline & \multirow[t]{2}{*}{ No } & Count & 16 & 28 & 21 & 10 & 20 & 12 \\
\hline & & Column \% & $42.1 \%$ & $20.3 \%$ & $41.2 \%$ & $8.8 \%$ & $25.3 \%$ & $8.7 \%$ \\
\hline & \multirow{2}{*}{ Don't Know } & Count & 18 & 39 & 13 & 28 & 27 & 32 \\
\hline & & Column \% & $47.4 \%$ & $28.3 \%$ & $25.5 \%$ & $24.6 \%$ & $34.2 \%$ & $23.2 \%$ \\
\hline \multirow{6}{*}{$\begin{array}{l}\text { Were the } \\
\text { Police } \\
\text { Involved in } \\
\text { Any of These } \\
\text { Activities?** }\end{array}$} & \multirow[t]{2}{*}{ Yes } & Count & 19 & 51 & 38 & 45 & 15 & 61 \\
\hline & & Column \% & $50 \%$ & $37 \%$ & $74.5 \%$ & $39.5 \%$ & $19 \%$ & $44.2 \%$ \\
\hline & \multirow[t]{2}{*}{ No } & Count & 7 & 21 & 3 & 20 & 24 & 15 \\
\hline & & Column \% & $18.4 \%$ & $15.2 \%$ & $5.9 \%$ & $17.5 \%$ & $30.4 \%$ & $10.9 \%$ \\
\hline & \multirow[t]{2}{*}{ Don't Know } & Count & 12 & 66 & 10 & 49 & 40 & 62 \\
\hline & & Column \% & $31.6 \%$ & $47.8 \%$ & $19.6 \%$ & $43 \%$ & $50.6 \%$ & $44.9 \%$ \\
\hline \multirow{6}{*}{$\begin{array}{l}\text { Did Any of } \\
\text { These } \\
\text { Activities } \\
\text { Include Any } \\
\text { Changes to the } \\
\text { Road or the } \\
\text { Physical } \\
\text { Environment? } \\
* * *\end{array}$} & \multirow[t]{2}{*}{ Yes } & Count & 9 & 106 & 7 & 51 & 50 & 133 \\
\hline & & Column \% & $23.7 \%$ & $77.9 \%$ & $14 \%$ & $45.1 \%$ & $64.1 \%$ & $95.7 \%$ \\
\hline & \multirow[t]{2}{*}{ No } & Count & 20 & 17 & 38 & 51 & 19 & 3 \\
\hline & & Column \% & $52.6 \%$ & $12.5 \%$ & $76 \%$ & $45.1 \%$ & $24.4 \%$ & $2.2 \%$ \\
\hline & \multirow{2}{*}{ Don't Know } & Count & 9 & 13 & 5 & 11 & 9 & 3 \\
\hline & & Column \% & $23.7 \%$ & $9.6 \%$ & $10 \%$ & $9.7 \%$ & $11.5 \%$ & $2.2 \%$ \\
\hline
\end{tabular}

$*$ Chi square significance for all neighborhoods $=.000$

$* *$ Chi square significance for Desert Harbor and Bell Park $=.000$

$* * *$ Chi square significance for all neighborhoods $=.000$

Table 39 also shows a significant increase in awareness of roadway treatments for Peoria neighborhoods. Awareness increased from 23.7 percent to 77.9 percent for $95^{\text {th }}$ Avenue, from 14.0 percent to 45.1 percent for Desert Harbor and from 64.1 percent to 95.7 percent for Bell Park. The relatively low level of awareness of road treatments for $91^{\text {st }}$ Avenue in comparison to the other two neighborhoods is consistent with the fact that no road treatments were implemented in that neighborhood. The very large awareness of road treatments for Bell Park is likely the result of the speed humps that existed on $85^{\text {th }}$ Lane when the pre-program survey was done and the speed tables and 3-D markings that were installed on $84^{\text {th }}$ Avenue as part of the Heed the Speed program.

It is interesting to note that there was a decrease in awareness of police activities among both $95^{\text {th }}$ Avenue and Desert Harbor respondents. There was a non-significant drop from 50 percent to 37 percent in $95^{\text {th }}$ Avenue and a significant drop from 74.5 percent to 39.5 percent in Desert Harbor. In Bell Park there was a significant increase from 19 percent to 44.2 percent . There is no apparent explanation for these changes in awareness of police activities as they are not consistent with the special enforcement data presented earlier.

Table 40 provides similar data on the awareness of the different types of program activities by neighborhood and survey wave for Phoenix residents. This table shows a 
significant increase in awareness of publicity from pre- program to follow-on respondents for Sweetwater from 14.3 percent to 62.8 percent and a non-significant increase from 44.1 percent to 55.4 percent for Moon Valley. For Clarendon, a decrease in publicity awareness from 35.1 percent to 24.2 percent was noted. As indicated previously, this is likely due to the high baseline rate of awareness and the absence of an organized group in the Clarendon area to distribute program literature.

Table 40. Category of Awareness by Neighborhood (Phoenix)

\begin{tabular}{|c|c|c|c|c|c|c|c|c|}
\hline \multirow{3}{*}{\multicolumn{3}{|c|}{$\begin{array}{l}\text { Category of Awareness - Publicity, Police } \\
\text { Involvement, and Roadway Treatment }\end{array}$}} & \multicolumn{6}{|c|}{ Phoenix Neighborhoods } \\
\hline & & & \multicolumn{2}{|c|}{ Sweetwater } & \multicolumn{2}{|c|}{$\begin{array}{l}\text { Moon Valley/ } \\
\text { Coral Gables }\end{array}$} & \multicolumn{2}{|c|}{ Clarendon } \\
\hline & & & Pre- & Follow- & Pre- & Follow- & Pre- & Follow- \\
\hline \multirow{6}{*}{$\begin{array}{l}\text { Did Any of These } \\
\text { Activities Include } \\
\text { Any Publicity?* }\end{array}$} & \multirow[t]{2}{*}{ Yes } & Count & 6 & 98 & 26 & 92 & 20 & 16 \\
\hline & & Column \% & $14.3 \%$ & $62.8 \%$ & $44.1 \%$ & $55.4 \%$ & $35.1 \%$ & $24.2 \%$ \\
\hline & \multirow[t]{2}{*}{ No } & Count & 28 & 27 & 16 & 30 & 21 & 27 \\
\hline & & Column \% & $66.7 \%$ & $17.3 \%$ & $27.1 \%$ & $18.1 \%$ & $36.8 \%$ & $40.9 \%$ \\
\hline & \multirow[t]{2}{*}{ Don't Know } & Count & 8 & 31 & 17 & 44 & 16 & 23 \\
\hline & & Column \% & $19 \%$ & $19.9 \%$ & $28.8 \%$ & $26.5 \%$ & $28.1 \%$ & $34.8 \%$ \\
\hline \multirow{6}{*}{$\begin{array}{l}\text { Were the Police } \\
\text { Involved in Any of } \\
\text { These Activities?** }\end{array}$} & \multirow[t]{2}{*}{ Yes } & Count & 15 & 106 & 23 & 98 & 7 & 12 \\
\hline & & Column \% & $35.7 \%$ & $66.3 \%$ & $39 \%$ & $58.3 \%$ & $12.1 \%$ & $18.2 \%$ \\
\hline & \multirow[t]{2}{*}{ No } & Count & 16 & 12 & 13 & 18 & 19 & 23 \\
\hline & & Column \% & $38.1 \%$ & $7.5 \%$ & $22 \%$ & $10.7 \%$ & $32.8 \%$ & $34.8 \%$ \\
\hline & \multirow[t]{2}{*}{ Don't Know } & Count & 11 & 42 & 23 & 52 & 32 & 31 \\
\hline & & Column \% & $26.2 \%$ & $26.3 \%$ & $39.0 \%$ & $31 \%$ & $55.2 \%$ & $47 \%$ \\
\hline \multirow{6}{*}{$\begin{array}{l}\text { Did Any of These } \\
\text { Activities Include } \\
\text { Any Changes to the } \\
\text { Road or the } \\
\text { Physical } \\
\text { Environment? } \\
* * *\end{array}$} & \multirow[t]{2}{*}{ Yes } & Count & 33 & 115 & 24 & 133 & 52 & 60 \\
\hline & & Column \% & $76.7 \%$ & $71.9 \%$ & $41.4 \%$ & $80.6 \%$ & $89.7 \%$ & $88.2 \%$ \\
\hline & \multirow[t]{2}{*}{ No } & Count & 10 & 31 & 28 & 23 & 3 & 6 \\
\hline & & Column \% & $23.3 \%$ & $19.4 \%$ & $48.3 \%$ & $13.9 \%$ & $5.2 \%$ & $8.8 \%$ \\
\hline & \multirow[t]{2}{*}{ Don't Know } & Count & 0 & 14 & 6 & 9 & 3 & 2 \\
\hline & & Column \% & $0 \%$ & $8.8 \%$ & $10.3 \%$ & $5.5 \%$ & $5.2 \%$ & $2.9 \%$ \\
\hline
\end{tabular}

$*$ Chi square significance for Sweetwater $=.000$

$* *$ Chi square significance for Sweetwater $=.000$ and for Moon Valley $=.018$

$* * *$ Chi square significance for Moon Valley $=.000$

With regard to police involvement, all Phoenix neighborhoods showed an increase in awareness from pre-program to follow-on study waves. There were significant increases in the Sweetwater neighborhood from 35.7 percent to 66.3 percent and in the Moon Valley neighborhood from 39 percent to 58.3 percent. There was a non-significant increase in Clarendon from 12.1 percent to 18.2 percent.

Finally, with regard to roadway treatments, only residents of the Moon Valley neighborhood reported an increased awareness in roadway treatments. This was a large and statistically significant increase from 41.4 percent to 80.6 percent. Both the Sweetwater and Clarendon respondents reported a decrease in awareness of roadway treatments from preprogram to follow-on waves. However, they both reported a very high awareness of roadway treatments in both waves. Sweetwater respondents indicated a 76.7 percent pre-program awareness of roadway treatments and a 71.9 percent follow-on awareness. These data for Clarendon were 89.7 percent and 88.2 percent, respectively. These results are fully consistent with actual program activities as reported earlier. Moon Valley received new treatments during 
the program and had no pre-existing treatments. Sweetwater had pre-existing treatments on the side streets and received no new vertical treatments during the program. Clarendon had speed humps on the street itself when the program began and received no other roadway treatments.

\subsubsection{Awareness of Specific Publicity Activities}

Respondents who indicated that they were aware of activities to control speeds in their neighborhoods were asked if the activities included any publicity and, if so, what specific publicity. The open-ended comments made by follow-on respondents were coded as being definitely, probably or not related to the Heed the Speed program. The results for the two cities are tabulated in Table 41. The percentages in that table are based on the number of respondents who indicated that they had been aware of publicity activities. Respondents could (and did) make more than one comment.

The table shows that respondents tended to indicate the source of the publicity, not the specific information included. In all, only nine respondents referred specifically to the entire Heed the Speed campaign as a publicity source - six from Phoenix and three from Peoria, but it was clear from many of the other responses that the program had to be the source of the respondent's information.

Table 41 shows that, by far, the largest number of respondents from both cities referred to signs as a publicity item or source. The comments included lawn signs as well as traffic signs. It should be noted again that the coding of program relationship was conservative. In order to be coded as "definitely program related," there needed to be something on the survey form that indicated that it was a program sign. As an example, the word "sign" alone would have merited a "probably program related" code. The words "yellow signs" (the color of the yard signs that were widely distributed) would have merited a "definitely program related" code. Signs were indicated as definitely or probably program related by 73.8 percent of the Phoenix respondents and 58.9 percent of the Peoria respondents.

The next most frequent comment made by respondents from both cities identified flyers, bulletins and newsletters as the source of publicity. Homeowner's associations were often identified as the source of these materials. In Peoria, 21.2 percent of these comments were coded as definitely or probably program related in contrast to 13.6 percent in Phoenix. Other relatively frequent sources of publicity identified by Peoria residents and coded as definitely or probably program-related were mail/letters (19.9\%) and newspapers (16.1\%). Far fewer indications of these publicity sources were noted among Phoenix residents $(9.8 \%$ and $2 \%$, respectively). This is not surprising since the neighborhood association for the Desert Harbor neighborhood in Peoria was particularly active in distributing the program's printed materials. 
Table 41. Comments on Publicity Made by Follow-On Survey Respondents (Phoenix and Peoria)*

\begin{tabular}{|c|c|c|c|c|c|c|c|}
\hline \multicolumn{2}{|c|}{ Publicity Category** } & \multicolumn{2}{|c|}{ Phoenix } & \multicolumn{2}{|c|}{ Peoria } & \multicolumn{2}{|c|}{ Total } \\
\hline & & Count & Percent & Count & Percent & Count & Percent \\
\hline \multirow{3}{*}{ Signs } & Definitely Program-Related & 131 & $63.6 \%$ & 70 & $29 \%$ & 201 & $45 \%$ \\
\hline & Probably Program-Related & 21 & $10.2 \%$ & 72 & $29.9 \%$ & 93 & $20.8 \%$ \\
\hline & No/Unknown Program Relation & 2 & $1 \%$ & 1 & $.4 \%$ & 3 & $.7 \%$ \\
\hline \multirow{3}{*}{$\begin{array}{l}\text { Flyers, } \\
\text { Bulletins, } \\
\text { Newsletters }\end{array}$} & Definitely Program-Related & 14 & $6.8 \%$ & 7 & $2.9 \%$ & 21 & $4.7 \%$ \\
\hline & Probably Program-Related & 14 & $6.8 \%$ & 44 & $18.3 \%$ & 58 & $13 \%$ \\
\hline & No/Unknown Program Relation & 1 & $.5 \%$ & 0 & $0 \%$ & 1 & $.2 \%$ \\
\hline \multirow{3}{*}{ Mail/Letters } & Definitely Program-Related & 10 & $4.9 \%$ & 7 & $2.9 \%$ & 17 & $3.8 \%$ \\
\hline & Probably Program-Related & 10 & $4.9 \%$ & 41 & $17 \%$ & 51 & $11.4 \%$ \\
\hline & No/Unknown Program Relation & 0 & $0 \%$ & 1 & $.4 \%$ & 1 & $.2 \%$ \\
\hline \multirow{3}{*}{ Meetings } & Definitely Program-Related & 4 & $1.9 \%$ & 1 & $.4 \%$ & 5 & $1.1 \%$ \\
\hline & Probably Program-Related & 11 & $5.3 \%$ & 15 & $6.2 \%$ & 26 & $5.8 \%$ \\
\hline & No/Unknown Program Relation & 0 & $0 \%$ & 0 & $0 \%$ & 0 & $0 \%$ \\
\hline \multirow{3}{*}{ Newspapers } & Definitely Program Related & 3 & $1.5 \%$ & 3 & $1.2 \%$ & 6 & $1.3 \%$ \\
\hline & Probably Program Related & 1 & $.5 \%$ & 36 & $14.9 \%$ & 37 & $8.3 \%$ \\
\hline & No/Unknown Program Relation & 0 & $0 \%$ & 1 & $.4 \%$ & 1 & $.2 \%$ \\
\hline \multirow{3}{*}{$\begin{array}{l}\text { Canvassing/ } \\
\text { Petitions }\end{array}$} & Definitely Program-Related & 0 & $0 \%$ & 0 & $0 \%$ & 0 & $0 \%$ \\
\hline & Probably Program-Related & 6 & $2.9 \%$ & 0 & $0 \%$ & 6 & $1.3 \%$ \\
\hline & No/Unknown Program Relation & 1 & $.5 \%$ & 0 & $0 \%$ & 1 & $.2 \%$ \\
\hline \multirow{3}{*}{$\begin{array}{l}\text { Television, } \\
\text { Radio }\end{array}$} & Definitely Program-Related & 3 & $1.5 \%$ & 1 & $.4 \%$ & 4 & $.9 \%$ \\
\hline & Probably Program-Related & 0 & $0 \%$ & 7 & $2.9 \%$ & 7 & $1.6 \%$ \\
\hline & No/Unknown Program Relation & 0 & $0 \%$ & 0 & $0 \%$ & 0 & $0 \%$ \\
\hline \multirow{3}{*}{$\begin{array}{l}\text { Heed the Speed } \\
\text { Campaign }\end{array}$} & Definitely Program-Related & 6 & $2.9 \%$ & 3 & $1.2 \%$ & 9 & $2 \%$ \\
\hline & Probably Program-Related & 0 & $0 \%$ & 0 & $0 \%$ & 0 & $0 \%$ \\
\hline & No/Unknown Program Relation & 0 & $0 \%$ & 0 & $0 \%$ & 0 & $0 \%$ \\
\hline \multicolumn{2}{|c|}{ Base Number of Respondents } & 206 & $100 \%$ & 241 & $100 \%$ & 447 & $100 \%$ \\
\hline
\end{tabular}

*Percentages are based on the number of respondents in each city who indicated an awareness of program publicity as shown in the last row of the table.

**Respondents could make more than one comment.

Specific publicity mentions by follow-on respondents in the Peoria neighborhoods are shown in Table 42. Again, the percentages are based on those who responded positively to an awareness of publicity in the neighborhood.

The table shows that signs were noted by more than 50 percent of the neighborhood respondents who indicated an awareness of publicity. The percentage of sign mentions coded as definitely or probably program-related was 52.1 percent for the $95^{\text {th }}$ Avenue respondents, 68.5 percent for the Desert Harbor respondents and 54.2 percent for the Bell Park respondents. The corresponding percentages for flyers, bulletins, and newsletters were 25.3 percent, 18.4 percent, and 20.2 percent, respectively. The percentages for newspapers were 15.5 percent, 15.8 percent, and 17.1 percent, respectively. These results are consistent with observations of yard sign deployments during the program. 
Table 42. Comments on Publicity Made by Follow-On Survey Respondents by Neighborhood (Peoria)*

\begin{tabular}{|c|c|c|c|c|c|c|c|}
\hline \multirow{3}{*}{\multicolumn{2}{|c|}{ Publicity Category** }} & \multicolumn{6}{|c|}{ Peoria Neighborhoods } \\
\hline & & \multicolumn{2}{|c|}{ 95th Ave } & \multicolumn{2}{|c|}{$\begin{array}{c}\text { Desert Harbor/ } \\
\text { 91st Ave }\end{array}$} & \multicolumn{2}{|c|}{$\begin{array}{c}\text { Bell Park/84th } \\
\text { Ave }\end{array}$} \\
\hline & & Count & Percent & Count & Percent & Count & Percent \\
\hline \multirow{3}{*}{ Signs } & Definitely Program-Related & 23 & $32.4 \%$ & 29 & $38.2 \%$ & 18 & $19.1 \%$ \\
\hline & Probably Program-Related & 14 & $19.7 \%$ & 23 & $30.3 \%$ & 33 & $35.1 \%$ \\
\hline & No/Unknown Program Relation & 1 & $1.4 \%$ & 0 & $0 \%$ & 0 & $0 \%$ \\
\hline \multirow{3}{*}{$\begin{array}{l}\text { Flyers, Bulletins, } \\
\text { Newsletters }\end{array}$} & Definitely Program-Related & 3 & $4.2 \%$ & 2 & $2.6 \%$ & 2 & $2.1 \%$ \\
\hline & Probably Program-Related & 15 & $21.1 \%$ & 12 & $15.8 \%$ & 17 & $18.1 \%$ \\
\hline & No/Unknown Program Relation & 0 & $0 \%$ & 0 & $0 \%$ & 0 & $0 \%$ \\
\hline \multirow{3}{*}{ Mail/Letters } & Definitely Program-Related & 0 & $0 \%$ & 0 & $0 \%$ & 7 & $7.4 \%$ \\
\hline & Probably Program-Related & 9 & $12.7 \%$ & 1 & $1.3 \%$ & 30 & $31.9 \%$ \\
\hline & No/Unknown Program Relation & 0 & $0 \%$ & 1 & $1.3 \%$ & 0 & $0 \%$ \\
\hline \multirow{3}{*}{ Meetings } & Definitely Program-Related & 0 & $0 \%$ & 0 & $0 \%$ & 1 & $1.1 \%$ \\
\hline & Probably Program-Related & 4 & $5.6 \%$ & 1 & $1.3 \%$ & 10 & $10.6 \%$ \\
\hline & No/Unknown Program Relation & 0 & $0 \%$ & 0 & $0 \%$ & 0 & $0 \%$ \\
\hline \multirow{3}{*}{ Newspapers } & Definitely Program-Related & 1 & $1.4 \%$ & 1 & $1.3 \%$ & 1 & $1.1 \%$ \\
\hline & Probably Program-Related & 10 & $14.1 \%$ & 11 & $14.5 \%$ & 15 & $16 \%$ \\
\hline & No/Unknown Program Relation & 0 & $0 \%$ & 1 & $1.3 \%$ & 0 & $0 \%$ \\
\hline \multirow{3}{*}{ Canvassing/Petitions } & Definitely Program-Related & 0 & $0 \%$ & 0 & $0 \%$ & 0 & $0 \%$ \\
\hline & Probably Program-Related & 0 & $0 \%$ & 0 & $0 \%$ & 0 & $0 \%$ \\
\hline & No/Unknown Program Relation & 0 & $0 \%$ & 0 & $0 \%$ & 0 & $0 \%$ \\
\hline \multirow{3}{*}{ Television, Radio } & Definitely Program-Related & 1 & $1.4 \%$ & 0 & $0 \%$ & 0 & $0 \%$ \\
\hline & Probably Program-Related & 3 & $4.2 \%$ & 1 & $1.3 \%$ & 3 & $3.2 \%$ \\
\hline & No/Unknown Program Relation & 0 & $0 \%$ & 0 & $0 \%$ & 0 & $0 \%$ \\
\hline \multirow{3}{*}{$\begin{array}{l}\text { Heed the Speed } \\
\text { Campaign }\end{array}$} & Definitely Program-Related & 1 & $1.4 \%$ & 1 & $1.3 \%$ & 1 & $1.1 \%$ \\
\hline & Probably Program-Related & 0 & $0 \%$ & 0 & $0 \%$ & 0 & $0 \%$ \\
\hline & No/Unknown Program Relation & 0 & $0 \%$ & 0 & $0 \%$ & 0 & $0 \%$ \\
\hline \multicolumn{2}{|c|}{ Base Number of Respondents } & 71 & $100 \%$ & 76 & $100 \%$ & 94 & $100 \%$ \\
\hline
\end{tabular}

*Percentages are based on the number of respondents in each neighborhood who indicated an awareness of program publicity as shown in the last row of the table.

**Respondents could make more than one comment.

Specific publicity references made by follow-on respondents in Phoenix neighborhoods are shown in Table 43. Again, the percentages are of those who responded positively to an awareness of publicity in the neighborhood.

Table 43 indicates that signs were mentioned very frequently in Phoenix except for the Clarendon neighborhood. This is fully consistent with observations during the program. The percentages in which they were coded as definitely or probably program related were 82.7 percent for Sweetwater and 75 percent in Moon Valley. The percentage for Clarendon was 12.5. For Clarendon, the largest percentage $(25 \%)$ was for flyers, bulletins, and newsletters. The percentages for Sweetwater and Moon Valley for this category were 5.1 percent and 20.7 percent, respectively. For mail and letters, Clarendon had a percentage of 6.3 in contrast to 15.3 percent for Sweetwater and 4.4 percent for Moon Valley. Aside from meetings, with a percentage of 16.3 percent for Moon Valley returns, other mentions of publicity categories were small. 
Table 43. Comments on Publicity Made by Follow-On Survey Respondents by Neighborhood (Phoenix)*

\begin{tabular}{|c|c|c|c|c|c|c|c|}
\hline \multirow{3}{*}{\multicolumn{2}{|c|}{ Publicity Category** }} & \multicolumn{6}{|c|}{ Phoenix Neighborhoods } \\
\hline & & \multicolumn{2}{|c|}{ Sweetwater } & \multicolumn{2}{|c|}{$\begin{array}{l}\text { Moon Valley/ } \\
\text { Coral Gables } \\
\end{array}$} & \multicolumn{2}{|c|}{ Clarendon } \\
\hline & & Count & Percent & Count & Percent & Count & Percent \\
\hline \multirow{3}{*}{ Signs } & Definitely Program-Related & 73 & $74.5 \%$ & 58 & $63 \%$ & 0 & $0 \%$ \\
\hline & Probably Program-Related & 8 & $8.2 \%$ & 11 & $12 \%$ & 2 & $12.5 \%$ \\
\hline & $\begin{array}{l}\text { No/Unknown Program } \\
\text { Relation }\end{array}$ & 1 & $1 \%$ & 0 & $0 \%$ & 1 & $6.3 \%$ \\
\hline \multirow{3}{*}{$\begin{array}{l}\text { Flyers, Bulletins, } \\
\text { Newsletters }\end{array}$} & Definitely Program-Related & 4 & $4.1 \%$ & 10 & $10.9 \%$ & 0 & $0 \%$ \\
\hline & Probably Program-Related & 1 & $1 \%$ & 9 & $9.8 \%$ & 4 & $25 \%$ \\
\hline & $\begin{array}{l}\text { No/Unknown Program } \\
\text { Relation }\end{array}$ & 0 & $0 \%$ & 0 & $0 \%$ & 1 & $6.3 \%$ \\
\hline \multirow{3}{*}{ Mail/Letters } & Definitely Program-Related & 7 & $7.1 \%$ & 3 & $3.3 \%$ & 0 & $0 \%$ \\
\hline & Probably Program-Related & 8 & $8.2 \%$ & 1 & $1.1 \%$ & 1 & $6.3 \%$ \\
\hline & $\begin{array}{l}\text { No/Unknown Program } \\
\text { Relation }\end{array}$ & 0 & $0 \%$ & 0 & $0 \%$ & 0 & $0 \%$ \\
\hline \multirow{3}{*}{ Meetings } & Definitely Program-Related & 0 & $0 \%$ & 4 & $4.3 \%$ & 0 & $0 \%$ \\
\hline & Probably Program-Related & 0 & $0 \%$ & 11 & $12 \%$ & 0 & $0 \%$ \\
\hline & $\begin{array}{l}\text { No/Unknown Program } \\
\text { Relation }\end{array}$ & 0 & $0 \%$ & 0 & $0 \%$ & 0 & $0 \%$ \\
\hline \multirow{3}{*}{ Newspapers } & Definitely Program-Related & 0 & $0 \%$ & 3 & $3.3 \%$ & 0 & $0 \%$ \\
\hline & Probably Program-Related & 1 & $1 \%$ & 0 & $0 \%$ & 0 & $0 \%$ \\
\hline & $\begin{array}{l}\text { No/Unknown Program } \\
\text { Relation }\end{array}$ & 0 & $0 \%$ & 0 & $0 \%$ & 0 & $0 \%$ \\
\hline \multirow{3}{*}{ Canvassing/Petitions } & Definitely Program-Related & 0 & $0 \%$ & 0 & $0 \%$ & 0 & $0 \%$ \\
\hline & Probably Program-Related & 0 & $0 \%$ & 5 & $5.4 \%$ & 1 & $6.3 \%$ \\
\hline & $\begin{array}{l}\text { No/Unknown Program } \\
\text { Relation }\end{array}$ & 0 & $0 \%$ & 0 & $0 \%$ & 1 & $6.3 \%$ \\
\hline \multirow{3}{*}{ Television, Radio } & Definitely Program-Related & 2 & $2 \%$ & 1 & $1.1 \%$ & 0 & $0 \%$ \\
\hline & Probably Program-Related & 0 & $0 \%$ & 0 & $0 \%$ & 0 & $0 \%$ \\
\hline & $\begin{array}{l}\text { No/Unknown Program } \\
\text { Relation }\end{array}$ & 0 & $0 \%$ & 0 & $0 \%$ & 0 & $0 \%$ \\
\hline \multirow{3}{*}{$\begin{array}{l}\text { Heed the Speed } \\
\text { Campaign }\end{array}$} & Definitely Program-Related & 4 & $4.1 \%$ & 2 & $2.2 \%$ & 0 & $0 \%$ \\
\hline & Probably Program-Related & 0 & $0 \%$ & 0 & $0 \%$ & 0 & $0 \%$ \\
\hline & $\begin{array}{l}\text { No/Unknown Program } \\
\text { Relation }\end{array}$ & 0 & $0 \%$ & 0 & $0 \%$ & 0 & $0 \%$ \\
\hline \multicolumn{2}{|c|}{ Base Number of Respondents } & 98 & $100 \%$ & 92 & $100 \%$ & 16 & $100 \%$ \\
\hline
\end{tabular}

*Percentages are based on the number of respondents in each neighborhood who indicated an awareness of program publicity as shown in the last row of the table.

**Respondents could make more than one comment.

\subsubsection{Awareness of Police Activities}

Respondents who indicated that they were aware of activities to control speeds in their neighborhoods were asked if the activities included any police involvement and, if so, what specific activities. The comments made by follow-on respondents in the two cities are shown in Table 44. The percentages in that table are based on the number of respondents who indicated 
that they had been aware of police activities. Respondents could (and did) make more than one comment.

Table 44. Comments on Police Involvement Made by Follow-On Survey Respondents (Phoenix and Peoria)*

\begin{tabular}{|c|c|c|c|c|c|c|c|}
\hline \multicolumn{2}{|c|}{ Police Involvement Category** } & \multicolumn{2}{|c|}{ Phoenix } & \multicolumn{2}{|c|}{ Peoria } & \multicolumn{2}{|c|}{ Total } \\
\hline & & Count & Percent & Count & Percent & Count & Percent \\
\hline \multirow{3}{*}{ Enforcement } & Definitely Program-Related & 4 & $1.9 \%$ & 9 & $5.7 \%$ & 13 & $3.5 \%$ \\
\hline & Probably Program-Related & 112 & $51.9 \%$ & 83 & $52.9 \%$ & 195 & $52.3 \%$ \\
\hline & No/Unknown Program Relation & 2 & $.9 \%$ & 1 & $.6 \%$ & 3 & $.8 \%$ \\
\hline \multirow{3}{*}{ Radar Checks } & Definitely Program-Related & 3 & $1.4 \%$ & 0 & $0 \%$ & 3 & $.8 \%$ \\
\hline & Probably Program-Related & 81 & $37.5 \%$ & 31 & $19.7 \%$ & 112 & $30 \%$ \\
\hline & No/Unknown Program Relation & 0 & $0 \%$ & 0 & $0 \%$ & 0 & $0 \%$ \\
\hline \multirow{3}{*}{$\begin{array}{l}\text { Deployment of } \\
\text { Speed Trailers }\end{array}$} & Definitely Program-Related & 1 & $.5 \%$ & 0 & $0 \%$ & 1 & $.3 \%$ \\
\hline & Probably Program-Related & 8 & $3.7 \%$ & 29 & $18.5 \%$ & 37 & $9.9 \%$ \\
\hline & No/Unknown Program Relation & 0 & $0 \%$ & 1 & $.6 \%$ & 1 & $.3 \%$ \\
\hline \multirow{3}{*}{$\begin{array}{l}\text { Attendance at } \\
\text { Meetings }\end{array}$} & Definitely Program-Related & 1 & $.5 \%$ & 3 & $1.9 \%$ & 4 & $1.1 \%$ \\
\hline & Probably Program-Related & 4 & $1.9 \%$ & 12 & $7.6 \%$ & 16 & $4.3 \%$ \\
\hline & No/Unknown Program Relation & 0 & $0 \%$ & 0 & $0 \%$ & 0 & $0 \%$ \\
\hline \multirow{3}{*}{ Miscellaneous } & Definitely Program-Related & 0 & $0 \%$ & 3 & $1.9 \%$ & 3 & $.8 \%$ \\
\hline & Probably Program-Related & 1 & $.5 \%$ & 0 & $0 \%$ & 1 & $.3 \%$ \\
\hline & No/Unknown Program Relation & 2 & $.9 \%$ & 1 & $.6 \%$ & 3 & $.8 \%$ \\
\hline \multicolumn{2}{|c|}{ Base Number of Respondents } & 216 & $100 \%$ & 157 & $100 \%$ & 373 & $100 \%$ \\
\hline
\end{tabular}

Table 44 shows that large percentages of respondents who were aware of police activities in both cities noticed police enforcement and radar checks. In Phoenix, enforcement was definitely or probably program-related in 53.8 percent of the mentions. The value for Peoria was 58.6 percent of the comments. Respondents mentioned radar checks proportionately more frequently in Phoenix (38.9\%) than in Peoria (19.7\%). The speed trailer was noticed proportionately more frequently in Peoria (18.5\%) than was the photo speed enforcement trailer in Phoenix (4.2\%). Attendance at meetings was cited in 9.5 percent of the cases in Peoria and in 2.4 percent of the cases in Phoenix.

Specific comments on police involvement broken down by Peoria neighborhoods are shown in Table 45. Even though the number of comments is quite small, the table shows some interesting patterns. For example, large percentages of respondents in all neighborhoods were aware of police enforcement activities. The observations of 62.7 percent of the $95^{\text {th }}$ Avenue respondents, 60.6 percent of Bell Park residents and 51.1 percent of Desert Harbor residents were definitely or probably program related. Radar checks were noticed most frequently in Bell Park (24.6\%) and Desert Harbor (20\%). Curiously, deployment of the speed trailer was noticed most frequently in Desert Harbor (26.7\%) even though it was deployed least in that neighborhood (eight times in $95^{\text {th }}$ Avenue, six times in Bell Park, and three times in Desert Harbor). 
Table 45. Comments on Police Involvement Made by Follow-On Survey Respondents by Neighborhood (Peoria)*

\begin{tabular}{|c|c|c|c|c|c|c|c|}
\hline \multirow{3}{*}{\multicolumn{2}{|c|}{ Police Involvement Category** }} & \multicolumn{6}{|c|}{ Peoria Neighborhoods } \\
\hline & & \multicolumn{2}{|c|}{ 95th Ave } & \multicolumn{2}{|c|}{$\begin{array}{c}\text { Desert Harbor/ } \\
\text { 91st Ave }\end{array}$} & \multicolumn{2}{|c|}{ Bell Park/84th Ave } \\
\hline & & Count & Percent & Count & Percent & Count & Percent \\
\hline \multirow{3}{*}{ Enforcement } & Definitely Program-Related & 0 & $0 \%$ & 3 & $6.7 \%$ & 6 & $9.8 \%$ \\
\hline & Probably Program-Related & 32 & $62.7 \%$ & 20 & $44.4 \%$ & 31 & $50.8 \%$ \\
\hline & $\begin{array}{l}\text { No/Unknown Program } \\
\text { Relation }\end{array}$ & 0 & $0 \%$ & 0 & $0 \%$ & 1 & $1.6 \%$ \\
\hline \multirow{3}{*}{ Radar Checks } & Definitely Program-Related & 0 & $0 \%$ & 0 & $0 \%$ & 0 & $0 \%$ \\
\hline & Probably Program-Related & 7 & $13.7 \%$ & 9 & $20 \%$ & 15 & $24.6 \%$ \\
\hline & $\begin{array}{l}\text { No/Unknown Program } \\
\text { Relation }\end{array}$ & 0 & $0 \%$ & 0 & $0 \%$ & 0 & $0 \%$ \\
\hline \multirow{3}{*}{$\begin{array}{l}\text { Deployment of } \\
\text { Speed Trailers }\end{array}$} & Definitely Program-Related & 0 & $0 \%$ & 0 & $0 \%$ & 0 & $0 \%$ \\
\hline & Probably Program-Related & 7 & $13.7 \%$ & 12 & $26.7 \%$ & 10 & $16.4 \%$ \\
\hline & $\begin{array}{l}\text { No/Unknown Program } \\
\text { Relation }\end{array}$ & 1 & $2 \%$ & 0 & $0 \%$ & 0 & $0 \%$ \\
\hline \multirow{3}{*}{$\begin{array}{l}\text { Attendance at } \\
\text { Meetings }\end{array}$} & Definitely Program-Related & 0 & $0 \%$ & 1 & $2.2 \%$ & 2 & $3.3 \%$ \\
\hline & Probably Program-Related & 4 & $7.8 \%$ & 3 & $6.7 \%$ & 5 & $8.2 \%$ \\
\hline & $\begin{array}{l}\text { No/Unknown Program } \\
\text { Relation }\end{array}$ & 0 & $0 \%$ & 0 & $0 \%$ & 0 & $0 \%$ \\
\hline \multirow{3}{*}{ Miscellaneous } & Definitely Program-Related & 0 & $0 \%$ & 2 & $4.4 \%$ & 1 & $1.6 \%$ \\
\hline & Probably Program-Related & 0 & $0 \%$ & 0 & $0 \%$ & 0 & $0 \%$ \\
\hline & $\begin{array}{l}\text { No/Unknown Program } \\
\text { Relation }\end{array}$ & 1 & $2 \%$ & 0 & $0 \%$ & 0 & $0 \%$ \\
\hline \multicolumn{2}{|c|}{ Base Number of Respondents } & 51 & $100 \%$ & 45 & $100 \%$ & 61 & $100 \%$ \\
\hline
\end{tabular}

*Percentages are based on the number of respondents who indicated an awareness of program police involvement as shown in the last row of the table.

**Respondents could make more than one comment.

The equivalent neighborhood breakdown of comments on police involvement made by Phoenix residents is shown in Table 46. The table shows that over 50 percent of the responses received from both Sweetwater and Moon Valley residents included comments on police enforcement that were either definitely or probably related to the program. These percentages were 55.1 percent for Moon Valley and 51.9 percent for Sweetwater. As for radar checks, 46.2 percent of the Sweetwater comments and 35.7 percent of the Moon Valley comments were definitely or probably program-related. A small number of residents in Moon Valley (8.2\%) noted deployment of the photo speed enforcement trailer. There were too few comments from Clarendon residents in all categories to be meaningfully tabulated.

\subsubsection{Awareness of Roadway Treatments}

Respondents who indicated that they were aware of activities to control speeds in their neighborhoods were asked if the activities included any changes to the roadway or physical environment and, if so, what specific changes. The comments made by follow-on respondents in the two cities are shown in Table 47. The percentages in that table are based on the number of respondents who indicated that they had been aware of roadway changes. Respondents could make more than one comment. 
Table 46. Comments on Police Involvement Made by Follow-On Survey Respondents by Neighborhood (Phoenix)*

\begin{tabular}{|c|c|c|c|c|c|c|c|}
\hline \multirow{2}{*}{\multicolumn{2}{|c|}{ Police Involvement Category** }} & \multicolumn{6}{|c|}{ Phoenix Neighborhoods } \\
\hline & & \multicolumn{2}{|c|}{ Sweetwater } & \multicolumn{2}{|c|}{$\begin{array}{l}\text { Moon Valley/ } \\
\text { Coral Gables }\end{array}$} & \multicolumn{2}{|c|}{ Clarendon } \\
\hline & & Count & Percent & Count & Percent & Count & Percent \\
\hline \multirow{3}{*}{ Enforcement } & Definitely Program-Related & 3 & $2.8 \%$ & 1 & $1 \%$ & 0 & $0 \%$ \\
\hline & Probably Program-Related & 52 & $49.1 \%$ & 53 & $54.1 \%$ & 7 & $58.3 \%$ \\
\hline & No/Unknown Program Relation & 0 & $0 \%$ & 0 & $0 \%$ & 2 & $16.7 \%$ \\
\hline \multirow{3}{*}{ Radar Checks } & Definitely Program-Related & 2 & $1.9 \%$ & 1 & $1 \%$ & 0 & $0 \%$ \\
\hline & Probably Program-Related & 47 & $44.3 \%$ & 34 & $34.7 \%$ & 0 & $0 \%$ \\
\hline & No/Unknown Program Relation & 0 & $0 \%$ & 0 & $0 \%$ & 0 & $0 \%$ \\
\hline \multirow{3}{*}{$\begin{array}{l}\text { Deployment of } \\
\text { Speed Trailers }\end{array}$} & Definitely Program-Related & 0 & $0 \%$ & 0 & $0 \%$ & 1 & $8.3 \%$ \\
\hline & Probably Program-Related & 0 & $0 \%$ & 8 & $8.2 \%$ & 0 & $0 \%$ \\
\hline & No/Unknown Program Relation & 0 & $0 \%$ & 0 & $0 \%$ & 0 & $0 \%$ \\
\hline \multirow{3}{*}{$\begin{array}{l}\text { Attendance at } \\
\text { Meetings }\end{array}$} & Definitely Program-Related & 0 & $0 \%$ & 1 & $1 \%$ & 0 & $0 \%$ \\
\hline & Probably Program-Related & 0 & $0 \%$ & 4 & $4.1 \%$ & 0 & $0 \%$ \\
\hline & No/Unknown Program Relation & 0 & $0 \%$ & 0 & $0 \%$ & 0 & $0 \%$ \\
\hline \multirow{3}{*}{ Miscellaneous } & Definitely Program-Related & 0 & $0 \%$ & 0 & $0 \%$ & 0 & $0 \%$ \\
\hline & Probably Program-Related & 0 & $0 \%$ & 1 & $1 \%$ & 0 & $0 \%$ \\
\hline & No/Unknown Program Relation & 0 & $0 \%$ & 1 & $1 \%$ & 1 & $8.3 \%$ \\
\hline \multicolumn{2}{|c|}{ Base Number of Respondents } & 106 & $100 \%$ & 98 & $100 \%$ & 12 & $100 \%$ \\
\hline
\end{tabular}

*Percentages are based on the number of respondents who indicated an awareness of program police involvement as shown in the last row of the table.

**Respondents could make more than one comment.

The table shows that 46.9 percent of the Peoria respondents made comments on speed humps or tables that were definitely or probably program-related. In contrast, 23.4 percent of Phoenix residents made similar comments. Comments on road signs that were definitely or probably program-related were made by 15.2 percent of the Phoenix respondents and by 42.4 percent of the Peoria respondents. The 3-D markings were mentioned by 42.4 percent of the Peoria residents in contrast to 10.3 percent of the Phoenix residents. Road pavement changes (e.g., Tyregrip ${ }^{\mathrm{TM}}$ ) were noted by 44.1 percent of the Phoenix residents. This product was not used in Peoria. A small number of individuals in both cities mentioned the tubes - likely a reference to the speed measurement devices used for the evaluation.

A breakdown by neighborhood of the specific comments on roadway changes made by follow-on respondents in Peoria neighborhoods is shown in Table 48. The table indicates an awareness of Heed the Speed roadway changes that were made in the various Peoria neighborhoods. In fact, 91 percent of the responses in Bell Park that mentioned road humps/tables were judged to be definitely or probably related to the Heed the Speed program. The 13.2 percent mentioned for humps/tables for $95^{\text {th }}$ Avenue may well have been a reference to the 3-D markings, which were prevalent on the street, instead of the humps themselves. In fact, 78.3 percent of the responses made for $95^{\text {th }}$ Avenue for 3-D markings were judged to be definitely or probably program-related. Signs were mentioned often by residents of $91^{\text {st }}$ Avenue (68.6\% definitely or probably program-related) followed by $95^{\text {th }}$ Avenue $(51.9 \%$ definitely or probably program-related) and Bell Park (24.8\% definitely or probably program-related). 
Table 47. Comments on Roadway Changes Made by Follow-On Survey Respondents (Phoenix and Peoria)*

\begin{tabular}{|c|c|c|c|c|c|c|c|}
\hline \multirow{2}{*}{\multicolumn{2}{|c|}{ Road Change Category** }} & \multicolumn{2}{|c|}{ Phoenix } & \multicolumn{2}{|c|}{ Peoria } & \multicolumn{2}{|c|}{ Total } \\
\hline & & Count & Percent & Count & Percent & Count & Percent \\
\hline \multirow{3}{*}{ Speed Humps/Tables } & Definitely Program-Related & 63 & $20.5 \%$ & 47 & $16.2 \%$ & 110 & $18.4 \%$ \\
\hline & Probably Program-Related & 9 & $2.9 \%$ & 89 & $30.7 \%$ & 98 & $16.4 \%$ \\
\hline & $\begin{array}{l}\text { No/Unknown Program } \\
\text { Relation }\end{array}$ & 53 & $17.2 \%$ & 4 & $1.4 \%$ & 57 & $9.5 \%$ \\
\hline \multirow{3}{*}{ Road Signs } & Definitely Program-Related & 34 & $11 \%$ & 63 & $21.7 \%$ & 97 & $16.2 \%$ \\
\hline & Probably Program-Related & 13 & $4.2 \%$ & 60 & $20.7 \%$ & 73 & $12.2 \%$ \\
\hline & $\begin{array}{l}\text { No/Unknown Program } \\
\text { Relation }\end{array}$ & 5 & $1.6 \%$ & 2 & $.7 \%$ & 7 & $1.2 \%$ \\
\hline \multirow{3}{*}{ 3-D Markings } & Definitely Program-Related & 30 & $9.7 \%$ & 104 & $35.9 \%$ & 134 & $22.4 \%$ \\
\hline & Probably Program-Related & 2 & $.6 \%$ & 19 & $6.6 \%$ & 21 & $3.5 \%$ \\
\hline & $\begin{array}{l}\text { No/Unknown Program } \\
\text { Relation }\end{array}$ & 0 & $0 \%$ & 0 & $0 \%$ & 0 & $0 \%$ \\
\hline \multirow{3}{*}{$\begin{array}{l}\text { Road Pavement } \\
\text { Changes }\end{array}$} & Definitely Program-Related & 119 & $38.6 \%$ & 0 & $0 \%$ & 119 & $19.9 \%$ \\
\hline & Probably Program-Related & 17 & $5.5 \%$ & 0 & $0 \%$ & 17 & $2.8 \%$ \\
\hline & $\begin{array}{l}\text { No/Unknown Program } \\
\text { Relation }\end{array}$ & 0 & $0 \%$ & 0 & $0 \%$ & 0 & $0 \%$ \\
\hline \multirow{3}{*}{$\begin{array}{l}\text { Speed Measurement } \\
\text { Tubes }\end{array}$} & Definitely Program-Related & 0 & $.0 \%$ & 0 & $0 \%$ & 0 & $0 \%$ \\
\hline & Probably Program-Related & 6 & $1.9 \%$ & 9 & $3.1 \%$ & 15 & $2.5 \%$ \\
\hline & $\begin{array}{l}\text { No/Unknown Program } \\
\text { Relation }\end{array}$ & 0 & $0 \%$ & 0 & $0 \%$ & 0 & $0 \%$ \\
\hline \multirow{3}{*}{ Miscellaneous } & Definitely Program-Related & 0 & $0 \%$ & 0 & $0 \%$ & 0 & $0 \%$ \\
\hline & Probably Program-Related & 0 & $0 \%$ & 0 & $0 \%$ & 0 & $0 \%$ \\
\hline & $\begin{array}{l}\text { No/Unknown Program } \\
\text { Relation }\end{array}$ & 9 & $2.9 \%$ & 3 & $1 \%$ & 12 & $2 \%$ \\
\hline \multicolumn{2}{|c|}{ Base Number of Respondents } & 308 & $100 \%$ & 290 & $100 \%$ & 598 & $100 \%$ \\
\hline
\end{tabular}

*Percentages are based on the number of respondents in each city who indicated an awareness of roadway changes as shown in the last row of the table.

**Respondents could make more than one comment.

The neighborhood-by-neighborhood listing of comments on roadway changes made by Phoenix residents is shown in Table 49. As might be expected, 52.6 percent of the Moon Valley responses identifying speed humps/tables as road changes were rated as definitely or probably program-related. A very large number of similar codes for Clarendon (85\%) were coded as unrelated to the program since they referred to existing humps. Residents of Moon Valley mentioned the 3-D markings (24.1\% were coded as definitely or probably program-related). Both Moon Valley and Sweetwater residents mentioned roadway pavement changes (3-D marking and Tyregrip ${ }^{\mathrm{TM}}-36.1 \%$ and $76.5 \%$, respectively coded as definitely or probably program-related).

\subsubsection{Ratings of Neighborhood Speed}

Residents were asked the question, "Compared to six months ago, how would you rate the speeds in your neighborhood?" They were offered the response categories of "much slower," "a bit slower," "the same," "a bit faster," and "much faster." Responses are given in Table 50, which shows that respondents from both cities perceived a drop in speeds over the six months preceding the survey. Percentages in all of the categories changed in the desired direction - the perceptions of slower speeds increased, while those of the same speeds and those of faster speeds decreased. 
Table 50 shows that, from pre-program to follow-on periods, there was an increase in the percentage of individuals who felt that speeds have decreased. The percentages increased from 18.3 percent to 48.3 percent in Phoenix and from 14.2 percent to 44.2 percent in Peoria. Over the same period, the percentages of individuals who felt that speeds remained the same decreased - from 46.0 percent to 37.9 percent in Phoenix and from 45.9 percent to 35.1 percent in Peoria. Finally, there was a decrease in the percentage of individuals who felt that speeds had increased. From pre-program to follow-on periods, these percentages decreased from 35.8 percent to 13.7 percent in Phoenix and from 40 percent to 20.7 percent in Peoria.

Table 48. Comments on Roadway Changes Made by Follow-On Survey Respondents by Neighborhood (Peoria)*

\begin{tabular}{|c|c|c|c|c|c|c|c|}
\hline \multirow{3}{*}{\multicolumn{2}{|c|}{ Road Change Category** }} & \multicolumn{6}{|c|}{ Peoria Neighborhoods } \\
\hline & & \multicolumn{2}{|c|}{ 95th Ave } & \multicolumn{2}{|c|}{$\begin{array}{c}\text { Desert Harbor/ } \\
\text { 91st Ave }\end{array}$} & \multicolumn{2}{|c|}{$\begin{array}{l}\text { Bell Park/84th } \\
\text { Ave }\end{array}$} \\
\hline & & Count & Percent & Count & Percent & Count & Percent \\
\hline \multirow{3}{*}{$\begin{array}{l}\text { Speed } \\
\text { Humps/Tables }\end{array}$} & Definitely Program-Related & 3 & $2.8 \%$ & 0 & $0 \%$ & 44 & $33.1 \%$ \\
\hline & Probably Program-Related & 11 & $10.4 \%$ & 1 & $2 \%$ & 77 & $57.9 \%$ \\
\hline & $\begin{array}{l}\text { No/Unknown Program } \\
\text { Relation }\end{array}$ & 1 & $.9 \%$ & 3 & $5.9 \%$ & 0 & $0 \%$ \\
\hline \multirow{3}{*}{ Road Signs } & Definitely Program-Related & 28 & $26.4 \%$ & 26 & $51 \%$ & 9 & $6.8 \%$ \\
\hline & Probably Program-Related & 27 & $25.5 \%$ & 9 & $17.6 \%$ & 24 & $18 \%$ \\
\hline & $\begin{array}{l}\text { No/Unknown Program } \\
\text { Relation }\end{array}$ & 0 & $0 \%$ & 1 & $2 \%$ & 1 & $.8 \%$ \\
\hline \multirow{3}{*}{ 3-D Markings } & Definitely Program-Related & 67 & $63.2 \%$ & 0 & $0 \%$ & 36 & $27.1 \%$ \\
\hline & Probably Program-Related & 16 & $15.1 \%$ & 0 & $0 \%$ & 2 & $1.5 \%$ \\
\hline & $\begin{array}{l}\text { No/Unknown Program } \\
\text { Relation }\end{array}$ & 0 & $0 \%$ & 0 & $0 \%$ & 0 & $0 \%$ \\
\hline \multirow{3}{*}{$\begin{array}{l}\text { Road Pavement } \\
\text { Changes }\end{array}$} & Definitely Program-Related & 0 & $0 \%$ & 0 & $0 \%$ & 0 & $0 \%$ \\
\hline & Probably Program-Related & 0 & $0 \%$ & 0 & $0 \%$ & 0 & $0 \%$ \\
\hline & $\begin{array}{l}\text { No/Unknown Program } \\
\text { Relation }\end{array}$ & 0 & $0 \%$ & 0 & $.0 \%$ & 0 & $0 \%$ \\
\hline \multirow{3}{*}{$\begin{array}{l}\text { Speed Measurement } \\
\text { Tubes }\end{array}$} & Definitely Program-Related & 0 & $0 \%$ & 0 & $0 \%$ & 0 & $0 \%$ \\
\hline & Probably Program-Related & 2 & $1.9 \%$ & 5 & $9.8 \%$ & 2 & $1.5 \%$ \\
\hline & $\begin{array}{l}\text { No/Unknown Program } \\
\text { Relation }\end{array}$ & 0 & $0 \%$ & 0 & $0 \%$ & 0 & $0 \%$ \\
\hline \multirow{3}{*}{ Miscellaneous } & Definitely Program-Related & 0 & $0 \%$ & 0 & $0 \%$ & 0 & $0 \%$ \\
\hline & Probably Program-Related & 0 & $0 \%$ & 0 & $0 \%$ & 0 & $0 \%$ \\
\hline & $\begin{array}{l}\text { No/Unknown Program } \\
\text { Relation }\end{array}$ & 1 & $.9 \%$ & 1 & $2.0 \%$ & 1 & $.8 \%$ \\
\hline \multicolumn{2}{|c|}{ Base Number of Respondents } & 106 & $100 \%$ & 51 & $100 \%$ & 133 & $100 \%$ \\
\hline
\end{tabular}

*Percentages are based on the number of respondents in each neighborhood who indicated an awareness of roadway changes as shown in the last row of the table.

**Respondents could make more than one comment. 
Table 49. Comments on Roadway Changes Made by Follow-On Survey Respondents by Neighborhood (Phoenix)*

\begin{tabular}{|c|c|c|c|c|c|c|c|}
\hline \multirow{3}{*}{\multicolumn{2}{|c|}{ Road Change Category** }} & \multicolumn{6}{|c|}{ Phoenix Neighborhoods } \\
\hline & & \multicolumn{2}{|c|}{ Sweetwater } & \multicolumn{2}{|c|}{$\begin{array}{l}\text { Moon Valley/ } \\
\text { Coral Gables } \\
\end{array}$} & \multicolumn{2}{|c|}{ Clarendon } \\
\hline & & Count & Percent & Count & Percent & Count & Percent \\
\hline \multirow{3}{*}{$\begin{array}{l}\text { Speed } \\
\text { Humps/Tables }\end{array}$} & Definitely Program-Related & 0 & $0 \%$ & 62 & $46.6 \%$ & 1 & $1.7 \%$ \\
\hline & Probably Program-Related & 0 & $0 \%$ & 8 & $6 \%$ & 1 & $1.7 \%$ \\
\hline & No/Unknown Program Relation & 2 & $1.7 \%$ & 0 & $0 \%$ & 51 & $85 \%$ \\
\hline \multirow{3}{*}{ Road Signs } & Definitely Program-Related & 19 & $16.5 \%$ & 15 & $11.3 \%$ & 0 & $0 \%$ \\
\hline & Probably Program-Related & 7 & $6.1 \%$ & 6 & $4.5 \%$ & 0 & $0 \%$ \\
\hline & No/Unknown Program Relation & 3 & $2.6 \%$ & 0 & $0 \%$ & 2 & $3.3 \%$ \\
\hline \multirow{3}{*}{ 3-D Markings } & Definitely Program-Related & 0 & $0 \%$ & 30 & $22.6 \%$ & 0 & $0 \%$ \\
\hline & Probably Program-Related & 0 & $0 \%$ & 2 & $1.5 \%$ & 0 & $0 \%$ \\
\hline & No/Unknown Program Relation & 0 & $0 \%$ & 0 & $0 \%$ & 0 & $0 \%$ \\
\hline \multirow{3}{*}{$\begin{array}{l}\text { Road Pavement } \\
\text { Changes }\end{array}$} & Definitely Program-Related & 73 & $63.5 \%$ & 46 & $34.6 \%$ & 0 & $0 \%$ \\
\hline & Probably Program-Related & 15 & $13.0 \%$ & 2 & $1.5 \%$ & 0 & $0 \%$ \\
\hline & No/Unknown Program Relation & 0 & $0 \%$ & 0 & $0 \%$ & 0 & $0 \%$ \\
\hline \multirow{3}{*}{$\begin{array}{l}\text { Speed Measurement } \\
\text { Tubes }\end{array}$} & Definitely Program-Related & 0 & $0 \%$ & 0 & $0 \%$ & 0 & $0 \%$ \\
\hline & Probably Program-Related & 1 & $.9 \%$ & 4 & $3 \%$ & 1 & $1.7 \%$ \\
\hline & No/Unknown Program Relation & 0 & $0 \%$ & 0 & $0 \%$ & 0 & $0 \%$ \\
\hline \multirow{3}{*}{ Miscellaneous } & Definitely Program-Related & 0 & $0 \%$ & 0 & $0 \%$ & 0 & $0 \%$ \\
\hline & Probably Program-Related & 0 & $0 \%$ & 0 & $0 \%$ & 0 & $0 \%$ \\
\hline & No/Unknown Program Relation & 8 & $7 \%$ & 0 & $0 \%$ & 1 & $1.7 \%$ \\
\hline \multicolumn{2}{|c|}{ Base Number of Respondents } & 115 & $100 \%$ & 133 & $100 \%$ & 60 & $100 \%$ \\
\hline
\end{tabular}

*Percentages are based on the number of respondents in each neighborhood who indicated an awareness of roadway changes as shown in the last row of the table.

**Respondents could make more than one comment.

Table 50. Rating of Neighborhood Speeds (Phoenix and Peoria)

\begin{tabular}{|c|c|c|c|c|c|}
\hline \multirow{2}{*}{\multicolumn{2}{|c|}{$\begin{array}{c}\text { Compared to Six Months } \\
\text { Ago, How Would You Rate } \\
\text { the Speeds in Your } \\
\text { Neighborhood? }\end{array}$}} & \multicolumn{2}{|c|}{ Phoenix* } & \multicolumn{2}{|c|}{ Peoria** } \\
\hline & & \multirow{2}{*}{$\begin{array}{r}\begin{array}{c}\text { Pre- } \\
\text { Program }\end{array} \\
19\end{array}$} & \multirow{2}{*}{$\frac{\text { Follow-On }}{39}$} & \multirow{2}{*}{$\begin{array}{r}\begin{array}{c}\text { Pre- } \\
\text { Program }\end{array} \\
10\end{array}$} & \multirow{2}{*}{$\frac{\text { Follow-On }}{54}$} \\
\hline Much Slower & Count & & & & \\
\hline & Percent & $5.3 \%$ & $8.6 \%$ & $2.5 \%$ & $11.4 \%$ \\
\hline \multirow[t]{2}{*}{ A Bit Slower } & Count & 47 & 179 & 47 & 155 \\
\hline & Percent & $13 \%$ & $39.7 \%$ & $11.7 \%$ & $32.8 \%$ \\
\hline \multirow[t]{2}{*}{ The Same } & Count & 166 & 171 & 185 & 166 \\
\hline & Percent & $46 \%$ & $37.9 \%$ & $45.9 \%$ & $35.1 \%$ \\
\hline \multirow[t]{2}{*}{ A Bit Faster } & Count & 80 & 29 & 103 & 55 \\
\hline & Percent & $22.2 \%$ & $6.4 \%$ & $25.6 \%$ & $11.6 \%$ \\
\hline \multirow[t]{2}{*}{ Much Faster } & Count & 49 & 33 & 58 & 43 \\
\hline & Percent & $13.6 \%$ & $7.3 \%$ & $14.4 \%$ & $9.1 \%$ \\
\hline
\end{tabular}

*Phoenix chi-square significance $=.000$

$* *$ Peoria chi-square significance $=.000$ 
Table 51 shows the speed ratings made by Peoria respondents as a function of neighborhood. The results for the three neighborhoods follow the pattern established for the city as a whole with the exception that proportionately more follow-on than pre-program Desert Harbor respondents felt that speeds remained the same.

Table 51. Rating of Neighborhood Speeds by Neighborhood (Peoria)

\begin{tabular}{|c|c|c|c|c|c|c|c|}
\hline \multirow{3}{*}{\multicolumn{2}{|c|}{$\begin{array}{l}\text { Compared to Six Months } \\
\text { Ago, How Would You } \\
\text { Rate the Speeds in Your } \\
\text { Neighborhood? }\end{array}$}} & \multicolumn{6}{|c|}{ Peoria Neighborhoods } \\
\hline & & \multicolumn{2}{|c|}{ 95th Ave* } & \multicolumn{2}{|c|}{$\begin{array}{c}\text { Desert Harbor/ } \\
\text { 91st Ave** }\end{array}$} & \multicolumn{2}{|c|}{ Bell Park/84th Ave ${ }^{* * *}$} \\
\hline & & $\begin{array}{c}\text { Pre- } \\
\text { Program }\end{array}$ & $\begin{array}{l}\text { Follow- } \\
\text { On }\end{array}$ & $\begin{array}{c}\text { Pre- } \\
\text { Program }\end{array}$ & $\begin{array}{l}\text { Follow- } \\
\text { On }\end{array}$ & $\begin{array}{c}\text { Pre- } \\
\text { Program }\end{array}$ & $\begin{array}{l}\text { Follow- } \\
\text { On }\end{array}$ \\
\hline \multirow[t]{2}{*}{ Much Slower } & Count & 4 & 19 & 1 & 7 & 5 & 28 \\
\hline & Percent & $3.1 \%$ & $12.2 \%$ & $.9 \%$ & $4.4 \%$ & $3.1 \%$ & $17.8 \%$ \\
\hline \multirow[t]{2}{*}{ A Bit Slower } & Count & 8 & 49 & 13 & 37 & 25 & 67 \\
\hline & Percent & $6.2 \%$ & $31.4 \%$ & $11.9 \%$ & $23.4 \%$ & $15.4 \%$ & $42.7 \%$ \\
\hline \multirow[t]{2}{*}{ The Same } & Count & 59 & 55 & 43 & 68 & 82 & 43 \\
\hline & Percent & $45.4 \%$ & $35.3 \%$ & $39.4 \%$ & $43 \%$ & $50.6 \%$ & $27.4 \%$ \\
\hline \multirow[t]{2}{*}{ A Bit Faster } & Count & 41 & 18 & 33 & 24 & 29 & 13 \\
\hline & Percent & $31.5 \%$ & $11.5 \%$ & $30.3 \%$ & $15.2 \%$ & $17.9 \%$ & $8.3 \%$ \\
\hline \multirow[t]{2}{*}{ Much Faster } & Count & 18 & 15 & 19 & 22 & 21 & 6 \\
\hline & Percent & $13.8 \%$ & $9.6 \%$ & $17.4 \%$ & $13.9 \%$ & $13.0 \%$ & $3.8 \%$ \\
\hline
\end{tabular}

$* 95^{\text {th }}$ Avenue chi square significance $=.000$

$* *$ Desert Harbor chi square significance $=.005$

$* * *$ Bell Park chi square significance $=.000$

The ratings of perceived speed changes made by Phoenix respondents for each of their neighborhoods are shown in Table 52. With the exception of the Clarendon neighborhood, the results are significant and follow the pattern for the city as a whole. Clarendon showed no clear pattern across the two survey waves in their ratings of neighborhood speed. This is not inconsistent with the speed data discussed below and the fact that speed humps had been in place on Clarendon for some time before the program began.

\subsubsection{Respondent Exposure to the Heed the Speed Program}

Two variables were subjectively coded from the information collected by the questionnaire as indicators of likely respondent exposure to the Heed the Speed program. One simply provided an indication of whether or not the respondent referred to the Heed the Speed program by name. The other came from an examination of the entire survey and provision of an overall assessment of whether or not the individual had definitely been exposed to the program, probably been exposed to the program, or not been exposed to the program (including exposure unknown). The resulting Tables 53-58 are based on follow-on data only since there was no possible exposure to Heed the Speed prior to the program. 
Table 52. Rating of Neighborhood Speeds by Neighborhood (Phoenix)

\begin{tabular}{|c|c|c|c|c|c|c|c|}
\hline \multirow{3}{*}{\multicolumn{2}{|c|}{$\begin{array}{c}\text { Compared to Six Months } \\
\text { Ago, How Would You } \\
\text { Rate } \\
\text { the Speeds in Your } \\
\text { Neighborhood? }\end{array}$}} & \multicolumn{6}{|c|}{ Phoenix Neighborhoods } \\
\hline & & \multicolumn{2}{|c|}{ Sweetwater* } & \multicolumn{2}{|c|}{$\begin{array}{c}\text { Moon Valley/ } \\
\text { Coral Gables** }\end{array}$} & \multicolumn{2}{|c|}{ Clarendon } \\
\hline & & \multirow{2}{*}{$\begin{array}{r}\begin{array}{c}\text { Pre- } \\
\text { Program }\end{array} \\
6\end{array}$} & \multirow{2}{*}{$\begin{array}{r}\begin{array}{c}\text { Follow- } \\
\text { On }\end{array} \\
14 \\
\end{array}$} & \multirow{2}{*}{$\begin{array}{r}\begin{array}{c}\text { Pre- } \\
\text { Program }\end{array} \\
0\end{array}$} & \multirow{2}{*}{$\begin{array}{c}\text { Follow- } \\
\text { On } \\
16 \\
\end{array}$} & \multirow{2}{*}{$\begin{array}{r}\begin{array}{c}\text { Pre- } \\
\text { Program }\end{array} \\
13 \\
\end{array}$} & \multirow{2}{*}{$\begin{array}{c}\text { Follow- } \\
\text { On }\end{array}$} \\
\hline Much & Count & & & & & & \\
\hline slower & Percent & $4.8 \%$ & $8.4 \%$ & $0 \%$ & $9.4 \%$ & $13.3 \%$ & $7.9 \%$ \\
\hline \multirow[t]{2}{*}{ A Bit Slower } & Count & 14 & 72 & 9 & 74 & 24 & 33 \\
\hline & Percent & $11.2 \%$ & $43.4 \%$ & $6.5 \%$ & $43.3 \%$ & $24.5 \%$ & $28.9 \%$ \\
\hline \multirow[t]{2}{*}{ The Same } & Count & 63 & 62 & 72 & 73 & 31 & 36 \\
\hline & Percent & $50.4 \%$ & $37.3 \%$ & $52.2 \%$ & $42.7 \%$ & $31.6 \%$ & $31.6 \%$ \\
\hline \multirow[t]{2}{*}{ A Bit Faster } & Count & 23 & 9 & 37 & 5 & 20 & 15 \\
\hline & Percent & $18.4 \%$ & $5.4 \%$ & $26.8 \%$ & $2.9 \%$ & $20.4 \%$ & $13.2 \%$ \\
\hline \multirow[t]{2}{*}{ Much Faster } & Count & 19 & 9 & 20 & 3 & 10 & 21 \\
\hline & Percent & $15.2 \%$ & $5.4 \%$ & $14.5 \%$ & $1.8 \%$ & $10.2 \%$ & $18.4 \%$ \\
\hline
\end{tabular}

$*$ Sweetwater chi square significance $=.000$

$* *$ Moon Valley chi square significance $=.000$

Whether or not the respondent used the words Heed the Speed on the survey form is shown for the two cities in Table 53. A respondent's survey was coded as "yes" if the respondent used the same or similar words. No respondents mentioned Heed the Speed during the pre-program survey. The table shows that 28.5 percent of the follow-on Phoenix respondents referred to the program by name as did 23 percent of the follow-on Peoria respondents.

Table 53. Respondent Follow-On Mention of Heed the Speed (Phoenix and Peoria)

\begin{tabular}{|c|c|c|c|c|}
\hline \multirow{3}{*}{$\begin{array}{l}\text { Did Respondent } \\
\text { Mention Heed the } \\
\text { Speed? }\end{array}$} & \multicolumn{4}{|c|}{ City } \\
\hline & \multicolumn{2}{|c|}{ Phoenix } & \multicolumn{2}{|c|}{ Peoria } \\
\hline & Count & Percent & Count & Percent \\
\hline Yes & 130 & $28.5 \%$ & 111 & $23 \%$ \\
\hline No & 325 & $71.5 \%$ & 372 & $77 \%$ \\
\hline
\end{tabular}

Use of the program slogan as a function of Peoria neighborhoods is shown in Table 54. It shows that the program was mentioned by respondents from all neighborhoods - most frequently by respondents from Desert Harbor $(31.5 \%)$, followed by respondents from $95^{\text {th }}$ Avenue $(25 \%)$, and respondents from Bell Park (12.6\%).

Use of the program slogan in questionnaire responses by Phoenix neighborhoods is shown in Table 55. Again, it shows that respondents from all neighborhoods mentioned the program, although the number of mentions from Clarendon was extremely small. The slogan was mentioned most frequently by respondents from Sweetwater (43.6\%), followed by respondents from Moon Valley (30.6\%) and Clarendon (1.8\%). 
Table 54. Respondent Follow-On Mention of Heed the Speed (Peoria)

\begin{tabular}{|l|r|r|r|r|r|r|}
\hline \multirow{2}{*}{$\begin{array}{c}\text { Did Respondent } \\
\begin{array}{c}\text { Mention Heed the } \\
\text { Speed? }\end{array}\end{array}$} & \multicolumn{4}{|c|}{ Peoria Neighborhoods } \\
\cline { 2 - 8 } & \multicolumn{2}{|c|}{ 95th Ave } & \multicolumn{2}{c|}{$\begin{array}{c}\text { Desert Harbor/91st } \\
\text { Ave }\end{array}$} & \multicolumn{2}{c|}{ Bell Park/84th Ave } \\
\hline Yes & 40 & $25 \%$ & 51 & $31.5 \%$ & 20 & $12.6 \%$ \\
\hline No & 120 & $75 \%$ & 111 & $68.5 \%$ & 139 & $87.4 \%$ \\
\hline
\end{tabular}

Table 55. Respondent Follow-On Mention of Heed the Speed (Phoenix)

\begin{tabular}{|c|c|c|c|c|c|c|}
\hline \multirow{3}{*}{$\begin{array}{l}\text { Did Respondent } \\
\text { Mention Heed the } \\
\text { Speed? }\end{array}$} & \multicolumn{6}{|c|}{ Phoenix Neighborhoods } \\
\hline & \multicolumn{2}{|c|}{ Sweetwater } & \multicolumn{2}{|c|}{$\begin{array}{l}\text { Moon Valley/ } \\
\text { Coral Gables }\end{array}$} & \multicolumn{2}{|c|}{ Clarendon } \\
\hline & Count & Percent & Count & Percent & Count & Percent \\
\hline Yes & 75 & $43.6 \%$ & 53 & $30.6 \%$ & 2 & $1.8 \%$ \\
\hline No & 97 & $56.4 \%$ & 120 & $69.4 \%$ & 109 & $98.2 \%$ \\
\hline
\end{tabular}

Clearly the materials associated with the speed reduction program made a sufficient impression to have a large proportion of respondents volunteer the program slogan - Heed the Speed - on the questionnaire. It must be remembered that the data presented above represent totally unaided responses. There was no mention of Heed the Speed in the questionnaire or the cover letter on its reverse side.

Each returned survey was also coded based on a project staff member's overall impression from reading all of the responses it contained of whether or not the respondent had been definitely exposed to the Heed the Speed program, probably exposed to the program or not exposed to the program. The follow-on results for the two cities are given in Table 56, which shows that approximately 70 percent of respondents from both cities were judged to have been definitely or probably exposed to some aspect of the program.

Table 56. Respondent Follow-On Exposure to the Heed the Speed Program (Phoenix and Peoria)

\begin{tabular}{|l|l|r|r|r|}
\hline \multirow{2}{*}{$\begin{array}{c}\text { Was Respondent Exposed } \\
\text { to the Heed the Speed } \\
\text { Program? }\end{array}$} & \multicolumn{3}{|c|}{ City } \\
\cline { 2 - 5 } & Phoenix & \multicolumn{1}{c|}{ Peoria } & \multicolumn{1}{c|}{ Total } \\
\hline \multirow{3}{*}{ Yes, Definitely } & Count & 261 & 210 & 471 \\
\cline { 2 - 5 } & Row $\%$ & $55.4 \%$ & $44.6 \%$ & $100 \%$ \\
\cline { 2 - 5 } & Column \% & $57.2 \%$ & $43.5 \%$ & $50.2 \%$ \\
\hline \multirow{3}{*}{ Yes, Probably } & Count & 56 & 132 & 188 \\
\cline { 2 - 5 } & Row $\%$ & $29.8 \%$ & $70.2 \%$ & $100 \%$ \\
\cline { 2 - 5 } & Column $\%$ & $12.3 \%$ & $27.3 \%$ & $20 \%$ \\
\hline \multirow{3}{*}{ No } & Count & 139 & 141 & 280 \\
\cline { 2 - 5 } & Row $\%$ & $49.6 \%$ & $50.4 \%$ & $100 \%$ \\
\cline { 2 - 5 } & Column $\%$ & $30.5 \%$ & $29.2 \%$ & $29.8 \%$ \\
\hline
\end{tabular}


Follow-on exposure broken down by Peoria neighborhoods is provided in Table 57. That table shows that the largest proportion of respondents who were definitely or probably exposed to the program came from the Bell Park neighborhood $(83.6 \%)$. It was followed by $95^{\text {th }}$ Avenue $(68.2 \%)$ and Desert Harbor (60.5\%). 
Table 57. Respondent Follow-On Exposure to the Heed the Speed Program by Neighborhood (Peoria)

\begin{tabular}{|l|l|r|r|r|}
\hline \multirow{2}{*}{$\begin{array}{c}\text { Was Respondent Exposed } \\
\text { to the Heed the Speed } \\
\text { Program? }\end{array}$} & \multicolumn{3}{|c|}{ Peoria Neighborhoods } \\
\cline { 3 - 5 } & & $\begin{array}{c}\text { Desert } \\
\text { Harbor/ } \\
\text { 91st Ave }\end{array}$ & $\begin{array}{c}\text { Bell Park/84th } \\
\text { Ave }\end{array}$ \\
\hline \multirow{3}{*}{$\begin{array}{l}\text { Yes, } \\
\text { Definitely }\end{array}$} & Count & 79 & 53 & 77 \\
\cline { 2 - 5 } & Row \% & $37.8 \%$ & $25.4 \%$ & $36.8 \%$ \\
\cline { 2 - 5 } & Column \% & $49.4 \%$ & $32.7 \%$ & $48.4 \%$ \\
\hline \multirow{3}{*}{ Yes, Probably } & Count & 30 & 45 & 56 \\
\cline { 2 - 5 } & Row \% & $22.9 \%$ & $34.4 \%$ & $42.7 \%$ \\
\cline { 2 - 5 } & Column \% & $18.8 \%$ & $27.8 \%$ & $35.2 \%$ \\
\hline \multirow{3}{*}{ No } & Count & 51 & 64 & $18.4 \%$ \\
\cline { 2 - 5 } & Row \% & $36.2 \%$ & $45.4 \%$ & $16.4 \%$ \\
\cline { 2 - 5 } & Column \% & $31.9 \%$ & $39.5 \%$ & 26 \\
\hline
\end{tabular}

Similar data for Phoenix neighborhoods are given in Table 58. That table shows that the largest proportion of respondents who were definitely or probably exposed to the program came from the Moon Valley neighborhood (91.3\%) followed by the Sweetwater neighborhood $(84.3 \%)$. Only 12.6 percent of the follow-on Clarendon respondents indicated an awareness of the program.

Table 58. Respondent Follow-On Exposure to the Heed the Speed Program by Neighborhood (Phoenix)

\begin{tabular}{|l|l|r|r|r|}
\hline \multirow{2}{*}{$\begin{array}{c}\text { Was Respondent Exposed } \\
\text { to } \begin{array}{c}\text { P Heed the Speed } \\
\text { Program? }\end{array}\end{array}$} & \multicolumn{2}{|c|}{ Phoenix Neighborhoods } \\
\cline { 3 - 5 } & Sweetwater & $\begin{array}{c}\text { Moon Valley/ } \\
\text { Coral Gables }\end{array}$ & Clarendon \\
\hline \multirow{3}{*}{ Yes, Definitely } & Count & 118 & 141 & 2 \\
\cline { 2 - 5 } & Row $\%$ & $45.2 \%$ & $54 \%$ & $.8 \%$ \\
\cline { 2 - 5 } & Column \% & $68.6 \%$ & $81.5 \%$ & $1.8 \%$ \\
\hline \multirow{3}{*}{ Yes, Probably } & Count & 27 & 17 & 12 \\
\cline { 2 - 5 } & Row $\%$ & $48.2 \%$ & $30.4 \%$ & $21.4 \%$ \\
\cline { 2 - 5 } & Column $\%$ & $15.7 \%$ & $9.8 \%$ & $10.8 \%$ \\
\hline \multirow{3}{*}{ No } & Count & 27 & 15 & 97 \\
\cline { 2 - 5 } & Row $\%$ & $19.4 \%$ & $10.8 \%$ & $69.8 \%$ \\
\cline { 2 - 5 } & Column $\%$ & $15.7 \%$ & $8.7 \%$ & $87.4 \%$ \\
\hline
\end{tabular}

\subsubsection{Survey Summary}

Neighborhood surveys were mailed to half of a sample of residents of each of the six study neighborhoods in two waves - before the start of the program and following the completion of the program in Peoria and following installation of roadway treatments in Phoenix. Pre- and follow-on returns in Peoria were 58.1 percent and 62 percent, respectively. Comparable returns for Phoenix were 60.2 percent and 63.4 percent. This is an extremely high 
response rate for a mailed survey, particularly one addressed to "Resident." This high response suggests an interest in the subject of speeding and a population willing to assist a neighborhood safety program.

All neighborhoods in both cities exhibited a significant increase in follow-on awareness of program publicity except for the Clarendon neighborhood in Phoenix, the neighborhood among the six with no neighborhood association or vocal spokespeople and a large number of Spanish-speaking residents. It is curious that Clarendon respondents did not indicate increased awareness because there was increased enforcement in the neighborhood that resulted in significantly lower speeds (see below). In the balance of the studied neighborhoods, there was a significant increase in awareness of publicity related to speeding with three neighborhoods showing a doubling or more in the percentage of people indicating they were exposed to publicity on speed control.

The specific publicity item that received the largest proportion of follow-on mentions judged to be definitely or probably related to the program in both cities consisted of the program signs with reports ranging from 52.1 percent to 82.7 percent of the respondents) except Clarendon where the percentage was 12.5. Flyers, bulletins, and newsletters were also mentioned, as were mail/letters, meetings, and newspapers, although the mentions for some neighborhoods were not large.

With regard to police involvement, the specific activities mentioned most frequently and considered to be definitely or probably program related were visible enforcement (ranging from $51.1 \%$ to $62.7 \%$ ) and radar checks (ranging from $13.7 \%$ to $46.2 \%$ ). Deployment of the speed trailer was noted in all Peoria neighborhoods. The photo speed enforcement trailer was noted in the Moon Valley neighborhood of Phoenix.

With regard to roadway treatments, signs again were mentioned frequently by respondents from all neighborhoods except Clarendon. In addition, respondents in each neighborhood noticed the roadway treatments that were installed in that neighborhood as part of the program. For example, speed humps/tables were mentioned and classified as definitely or probably related to the Heed the Speed program by 91 percent of the respondents in the Bell Park neighborhood of Peoria and in 52.6 percent of the respondents in Moon Valley; 3-D markings by all neighborhoods in Peoria and in Moon Valley in Phoenix; and pavement treatments (Tyregrip $^{\text {TM}}$ ) by both Sweetwater and Moon Valley respondents in Phoenix. A small number of respondents in each community noticed the tubes used by the program to measure neighborhood speeds.

Respondents were asked to rate the speeds in their neighborhoods compared to six months ago. With the exception of Clarendon, all neighborhood respondents reported a perceived decrease in speeding in their neighborhoods in the last six months.

An evaluation of each survey respondent's form led to the judgment that a large proportion of the survey respondents had definitely or probably been exposed to the Heed the Speed program. Thus, there was significant evidence from the survey that the countermeasure program was active and successful in conveying its message. This suggests that there is a basis for attributing any significant speed reductions in the test neighborhoods across the study period to the effects of Heed the Speed. 


\subsection{Speed Data}

The ultimate criterion measure for the present study was the speed of vehicles on the test street segments before and after the various countermeasures were implemented. This section details the speed data collection and data management methods, the analytic approach adopted and the results.

\subsubsection{Data Collection and Management}

All speed data for the study were collected using traffic counters. These devices use multiple pneumatic tubes placed on the roadway to record the presence of a vehicle and its speed. The speed data collection was accomplished for the project by the regular traffic count contractors for Phoenix and Peoria as part of the contribution of the two cities to the study effort.

All counts were for a consecutive 48-hour period. Multiple counters were placed on each test segment with the number of counters used dependent on both the length of the segment and the features of interest along it. For example, an attempt was made to acquire counts adjacent to newly installed vertical treatments and coincident with the positions of 3-D markings and Tyregrip $^{\mathrm{TM}}$ installations. The counters on each segment, although deployed at approximately the same time, did not have their internal timers synchronized. They were put in place, started and subsequently retrieved. Then, during downloading of the data, 48 hours of information was kept and the rest discarded for purposes of these analyses. Counters were located at the same place on each road segment during each measurement period.

The counters used by the Peoria contractor recorded an entry for each detected vehicle. This record included the time of the measurement, the vehicle's speed and an estimate of the class or type of vehicle based on the axle length inferred from the data. This vehicle class information was validated as highly accurate by the contractor and the manufacturer of the counter for passenger cars and light trucks. The validity of data for larger vehicle classes such as heavy trucks and buses was suspect. There are many known technical reasons for this pattern of results. For example, if the counter recorded the front wheels of a lead car but missed the rear wheels, the front wheels of a closely trailing vehicle could be erroneously interpreted as the rear wheels of a large truck or bus. Because of this known problem and the fact that there are typically relatively few trucks and buses except delivery vehicles on the test road segments, only cars and light trucks were included in the Peoria data analysis set.

In Phoenix, a different type of counter was used that only collected speeds in "bins" or class intervals. The output of these counters was an hourly count of the number of vehicles in the following speed ranges: 
- $0-15 \mathrm{mph}$

- $16-20 \mathrm{mph}$

- 21-25 mph

- 26-30 mph

- 31-33 mph

- $34-35 \mathrm{mph}$

- $\quad 36-37 \mathrm{mph}$

- $\quad 38-40 \mathrm{mph}$

- 41-45 mph

- $46-50 \mathrm{mph}$

- $51-55 \mathrm{mph}$

- $56-80 \mathrm{mph}$

It can be seen that these speed class intervals are not of equal size and become tighter in the 30 to 40 mph range.

In order to support an analysis of variance (ANOVA) approach to data analysis (see below), the Phoenix data had to be expressed in terms of individual vehicles in the same manner as the Peoria information. This was accomplished by generating a record for each vehicle counted in each interval. The vehicle was assigned a time at the midpoint of the hour in which it was recorded and a speed at the midpoint of the interval in which it was placed by the counter. For example, a vehicle counted in the $26-30 \mathrm{mph}$ (actually 26.00 to 30.99 ) $\mathrm{mph}$ interval from noon to 12:59 p.m. would be assigned a speed of $28.5 \mathrm{mph}$ and a time of 12:30 p.m. This approach disaggregated the class interval data into a set of individual vehicle records for analysis. The effect of this approach is to suppress variance somewhat in the raw data since many speed values (i.e., those not at the midpoint of one of the intervals) simply cannot exist in the data.

The data from each city were aggregated into separate databases for analysis. This resulted in files of 435,421 vehicles for Phoenix and 363,143 vehicles for Peoria. These files were imported into the SPSS $®$ Release 11.5 software for analysis. ${ }^{8}$

\subsubsection{Analytic Approach}

The objective of the speed analysis was to uncover any changes in the speeds of vehicles on the test segments between the first wave of measurement when no countermeasures had been mounted by this program and the subsequent data collection waves. Two decisions concerning the nature of the analyses conducted were essentially dictated by the data themselves and the particulars of the test. First, it was decided not to compare the results from Phoenix and Peoria in the same analysis. Combining the data from the two cities would have been of questionable validity because of the different underlying variances as a result of the use of the bin counters in Phoenix.

The second decision was to address the speed analysis as a set of 10 case studies based on each of the 10 test segments described earlier. As shown in Table 59, the widely varying

\footnotetext{
${ }^{8}$ SPSS, Inc. Chicago, Illinois
} 
countermeasures applied across the segments suggested that aggregate, citywide analyses would be largely uninformative with respect to the efficacy of individual specific interventions.

Table 59 also references the table number in which the speed results for each segment can be found.

Since the primary objective of the statistical analysis was to assess the relationship between the various speed countermeasures and reductions in speed, ANOVA was the indicated primary statistical technique. The ANOVAs for the study were executed through the General Linear Model routine in SPSS $®$ Release 11.5. This technique provided parameter estimates and hypotheses tests of the main and interactive effects of the various countermeasures or experimental factors. Statistically significant main effects and interactions were followed by inspection of the respective subgroup and cell means involved in those effects. All pairwise comparisons of the individual means were evaluated by the Sidak Test. This is a multiple comparison technique for adjusting t-tests for alpha inflation that results when a large number of contrasts are tested. All hypotheses were tested at $\mathrm{p} \leq .05$. That is, any difference that would be expected by chance less than $5 \%$ of the time was considered to be a true effect.

Chi-square tests were used to evaluate effects on certain binary and nominal transforms of the speed scale (e.g., proportion driving seven or more miles over the speed limit).

The complexity of the experimental plan and absence of countermeasures for some of the waves of measurement required several ANOVA models based on different subsets of the data. For example, in Phoenix waves two and three of measurement were only done on one road which was of particular interest to the participating city personnel. Therefore, these two waves were deleted for some of the ANOVAs so that there would be a full replication of measures at all test locations.

The final analytical strategy involved conducting separate wave $\mathrm{x}$ road segment ANOVAs for each city with speed as the dependent variable. The expectation was that road would show a significant main effect since the test segments within each city were quite different as described earlier. A significant main effect of wave would suggest that speeds had changed in the city over the various measurement periods. A significant wave $\mathrm{x}$ road segment interaction would suggest that any speed effect was differential across the test sites.

The ANOVAs for both Phoenix and Peoria yielded main effects of wave and road segment as well as a wave $\mathrm{x}$ road segment interaction that were significant with a $\mathrm{P}<.0001$. Thus, it was meaningful to examine the pairwise comparisons in light of the known changes on each roadway. This was accomplished by combining the wave and road variables into a single variate and re-running the ANOVAs to produce a comparison of all wave and road pairs. The result was a mean speed differential between each pair of waves on each test segment along with a test of the significance of that difference. 
Table 59. Summary of Countermeasures Implemented on Each Test Segment

\begin{tabular}{|c|c|c|c|c|c|c|c|}
\hline \multirow[b]{2}{*}{$\begin{array}{l}\text { TEST } \\
\text { SEGMENT }\end{array}$} & \multicolumn{7}{|c|}{ בCOUNTERMEASURE TYPE } \\
\hline & $\begin{array}{l}\text { Education (as } \\
\text { Reported by } \\
\text { Participants) }\end{array}$ & $\begin{array}{c}\text { Special } \\
\text { Enforcement } \\
\text { (as Reported } \\
\text { by Police) }\end{array}$ & $\begin{array}{c}\text { Pre- } \\
\text { Existing } \\
\text { Vertical } \\
\text { Treatments } \\
\text { On Test } \\
\text { Road }\end{array}$ & $\begin{array}{c}\text { Pre- } \\
\text { Existing } \\
\text { Vertical } \\
\text { Treatments } \\
\text { On } \\
\text { Adjacent } \\
\text { Roads }\end{array}$ & $\begin{array}{c}\text { New } \\
\text { Vertical } \\
\text { Treatments } \\
\text { on Test } \\
\text { Road }\end{array}$ & $\begin{array}{c}\text { 3-D"M } \\
\text { Marking }\end{array}$ & Tyregrip $^{\mathrm{TM}}$ \\
\hline \multicolumn{8}{|c|}{ Phoenix } \\
\hline $\begin{array}{l}\text { Sweetwater } \\
(\text { Table } 65)^{*}\end{array}$ & $\begin{array}{l}\text { Intensive by } \\
\text { Active Residents }\end{array}$ & $\begin{array}{l}\text { Very High } \\
\text { Prompted by } \\
\text { Citizen } \\
\text { Complaints }\end{array}$ & & $\sqrt{ }$ & & & $\sqrt{ }$ \\
\hline $\begin{array}{l}\text { Clarendon } \\
\text { (Table 64) }\end{array}$ & $\begin{array}{l}\text { Mostly by Police } \\
\text { and City } \\
\text { Personnel } \\
\text { English and } \\
\text { Spanish }\end{array}$ & High & $\sqrt{ }$ & $\sqrt{ }$ & & & \\
\hline $\begin{array}{l}\text { Moon } \\
\text { Valley } \\
\text { East/West } \\
\text { (Table 66) } \\
\end{array}$ & \multirow{4}{*}{$\begin{array}{l}\text { Very Active and } \\
\text { Involved } \\
\text { Neighborhood } \\
\text { Association }\end{array}$} & \multirow{4}{*}{ High } & & & & & \\
\hline $\begin{array}{l}\text { Moon } \\
\text { Valley } \\
\text { North/South } \\
\text { (Table 67) }\end{array}$ & & & & & $\sqrt{ }$ & & \\
\hline $\begin{array}{l}\text { Coral } \\
\text { Gables } \\
\text { East/West } \\
\text { (Table 68) } \\
\end{array}$ & & & & & & $\sqrt{ }$ & \\
\hline $\begin{array}{l}\text { Coral } \\
\text { Gables } \\
\text { North/South } \\
\text { (Table 69) }\end{array}$ & & & & & & & $\sqrt{ }$ \\
\hline \multicolumn{8}{|c|}{ Peoria } \\
\hline $\begin{array}{l}\text { Bell Park } \\
\text { 84 }^{\text {th }} \text { Ave. } \\
\text { (Table 60) }\end{array}$ & \multirow{2}{*}{$\begin{array}{l}\text { Moderately } \\
\text { Active } \\
\text { Neighborhood } \\
\text { Association }\end{array}$} & $\begin{array}{l}\text { High Before } \\
\text { Vertical } \\
\text { Treatments } \\
\text { Installed }\end{array}$ & & $\sqrt{ }$ & $\sqrt{ }$ & $\sqrt{ }$ & \\
\hline $\begin{array}{l}\text { Bell Park } \\
\text { 85 }^{\text {th }} \text { Lane } \\
(\text { Table 61) }\end{array}$ & & $\begin{array}{l}\text { Moderate - } \\
\text { Quiet Side } \\
\text { Street Without } \\
\text { a Speed } \\
\text { Problem }\end{array}$ & $\sqrt{ }$ & & & $\sqrt{ }$ & \\
\hline $\begin{array}{l}\text { Desert } \\
\text { Harbor } \\
\text { 91 } 1^{\text {st }} \text { Ave. } \\
\text { (Table 62) }\end{array}$ & $\begin{array}{l}\text { Very Active, } \\
\text { Innovative and } \\
\text { Involved } \\
\text { Neighborhood } \\
\text { Association }\end{array}$ & $\begin{array}{l}\text { Very High } \\
\text { Prompted by } \\
\text { Citizen } \\
\text { Complaints }\end{array}$ & & & & & \\
\hline $\begin{array}{l}\text { 95 }^{\text {th }} \text { Ave. } \\
\text { (Table 63) }\end{array}$ & $\begin{array}{l}\text { Some Citizen } \\
\text { Involvement } \\
\text { With Direct } \\
\text { Efforts of City } \\
\text { Personnel }\end{array}$ & High & & & & $\sqrt{ }$ & \\
\hline
\end{tabular}

*Location of speed results 


\subsubsection{Speed Results}

The descriptions and tables below present the speed results by road segment. Before turning to the results themselves, however, it is important to highlight several points with respect to the analyses.

There were five waves of speed data taken, but not all roads were included in each wave. Almost all Peoria sites had five measurements. In Phoenix, every site was included in Waves 1 , 4, and 5. Waves 2 and 3 were done in Phoenix at only one location before and immediately after 3-D markings were installed. This permitted the assessment of the additive influence of these markings above any effect of the education and enforcement countermeasures previously deployed.

Wave 1 was in October 2002 before any countermeasures were implemented. The remaining waves were taken monthly in the succeeding months with Wave 5 in the February/March 2003 time period.

The measures used to examine speed were:

- Average speed on the road segment ("Mean Speed"). Using the mean was judged to be more illustrative for this research effort than the $85^{\text {th }}$ percentile speed that is commonly used in assessing traffic calming efforts because the present study was also utilizing several other measures of the highest speeds.

- Mean difference in speed from the Wave 1 (baseline) value. This measure indicates the change in mean speed from the value before the study. In addition to a statistically significant decline, changes were sought that would be meaningful for safety.

- Average speed above the speed limit ("Mean Above Limit"). This is the average of each vehicle's speed minus the prevailing speed limit. A reduction in this measure could indicate either a moderation of high speeds or both a change in high speeds and a lowering of the speeds of those driving below the limit. For example, in a $30 \mathrm{mph}$ zone with four cars doing $25,25,40$ and 50 , this average would be $5 \mathrm{mph}(-5,-5,10,20)$. If the speeds changed to $20,25,40,45$, the average would be $2.5 \mathrm{mph}(-10,-5,10,15)$. This same value would result if the new speeds were $25,25,40,40(-5,-5,10,10)$.

- Average speed of those exceeding the speed limit ("Mean of Speeders"). This average excludes all vehicles going the speed limit or below. In the example above, the values would be $15 \mathrm{mph}(10,20), 12.5 \mathrm{mph}(10,15)$ and $10 \mathrm{mph}(10,10)$. This measure focuses in on the extent of excessive speed.

- The percentage of drivers going: the speed limit or less; over the limit but less than $7 \mathrm{mph}$ over; $7 \mathrm{mph}$ or more over the limit. This last category is the aberrant group that flouts the law and compromises safety. The cutoff of $7 \mathrm{mph}$ was selected because both the expert panel and the involved Phoenix and Peoria police indicated that this was the threshold at which they became concerned and would typically issue tickets.

Basically, changes in the mean were used to assess whether the speed profile on a road segment had changed significantly while the other measures were included to assess the nature or 
profile of any speed change that did occur. This is consistent with the findings from the literature discussed earlier that indicate that the largest safety benefit would arise from eliminating the upper or fastest tail of the speed distribution.

Each of the 10 roadway studies is summarized in terms of these measures in the sections that follow.

\subsubsection{Peoria $-84^{\text {th }}$ Avenue}

The $84^{\text {th }}$ Avenue test segment is part of the Bell Park neighborhood. It is a typical residential street with a $25 \mathrm{mph}$ speed limit. It received a moderate-to-high education effort consisting of many of the yard and street signs and some literature distributed locally by the neighborhood association. The police focused their special enforcement around the time of Wave 2, which was before any physical changes in the roadway. Prior to Wave 3, both speed tables and 3-D markings were installed. Speed was then measured in Waves 3, 4, and 5. The results are shown in Table $60 .{ }^{9}$

Table 60. Peoria $84^{\text {th }}$ Avenue Speed Results

\begin{tabular}{|c|c|c|c|c|c|c|c|c|}
\hline \multirow[b]{2}{*}{ Wave } & \multicolumn{8}{|c|}{ Measure } \\
\hline & $\begin{array}{l}\text { Mean } \\
\text { Speed } \\
(\text { mph })\end{array}$ & $\begin{array}{c}\text { Mean } \\
\text { Difference } \\
\text { From } \\
\text { Wave 1 } \\
\text { (mph) }\end{array}$ & $\begin{array}{l}\text { Mean } \\
\text { Above } \\
\text { Limit } \\
(\mathrm{mph})\end{array}$ & $\begin{array}{c}\text { Mean of } \\
\text { Speeders } \\
(\mathrm{mph})\end{array}$ & $\begin{array}{c}\text { N and } \\
\% \text { At or } \\
\text { Under } \\
\text { Limit }\end{array}$ & $\begin{array}{c}\mathrm{N} \text { and } \% \\
<7 \text { mph } \\
\text { Over }\end{array}$ & $\begin{array}{l}\mathrm{N} \text { and } \\
\% 7+ \\
\text { mph } \\
\text { Over }\end{array}$ & $\begin{array}{c}\text { Total } \\
\mathbf{N}\end{array}$ \\
\hline 1 & 25.962 & & .963 & 3.932 & $\begin{array}{l}5031 \\
42.7 \%\end{array}$ & $\begin{array}{l}5703 \\
48.4 \%\end{array}$ & $\begin{array}{l}1042 \\
8.8 \%\end{array}$ & 11,776 \\
\hline 2 & 26.037 & $\begin{array}{l}0.075^{10} \\
\mathrm{~ns}^{11}\end{array}$ & $\begin{array}{l}1.0372 \\
\mathrm{~ns}^{12}\end{array}$ & $\begin{array}{l}3.773 \\
\text { ns }\end{array}$ & $\begin{array}{l}4812 \\
42.9 \% \\
\end{array}$ & $\begin{array}{l}5574 \\
49.7 \% \\
\end{array}$ & $\begin{array}{l}823 \\
7.3 \% \\
\end{array}$ & 11,209 \\
\hline 3* & 22.874 & $-3.088(.000)$ & $\begin{array}{l}-2.126 \\
(.000) \\
\end{array}$ & $\begin{array}{l}2.901 \\
(.000) \\
\end{array}$ & $\begin{array}{l}7037 \\
74.4 \% \\
\end{array}$ & $\begin{array}{l}2236 \\
23.6 \% \\
\end{array}$ & $\begin{array}{l}182 \\
1.9 \% \\
\end{array}$ & 9,455 \\
\hline $4 *$ & 23.857 & $-2.106(.000)$ & $\begin{array}{l}-1.143 \\
(.000)\end{array}$ & $\begin{array}{l}3.070 \\
(.000)\end{array}$ & $\begin{array}{l}5779 \\
64.3 \%\end{array}$ & $\begin{array}{l}2943 \\
32.7 \%\end{array}$ & $\begin{array}{l}268 \\
3 \%\end{array}$ & 8,990 \\
\hline $5^{*}$ & 23.335 & $-2.627(.000)$ & $\begin{array}{l}-1.665 \\
(.000)\end{array}$ & $\begin{array}{l}3.540 \\
(.000)\end{array}$ & $\begin{array}{l}5810 \\
70.2 \%\end{array}$ & $\begin{array}{l}2266 \\
27.4 \% \\
\end{array}$ & $\begin{array}{l}205 \\
2.5 \%\end{array}$ & 8,281 \\
\hline
\end{tabular}

*Speed humps and 3-D Markings in place

The results on $84^{\text {th }}$ Avenue are quite dramatic. The initial drop in mean speed at Wave 3 (3.088 mph) is almost completely sustained two months later. Also, the drop is largely the result of elimination of the highest speeds. The percentage of those going $7+$ mph over the limit drops from 8.8 percent to 2.5 percent, a 71.6-percent decrease. This is not unexpected from the installation of vertical treatments (the speed tables). Figure 8 displays the percentage of cars in

\footnotetext{
${ }^{9}$ Speed data are reported in this and subsequent tables to three decimal points. This has been done for convenience since this is the format of the output of the statistical routines employed. It is neither intended to imply that speeds were measured with this degree of precision nor that this level of precision was required to test statistical significance.

${ }^{10}$ In this and all of the speed result tables positive mean differences indicate an increase in mean speed from baseline (wave 1) to the particular wave's value and negative results indicate a speed reduction.

${ }^{11} \mathrm{~ns}=$ not significant; exact probabilities are shown in parenthesis for significant results with .000 indicating $\mathrm{p}<$ .001

${ }^{12}$ Significance here and for mean of speeders is related to the Wave 1 value.
} 
the three speed categories (at or under the limit, less than $7 \mathrm{mph}$ over the limit and 7 or more mph over the limit). It depicts the major drop in the faster vehicles in favor of those going at or below the speed limit.

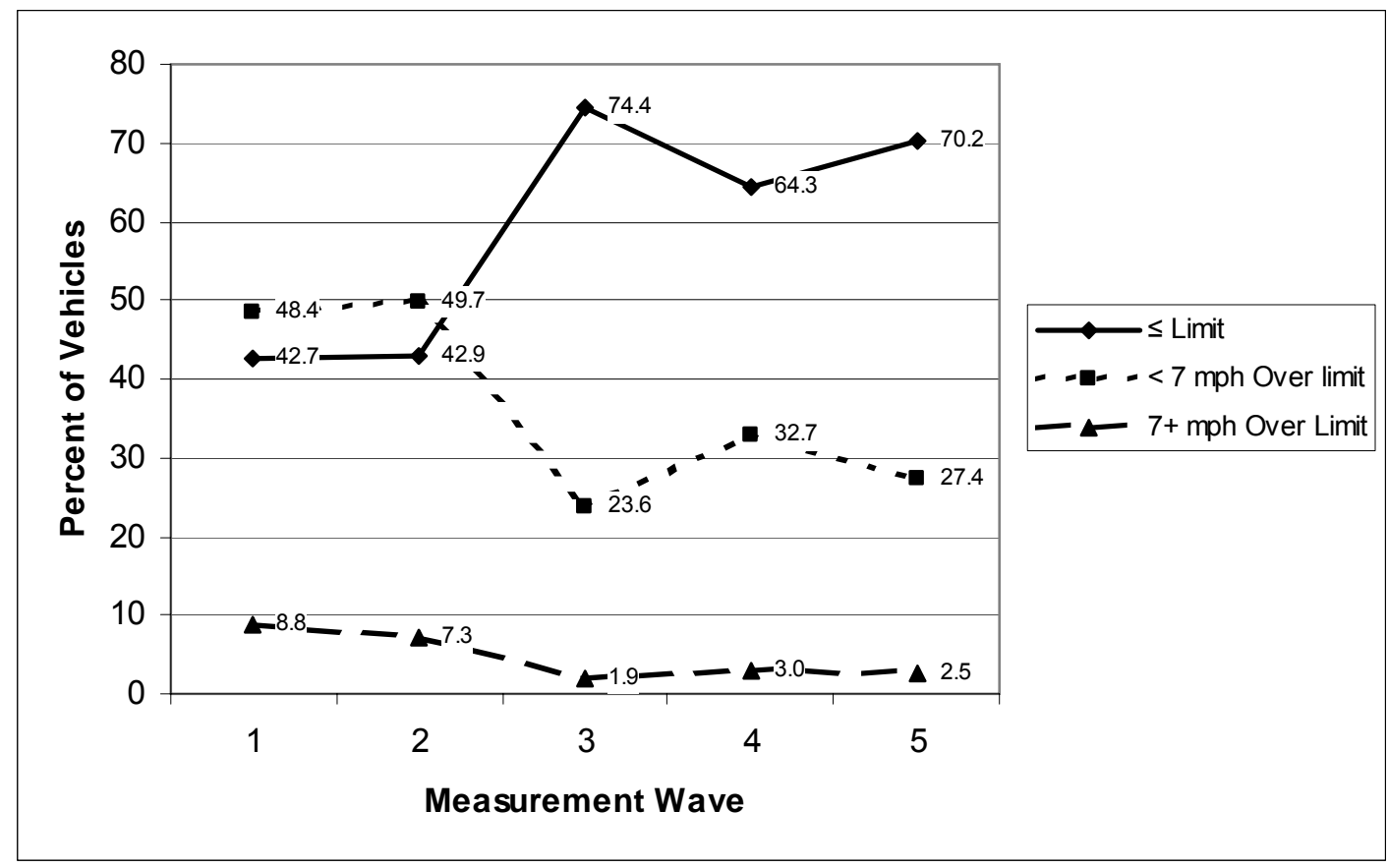

Figure 8. Speed Classes on Peoria $-84^{\text {th }}$ Avenue

The number of cars counted in each wave declined somewhat on this test segment after the installation of the speed humps. This is not an unusual result when vertical treatments are installed. Some drivers simply do not want to contend with them and find other routes. The effect of this diversion, which reached 23.7 percent of the traffic between Waves 1 and 5 on this segment, represents a further reduction in risk for this specific roadway. If the diverted drivers speed on other roads, however, this safety benefit might be partially offset.

\subsubsection{Peoria $-85^{\text {th }}$ Lane}

This is a quiet side street off $84^{\text {th }}$ Avenue in Bell Park with a $25 \mathrm{mph}$ speed limit. It had three speed humps installed well before the study began, but the residents were still not happy and wanted another hump. Since an additional vertical treatment was not warranted, other elements of Heed the Speed were employed. There was some limited education on this street prior to Wave 2 from the yard and fixed signs but little enforcement because of the low traffic volumes. The 3-D markings were installed prior to Wave 3. Five waves of data were collected with the results shown in Table 61 and Figure 9.

There was no meaningful change on $85^{\text {th }}$ Lane, which is not surprising given the low baseline speeds and the extremely small proportion of drivers going 7 or more miles over the limit. It is curious that the residents were complaining to the city prior to the study as the baseline (Wave 1) speed profile seems quite benign. The quiet nature of the test segment is also clearly indicated by the relatively low volume of traffic. The 48 -hour volumes on $85^{\text {th }}$ Lane were just over 10 percent of the number of vehicles seen on $84^{\text {th }}$ Avenue, an adjacent street. Also, the traffic volume is largely steady from wave-to-wave suggesting no significant diversion. 
Table 61. Peoria $-85^{\text {th }}$ Lane Speed Results

\begin{tabular}{|c|c|c|c|c|c|c|c|c|}
\hline \multirow[b]{2}{*}{ Wave } & \multicolumn{8}{|c|}{ Measure } \\
\hline & $\begin{array}{l}\text { Mean } \\
\text { Speed } \\
(\text { mph })\end{array}$ & $\begin{array}{c}\text { Mean } \\
\text { Difference } \\
\text { from } \\
\text { Wave 1 } \\
\text { (mph) }\end{array}$ & $\begin{array}{l}\text { Mean } \\
\text { Above } \\
\text { Limit } \\
(\mathrm{mph})\end{array}$ & $\begin{array}{c}\text { Mean of } \\
\text { Speeders } \\
\text { (mph) }\end{array}$ & $\begin{array}{l}\text { N and } \\
\% \text { At or } \\
\text { Under } \\
\text { Limit }\end{array}$ & $\begin{array}{c}\mathrm{N} \text { and } \% \\
<7 \mathrm{mph} \\
\text { Over }\end{array}$ & $\begin{array}{c}\mathrm{N} \text { and } \% \\
7+\mathrm{mph} \\
\text { Over }\end{array}$ & $\begin{array}{c}\text { Total } \\
\mathbf{N}\end{array}$ \\
\hline $1 *$ & 19.675 & & -5.325 & 2.391 & $\begin{array}{l}1048 \\
86.7 \%\end{array}$ & $\begin{array}{l}156 \\
12.9 \%\end{array}$ & $\begin{array}{l}5 \\
0.4 \%\end{array}$ & 1,209 \\
\hline 2 & 21.078 & $1.403(.000)$ & $\begin{array}{l}-3.922 \\
(.000)\end{array}$ & $3.879 \mathrm{~ns}$ & $\begin{array}{l}790 \\
82.5 \%\end{array}$ & $\begin{array}{l}149 \\
15.6 \%\end{array}$ & $\begin{array}{l}19 \\
2 \%\end{array}$ & 958 \\
\hline $3 * *$ & 20.285 & $0.610 \mathrm{~ns}$ & $-4.715 \mathrm{~ns}$ & $3.829 \mathrm{~ns}$ & $\begin{array}{l}942 \\
86.4 \%\end{array}$ & $\begin{array}{l}131 \\
12 \%\end{array}$ & $\begin{array}{l}17 \\
1.6 \%\end{array}$ & 1,090 \\
\hline $4^{* *}$ & 19.720 & $0.045 \mathrm{~ns}$ & $-5.280 \mathrm{~ns}$ & $2.429 \mathrm{~ns}$ & $\begin{array}{l}977 \\
89.6 \% \\
\end{array}$ & $\begin{array}{l}110 \\
10.1 \% \\
\end{array}$ & $\begin{array}{l}3 \\
0.3 \% \\
\end{array}$ & 1,090 \\
\hline $5 * *$ & 20.294 & $0.619 \mathrm{~ns}$ & $-4.706 \mathrm{~ns}$ & $2.897 \mathrm{~ns}$ & $\begin{array}{l}907 \\
88.8 \%\end{array}$ & $\begin{array}{l}108 \\
10.6 \%\end{array}$ & $\begin{array}{l}6 \\
0.6 \%\end{array}$ & 1,021 \\
\hline
\end{tabular}

*3 Speed humps installed well before the project began

**3-D Markings in place

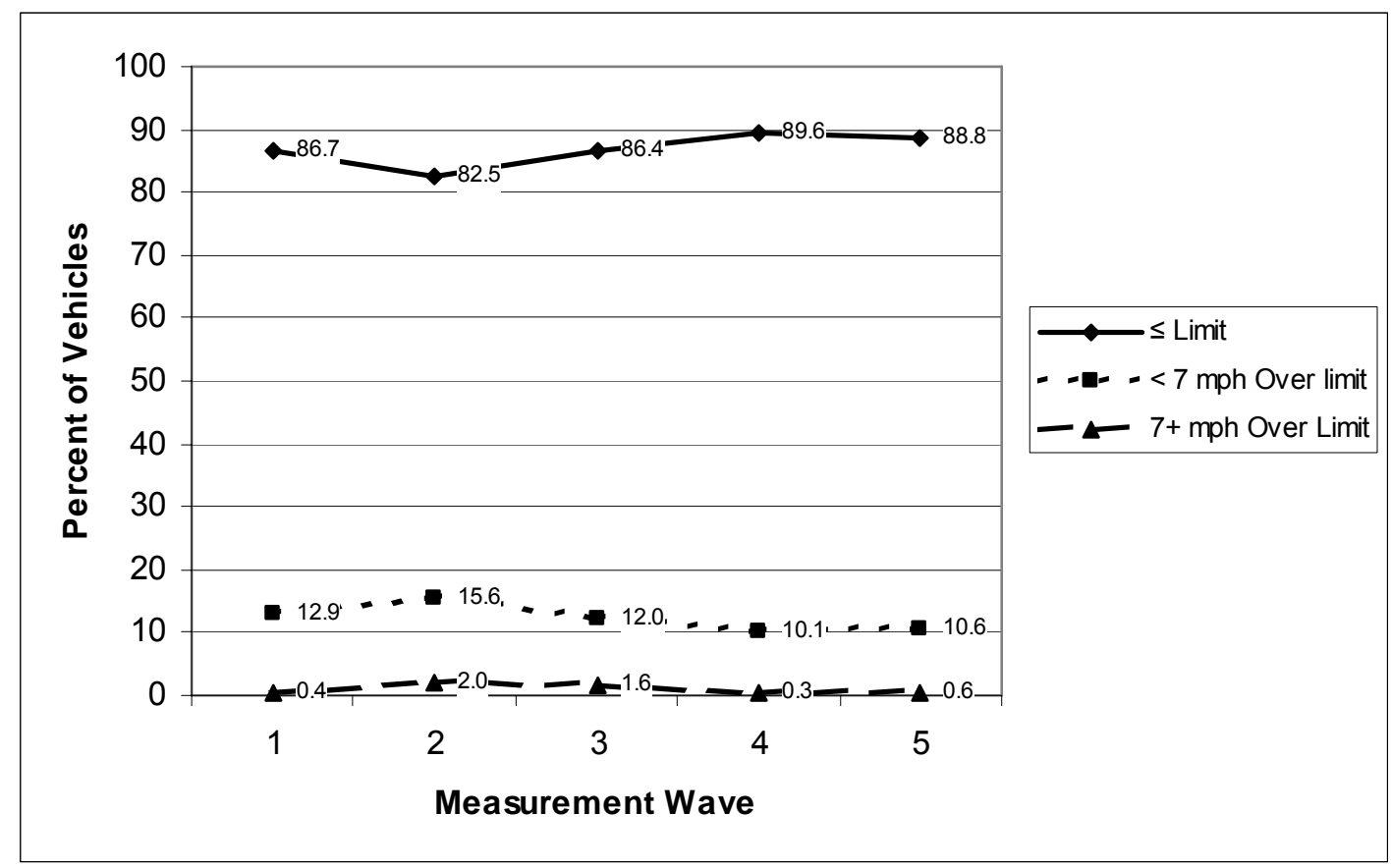

Figure 9. Speed Classes on Peoria $-85^{\text {th }}$ Lane

\subsubsection{Peoria $-91^{\text {st }}$ Avenue}

The $91^{\text {st }}$ Avenue test segment is part of a neighborhood known as Desert Harbor. It is a relatively wide street that is conducive to high speeds and has a $30 \mathrm{mph}$ speed limit. No roadway treatments of any kind were applied as part of Heed the Speed. The education program, however, was intensive and sustained because of the high level of effort by the neighborhood association. Enforcement was also applied because of the known propensity for speeding. Five waves of data were collected. The results are shown in Table 62. 
Table 62. Peoria $-91^{\text {st }}$ Avenue speed results

\begin{tabular}{|c|c|c|c|c|c|c|c|c|}
\hline \multirow[b]{2}{*}{ Wave } & \multicolumn{8}{|c|}{ Measure } \\
\hline & $\begin{array}{l}\text { Mean } \\
\text { Speed } \\
(\text { mph })\end{array}$ & $\begin{array}{c}\text { Mean } \\
\text { Difference } \\
\text { from } \\
\text { Wave 1 } \\
\text { (mph) } \\
\end{array}$ & $\begin{array}{l}\text { Mean } \\
\text { Above } \\
\text { Limit } \\
(\mathrm{mph})\end{array}$ & $\begin{array}{c}\text { Mean of } \\
\text { Speeders } \\
(\mathrm{mph})\end{array}$ & $\begin{array}{c}\text { N and \% } \\
\text { At or } \\
\text { Under } \\
\text { Limit }\end{array}$ & $\begin{array}{l}\mathrm{N} \text { and } \\
\%<7 \\
\text { mph } \\
\text { Over }\end{array}$ & $\begin{array}{c}\mathrm{N} \text { and } \% \\
7+\text { mph } \\
\text { Over }\end{array}$ & $\begin{array}{c}\text { Total } \\
\mathbf{N}\end{array}$ \\
\hline 1 & 33.749 & & $\begin{array}{l}3.749 \\
(.000)\end{array}$ & 5.611 & $\begin{array}{l}9407 \\
21.7 \%\end{array}$ & $\begin{array}{l}23548 \\
54.2 \%\end{array}$ & $\begin{array}{l}10490 \\
24.1 \%\end{array}$ & 43,445 \\
\hline $2 *$ & 32.466 & $-1.283(.000)$ & $\begin{array}{l}2.466 \\
(.000) \\
\end{array}$ & $\begin{array}{l}4.645 \\
(.000) \\
\end{array}$ & $\begin{array}{l}13369 \\
29.7 \% \\
\end{array}$ & $\begin{array}{l}24901 \\
55.3 \% \\
\end{array}$ & $\begin{array}{l}6733 \\
15 \% \\
\end{array}$ & 45,003 \\
\hline $3 *$ & 33.424 & $-0.325(.000)$ & $\begin{array}{l}3.424 \\
(.000)\end{array}$ & $\begin{array}{l}5.735 \\
(.023)^{13}\end{array}$ & $\begin{array}{l}10303 \\
26.4 \%\end{array}$ & $\begin{array}{l}19539 \\
50.1 \%\end{array}$ & $\begin{array}{l}9122 \\
23.4 \%\end{array}$ & 38,964 \\
\hline $4 *$ & 32.771 & $-0.978(.000)$ & $\begin{array}{l}2.771 \\
(.000)\end{array}$ & $\begin{array}{l}5.010 \\
(.000)\end{array}$ & $\begin{array}{l}10443 \\
28.5 \%\end{array}$ & $\begin{array}{l}19687 \\
53.8 \%\end{array}$ & $\begin{array}{l}6449 \\
17.6 \%\end{array}$ & 36,579 \\
\hline $5 *$ & 33.261 & $-0.488(.000)$ & $\begin{array}{l}3.261 \\
(.000)\end{array}$ & $\begin{array}{l}5.347 \\
(.000)\end{array}$ & $\begin{array}{l}11043 \\
25.4 \%\end{array}$ & $\begin{array}{l}23426 \\
53.9 \%\end{array}$ & $\begin{array}{l}9005 \\
20.7 \%\end{array}$ & 43,474 \\
\hline
\end{tabular}

*Ongoing education and enforcement efforts

The initial education and enforcement efforts produced a significant although small effect. After a return toward baseline in Wave 3, the renewed efforts of the neighborhood association and police revived a larger impact. This is demonstrated clearly in Figure 10. Although the effect is relatively small compared with the streets that had physical changes, it is encouraging that it appears to come almost entirely from drivers in the highest speed class. Those going over the limit but less than 7 miles over stayed virtually constant while those at or under the limit increased and those $7+$ over the limit decreased. The mean speed above the speed limit was also down significantly in all follow-on waves.

The number of vehicles using this test segment was approximately equal in Waves 1,2 and 5. The reduction in counts in Waves 3 and 4 is likely the result of vehicle counter equipment malfunctions rather than a traffic diversion. The count contractor reported specific problems and lost data in Wave 3 and also suspected some problems from equipment malfunctions or vandalism during Wave 4.

${ }^{13}$ Increase from baseline 


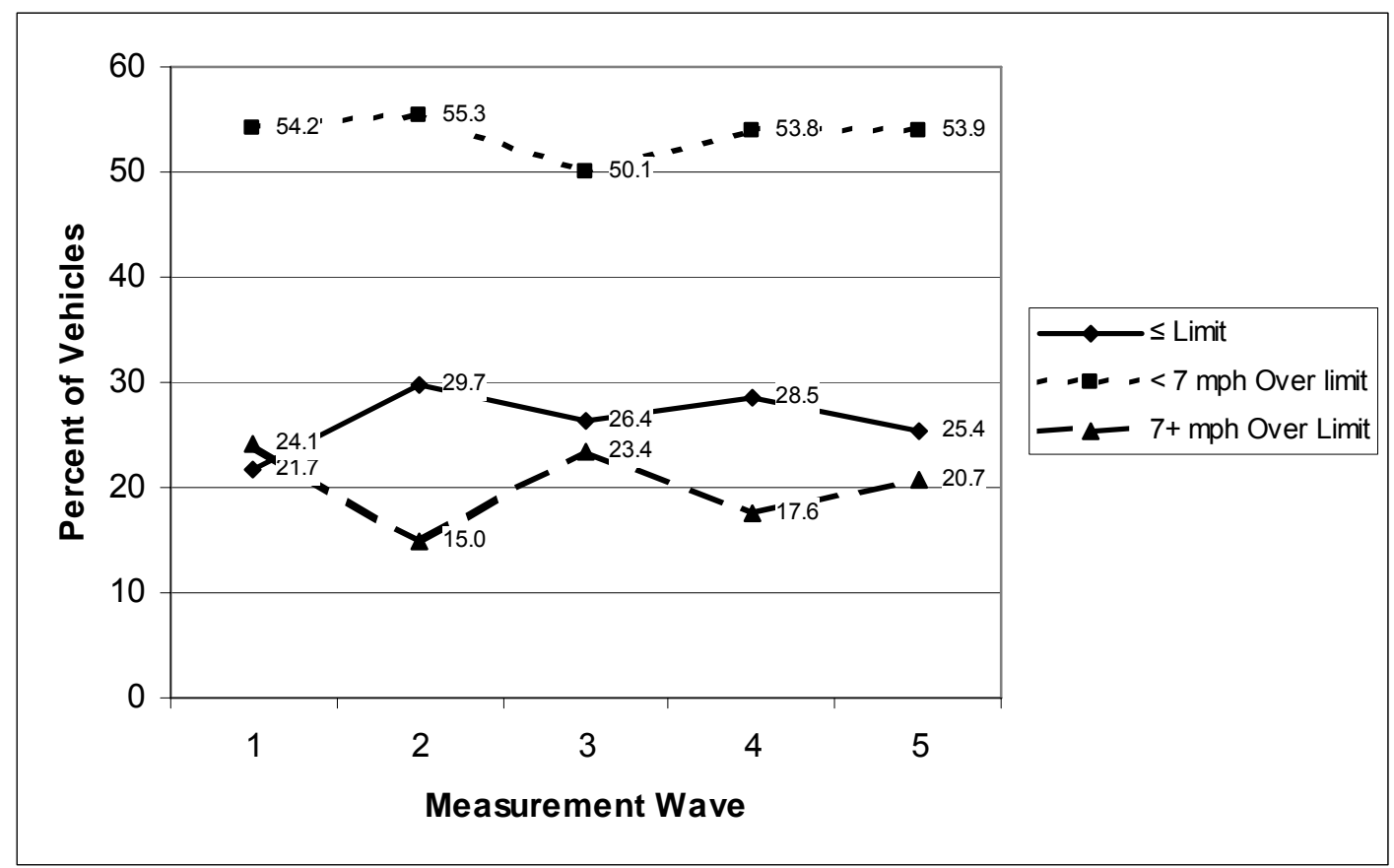

Figure 10. Speed Classes on Peoria $-91^{\text {st }}$ Avenue

\subsubsection{Peoria $-95^{\text {th }}$ Avenue}

This is a straight roadway with a $30 \mathrm{mph}$ speed limit. Only four waves of data were collected on this street. Wave 3 data were lost due to equipment failure. In addition to a moderate to high level of education and moderate enforcement, five sets of 3-D markings were placed on the roadway prior to Wave 4. The resulting speed profiles are shown in Table 63 and Figure 11.

On $95^{\text {th }}$ Avenue, the initial education and enforcement produced a noteworthy effect with a drop in mean speed and a particularly large drop in the number of high-speed drivers and the mean of their speeds. This effect increased in Wave 4 with the addition of the 3-D markings and was still evident, although somewhat diminished, at the end of the data collection period. It is unfortunate that data for Wave 3 were lost due to an equipment malfunction as they would have shed some light on the short-term persistence of the education and enforcement efforts before the installation of the 3-D markings. It is promising, however, that a meaningful reduction in mean speed with almost a halving of drivers in the $7+$ mph over the limit category could be achieved by moderate education and enforcement alone.

The vehicle counts are quite consistent for Waves 1, 2, and 4 and then increase markedly in Wave 5 for no apparent reason. The fact that the speeds remain significantly below the baseline in spite of this increase in traffic suggests that the countermeasures were still working. 
Table 63. Peoria $-95^{\text {th }}$ Avenue Speed Results

\begin{tabular}{|c|c|c|c|c|c|c|c|c|}
\hline \multirow[b]{2}{*}{ Wave } & \multicolumn{8}{|c|}{ Measure } \\
\hline & $\begin{array}{l}\text { Mean } \\
\text { Speed } \\
(\text { mph })\end{array}$ & $\begin{array}{c}\text { Mean } \\
\text { Difference } \\
\text { from } \\
\text { Wave 1 } \\
\text { (mph) }\end{array}$ & $\begin{array}{l}\text { Mean } \\
\text { Above } \\
\text { Limit } \\
(\mathrm{mph})\end{array}$ & $\begin{array}{c}\text { Mean of } \\
\text { Speeders } \\
\text { (mph) }\end{array}$ & $\begin{array}{c}\text { N and \% } \\
\text { At or } \\
\text { Under } \\
\text { Limit }\end{array}$ & $\begin{array}{c}\text { N and } \\
\%<7 \\
\text { mph } \\
\text { Over }\end{array}$ & $\begin{array}{c}\mathrm{N} \text { and } \% \\
7+\mathrm{mph} \\
\text { Over }\end{array}$ & $\begin{array}{c}\text { Total } \\
\mathbf{N}\end{array}$ \\
\hline 1 & 31.949 & & $\begin{array}{l}1.945 \\
(.000)\end{array}$ & $\begin{array}{l}4.727 \\
(.000)\end{array}$ & $\begin{array}{l}7386 \\
35.3 \% \\
\end{array}$ & $\begin{array}{l}10488 \\
50.1 \%\end{array}$ & $\begin{array}{l}3052 \\
14.6 \% \\
\end{array}$ & 20,926 \\
\hline $2 *$ & 30.581 & $-1.369(.000)$ & $\begin{array}{l}.5808 \\
(.000)\end{array}$ & $\begin{array}{l}3.856 \\
(.000)\end{array}$ & $\begin{array}{l}11154 \\
47.0 \%\end{array}$ & $\begin{array}{l}10715 \\
45.1 \%\end{array}$ & $\begin{array}{l}1885 \\
7.9 \%\end{array}$ & 23,754 \\
\hline $3 *$ & & & & & & & & \\
\hline $4 * *$ & 30.017 & $-1.933(.000)$ & $\begin{array}{l}.0169 \\
(.000) \\
\end{array}$ & $\begin{array}{l}3.759 \\
(.000) \\
\end{array}$ & $\begin{array}{l}11354 \\
52.9 \% \\
\end{array}$ & $\begin{array}{l}8698 \\
40.6 \% \\
\end{array}$ & $\begin{array}{l}1405 \\
6.5 \% \\
\end{array}$ & 21,457 \\
\hline $5 * *$ & 30.921 & $-1.029(.000)$ & $\begin{array}{l}.9208 \\
(.000)\end{array}$ & $\begin{array}{l}3.997 \\
(.000)\end{array}$ & $\begin{array}{l}15025 \\
43.6 \%\end{array}$ & $\begin{array}{l}16393 \\
47.6 \%\end{array}$ & $\begin{array}{l}3044 \\
8.8 \%\end{array}$ & 34,462 \\
\hline
\end{tabular}

*Education and enforcement efforts

**3-D Markings added to education and enforcement

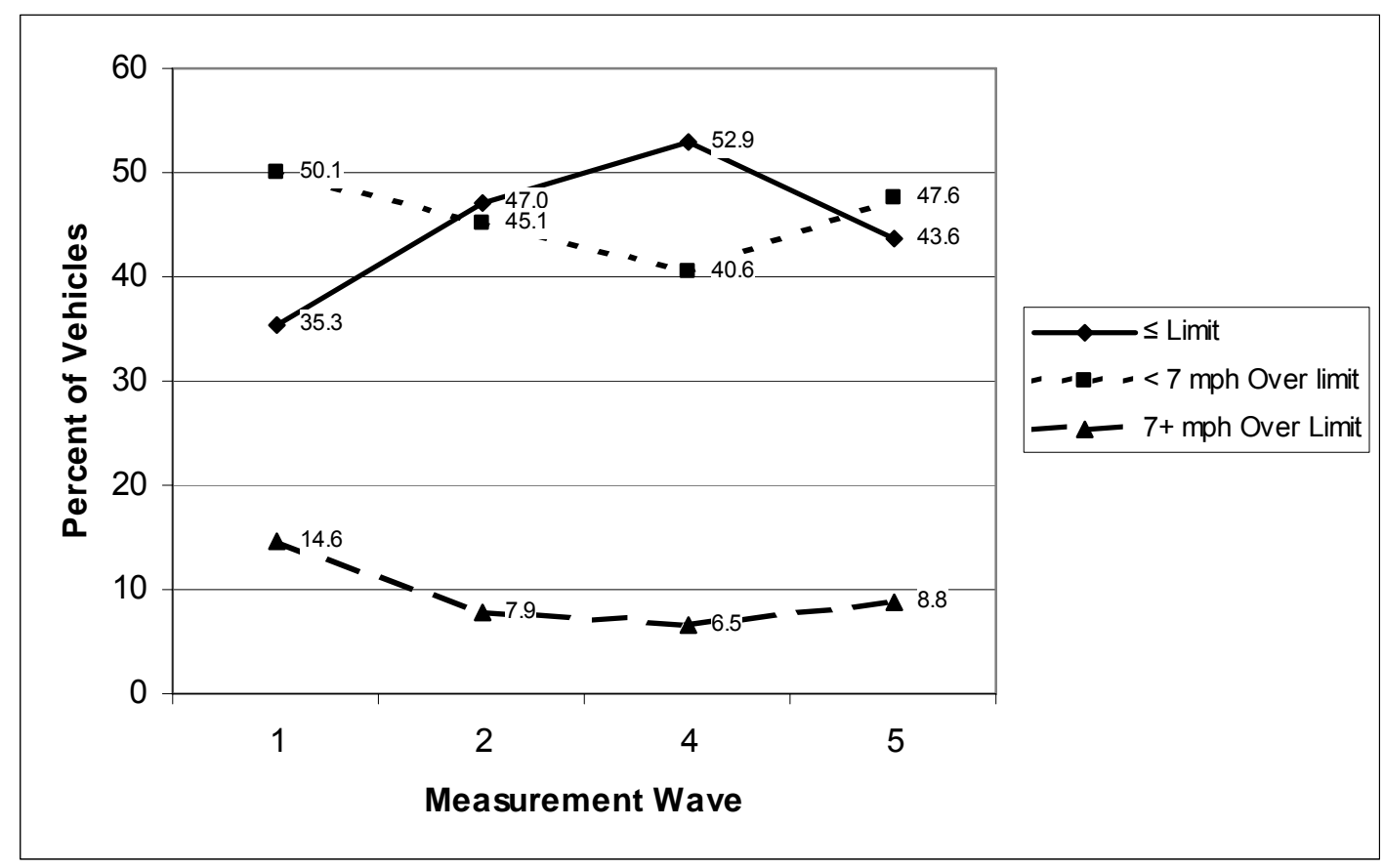

Figure 11. Speed Classes on Peoria $-95^{\text {th }}$ Avenue

\subsubsection{Phoenix - Clarendon}

Clarendon is a through street with a $25 \mathrm{mph}$ speed limit that has had speed humps for some time. The test was conducted there not only to see what would happen to speeds overall but also to determine if a change could be induced on the sections between the humps. As stated earlier, residents were complaining that the existing vertical treatments were spaced too far apart thereby prompting motorists to speed between the humps. 
There is no neighborhood association for Clarendon, and much of the population is Spanish-speaking. As a result, the education campaign likely had moderate intensity even though many of the materials were translated into Spanish. Police enforcement was applied at a level the police administrators considered commensurate with the low baseline mean speeds.

The data collection procedure on Clarendon had counters installed coincident with each of the three existing speed humps as well as two additional counters between them (see Appendix E). Three waves of measurements were taken (Waves 1, 4, and 5). The mean speed at the three existing speed humps actually went up slightly across the waves from $11.164 \mathrm{mph}$ (Wave 1) to $11.515 \mathrm{mph}$ (Wave 4) and $12.005 \mathrm{mph}$ (Wave 5). These speeds are still half of the prevailing speed limit. Thus, there was no correctable issue with the speeds at the humps, and therefore no detailed results are presented for the measurements taken directly at the speed humps.

The speeds at the two locations between the humps, however, showed a significant drop as indicated in Table 64 and Figure 12. These data for measurements taken at the two sensors between the speed humps show a distinct drop in speeds that is sustained through both post waves. The reduction in drivers going $7+\mathrm{mph}$ over the prevailing $25 \mathrm{mph}$ limit is particularly noteworthy. The pattern in Table 64 suggests that the original complaints of the residents may have been caused either by the large differential in average speed between the humps and the inter-hump areas or as a result of the surprisingly large percentage of drivers $(16.7 \%)$ going $7+$ mph above the limit between the speed humps during the baseline (Wave 1).

Table 64. Phoenix - Clarendon Speed Results (Only Sensors Between the Existing Speed Humps)

\begin{tabular}{|c|c|c|c|c|c|c|c|c|}
\hline \multirow[b]{2}{*}{ Wave } & \multicolumn{8}{|c|}{ Measure } \\
\hline & $\begin{array}{l}\text { Mean } \\
\text { Speed } \\
(\text { mph })\end{array}$ & $\begin{array}{c}\text { Mean } \\
\text { Difference } \\
\text { From } \\
\text { Wave 1 } \\
\text { (mph) }\end{array}$ & $\begin{array}{l}\text { Mean } \\
\text { Above } \\
\text { Limit } \\
(\mathrm{mph})\end{array}$ & $\begin{array}{c}\text { Mean of } \\
\text { Speeders } \\
\text { (mph) }\end{array}$ & $\begin{array}{l}\mathrm{N} \text { and } \\
\% \text { At or } \\
\text { Under } \\
\text { Limit }\end{array}$ & $\begin{array}{c}\mathrm{N} \text { and } \% \\
<7 \text { mph } \\
\text { Over }\end{array}$ & $\begin{array}{c}\mathrm{N} \text { and } \% \\
7+\text { mph } \\
\text { Over }\end{array}$ & $\begin{array}{c}\text { Total } \\
\text { N }\end{array}$ \\
\hline 1 & 23.069 & & -.431 & 3.099 & $\begin{array}{l}2804 \\
64.4 \% \\
\end{array}$ & $\begin{array}{l}825 \\
18.9 \% \\
\end{array}$ & $\begin{array}{l}727 \\
16.7 \% \\
\end{array}$ & 4,356 \\
\hline 2 & & & & & & & & \\
\hline 3 & & & & & & & & \\
\hline $4 *$ & 20.563 & $-2.506(.000)$ & $\begin{array}{l}-2.937 \\
(.000)\end{array}$ & $\begin{array}{l}1.235 \\
(.000)\end{array}$ & $\begin{array}{l}3395 \\
80.2 \%\end{array}$ & $\begin{array}{l}670 \\
15.8 \%\end{array}$ & $\begin{array}{l}170 \\
4 \%\end{array}$ & 4,235 \\
\hline $5 *$ & 20.556 & $-2.513(.000)$ & $\begin{array}{l}-2.944 \\
(.000)\end{array}$ & $\begin{array}{l}1.333 \\
(.000)\end{array}$ & $\begin{array}{l}3256 \\
79.8 \%\end{array}$ & $\begin{array}{l}619 \\
15.2 \%\end{array}$ & $\begin{array}{l}207 \\
5.1 \%\end{array}$ & 4,082 \\
\hline
\end{tabular}

*After the application of education and enforcement

The number of vehicles measured on Clarendon between the humps stayed relatively constant across the measurement waves. This suggests that there was no meaningful diversion of traffic from the road as a result of the education and enforcement efforts. 


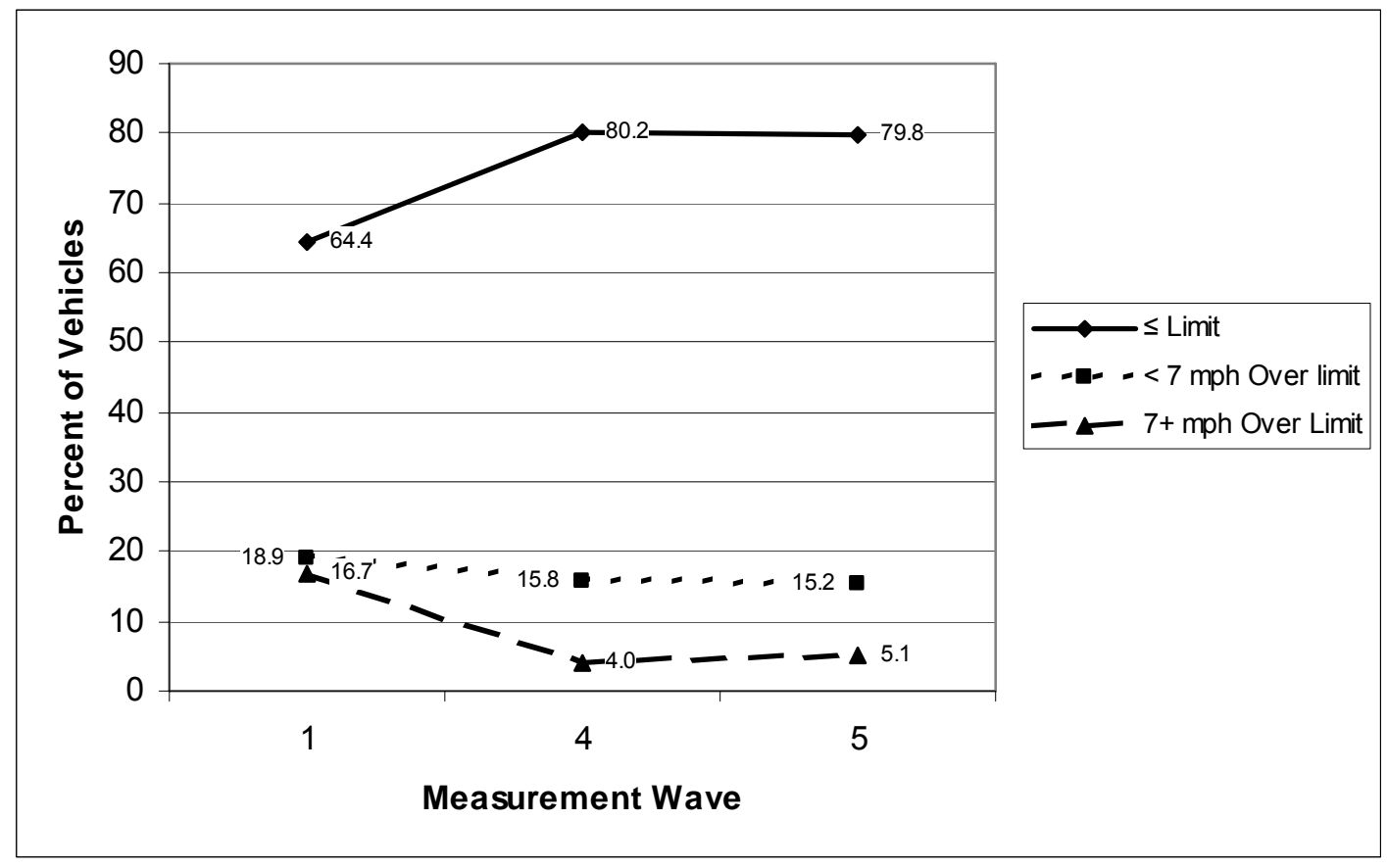

Figure 12. Speed Classes on Phoenix - Clarendon Between the Speed Humps

\subsubsection{Phoenix - Sweetwater}

Sweetwater received intensive education and enforcement spurred by the efforts of a vocal and active neighborhood association. In addition, the Tyregrip ${ }^{\mathrm{TM}}$ material was installed prior to Wave 5 of measurement. Three waves of speed measurement in total were collected (Waves 1, 4 and 5). The results are shown in Table 65 and Figure 13.

Table 65. Phoenix - Sweetwater Speed Results

\begin{tabular}{|c|c|c|c|c|c|c|c|c|}
\hline \multirow[b]{2}{*}{ Wave } & \multicolumn{8}{|c|}{ Measure } \\
\hline & $\begin{array}{l}\text { Mean } \\
\text { Speed } \\
(\text { mph })\end{array}$ & $\begin{array}{c}\text { Mean } \\
\text { Difference } \\
\text { from } \\
\text { Wave 1 } \\
\text { (mph) }\end{array}$ & $\begin{array}{l}\text { Mean } \\
\text { Above } \\
\text { Limit } \\
(\mathrm{mph})\end{array}$ & $\begin{array}{c}\text { Mean of } \\
\text { Speeders } \\
\text { (mph) }\end{array}$ & $\begin{array}{c}\mathbf{N} \text { and } \% \\
\text { Under } \\
\text { Limit }\end{array}$ & $\begin{array}{c}\mathrm{N} \text { and } \% \\
<7 \text { mph } \\
\text { Over }\end{array}$ & $\begin{array}{c}\mathrm{N} \text { and } \% \\
7+\mathrm{mph} \\
\text { Over }\end{array}$ & $\begin{array}{c}\text { Total } \\
\mathbf{N}\end{array}$ \\
\hline 1 & 36.675 & & 8.175 & 10.049 & $\begin{array}{l}3198 \\
12.5 \%\end{array}$ & $\begin{array}{l}7349 \\
28.8 \%\end{array}$ & $\begin{array}{l}14959 \\
58.6 \%\end{array}$ & 25,506 \\
\hline 2 & & & & & & & & \\
\hline 3 & & & & & & & & \\
\hline 4* & 33.065 & $-3.610(.000)$ & $\begin{array}{l}4.565 \\
(.000)\end{array}$ & $\begin{array}{l}8.017 \\
(.000)\end{array}$ & $\begin{array}{l}6354 \\
29.8 \%\end{array}$ & $\begin{array}{l}8032 \\
37.7 \%\end{array}$ & $\begin{array}{l}6908 \\
32.4 \%\end{array}$ & 21,294 \\
\hline $5 * *$ & 33.462 & $-3.213(.000)$ & $\begin{array}{l}4.962 \\
(.000)\end{array}$ & $\begin{array}{l}7.634 \\
(.000)\end{array}$ & $\begin{array}{l}5556 \\
26.9 \%\end{array}$ & $\begin{array}{l}8735 \\
42.3 \%\end{array}$ & $\begin{array}{l}6353 \\
30.8 \%\end{array}$ & 20,644 \\
\hline
\end{tabular}

* After the application of education and enforcement

**After the installation of Tyregrip ${ }^{\mathrm{TM}}$

The Sweetwater results show almost a 50-percent reduction in the number of drivers going $7 \mathrm{mph}$ or more over the limit. The reduction is largest in the last wave. The mean speed of the speeders also was reduced markedly as well as statistically significantly in both post 
waves when compared with the Wave 1 baseline. The reduction in the mean of speeders from $8.017 \mathrm{mph}$ in Wave 4 to $7.634 \mathrm{mph}$ in Wave 5 is also statistically significant $(\mathrm{p}<.001)$.

It should be noted that across the three waves of measurement the shift in speeds is largest to the lowest category (under the speed limit). This category more than doubles from Wave 1 to Wave 4 and is still more than double in Wave 5. At the same time, the intermediate category of people going less than $7 \mathrm{mph}$ above the limit goes from 28.8 percent to 42.3 percent, an increase of 46.9 percent. Thus, the distribution shifts from the 7+ miles over the limit category to the two lower class intervals.

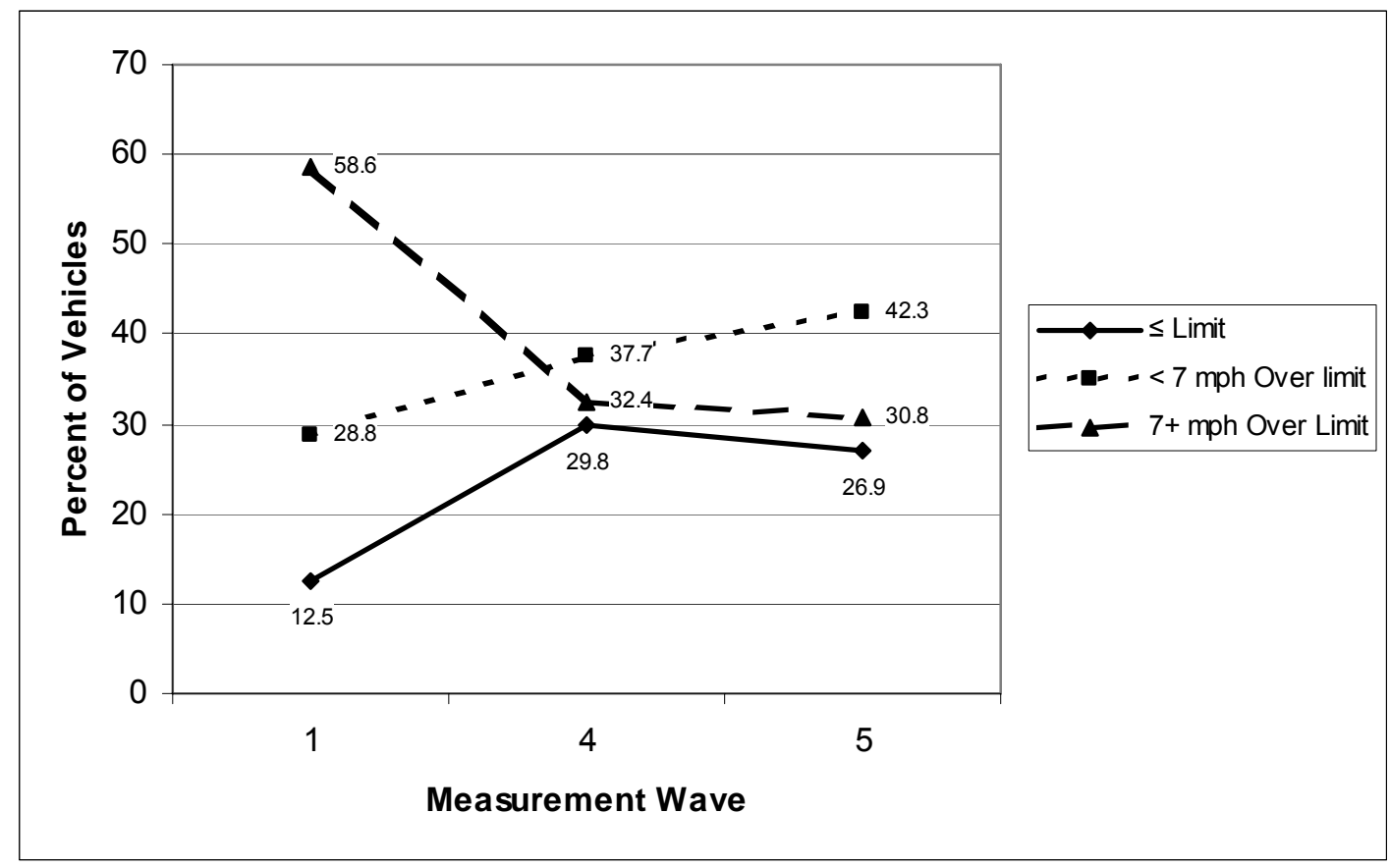

Figure 13. Speed Classes on Phoenix - Sweetwater

The mean of speeders shows continued improvement from Wave 4 to Wave 5. This suggests that the Tyregrip ${ }^{\mathrm{TM}}$ installation may have yielded a further moderation in the most aberrant speeds even though the mean speed rose slightly. Since there was only a single wave of measurement after the appearance of the Tyregrip ${ }^{\mathrm{TM}}$, no inference can be drawn concerning its long-term effectiveness.

The data for Sweetwater show a drop in traffic volume of 16.5 percent from Wave 1 to Wave 4. This volume reduction increases slightly from Wave 4 to Wave 5 . This could be indicative of a small diversion of traffic to other parallel through streets. This is consistent with the opinion of the neighborhood association members who felt that many of the speeders were people cutting through the neighborhood on east/west trips. It is also supported by the police stop data shown previously in Table 23 which indicated that Sweetwater had the lowest percentage in Phoenix of people stopped who lived in or near the neighborhood. If there was a diversion, however, it cannot explain the marked reduction in those traveling 7+ miles over the limit. This number dropped by 8,606 between Wave 1 and Wave 5 while the total sample only decreased by only 4,862 vehicles. 


\subsubsection{Phoenix - Moon Valley Drive East/West Segment}

Moon Valley Drive is a $25 \mathrm{mph}$ speed limit road with a segment that runs east and west on which only education and enforcement were applied. Three waves of speed measurement were collected (Waves 1, 4, and 5).

Table 66 and Figure 14 show that significant speed reductions were achieved on the east/west section of Moon Valley Drive without the use of any physical measures. The magnitude of the reduction is not as great as on Sweetwater, but the pattern is somewhat the same - a reduction in average speed and a shift to the lower class intervals from the $7+$ miles over the limit category. A particularly interesting aspect of the results at this site was that the effect was maintained and even increased significantly between Waves 4 and 5 . This suggests the possibility of some persistence of the education plus enforcement approach.

Table 66. Phoenix - Moon Valley Drive East/West Segment Speed Results

\begin{tabular}{|c|c|c|c|c|c|c|c|c|}
\hline \multirow[b]{2}{*}{ Wave } & \multicolumn{8}{|c|}{ Measure } \\
\hline & $\begin{array}{l}\text { Mean } \\
\text { Speed } \\
\text { (mph) }\end{array}$ & $\begin{array}{c}\text { Mean } \\
\text { Difference } \\
\text { from } \\
\text { Wave 1 } \\
\text { (mph) }\end{array}$ & $\begin{array}{l}\text { Mean } \\
\text { Above } \\
\text { Limit } \\
\text { (mph) }\end{array}$ & $\begin{array}{c}\text { Mean of } \\
\text { Speeders } \\
\text { (mph) }\end{array}$ & $\begin{array}{c}\text { N and } \\
\% \text { At or } \\
\text { Under } \\
\text { Limit }\end{array}$ & $\begin{array}{c}\mathrm{N} \text { and } \% \\
<7 \text { mph } \\
\text { Over }\end{array}$ & $\begin{array}{c}\mathrm{N} \text { and } \% \\
7+\text { mph } \\
\text { Over }\end{array}$ & $\begin{array}{c}\text { Total } \\
\mathbf{N}\end{array}$ \\
\hline 1 & 29.234 & & 5.734 & 9.457 & $\begin{array}{l}2162 \\
26.4 \%\end{array}$ & $\begin{array}{l}2248 \\
27.4 \%\end{array}$ & $\begin{array}{l}3785 \\
46.2 \% \\
\end{array}$ & 8,195 \\
\hline 2 & & & & & & & & \\
\hline 3 & & & & & & & & \\
\hline 4* & 28.393 & $-0.841(.000)$ & $\begin{array}{l}4.893 \\
(.000)\end{array}$ & $\begin{array}{l}8.689 \\
(.000)\end{array}$ & $\begin{array}{l}2311 \\
29 \%\end{array}$ & $\begin{array}{l}2512 \\
31.6 \%\end{array}$ & $\begin{array}{l}3137 \\
39.4 \%\end{array}$ & 7,960 \\
\hline $5 *$ & 27.656 & $-1.578(.000)$ & $\begin{array}{l}4.156 \\
(.000)\end{array}$ & $\begin{array}{l}8.286 \\
(.000)\end{array}$ & $\begin{array}{l}2660 \\
34.5 \%\end{array}$ & $\begin{array}{l}2497 \\
32.4 \%\end{array}$ & $\begin{array}{l}2544 \\
33 \%\end{array}$ & 7,701 \\
\hline
\end{tabular}

*After the application of education and enforcement

Although the number of vehicles observed dropped slightly from the baseline to the post waves, this drop cannot explain the observed pattern of results. For example, the total number of vehicles observed in Wave 5 was only 494 less than seen in Wave 1. Across the same measurement periods, the reduction in those going 7+ miles over the limit was 1,241, almost four times as great. 


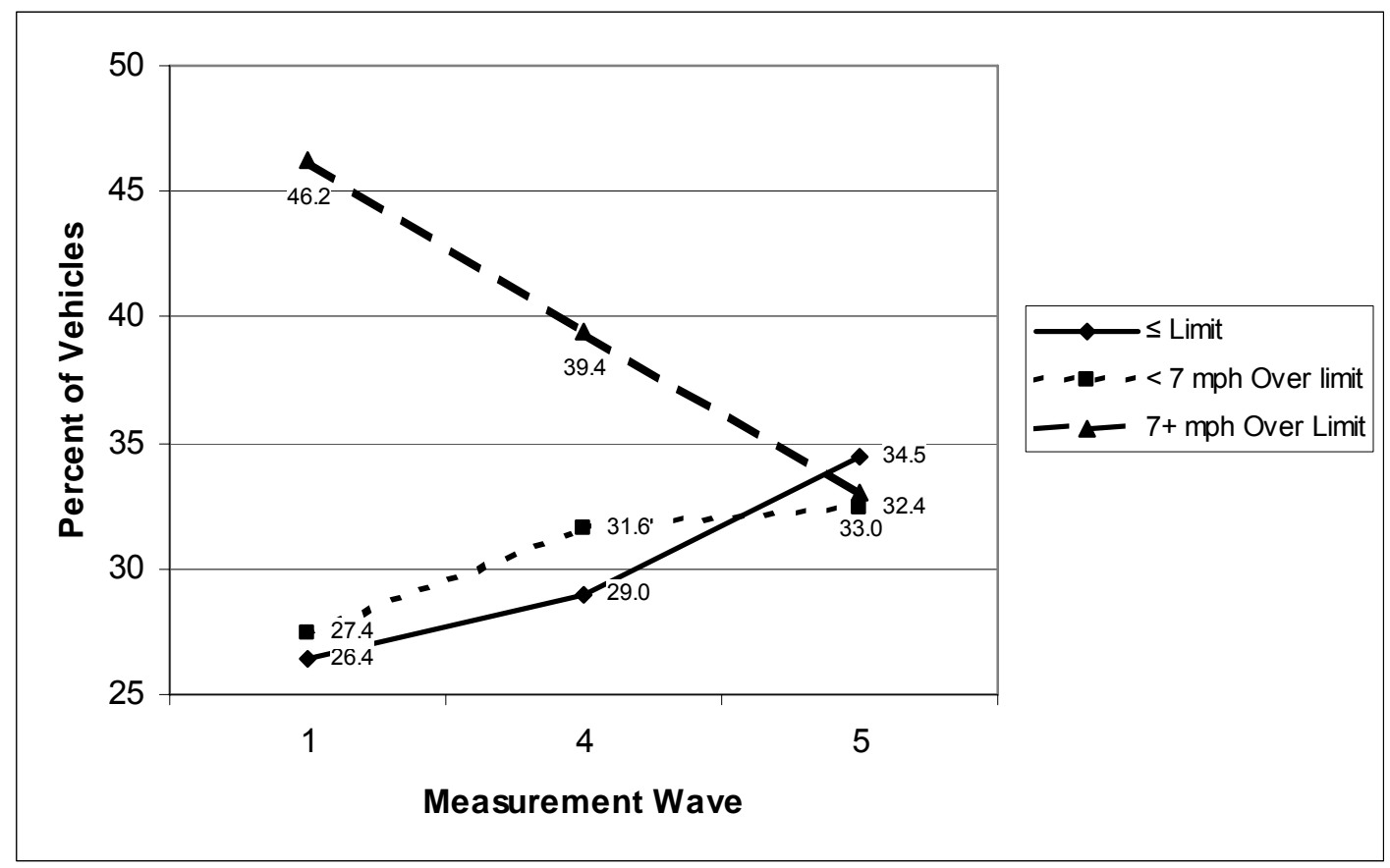

Figure 14. Speed Classes on Phoenix - Moon Valley Drive East/West Segment

\subsubsection{Phoenix - Moon Valley Drive North/South Segment}

The segment of Moon Valley Drive running north and south received essentially the same education and enforcement as the east/west segment but also had two speed humps installed between Waves 4 and 5. The speed limit on this segment is also $25 \mathrm{mph}$.

The results shown in Table 67 and Figure 15 indicate that the effect of education and enforcement alone on speed on this roadway through Wave 4, although significant, is somewhat less than on the east/west segment of Moon Valley Drive. The influence of the addition of a speed hump before Wave 5 is large and consistent with what was seen on $84^{\text {th }}$ Avenue in Peoria.

As with the East/West segment on Moon Valley and at Sweetwater, there is a slight reduction in the overall vehicle count between Wave 1 and Waves 4 and 5. The magnitude of this drop (484) from Wave 1 to Wave 4 could possibly account for the reduction of 468 in the number of cars observed going 7+ over the limit across these waves if all the diversions were speeders. The overall reduction in vehicles from Wave 1 to Wave 5 (518), however, cannot explain the extremely large drop in those going $7+$ over the limit across those time periods $(1,398)$. 
Table 67. Phoenix - Moon Valley Drive North/South Segment Speed Results

\begin{tabular}{|c|c|c|c|c|c|c|c|c|}
\hline \multirow[b]{2}{*}{ Wave } & \multicolumn{8}{|c|}{ Measure } \\
\hline & $\begin{array}{l}\text { Mean } \\
\text { Speed } \\
(\text { mph })\end{array}$ & $\begin{array}{c}\text { Mean } \\
\text { Difference } \\
\text { from } \\
\text { Wave 1 } \\
\text { (mph) }\end{array}$ & $\begin{array}{l}\text { Mean } \\
\text { Above } \\
\text { Limit } \\
(\mathrm{mph})\end{array}$ & $\begin{array}{c}\text { Mean of } \\
\text { Speeders } \\
\text { (mph) }\end{array}$ & $\begin{array}{l}\text { N and } \\
\% \text { At or } \\
\text { Under } \\
\text { Limit }\end{array}$ & $\begin{array}{c}\mathrm{N} \text { and } \% \\
<7 \mathrm{mph} \\
\text { Over }\end{array}$ & $\begin{array}{c}\mathrm{N} \text { and } \% \\
7+\mathrm{mph} \\
\text { Over }\end{array}$ & $\begin{array}{c}\text { Total } \\
\mathbf{N}\end{array}$ \\
\hline 1 & 30.084 & & 6.584 & 9.040 & $\begin{array}{l}763 \\
18.0 \% \\
\end{array}$ & $\begin{array}{l}1307 \\
30.8 \% \\
\end{array}$ & $\begin{array}{l}2171 \\
51.2 \%\end{array}$ & 4,241 \\
\hline 2 & & & & & & & & \\
\hline 3 & & & & & & & & \\
\hline $4 *$ & 29.391 & $-0.693(.014)$ & $\begin{array}{l}5.891 \\
(.000)\end{array}$ & $\begin{array}{l}8.608 \\
(.036)\end{array}$ & $\begin{array}{l}781 \\
20.8 \%\end{array}$ & $\begin{array}{l}1273 \\
33.9 \%\end{array}$ & $\begin{array}{l}1703 \\
45.3 \%\end{array}$ & 3,757 \\
\hline $5 * *$ & 26.851 & $-3.233(.000)$ & $\begin{array}{l}3.351 \\
(.000)\end{array}$ & $\begin{array}{l}6.976 \\
(.000)\end{array}$ & $\begin{array}{l}1458 \\
39.2 \%\end{array}$ & $\begin{array}{l}1492 \\
40.1 \%\end{array}$ & $\begin{array}{l}773 \\
20.8 \%\end{array}$ & 3,723 \\
\hline
\end{tabular}

* After the application of education and enforcement

** Speed humps added prior to Wave 5

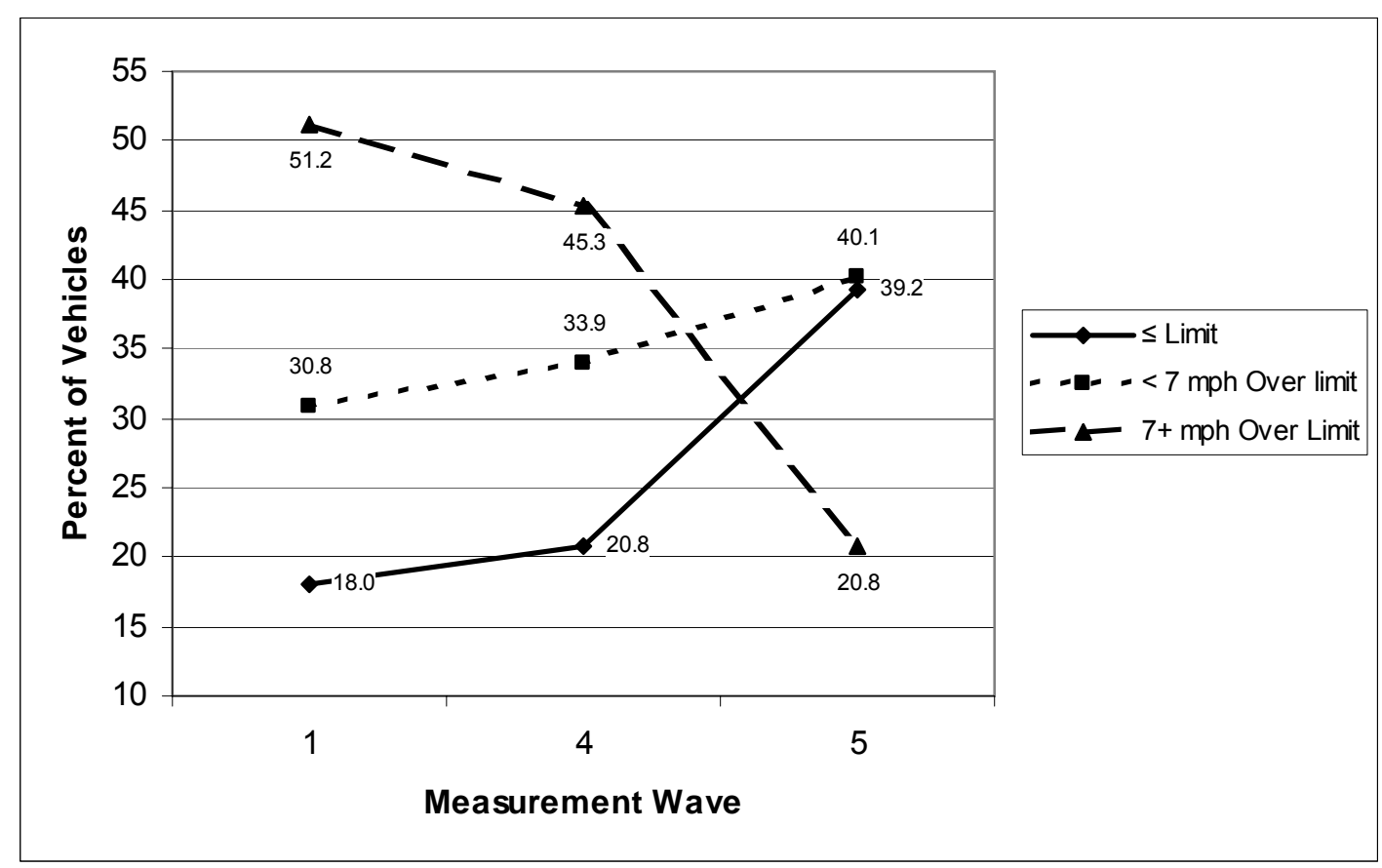

Figure 15. Speed Classes on Phoenix - Moon Valley Drive North/South Segment

\subsubsection{Phoenix - Coral Gables Drive East/West Segment}

The east/west segment of Coral Gables Drive was treated with 3-D and Tyregrip ${ }^{\mathrm{TM}}$ materials as well as education and enforcement. Five waves of measurement were made to be sure to encompass the installation of all of the pavement treatments. The 3-D markings were installed between Waves 2 and 3 at the east end of the segment. The Tyregrip ${ }^{\mathrm{TM}}$ was installed between Waves 4 and 5 at the west end of the roadway. This section of Coral Gables passes a school and park. 
Table 68 and Figure 16 show that overall speed was significantly below baseline by in excess of $2 \mathrm{mph}$ in all post waves. The number of drivers exceeding the limit by $7 \mathrm{mph}$ or more dropped almost threefold from Wave 1 to Wave 5. The increase in the mean speed of speeders in Wave 3 is curious because the proportion of the sample in the lowest category increased and the number and percent of drivers in the highest speed category stayed virtually steady. In any event, the reversal was transitory, and Waves 4 and 5 show markedly lower speeds by speeders. The addition of Tyregrip ${ }^{\mathrm{TM}}$ was associated with a significant increase of $0.489 \mathrm{mph}$ in overall speed from the preceding wave but a significant decrease of $0.434 \mathrm{mph}$ in the mean speed of speeders between Waves 4 and 5. The Wave 5 mean speed of $30.006 \mathrm{mph}$, however, was still well below the baseline speed of $33.683 \mathrm{mph}$.

Table 68. Phoenix - Coral Gables Drive East/West Segment Speed Results

\begin{tabular}{|c|c|c|c|c|c|c|c|c|}
\hline \multirow[b]{2}{*}{ Wave } & \multicolumn{8}{|c|}{ Measure } \\
\hline & $\begin{array}{l}\text { Mean } \\
\text { Speed } \\
(\text { mph })\end{array}$ & $\begin{array}{c}\text { Mean } \\
\text { Difference } \\
\text { from } \\
\text { Wave 1 } \\
\text { (mph) }\end{array}$ & $\begin{array}{l}\text { Mean } \\
\text { Above } \\
\text { Limit } \\
(\mathrm{mph})\end{array}$ & $\begin{array}{c}\text { Mean of } \\
\text { Speeders } \\
(\mathrm{mph})\end{array}$ & $\begin{array}{c}\text { N and \% } \\
\text { At or } \\
\text { Under } \\
\text { Limit }\end{array}$ & $\begin{array}{l}\mathrm{N} \text { and } \\
\%<7 \\
\text { mph } \\
\text { Over }\end{array}$ & $\begin{array}{c}\mathrm{N} \text { and } \% \\
7+\text { mph } \\
\text { Over }\end{array}$ & $\begin{array}{c}\text { Total } \\
\mathbf{N}\end{array}$ \\
\hline 1 & 33.683 & & 5.183 & 8.332 & $\begin{array}{l}9167 \\
25.6 \% \\
\end{array}$ & $\begin{array}{l}12840 \\
35.9 \% \\
\end{array}$ & $\begin{array}{l}13798 \\
38.5 \% \\
\end{array}$ & 35,805 \\
\hline $2 *$ & 31.509 & $-2.174(.000)$ & $\begin{array}{l}3.009 \\
(.000)\end{array}$ & $\begin{array}{l}7.416 \\
(.000) \\
\end{array}$ & $\begin{array}{l}16166 \\
39.5 \% \\
\end{array}$ & $\begin{array}{l}14866 \\
36.3 \% \\
\end{array}$ & $\begin{array}{l}9924 \\
24.2 \% \\
\end{array}$ & 40,956 \\
\hline $3 * *$ & 31.294 & $-2.389(.000)$ & $\begin{array}{l}2.794 \\
(.000)\end{array}$ & $\begin{array}{l}9.499 \\
(.000)^{14}\end{array}$ & $\begin{array}{l}21887 \\
49.1 \% \\
\end{array}$ & $\begin{array}{l}11800 \\
26.5 \%\end{array}$ & $\begin{array}{l}10858 \\
24.4 \% \\
\end{array}$ & 44,545 \\
\hline $4 * *$ & 29.517 & $-4.166(.000)$ & $\begin{array}{l}1.017 \\
(.000)\end{array}$ & $\begin{array}{l}7.048 \\
(.000)\end{array}$ & $\begin{array}{l}22806 \\
45.5 \%\end{array}$ & $\begin{array}{l}17858 \\
35.6 \%\end{array}$ & $\begin{array}{l}9432 \\
18.8 \%\end{array}$ & 50,096 \\
\hline $5 * * *$ & 30.006 & $-3.677(.000)$ & $\begin{array}{l}1.506 \\
(.000)\end{array}$ & $\begin{array}{l}6.614 \\
(.000)\end{array}$ & $\begin{array}{l}24255 \\
49.6 \%\end{array}$ & $\begin{array}{l}17408 \\
35.6 \%\end{array}$ & $\begin{array}{l}7201 \\
14.7 \%\end{array}$ & 48,864 \\
\hline
\end{tabular}

* After the application of education and enforcement

**After addition of 3-D material to education and enforcement

$* * *$ After addition of Tyregrip ${ }^{\mathrm{TM}}$ material to education, enforcement and 3-D material

There was clearly no diversion of traffic on this segment of Coral Gables Drive. The vehicle counts for every post wave are well above the count for the baseline. There is no ready explanation for why the traffic volume would have increased to the extent measured. It is possible that the novelty value of the innovative markings actually attracted traffic. Even if this, in fact, occurred, the desired speed reductions were nevertheless achieved.

\footnotetext{
${ }^{14}$ Significant increase from Wave 1
} 


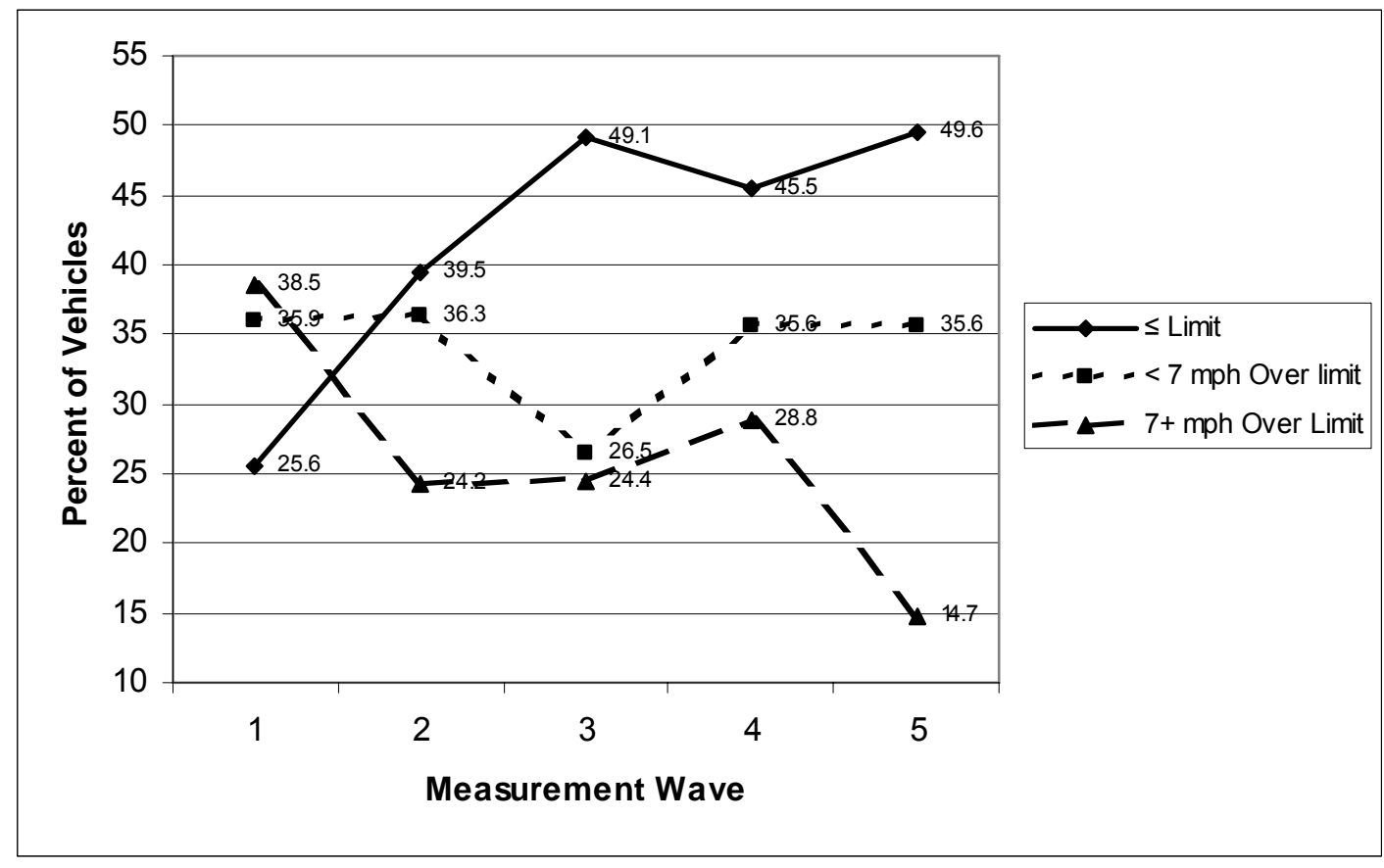

Figure 16. Speed Classes on Phoenix - Coral Gables East/West Segment

\subsubsection{Phoenix - Coral Gables Drive North/South Segment}

The north/south portion of Coral Gables Drive is wide and lined with expensive single family homes. This segment received enforcement and education as well as a Tyregrip ${ }^{\mathrm{TM}}$ installation between Waves 4 and 5. Only three waves of data (Waves 1, 4, and 5) were collected. The speed results for this segment are presented in Table 69 and Figure 17.

Table 69. Phoenix - Coral Gables Drive North/South Segment Speed Results

\begin{tabular}{|c|c|c|c|c|c|c|c|c|}
\hline \multirow[b]{2}{*}{ Wave } & \multicolumn{8}{|c|}{ Measure } \\
\hline & $\begin{array}{l}\text { Mean } \\
\text { Speed } \\
(\mathrm{mph})\end{array}$ & $\begin{array}{c}\text { Mean } \\
\text { Difference } \\
\text { From } \\
\text { Wave 1 } \\
\text { (mph) }\end{array}$ & $\begin{array}{l}\text { Mean } \\
\text { Above } \\
\text { Limit } \\
\text { (mph) }\end{array}$ & $\begin{array}{c}\text { Mean of } \\
\text { Speeders } \\
\text { (mph) }\end{array}$ & $\begin{array}{c}\text { N and \% } \\
\text { At or } \\
\text { Under } \\
\text { Limit }\end{array}$ & $\begin{array}{c}\mathrm{N} \text { and } \\
\%<7 \\
\text { mph } \\
\text { Over }\end{array}$ & $\begin{array}{c}\mathrm{N} \text { and } \% \\
7+\text { mph } \\
\text { Over }\end{array}$ & $\begin{array}{c}\text { Total } \\
\mathbf{N}\end{array}$ \\
\hline 1 & 32.937 & & 4.437 & 7.773 & $\begin{array}{l}7627 \\
28 \% \\
\end{array}$ & $\begin{array}{l}10807 \\
39.6 \% \\
\end{array}$ & $\begin{array}{l}8837 \\
32.4 \% \\
\end{array}$ & 27,271 \\
\hline 2 & & & & & & & & \\
\hline 3 & & & & & & & & \\
\hline $4 *$ & 32.513 & $-0.424(.000)$ & $\begin{array}{l}4.013 \\
(.000) \\
\end{array}$ & $\begin{array}{l}7.330 \\
(.000) \\
\end{array}$ & $\begin{array}{l}9223 \\
33.3 \% \\
\end{array}$ & $\begin{array}{l}11274 \\
40.7 \% \\
\end{array}$ & $\begin{array}{l}7183 \\
26 \% \\
\end{array}$ & 27,680 \\
\hline $5 * *$ & 31.467 & $-1.470(.000)$ & $\begin{array}{l}2.967 \\
(.000)\end{array}$ & $\begin{array}{l}6.545 \\
(.000)\end{array}$ & $\begin{array}{l}10603 \\
39.6 \% \\
\end{array}$ & $\begin{array}{l}11374 \\
42.5 \% \\
\end{array}$ & $\begin{array}{l}4776 \\
17.9 \% \\
\end{array}$ & 26,753 \\
\hline
\end{tabular}

* After the application of education and enforcement

**After addition of Tyregrip ${ }^{\mathrm{TM}}$ material to education and enforcement 
In addition to the significant drop in mean speed in each successive wave, there was a notable reduction in the number of vehicles traveling $7+$ miles over the limit. This drop of over 4,000 cars is far in excess of the overall reduction in vehicles counted of only 518 between Wave 1 and Wave 5. Thus, diversion cannot possibly explain the observed results. Also, the marked effect of the addition of the Tyregrip ${ }^{\mathrm{TM}}$ material on mean and excessive speeds is noteworthy.

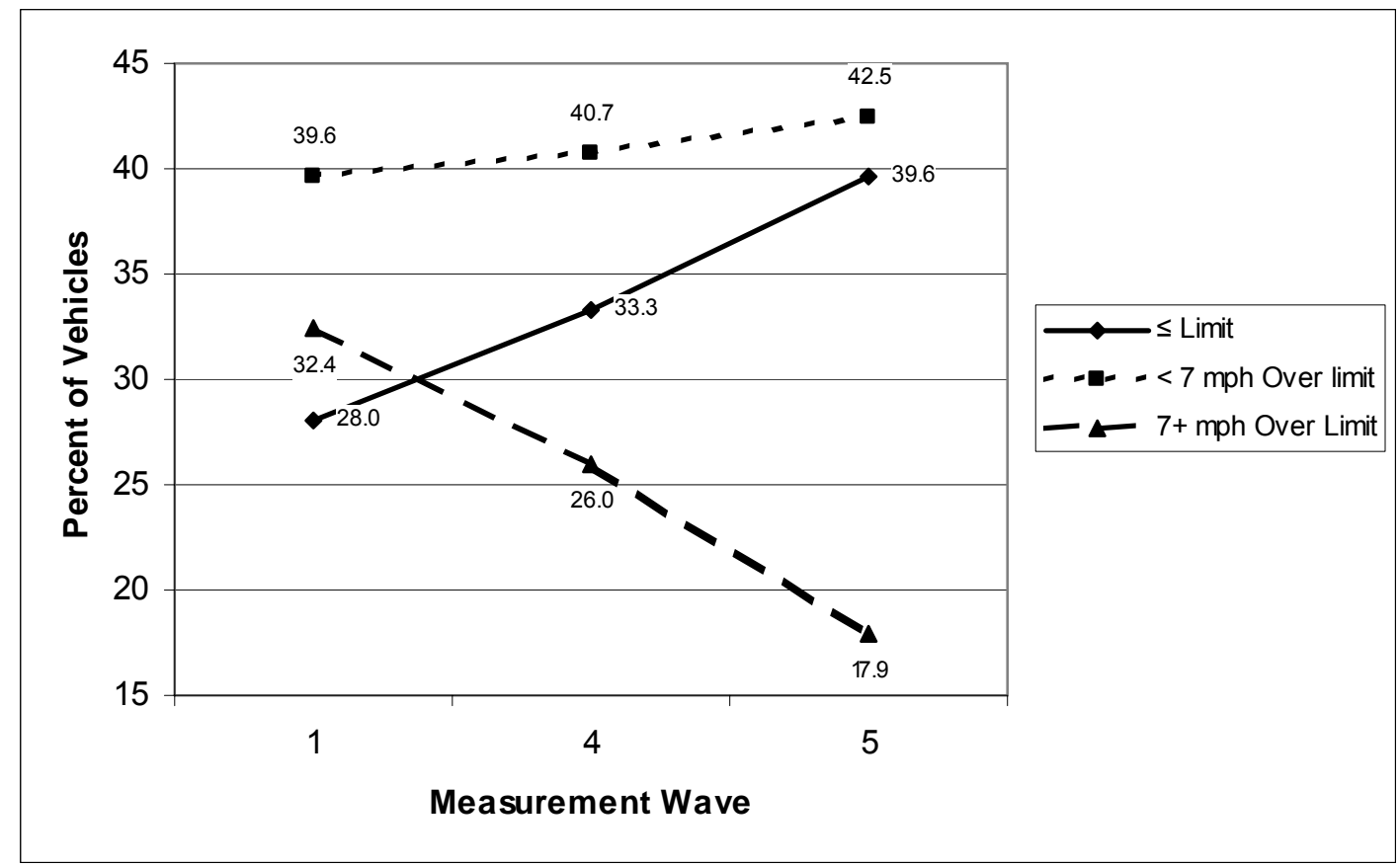

Figure 17. Speed Classes on Phoenix - Coral Gables North/South Segment

\subsubsection{Summary of Speed Results}

The large samples of speed data indicated a consistent pattern of reductions in all neighborhoods and on all test segments except $85^{\text {th }}$ Lane in Peoria. The general pattern of results is a decrease in mean speed accompanied by a moderate to large reduction of drivers exceeding the speed limit by $7 \mathrm{mph}$ or more and a concomitant increase in drivers proceeding at the speed limit or less. The mean speed above the speed limit and the mean speed of speeders also decline significantly at all sites except $85^{\text {th }}$ Lane in Peoria where the mean speed above the limit declines significantly from Wave 1 to Wave 2 but then returns to baseline in the subsequent measurement waves.

\subsubsection{Summary of Traffic Volume Results}

Traffic volumes varied across the various study measurements without a consistent pattern. At six of the study segments $\left(85^{\text {th }}\right.$ Lane, $91^{\text {st }}$ Avenue, Clarendon, Moon Valley East/West and North/South and Coral Gables North/South), the volume was essentially equal between the baseline and the last applicable measure. There was a meaningful decrease in traffic volume at two segments ( $84^{\text {th }}$ Avenue and Sweetwater) and a notable increase in traffic at two others $\left(95^{\text {th }}\right.$ Avenue and Coral Gables East/West). The decrease in volume on $84^{\text {th }}$ Avenue after the installation of speed humps is not surprising and has been previously noted when these 
vertical treatments were installed. The other decrease and the two increases cannot be readily explained but are likely just normal variability.

Importantly, there is nothing in the traffic volume results that suggests that the observed speed reduction effects were the result of diverting higher speed drivers to other, non-studied streets where they would continue to be a hazard. On $84^{\text {th }}$ Avenue, volume dropped 29.7 percent from the first (baseline) wave to the last measurement. Over the same time period, the number of vehicles traveling 7+ mph over the speed limit decreased by 80.3 percent. On Sweetwater, the number of vehicles counted declined by 4,862 from the baseline to the last measurement while the number of vehicles measured at $7+$ mph over the limit dropped by 8,606 .

\section{$5.4 \quad$ Process Assessment}

Following completion of the program, a joint meeting was held with the Peoria and Phoenix traffic engineering and police personnel who had served on the steering committee for the study The purpose of the meeting was to obtain their opinions on the effectiveness of the program and its components as well as suggestions for program improvement. Information was also sought on whether or not committee members would recommend that specific program components be included in a national guide for reducing speeds in neighborhoods.

Similar discussions were held with representatives from the neighborhoods under study. Two of these latter discussions were held by telephone. There was no discussion with representatives from the Clarendon Avenue neighborhood since the lack of either a homeowner's association or a vocal group of citizens prevented identifying residents to speak for the neighborhood.

Specific information obtained from these discussions is described in the following paragraphs.

\subsubsection{Program Conduct and Coordination}

When the two cities agreed to participate in the study, a committee was established to oversee the conduct of the program. It consisted of police and traffic representatives who met approximately monthly to oversee program activities. The committee members felt that the frequency of these meetings was adequate. They provided an opportunity for all involved to review accomplishments achieved to date, discuss and resolve any problems encountered since the last meeting, and make plans for the future.

It was noted that there was a great deal of media attention to the program at the beginning, and then it tapered off. It was suggested that adding a public information person to the basic committee might have been helpful in maintaining a higher level of earned media for the program.

\subsubsection{Selection of Program Neighborhoods}

All of the neighborhoods selected for study had previously requested city support for a speeding problem. Some had complained frequently to the police about speeders. In Peoria, both Desert Harbor and $95^{\text {th }}$ Avenue were considered by the police to be good selections for the program. Police representatives considered Desert Harbor to be best in terms of interest. There 
was a designated neighborhood coordinator for that site, many yard signs were displayed, and there was a great deal of neighborhood involvement In contrast, the residents of Bell Park, although vocal and persistent, concentrated on their desire for the installation of speed tables and appeared to be less interested in the other program activities.

In Phoenix, police representatives considered that Moon Valley and Sweetwater were good test sites - residents wanted them there. There was not much interest evident in the Clarendon neighborhood. Contributing to this problem was the lack of a homeowner's association. Police also felt that the existing speed humps on Clarendon slowed their movements and that it may not have been a good idea to select a test neighborhood with existing speed humps. This sentiment, however, was expressed before the foregoing speed results were available showing a marked decrease in speeds on the stretches of Clarendon between the speed humps.

Police representatives recommended that, in selecting neighborhoods for a model program, there should be evidence that the speeders are local and that the neighborhood residents want a police presence there. As stated previously, the latter was a requirement for the present study. It is not clear how a committee or decision-maker could determine the residence location of the speeders in a particular neighborhood unless the police made a series of stops such as those conducted in the present program as one test of the suitability of a neighborhood for participation in a Heed the Speed effort.

\subsubsection{Neighborhood Speed Watch}

Police in both cities trained a small group of volunteers to participate in a neighborhood speed watch program. The police reported that, although the concept of a neighborhood speed watch is good, the residents of the study neighborhoods did not show much interest once the training was completed. In Peoria, apparently a fair number of people signed up for training but, except for one resident, no reports documenting their efforts subsequent to the training were submitted to the police department. In fact, only the one resident in Desert Harbor actually made speed measurements, and that person was still making the measurements after the program ended. He felt that the neighborhood speed watches were good at reducing speeds. Police representatives reported that it is good to offer the training as a tool, but there may be better ways to use resources. This is especially true because most departments will have to invest in additional portable radars in order to support neighborhood speed watches.

Some neighborhood representatives reported that a speed watch "is not my job." They considered it to be a police function and that photo radar should be used instead. ${ }^{15}$ Residents reported that they did not actually make speed measurements after being trained to do so because they could not find another person to work with as called for in the protocol. They also noted that it was not fun anymore after the initial training. Other respondents felt that speed watches should be included in a model program since they teach people who the speeders are and that the problem may not be as big as it is perceived to be. Speed watches get the speeders and educate the neighborhood.

\footnotetext{
${ }^{15}$ In Phoenix, photo radars or other automated speed enforcement techniques are not permitted at all locations and are limited to school zones at the direction of the City Council.
} 


\subsubsection{Police Enforcement}

Peoria focused the first two weeks of police enforcement only in Bell Park. They then concentrated on $91^{\text {st }}$ and $95^{\text {th }}$ Avenues, and finally went back to Bell Park. They went out during rush hours and stopped as many speeders as they could. In Phoenix, assignment of neighborhoods was random. They tried to improve police visibility so they tried to be out there at rush hour and at school lunch time. They saturated the entire neighborhood in an attempt to get as much education out as possible.

The police liked the idea of stopping people for speeding but not ticketing them except in extreme cases because of the time it takes to issue and process a ticket - although some felt it was important to "hit them in the pocketbook." They noted that warnings could effectively be used the first week of a campaign, and that no one going 5 to 10 miles over the posted speed should be ticketed just for speeding. The courts in the area are not heavily overloaded, but any massive increase in speeding citations could tip the scales. It was noted that the Phoenix City Council likes a warning phase for programs of this type - it makes the program more acceptable to the public. It was noted that speeders just over the speed limit who receive warnings are not the problem.

Police reported that the forms provided by the project were easy to complete and were filled out on virtually all stops. During the stops, some officers gave a little talk on Heed the Speed, some read information to the driver from the flyer and some used data in the flyer to show how long it would take for the driver to stop at the speed the driver was traveling. Police liked the literature-education phase and the ticket concept for an established (not a transient) neighborhood.

Police felt the following should be added to this study's police stop form if it were ever to be used again as part of a Heed the Speed evaluation:

- Posted speed

- Actual speed

- Type of ticket(s) issued (e.g., speeding, lack of insurance, etc.)

- Any unusual activity.

Near the end of the study, police reported that people were aware of the program. They saw changes in the roadway. Some people stopped and asked how to get the program in their neighborhoods. Some asked if they could get something for the officers (like breakfast) and thanked them for being there. The citizens appeared to appreciate why the police were there. There were lots of "thumbs up" as cars drove by. Officers felt that education should be included to get the community interest.

Both police and neighborhood representatives felt that it would be a good idea to double the fine for speeding in residential neighborhoods as is done in road work zones in many states. An area could be designated as a Heed the Speed neighborhood for double fines. It would need to be done through the legislature or as an administrative action of the motor vehicle authority depending on the particular state. It was noted that the big financial impact of a ticket is the resulting increase in insurance rates. The cost of the fine is small compared to long-term increases in insurance rates. 
Neighborhood representatives found the police involvement to be very good and felt that the police stops decreased speeds. Some felt that all resources should be given to enforcement. In addition, they recommended that a police car be parked on the street on a regular basis.

\subsubsection{Signs}

The yellow program lawn signs were reported to be very conspicuous and to contribute to program awareness. At the beginning of the program many signs were displayed, but their use tapered off. Some just disappeared - particularly at Halloween. Keeping them up was a challenge. Use appeared to vary by neighborhood and seemed to be positively correlated with the presence of a strong neighborhood association. Phoenix and Peoria representatives were still getting requests for them long after the program ended. Neighborhood representatives liked them. They reported that their visibility is good, they are lightweight and easy to carry around, they are legible, they have a clear message and the quality and appearance are "great." It was recommended that the signs be moved around occasionally because after a while people don't see them when they remain in the same place. Children loved them and took them to school for "Show and Tell."

Neighborhood residents liked the metal street signs at the entry points to the neighborhood but would have preferred them to be more eye-catching so that they would stand out from other traffic signs. Some felt that they should be yellow to match the lawn signs. It was suggested that they be larger and more conspicuous. Also, some residents said they would like more of them. Police representatives also reported that they would like more of them. They said that, if a sign is there when the officer is writing a ticket or explaining the program, the officer can point to it.

\subsubsection{Other Publicity}

Comments on other publicity were varied. Some thought the printed materials were "great," one said they were not very effective, and one said he hadn't seen any of them but had seen an article in the newspaper. One neighborhood coordinator found them to be "good basic materials." That person found the material for car dealers to be the most helpful and claimed to have noticed a big decrease in test drives in the neighborhood after the flyer (that was designed specifically for car dealerships) had been delivered. The materials were reported to be worthwhile particularly in making people aware of the speeding problem. One neighborhood coordinator received permission from the school board to distribute materials to the children to take home to their parents. That person felt that, if the children are educated, the parents will follow. One coordinator paid children to deliver the program materials in the neighborhood.

\subsubsection{Traffic Calming}

At the start of the program, there were existing speed humps on $85^{\text {th }}$ Lane in Peoria and on Clarendon Avenue in Phoenix. Added as part of the Heed the Speed program were speed tables on $84^{\text {th }}$ Avenue in Peoria and speed humps on Moon Valley Drive in Phoenix. Comments on these traffic calming techniques were positive. They were installations that had been requested by neighborhood residents and had been approved through a prescribed consensus process. 


\subsubsection{Roadway Visual Treatments}

The committee felt that the 3-D markings and Tyregrip ${ }^{\mathrm{TM}}$ installations probably had no effect on speed except for the first time they were observed. Curiously, this opinion is not supported by the speed data which show some persistence of effect, although the follow-on measurement period is not very long. Neighborhood representatives confirmed this observation. They reported that the illusions fooled people for a while. One resident reported that they may have worked for about a week. One said they caused a few near rear-end collisions. Some drivers swerved to avoid them. Neighborhood residents did not see people slowing down for Tyregrip ${ }^{\mathrm{TM}}$.

Both the committee members and neighborhood representatives stated that these roadway treatments drew attention to the program. Suggestions were made to replace these treatments with striping or possibly road reflectors that make a noise when a vehicle goes over them. It was also noted that, if yellow is used in the signs, it also should be used in the roadway treatments. The word "SLOW" could be written in the road.

It was noted by engineering representatives that roadway treatments might beneficially have been incorporated earlier to draw attention to the program. These treatments were applied late in the program and were labor intensive. Certain directions of light caused glare and affected how the 3-D markings were noticed. Possibly a different pattern and more markings in the pattern would have been a better choice. Possibly signs could have been placed beside them as warnings that they were there.

It must be noted that these comments were made in the absence of the speed results presented earlier. It would be interesting to determine if some of these opinions might change after exposure to the speed findings. In particular, there is an apparent persistence, at least short term, of the speed reductions associated with the roadways visual treatments beyond one or two exposures. This may suggest that these markings produce two different effects. At first they trick the senses into believing there is an impediment in the roadway that requires a reduction in speed. After the motorist becomes familiar with them and realizes they do not impede motion, they may still serve as a reminder that the neighborhood is actively attempting to control speeds. This is supported by the compelling visual signal presented by both the 3-D and Tyregrip ${ }^{\mathrm{TM}}$ materials even when the viewer knows they are present and is aware of what they are.

\subsubsection{Program Suggestions}

Several suggestions were made for program materials/concepts in future Heed the Speed efforts. These included:

- It would be helpful to have a video to show on local TV that demonstrates the consequences of sudden stops due to excess speed, e.g., rear-end collisions.

- Possibly a different slogan should be used for Hispanic communities since Heed the Speed loses its alliterative character when translated.

- All program countermeasures should be implemented at once.

- There should be more police involvement. 
- There is a need for a train-the-trainer guide that contains both how-to and content. The information could be put on a pamphlet or in a CD-ROM. It is helpful to have all materials in one package. It would be good to "come back again" with different angles, e.g., e-mail, signs, video, neighborhood-oriented press release, etc.

- The program needs a maintenance schedule. Otherwise, speeding will go back to where it was.

\subsubsection{Citizen Comments}

The following comments were made by neighborhood residents:

- Speeds have decreased in the neighborhoods, particularly high end speeds. There has been no change in volume. Complaints have gone down.

- There are many neighborhoods that have requested the program.

- The program brought the community together - got them talking.

- The best part of the program was the police involvement and the signs.

- Overall the program was good and the program worked.

- The most important part of the program was increased enforcement.

- Presentations of police and street transportation representatives at homeowner's association meetings were very effective.

- Police were noticed many times - police were wonderful.

- Best parts of the program were the speed humps and the police. Also the signs were great.

- The overall program was good. There was a net benefit to the neighborhood. It was the "first time the neighborhood ever got anything done."

- Speeds were reduced by speed humps and the police.

- It's hard to keep people motivated. We would like to keep the program going. 


\subsubsection{Process Data Summary}

The Heed the Speed program elicited mostly positive and constructive comments from both those who helped mount it and the citizens it affected. Together with the survey data presented earlier, these follow-up commentaries on the process suggest that the concept of a multi-disciplinary, multi-faceted neighborhood speed reduction program is well accepted and can likely be improved in future implementations based on the experiences in Phoenix and Peoria and the suggestions made by the participants and citizens. 


\section{DISCUSSION}

The primary objective of the present study was to develop and test a behavior based program to reduce motorist speed in residential areas by adding education and enforcement to engineering. The Heed the Speed program that was mounted consisted of education, special police enforcement, application of innovative pavement markings and conventional vertical traffic calming treatments. It was evaluated by two waves of a knowledge and opinion survey, police data collection during stops for speeding and up to five waves of 48-hour speed measurements.

\subsection{General Results}

In addition to demonstrating speed reductions, in order to conclude that the Heed the Speed program was effective, it is necessary to show that one or more of its components was applied with sufficient intensity to yield a speed reduction. Further, it must be shown that the affected populations in the six test neighborhoods were aware of the countermeasures and likely responded to them. Thus, positive survey and process results are necessary for a conclusion that any observed decreases in the speed data were the result of Heed the Speed efforts.

The process data clearly indicate that the program countermeasures were applied with sufficient vigor to have been noticed by the residents of the test neighborhoods. The large number of police stop reports and high quantities of literature and signs distributed as well as the physical changes applied - both new vertical treatments and 3-D and Tyregrip ${ }^{\mathrm{TM}}$ markings - are compelling evidence of the activity levels of the Phoenix and Peoria Heed the Speed programs. This was confirmed by the survey results that showed large increases in awareness and in the perception that neighborhood speeds had moderated.

In the context of the survey, an additional point is noteworthy. The survey response rate of almost 61 percent is extremely high for a mailed questionnaire, particularly one addressed to "Resident." This is likely the result of a strong prevailing interest in traffic safety in general and speed management in particular among those dwelling in the test neighborhoods. This is not surprising as the participating cities selected the test sites based on previously expressed interest in achieving a speed reduction.

The number of police stops, both with and without the issuance of citations for speeding, suggests that the increased awareness of police activities can be attributed to Heed the Speed. It is unfortunate that there is no accurate record of the patrol hours assigned to each test road segment as that would have supported a more detailed examination of the relationship between increased enforcement presence and speeding.

The police stop data provide two other interesting findings. First, the vast majority of those stopped for speeding were residents of the test neighborhoods or regular users of its streets. This dispels any notion that aberrant speeding behavior stems primarily from outsiders who do not have a stake in the safety of the neighborhoods through which they travel. It also suggests that localized programs such as Heed the Speed can be effective because most of the targeted drivers will be exposed repeatedly to any deployed countermeasures. 
The second interesting finding from the police stop data is the high rate of safety belt use. It is counterintuitive and contrary to much of the safety literature to find 85 percent safety belt use among drivers who are speeding. The neighborhood locale of the stops and the relatively high socioeconomics of the test sites may have contributed to the high observed safety belt rate. Regardless of its origin, however, the existence of such a high safety belt use rate suggests that the target population for speed countermeasures, at least in residential neighborhoods such as the six used in this study, is likely safety conscious and desirous of being law-abiding. Thus, safety messages and the other types of activities employed by Heed the Speed should be more influential with this group than with a population less concerned with safety.

\subsection{Effect of the Heed the Speed Program}

The results presented earlier show conclusively that Heed the Speed produced significant changes in speeding behavior in the six test neighborhoods. Nine of the 10 individual road segment analyses showed statistically significant and operationally meaningful reductions in speed after the application of the Heed the Speed countermeasures. The one segment that did not show a reduction, $85^{\text {th }}$ Lane in Peoria, had baseline mean speeds almost $5 \mathrm{mph}$ below the speed limit.

On all nine segments that showed speed reductions, speeds (compliance with the limit and speeds 7+ over the limit) were still statistically lower than prior to the Heed the Speed countermeasures at Wave 5, almost five months after the program began.

\subsection{Effect of Individual Countermeasures}

The design of this study was not intended to isolate the effects of the individual countermeasures employed. Rather, the objective was to mount a multi-pronged effort focused on achieving speed reductions in the test neighborhoods. The realities of the implementation of the Heed the Speed program, however, afforded some insights into the effects of some of the individual interventions. This was because the various countermeasures were phased in as they were ready while periodic speed measurements were being made. The discussion that follows refers back to the speed data by test segment contained in the tables in Section 5.3.3. The focus in this discussion will be on mean speed changes since the other speed measures appeared to be consistent with changes in the average observed speed.

\subsubsection{Enforcement Alone}

There were no pre/post speed measurements collected when the only intervention mounted was enforcement. Several education measures, such as the traffic and lawn signs, were implemented at the outset and therefore were coincident with the special enforcement efforts. The survey and follow-up discussions with neighborhood leaders, however, suggest that the enforcement effort was visible and appreciated by the residents who were interested in better control of speeds. The large number of stops recorded also supports a conclusion that the enforcement efforts contributed meaningfully to the speed reduction results achieved.

Although not in total isolation, enforcement was a primary countermeasure in operation at the Clarendon Avenue test site in Phoenix. This neighborhood had no organized residents' association, and the predominance of Spanish-speaking residents limited the penetration of some of the educational materials. Thus, the reduction of approximately $2.5 \mathrm{mph}$ in mean speed 
between the speed humps on Clarendon can be largely attributed to the special police enforcement and its deterrent effect.

The Peoria police used essentially a neighborhood rotation approach to enforcement while Phoenix employed a more random deployment. The evaluation data do not provide any clear insights on which of these approaches is preferable. Perhaps a combined strategy in which there is a strong effort followed by random "boosters" would be best.

\subsubsection{Education Alone}

As with enforcement, there was no "pure" application of education in the test. The closest situation was likely the change between Wave 1 and Wave 2 at both $91^{\text {st }}$ Avenue and $95^{\text {th }}$ Avenue in Peoria. During this period, the Peoria police were focusing their enforcement primarily on $84^{\text {th }}$ Avenue in Bell Park. Taking this view, the education efforts on $91^{\text {st }}$ and $95^{\text {th }}$ Avenues can be credited with the observed reductions of $1.283 \mathrm{mph}$ and $1.369 \mathrm{mph}$, respectively, in mean speeds and reductions of 37.8 percent and 45.9 percent, respectively, in the percent of drivers going $7+\mathrm{mph}$ over the speed limit. It is therefore reasonable to conclude that the Heed the Speed education materials contributed positively to the overall program effectiveness.

\subsubsection{Education and Enforcement Together}

The data provide many replications of wave-to-wave speed measurements in which the operative countermeasures applied over the transition were education and enforcement in combination. These were the only countermeasures deployed at the outset of Heed the Speed because there was a delay in achieving the installation of the planned vertical treatments and innovative street markings.

The combination of education and enforcement only failed to yield a significant speed reduction in one instance - between Waves 1 and 2 at $84^{\text {th }}$ Avenue in Peoria. This may have been a result of the almost single-minded focus of the neighborhood leaders on getting speed tables installed as soon as possible. As a result, they devoted most of their effort to lobbying the city rather than on distributing literature to the neighborhood. In all of the other cases in which education and enforcement operated alone, a significant mean speed reduction was achieved. The largest observed decline in mean speed under these conditions was $3.610 \mathrm{mph}$ on Sweetwater Avenue in Phoenix between baseline (Wave 1) and the next measurement wave (Wave 4). The smallest (but still statistically significant) decline in mean speed for education and enforcement alone was 0.693 mph observed between the baseline (Wave 1) and second measurement wave (Wave 4) on the North/South segment of Moon Valley Drive in Phoenix.

These results lead to the conclusion that combining education and enforcement can provide synergism under the proper conditions. The decline in mean speed in excess of $3.5 \mathrm{mph}$ on Sweetwater is similar in magnitude to the reductions achieved by vertical treatments, although likely not as enduring. It is greater by far than what was apparently achieved by either education or enforcement alone.

\subsubsection{Vertical Treatments}

The study included two new installations of vertical roadway treatments - speed tables on $84^{\text {th }}$ Avenue in Peoria between Waves 2 and 3 of the speed measurements and speed humps on 
the North/South segment of Moon Valley Drive in Phoenix between Waves 4 and 5. The former was associated with a drop in wave-to-wave mean speed of $3.163 \mathrm{mph}$ while the latter wave-towave reduction was $2.540 \mathrm{mph}$. It must be remembered that these reductions are in addition to any changes in speed from the previous waves. On $84^{\text {th }}$ Avenue, there was no significant change in speed from Wave 1 to Wave 2. On Moon Valley, however, there was a significant drop of $0.693 \mathrm{mph}$ in mean speed from baseline (Wave 1) to Wave 4 (the first wave after the program start). Thus, the $2.540 \mathrm{mph}$ decline after the installation of the speed humps was actually a total mean speed reduction of $3.233 \mathrm{mph}$ from baseline.

It is not surprising to find that vertical engineering treatments are effective in achieving traffic calming. This has been reported before (e.g., Ewing, 1999). Their application within this study, however, provides both a replication of the effects reported in the literature and a benchmark against which to compare the other countermeasures used.

\subsubsection{Innovative Pavement Markings}

The study employed two types of innovative pavement markings - 3-D markings and Tyregrip $^{\mathrm{TM}}$ surfacing. The phasing of the installations provided some opportunities to examine the additive effects of these materials in some degree of isolation.

The 3-D marking was the only physical change installed on $85^{\text {th }}$ Lane where there was no significant change in speeds as discussed earlier. The baseline speeds on this quiet road were so low, that no reasonable speed reduction approach could be expected to work. The same material, however was installed on $95^{\text {th }}$ Avenue in Peoria and on the East/West segment of Coral Gables Drive in Phoenix after Wave 2 of measurements. For $95^{\text {th }}$ Avenue, the first available postinstallation measurement was Wave 4 because of a failure of the data collection equipment during Wave 3. The Wave 4 measurements show a statistically significant decrease from Wave 2 of $0.564 \mathrm{mph}$ on top of the previously observed decline of $1.369 \mathrm{mph}$ for a total reduction in mean speed of $1.933 \mathrm{mph}$. On Coral Gables, the decline after Wave 2 is $0.215 \mathrm{mph}$ on top of the $2.174 \mathrm{mph}$ decline observed between Wave 2 and baseline (total decline of $2.389 \mathrm{mph}$ ). The apparent effect of the 3-D installation, however, continues to climb with an additional reduction of $1.777 \mathrm{mph}$ in mean speed from Wave 3 to Wave 4 for a total Wave 4 reduction of $4.166 \mathrm{mph}$.

The Tyregrip ${ }^{\mathrm{TM}}$ material was installed between Waves 4 and 5 of speed measurement on three test segments in Phoenix - Sweetwater Avenue and both segments (East/West and North/South) of Coral Gables Drive in Phoenix. On Sweetwater, Wave 5 showed slightly higher mean speeds than Wave 4 but was still $3.213 \mathrm{mph}$ below baseline (Wave 1). Although no additional speed reduction was achieved, the Tyregrip ${ }^{\mathrm{TM}}$ installation may have slowed a return to higher speeds by keeping the increase to $0.397 \mathrm{mph}$. A similar phenomenon was observed on the East/West segment of Coral Gables Drive where a small $(0.489 \mathrm{mph})$ increase in mean speed was observed after Tyregrip ${ }^{\mathrm{TM}}$ was installed. It must be remembered that this segment was already associated with the previously discussed decline of $4.166 \mathrm{mph}$ and the prior installation of 3-D markings.

Perhaps the least confounded test of the Tyregrip ${ }^{\mathrm{TM}}$ material took place on the North/South segment of Coral Gables Drive. On this test road where Tyregrip ${ }^{\mathrm{TM}}$ was the only installed physical change, it was associated with a mean speed reduction of $1.045 \mathrm{mph}$ from Wave 4 to Wave 5 (1.470 mph decline from baseline). 
Based on these findings, it is reasonable to conclude that innovative pavement markings such as the ones tested as part of Heed the Speed are a viable addition to the speed reduction techniques available to program managers and merit serious consideration, particularly when used in combination with other types of speed reduction countermeasures. It might have been even more effective to integrate the innovative markings more closely with the remainder of the program, particularly the education materials. This could help give the innovative markings a dual purpose as both the illusion of an impediment in the roadway and as a symbolic reminder to slow down.

\subsection{Countermeasure Persistence}

The present study was only able to examine very short term persistence of the countermeasures. Even over this limited period there were conflicting findings. In four of the nine successful tests mean speed reductions were higher in the last measurement wave than in any of the preceding waves. In the remaining five tests, the last measurement represented some increase in speed from the lowest mean value obtained. In one of these five, although the last wave was not the slowest, it was significantly slower than the immediately preceding wave.

This pattern of results suggests that the present study simply did not have a good view of countermeasure persistence - short, intermediate or long term. New countermeasures were still being implemented on test segments just prior to the last speed measurement. Comments from the members of the Heed the Speed steering committee indicated that they believed reapplications of enforcement and education would be needed to sustain their effects. The consensus was that the vertical treatments would continue their effectiveness as they represent a true physical barrier to excess speed. Feelings were split with respect to the innovative markings. Some believed their effect would fade rapidly as motorists learned that they were merely illusions and not true barriers. Others felt that they would continue to have some effectiveness as a reminder that the neighborhood was trying to control speeds. Additional research would be needed to yield a definitive resolution of how long Heed the Speed continued to be successful.

\subsection{Traffic Diversion}

One potential counterproductive effect of traffic calming is the diversion of traffic to neighboring streets that have not been calmed. This is a natural behavior as drivers seek the path of least resistance to get to their destination quickly. In this study, there was no consistent pattern of reduced traffic flow after the implementation of any of the types of countermeasures deployed. Traffic on a few road segments went down while traffic on others increased. Most importantly, however, in the context of the current research is the clear finding that the speed reduction results observed could not possibly have been the result of diversion of higher speed traffic. Simply, in all cases, the reduction in cars going $7+m p h$ over the limit was either in excess of any concomitant decrease in traffic volume or so large that it would have necessitated all or most of the fastest vehicles to have been diverted. Thus, while there may have been some minor diversion, particularly on $84^{\text {th }}$ Avenue in Peoria after the installation of speed tables, there is no reasonable possibility that this diversion confounded the speed results reported herein.

It is also worth noting that no speed measurements were taken on the streets bordering the 10 test segments. It is theoretically possible that the fastest drivers simply changed their travel routes to avoid the enforcement activities or physical changes on the test segments. 
However, since there was not a major reduction in traffic volumes, this hypothesis could only be supported by a net increase in traffic in the test neighborhoods together with a significant diversion of high speed drivers from the test segments. The process data and anecdotal reports from the police strongly suggest that this did not happen. In particular, it must be remembered that survey respondents were drawn generally from the six neighborhoods and not just from the streets that were test segments. These survey respondents generally reported that they perceived lower speeds in their neighborhoods. It is likely that at least some responses would have noted a shift in the locus of speeding if, in fact, one had occurred.

\subsection{Safety Implications}

It is of interest to attempt to assess the safety benefits of the observed speed reductions. Unfortunately, as discussed in Section 2.1.2, there do not appear to be any simple formulas for estimating either crash reduction or the lessening of injury severity that will result from lowered vehicle speeds in residential neighborhoods. Even the fatality probabilities cited from the study in the United Kingdom (Department of Transport, 1997) cannot be directly applied to aggregate data such as those collected by this study because they only deal with the conditional case in which a crash has occurred. Although the current study documented a significant and operationally meaningful reduction in the number of vehicles traveling at the highest speeds on the test segments, there is no way to estimate how many of these vehicles would actually have been crash-involved. Any such estimate would have to include consideration of many other factors such as the environment on any particular street (e.g., the existence of visual screens, the prevailing speeds before the application of countermeasures). It would also have to include some measure of the likely pedestrian behavior on the street and the age distribution of the pedestrians.

The absence of any formulas to translate shifts in the speed distribution of vehicles to crash and injury effects means that any safety implications must necessarily be subjective. One way to accomplish this is by determining which of the previously proved conditions for safety improvements were, in fact, achieved by Heed the Speed. For example, Tester et al. (2004) showed that the speed reductions associated with traffic calming engineering treatments were associated with reduced child pedestrian crash risk. The level of speed change studied by Tester et al. (2004) was likely achieved on $84^{\text {th }}$ Avenue in Peoria and the Moon Valley North/South segment as a result of the installation of speed tables or speed humps. Likewise, speeds on Clarendon were reduced below what had been achieved from speed humps alone. Even $85^{\text {th }}$ Lane in Peoria, although its speeds did not change during the study, was already at a calmed level and therefore met the conditions studied by Tester et al. (2004). Thus, at least four of the test segments achieved or exceeded the speed reduction proved to alter child pedestrian crash probability favorably.

The balance of the test segments also exhibited significant speed reductions. In at least two cases (the East/West segment of Coral Gables and Sweetwater) the reduction in mean speed was even greater than on the segments that had been calmed with engineering changes, but the starting mean speeds were also notably higher. Based on the findings of Kallberg (1997), it would appear likely that these segments would also have experienced reductions in both crash probability and resulting injury severity if a crash did occur.

In summary, while there is no readily apparent way to make a quantitative estimate of the safety benefits of the Heed the Speed efforts, the guidance from the literature suggests that the 
results were of a sufficient magnitude to yield meaningful reductions in both pedestrian crash risk and likely injury severity if a crash occurs. Since the desirable speed changes obtained typically involved thousands of vehicles per day on each segment, it is reasonable to conclude that safety was enhanced. It is also noteworthy that the evidence from Kallberg (1997) and Lindenmann (2004) among others is that the speed reduction effects would also have yielded a safety benefit for all traffic crashes on the treated road segments not just pedestrians.

\subsection{Lessons Learned}

The answer to the basic research question addressed by this study is that education and enforcement can add to the effectiveness of physical traffic calming. It was also shown that at least in the short term a program such as Heed the Speed can produce speed reductions of a significant and meaningful magnitude on through streets and other roads within traffic calmed areas that were not candidates for physical treatments.

In the process of conducting this study, several principles emerged that appeared to be strongly associated with the success of Heed the Speed. These were:

- A multi-disciplinary steering committee of individuals who truly believe in the benefits of reducing speeds in neighborhoods is essential. This committee must have representation from enforcement, engineering, and public relations and be fully supported by the local government.

- For maximum impact, it is beneficial to have a well-organized and firmly committed neighborhood organization in any community where the program is to be applied.

- Yard signs can be effective in getting the word out to residents, but participating homeowners need to be cautioned about potential vandalism and spare yard signs should be provided.

- Using special enforcement stops for speeding as a way to train new police officers in the techniques for making traffic stops provides an additional benefit from the program.

- Multi-lingual education materials are essential in communities where there are significant subgroups of non-English-speaking residents.

- Addressing special groups such as car dealers or high school students can be productive and is worth the effort if there are data to indicate they may be part of the problem.

- If the program is going to have a limited duration, implement all countermeasures together whenever possible.

- In order to potentially give the program extended life after the major enforcement, education, and engineering countermeasures have waned, include some aspect that is durable in the environment. This was accomplished in Heed the Speed by including the fixed street signs that were left in place. 
- Consider the use of innovative approaches such as the pavement markings employed during Heed the Speed. If these types of approaches are used, integrate them as completely as possible in the program's education material at the inception of the program.

- Consider including a long-term plan for continuing to monitor and control speeds after the initial campaign. This should overcome any regression to the mean types of phenomena.

- Include multiple, longitudinal speed measurements as part of the effort. These will provide valuable feedback on program effectiveness. The survey for this study also suggested that the deployment of speed measurement tubes is noticed and may even serve as a countermeasure by itself.

\subsection{Guide for Future Heed the Speed Programs}

The lessons learned from this research application of Heed the Speed have been turned into a guide for future program implementations. This Guide is included as Appendix $\mathrm{F}$ to this report. It is important to view the recommendations in the Guide in the proper context. In particular, the application of Heed the Speed in six separate neighborhoods in two cities as part of this research clearly showed that localization is of the utmost importance. For example, although there was a clear benefit to the availability of an active neighborhood group, significant improvements were obtained even when there was no active community body. Therefore, it is prudent to work with the available resources and adapt Heed the Speed rather than attempting to change the local organization to meet any strict definition of a Heed the Speed implementation.

All of the tests in this study were guided and overseen by local representatives from the engineering, enforcement, and education communities. Thus, for example, even when new engineering was not implemented, the countermeasure planning process had the benefit of engineering input. This multi-disciplinary focus appears to have been one of the factors that contributed to the success of the Peoria and Phoenix Heed the Speed implementations. The question therefore arises whether the involvement of all three disciplines is a necessary condition for future Heed the Speed implementations. This is difficult to answer in the absolute. On the one hand, a broad base of experience and resources should aid success. On the other hand, there almost certainly will be locales in which a viable speed reduction program can be implemented without one or more of the central disciplines. For example, a strong enforcement program by itself should result in a reduction in speeding even if it is not as effective as the same enforcement effort coupled with education and/or engineering countermeasures.

Perhaps the most universal advice for using the guide is, therefore, to begin the entire process with a catalog of local resources. While the ideal is for every relevant discipline to join willingly and eagerly in Heed the Speed efforts, the reality is that local conditions will vary widely. As long as some involved group - citizens, enforcement, engineering or safety education - is eager to proceed, a successful Heed the Speed program is likely possible. Soliciting the help of all of the other participants, however, is clearly desirable and should be attempted. Once all of the players are identified and fully committed, the information in the Guide in Appendix F can be viewed in the proper context and adapted appropriately. 
This Page Intentionally Left Blank 


\section{REFERENCES}

Blomberg, R.D., Cleven, A.M. Development, implementation and evaluation of a pedestrian safety zone for elderly pedestrians. Final report to the National Highway Traffic Safety Administration, Contract No. DTNH22-90-C-07223, February 1998, Dunlap and Associates, Inc., Stamford, CT. Report No. DOT HS 808692.

Boyle, J., Dienstfrey, S. and Sothoron, A. National survey of speeding and other unsafe driving actions: Volume I - Methodology; Volume II - Driver attitudes and behavior; Volume IIICountermeasures, DOT HS 808 748, 808749 and 808 750, 1998.

Cambridge's traffic calming program: Pedestrians are the focus (Watkins). Paper presented at the Institute of Transportation annual meeting, August 2000.

Davis, G.A. Method for estimating effect of traffic volume and speed on pedestrian safety for residential streets. Transportation Research Record 1636, Transportation Research Board, paper 98-1330, 1998.

Department of Transport. Killing Speed and Saving Lives, U.K., 1997.

Ewing, R. Traffic calming: State of the practice. Institute of Transportation Engineers, Publication No. FHWA-RD-99-135, August 1999.

Kallberg, V. Speed can endanger your health. Nordic Road \& Transport Research, Vol. 9 (1997), No.2, p. 9-12. ISSN 1101-5179

Leaf, W.A. and Preusser, D.F. Literature review on vehicle travel speeds and pedestrian injuries. Final report to the National Highway Traffic Safety Administration, Contract DTNH22-97-D-05018, Task Order 97-03, October 1999. Preusser Research Group, Inc., Trumbull, CT. Report No. DOT HS 809021.

Lindenmann, H. P. Safety in numbers. Traffic Technology International. October/November 2004, pp. 94-98.

Managing speed: Review of current practice for setting and enforcing speed limits.

Transportation Research Board Special Report No. 254, National Research Council, National Academy Press, Washington, DC, 1998.

National Highway Traffic Safety Administration. May 2003 Click It or Ticket safety belt mobilization evaluation. Final Report available at universal resource locator (URL) http://www.nhtsa.dot.gov/people/injury/airbags/clickit_ticke03/ciotreport04/CIOT\%20May\%202003/index.htm.

Navin, F., Chow, K. and Kwan, T. Speed and probability of a crash. Transportation Research Board Paper 01-0532, 2001. 
Organization for Traffic Safety, South Holland County. 3D Roadmarking: Research results of the effects of 3-dimensional roadmarking. Final Report, De Bilt, The Netherlands, May 3, 2001.

Stuster, J., Coffman, Z and Warren, D, Synthesis of safety research related to speed and speed management. Publication No. FHWA-RD-98-154, July 1998.

Tester, J.M., Rutherford, G.W., Wald, Z. and Rutherford, M.W. A matched case-control study evaluating the effectiveness of speed humps in reducing child pedestrian injuries. American Journal of Public Health, (94:4) pp. 646-650, April 2004. 


\section{APPENDIX A \\ LITERATURE REVIEW REPORT}

This memorandum report was prepared early in the study and is described in Section 2 of this report. 


\section{Letter Report \\ Pilot Test of Novel Speed Reducing Program \\ Contract No. DTNH22-99-D-05099, Task Order 2 \\ October 11, 2000}

\section{SUPPLEMENTAL LITERATURE REVIEW}

The purpose of this effort was to update the literature review performed for NHTSA's vehicle speed report (1). It was therefore initiated with a review of the speed report itself. Searches were then made of the Transportation Research Board Transportation Research Information Services (TRIS) database to identify studies published from 1998 to the present on the topics of traffic calming, speed, enforcement, education, and pedestrian safety. In addition, contact was made with selected NHTSA/FHWA representatives, with bicycle/pedestrian professionals, and with contributors to the vehicle speed report to request additional references and materials. Finally, Web sites of cities with known traffic calming programs were accessed to obtain additional reports and information.

In all, over 175 documents were identified and abstracts of each were read. Those for which hard copies were obtained and reviewed are listed at the end of this supplemental review. The subject matter of the reviewed documents ranged widely and included descriptions of specific traffic calming techniques, legal aspects of traffic calming, crime issues, property value issues, and others. Although all hard-copy documents that were received were read, the major interest was in identifying evaluative studies of methods of traffic calming, especially those involving education and enforcement. Very few evaluative studies were located. However, reports that summarized and quoted results of evaluative studies were found and proved useful.

The supplemental research information is based largely on two major documents that were produced since publication of NHTSA's speed report. One is the ITE report on the state of the practice of traffic calming (2). Among other topics, it provides a brief history of traffic calming, a toolbox of traffic calming measures, engineering and aesthetic issues, impacts of traffic management measures, legal authority and liability issues, warrants, project selection procedures, public involvement, traffic calming on other than neighborhood and collector streets, and traffic calming in new developments. Twenty United States traffic calming programs are featured in the document. Specifications proposed by certain jurisdictions or professional groups for selected measures are included. A second major input to the supplemental review is the FHWA synthesis of safety research related to speed and speed management (3). That report covers speed-safety relationships, factors influencing speed, speed limits and speeds, speed limits and safety, enforcement and engineering measures.

In the following paragraphs, brief summaries of the information included in the vehicle speed report are presented first and followed by any additional or confirming information obtained from the above two documents and from other materials identified in the supplemental review. A brief summary of the review is included at the end of this letter report along with a listing of the documents reviewed. 


\section{Engineering Measures}

Vehicle speed report: NHTSA's vehicle speed report noted that speed humps can be successful in reducing both average and very high speeds and the result is often a reduction in crashes and crash severity. It noted the problem that humps affect different vehicles (e.g., trucks, buses, emergency vehicles) in different ways. Humps can be perceived as obstructions in the roadway. Roads that are narrower and less straight encourage lower speeds. Speeds through chicanes are reduced. Traffic islands and roundabouts also reduce vehicle speeds and have been shown to improve safety.

Supplementary Information: Additional or confirming information obtained on specific types of engineering traffic calming measures follows.

The ITE (2) report included speed, volume and crash data for many before and after studies in which various traffic calming techniques were used. ITE reported that speed humps have the greatest impact on $85^{\text {th }}$ percentile speeds of all traffic calming measures tested. Raised intersections, long speed tables and circles have the least impact. It reported that an international survey showed that traffic circles and chicanes had the most favorable impacts on safety. Although there are complaints about noise, traffic calming measures actually reduce noise levels. There have been legal threats, lawsuits and damage claims against communities for traffic calming and some jurisdictions have banned them.

FHWA (3) reported that the most effective traffic calming measures involve vertical shifts in the roadway. However, effectiveness is dependent on spacing. Greater reductions in speeds and crashes occur when combinations of measures are implemented systematically over an area wider than a single neighborhood.

The State of Delaware Department of Transportation (59) has produced a traffic calming design manual that provides guidance to state engineers regarding the appropriate use, design, and signing and marking of physical traffic calming measures. It does not cover measures that may improve street appearance (for example, planting streets on the roadway), nor does it cover education and enforcement measures. The manual outlines the procedural steps involved in effecting traffic calming in Delaware including a priority rating system. It describes appropriate volume and speed control measures, provides design guidance for each, and provides guidance on appropriate signing and marking for traffic calming measures

The City of Portland (24) reported that installation of 14 -foot speed humps reduced $85^{\text {th }}$ percentile speeds by $6.9 \mathrm{mph}$ to $25.8 \mathrm{mph}$, and speeds were not increased on parallel untreated streets. Twenty-two foot humps reduced $85^{\text {th }}$ percentile speeds by $8.2 \mathrm{mph}$ to $29.9 \mathrm{mph}$. Traffic was often diverted to collector streets and arterials. Twenty percent of the motorists traveled greater than $25 \mathrm{mph}$ after installation compared to 60 percent of motorists traveling above that speed prior to installation. Reductions in frequency were due largely to reductions in volume. Crashes were reduced 39 percent from 1.39 to 0.85 per year. Crash frequency increased on parallel streets. The crash rate was reduced 5 percent. Injury crashes were reduced 46 percent (a statistically significant reduction). 
The City of Portland (45) joined forces with Recycled Technology in the development of a rubber speed hump. It was designed for use on streets with frequent maintenance needs - it can be easily removed for street resurfacing, worn sections can be removed and replaced, inlaid markings are possible. It also has temporary uses, e.g., to slow vehicles in construction zones or near street fairs where there is high pedestrian activity. It is comparable in effectiveness to the asphalt hump.

The City of Portland (46) tested split 22-foot speed humps spaced 28 feet apart for their effect on emergency vehicles. They created a chicane effect that emergency vehicles could pass around. The split humps were effective in slowing speeds on the roadway without delay to emergency vehicles. The spacing between humps did not seem to influence driver behavior. Especially on high volume streets, drivers showed no tendency to cross over the center line to avoid the hump.

San Antonio (22) achieved an average speed reduction of $12 \mathrm{mph}$ at the hump and $7 \mathrm{mph}$ between pairs of humps on the 10 streets on which 12 -foot speed humps were installed. From questionnaires distributed to residents of the streets involved, the worst features of the humps were reported to be that they were noisy $(19 \%)$, that the height was too low $(18 \%)$ and that there were too few humps (11\%). The best features were that they reduced speed (67\%) and made streets safer $(5 \%)$.

In NHTSA's national survey (20), 78 percent of the respondents reported that "road design changes/speed bumps" were very or somewhat effective in reducing speeding but only 63 percent approved of road changes to reduce speeding.

In a summary report, San Francisco, California, (49) stated that the city had generally positive experiences with chokers, medians, and traffic circles while experiences with speed bumps, diverters, and street closures were less positive. The bumps jolted cars and bicyclists, and the city stopped installing them. The city has installed a few speed humps but there are concerns about proliferation, emergency vehicle delay and traffic diversion. The city's experience with chokers didn't result in much of a speed reduction. Their experience with traffic circles has been limited but fairly successful. No data were given.

In a pilot program, the City of San Leandro, California, (26) installed speed humps on five of six parallel neighborhood streets and traffic circles on five of the six streets. One street did not receive a hump and one did not receive a circle. Results were that noise increased, steeper humps ( 3 inches versus 2.5 inches) were considered better, residents and pedestrians did not like the traffic circles although they reduced speed by an average of $7 \mathrm{mph}$, no differences in vehicle volume were noted, residents who wanted the humps didn't want them "in my backyard," speed complaints on other streets increased when word got around about the speed humps, and a citywide policy is needed before traffic calming measures are installed.

In a series of case studies (31), it was shown that several jurisdictions have received complaints about traffic calming measures, particularly speed humps. Resentment is almost nonexistent on humps of height less than three inches. Some overly aggressive programs have resulted in a single lane for two-way traffic. 
In a survey (28) of agencies using traffic calming measures, speed humps were the most widely used and elicited mixed reactions - some used them successfully, some used them initially and then had them removed, some had policies against them. There were no reported crashes or litigation on use of the device. Street closures caused problems including emergency vehicle access, segregation of communities, minor crashes and litigation. There were no reported safety or legal concerns with traffic circles, diverters, and roundabouts. Gates were the least used of the devices.

A study of Watts and Seminole Profile speed humps (37) suggested variations in dimensions suitable for bus and non-bus routes having posted speeds of 30,40 , and $50 \mathrm{~km} / \mathrm{h}$.

Cambridge (7) created chicanes by shifting parking from one side of the street to the other. At a raised intersection and at a raised crosswalk, speeds were reduced and the number of drivers yielding to pedestrians tripled. In addition, Cambridge replaced a traffic light with curb extensions and a raised intersection because drivers were always trying to beat the light. Most residents found it a safety improvement.

Lakewood, Colorado, (8) changed a straight section of roadway. A bicycle lane was converted to a sidewalk. A series of medians and curbside islands were constructed to create a narrow serpentine alignment. Eighty-fifth percentile speeds were reduced. The project did not make the roadway any more or less safe.

ITE (2) reported crash data for various types of traffic calming measures. By far the most impressive data were reported for the City of Seattle which installed circles at 113 intersections. There were 185 intersection crashes in the calendar year before the circles were installed and 11 in the calendar year after installation - a 94-percent reduction. Crash data for circles installed in other jurisdictions involved eight intersections or fewer and were less impressive than the Seattle data and sometimes showed a crash gain after installation. Crash data were also reported for humps (12 feet) that were installed on 19 roads in Omaha, Nebraska, and 15 roads in Montgomery County, Maryland. Before and after data for Omaha showed a 33-percent increase (from 30 to 40) in crashes after installation of the humps. The data for Montgomery County showed a 40-percent reduction (from 15 to 9) in crashes after installation of the humps. Data for other jurisdictions and for one other traffic calming measure (22-foot tables) involved installations on five or fewer roads; some showed increases and some decreases in crashes.

After complaining about cut-through traffic, two Michigan (27) communities conducted a joint survey and learned that less than 7 percent of the traffic was cut-through traffic. They then decided not to institute any traffic calming measures. The author states that when citizens complain, the response is sometimes a placebo (e.g., stop signs, speed humps or bumps, or "changes in road geometry to make the road less safe, so motorists will reduce speed").

In New Mexico (29) the average speed at a temporary mid-block island on a paved street was $25 \mathrm{mph}$ and the $85^{\text {th }}$ percentile speed was $33 \mathrm{mph}$ compared to $41 \mathrm{mph}$ and $48 \mathrm{mph}$ on the same street without the island. On an unpaved street with a mid-block island, the average speed was $18 \mathrm{mph}$ and the $85^{\text {th }}$ percentile speed was $23 \mathrm{mph}$ in comparison to $28 \mathrm{mph}$ and $34 \mathrm{mph}$ without the island. It was concluded that the islands were slowing speeds as effectively as the humps that were located on nearby streets. 
Idaho (30) reported on a three-year effort to plan for speed control in Boise subdivision designs. The proposed street width was 29 feet but, since homeowners were concerned about narrow streets, developers usually used 32 feet as the width. The local traffic calming program called for road humps a minimum of 600 feet apart. With that as the goal for a maximum sight distance, the desired street curve radius was set at 350 feet. Chokers creating a 28 foot street width had no effect on speed. Restrictions down to 20 feet were required before any appreciable speed reduction was noted. Chokers caused problems for larger vehicles, improved visibility for drivers and pedestrians, and decreased pedestrian crossing time. A revised plan relocated chokers to mid-block locations which reduced speeds without impacting corner turning radii. Median islands had similar impacts. Limited data available on block length show minimal speed differences for long and short block lengths.

A summary of traffic calming support provided to a region of Connecticut (32) involved identification of "best practices" in traffic calming, conduct of workshops involving citizens and public officials, and interviews with available local staff. Three case studies were analyzed and a final report was prepared that included a toolbox on traffic calming. The effort also involved development of a traffic calming ordinance.

The Victoria Transportation Policy Institute (23) referenced articles in the Journal of Visual Impairment and Blindness that noted that some traffic calming measures may cause problems for blind people. These include raised crosswalks when there is no detectable warning and neckdowns. The journal also noted that roundabouts may be more difficult for the blind because traffic is not straight and there are no regular breaks in traffic flow.

The Local Government Commission Center for Livable Communities (58) is preparing a summary of the effects of various traffic calming techniques on emergency response times. Solutions are proposed. Those techniques reported to cause minimal or no delay are speed pillows, medians, and landscaping. Speed humps cause an average delay of 6 to 11 seconds.

\section{Roadway Perceptual Features}

Vehicle speed report: The NHTSA speed report did not cover perceptual features of the roadway except for a study on use of transverse lines which showed that speeds were reduced initially, but the effects wore off in three weeks.

Supplementary Information: Additional or confirming information on these perceptual features follows.

ITE (2) reported that results from Howard County, Maryland; Beaverton, Oregon; and San Antonio, Texas, have shown that vehicle speeds are as likely to increase as decrease with centerline or edgeline striping. However, the report noted that, even with the decreased widths, "pavement and lane widths remained substantial." Speeds were unaffected in Orlando, Florida, where widths were taken down to nine feet. Portland, Oregon, used them in combination with other physical measures (speed humps and chokers) and got good results. Portland created a bicycle lane. 
The Victoria Transport Policy Institute (23) reported that a study of 20,000 residentialarea automobile crashes found that annual crashes per mile increased as street width increased beyond 24 feet between curbs, particularly on straight streets with low traffic volumes where average traffic speeds tend to be highest. Crash rates were approximately 18 times higher on a 48 -foot wide street than a 24-foot wide street.

Smithfield (RI) (60) reported having two-way two-lane rural roads varying in width from 18 to 22 feet with neither curbs nor berms and open shoulders. The roads were often used as shortcuts, and speeding was common as motorists "hugged the middle." When double yellow centerlines were painted on the roads, motorists were forced to stay right of center and speeding was reduced. No data were given.

In a survey (28) of agencies using traffic calming measures, street narrowing had the most response of all the measures as a device to cause potential crashes and cause the most concern from legal departments.

ITE (2) reported that Eugene, Oregon, had a 5-percent speed reduction with transverse markings placed before a horizontal curve. Howard County, Maryland, had a 12-percent speed reduction with transverse markings.

ITE (2) reported that building setbacks seem to reduce speeds. It noted that street trees may or may not have the same effect.

ITE (2) presented a comparison of subdivision street standards proposed for the Delaware Department of Transportation with AASHTO standards. The proposed standards were based on a design speed of $20 \mathrm{mph}$ for local streets and $25 \mathrm{mph}$ for residential collectors, a 266-inch school bus as the largest vehicle to be accommodated, and priority to be given to pedestrians over motor vehicles. Among others, it recommends lower speeds and narrower road widths than those specified by AASHTO. The rationales for deviating from AASHTO standards are given.

\section{Education}

Vehicle speed report: The vehicle speed report identified no studies that used education alone as a speed reduction measure. Education was usually included as a minor adjunct to enforcement efforts. follows.

Supplementary Information: Additional or confirming information on education

ITE (2) noted the existence of neighborhood safety campaigns that typically consisted of personalized letters or general flyers distributed to residents. However, it found no empirical evidence regarding their impact.

FHWA (3) reported that a large proportion of studies mentioned some form of public information and education (PI\&E). None attributed a significant reduction in speed, speeding, crashes or crash severity to any campaign that was not closely tied to an enforcement or 
engineering program. PI\&E campaigns that accompany law enforcement programs increase positive public impressions toward police and result in safer driving habits.

It should be noted that cities that have established traffic calming programs, for example, Portland, Oregon, require neighborhood approval of a project prior to its initiation and involve residents in the planning process through neighborhood meetings and workshops.

The Safe Roads program (33) is a community traffic safety program in Massachusetts that is concerned with addressing the education and enforcement needs of speed management and transportation safety in general. A citizen speed watch pilot program was initiated on two streets. The program started with a one-month period of education in which citizens reported speeders' license plates and the location of speeding via a dedicated phone line. Law enforcement personnel reviewed each message and sent informational letters to the vehicle owners including a pamphlet on the safety risks of speeding. A loaner program of speed monitoring equipment was included as part of the citizen watch program as were increased law enforcement patrols. Before and after data showed average speed reductions of one and two mph on the two streets, $85^{\text {th }}$ percentile reductions of $5 \mathrm{mph}$ on both streets, and reductions in those exceeding the speed limit of 3.8 percent and 14.1 percent. Reductions in operating speeds were noted nearly three months after the educational campaign. The Safe Roads program (51) continued in the summer of 2000 in three additional communities in Western Massachusetts. Each community was provided with radar equipment and speed boards. Letters regarding the safety aspects of speeding were written by the police to owners of speeding vehicles. Communities erected signs regarding the program (e.g., entering speed zone, radar in use). The program at one of the three communities is still ongoing and data have not yet been analyzed for the three programs.

Boulder, Colorado, (50) has a Neighborhood Traffic Mitigation Program that is initiated with a neighborhood education program. It provides a variety of materials including information for a newsletter, information on how to run a speed watch program, and a neighborhood speed pledge. If speeds are not reduced, enforcement is the second step. Data on the education program were not reported.

ITE (2) reported that, in general, neighborhood speed watch programs have not been effective because speed reductions are small and residents lose interest. A program in Gwinnett County, Georgia - in which data were collected by transportation department personnel, the offending residents were visited personally, names of offenders were published in a neighborhood newsletter, and offenders' memberships in a swim and tennis club were suspended - resulted in a reduction in $85^{\text {th }}$ percentile speeds from $45 \mathrm{mph}$ to $35 \mathrm{mph}$. The program was labor intensive and fell victim to budget cuts. Tempe, Arizona, (47) and Tampa, Florida, (48) reported the existence of such programs.

In NHTSA's national survey (20), “increased public awareness of risks” was ranked by 72 percent of the respondents as very or somewhat effective in reducing speeding. In addition, 83 percent of the respondents strongly or somewhat approved of implementing this countermeasure to reduce speeding although only 40 percent felt it had some or a lot of effect on their driving. 
In NHTSA's national survey (20), only 52 percent of the respondents felt that encouraging citizens to report drivers was effective in reducing speeding. It received the lowest ranking of any of the countermeasures investigated in the survey. Fifty-seven percent strongly or somewhat approved of the countermeasure as a means of reducing speeding.

\section{Enforcement}

Vehicle speed report: The vehicle speed report discussed enforcement studies that involved police presence at specific points (with and without actual enforcement) and use of a variety of equipments including photo radar, radar and laser detectors, speed display boards, vehicle-activated speed reminder signs, and school warning signs. In general, all methods of enforcement were effective in reducing speeds at the time and place they were used, but speed reductions decreased when enforcement stopped. The speed report concluded that enforcement was most practical on high volume roadways and at specific sites (e.g., schools).

Supplementary Information: Additional or confirming information obtained on specific types of enforcement follows.

ITE (2) stated that targeted police enforcement is impractical and expensive on lowvolume streets. Boulder, Colorado, used targeted enforcement in four zones. No speed changes were noted in three targeted zones and speeds went up in a fourth.

FHWA (3) stated that compliance with speed limits is greatest in the vicinity of police vehicles and that aerial enforcement has a generally positive effect on reducing speeds.

An article on traffic issues in smaller communities (35) listed the following questions as issues that need reassessment: Is on-street parking associated with higher crash rates? Does onstreet parking reduce mobility? Do we need to use one-way streets to move traffic efficiently in downtown areas? Are speeds on one-way streets hazardous to pedestrian movement? With the current cutback in traffic departments, what are alternative means of enforcement?

NHTSA (43) has prepared guidelines for developing a municipal speed enforcement program based on successful programs implemented in Modesto and San Bernadino, California. It makes the following suggestions, among others: select zones for study; deploy at hours of greatest risk, but vary the hours; use radar equipment (and laser speed measuring equipment if possible); use decoy vehicles at the enforcement sites and elsewhere in the community; and develop a public information and education program.

In NHTSA's national survey (20) "more police assigned to traffic" was ranked by 85 percent and "more frequent ticketing" by 82 percent of the respondents as very or somewhat effective in reducing speeding. These were the highest rankings received by any of the survey countermeasures. Seventy-three percent approved of adding police and 77 percent approved of more frequent ticketing as countermeasures to reduce speeding.

An abstract of a Michigan State study (21) showed that average speed on an interstate was reduced right before a police car's location but, after passing the patrol car, speeds increased to normal and occasionally higher than normal levels. In an overview of automated enforcement 
(34), the following were listed as important to successful automated enforcement programs: public education and awareness, involvement of the local judiciary, and passage of enabling legislation. The following current issues are discussed: privacy, distribution of ticket revenue, and ticketing procedures.

FHWA (3) reported on a study in which traffic enforcement notification signs were placed at either end of an enforcement zone and traffic laws were strictly enforced within the zone. In the study, officers handed out cards identifying the dangerous intersections targeted in the community and asking motorists to drive more safely. There was a 30-percent reduction in traffic violations during the enforcement period (3 years).

FHWA (3) reported that speed display boards have been shown to reduce speeds at the placement site.

ITE (2) noted that San Jose, California, found speed display boards to be effective only when displayed, and Kirkland, Washington, found a speed reduction of 6 percent after 30 days on streets with traffic volumes below 600 vehicles per day where most traffic is local and the displays raised the consciousness of local residents. On higher volume streets, the long-term effects were negligible.

ITE (2) stated that San Jose found that speed reductions obtained with photo radar seemed to hold up over time without enforcement and may have spread over into nearby untreated streets. Because of its expense, photo radar is most cost-effective if deployed on high volume streets.

FHWA (3) reported that foreign studies have shown significant reductions in crashes when photo radar is in use.

One paper on photo radar (25) reported that it was widely used throughout Europe and Australia and to a limited extent in North America to supplement police enforcement efforts. For example, in Victoria, Australia there was a 50-percent reduction in motorist triggering of the devices within three months of installation. Fatalities declined by 30 percent and the percentage of vehicles significantly exceeding the speed limit decreased from 20 percent to 4 percent.

The Insurance Institute for Highway Safety (IIHS) (42) reported that photo radar can be effective on busy urban interstates. Researchers in British Columbia analyzing a program using 30 cameras found a 7-percent decline in crashes, a 10-percent decline in daytime injuries, and up to 20 percent fewer deaths the first year the cameras were used. Speeding vehicles declined from 66 percent to fewer than 40 percent a year later.

Using cameras to enforce speeding was reported to be not politically acceptable in Phoenix (18). Boulder, Colorado, (50) found no statistically conclusive evidence that photo radar reduced speeding.

In NHTSA's national survey (20), 65 percent of the respondents reported having heard of photo enforcement devices. Seventy-five percent felt that photo enforcement would have some or a lot of effect on reducing speeding, and 71 percent thought it was a good idea to use photo 
enforcement for speeding. More women (78\%) than men (63\%) thought it was a good idea. The largest number of reasons given for feeling that photo enforcement was a bad idea $(26 \%)$ was a concern over invasion of privacy, violation of rights, or government interference. Sixty-nine percent felt that photo enforcement was acceptable in school zones. Forty-three percent found it acceptable at sites where crashes are frequent, 36 percent at places where it is hazardous to stop, and 33 percent at places where stopping causes congestion.

FHWA (3) stated that laser guns were significantly more effective in identifying speeders than radar.

FHWA (3) reported that there was a slight reduction (of no practical use) in vehicle speed when drone radar was in use

\section{Regulatory Actions}

Vehicle speed report: The vehicle speed report noted that changes in speed limits were found to change speeds significantly but by very small amounts. It also noted that a pavement marked with the word "Slow" and a large arrow placed before a sharp curve resulted in drops of mean speeds compared to nearby untreated curves. Other regulatory measures were not covered.

Supplementary Information: Additional or confirming information obtained on specific types of regulatory actions follows.

FHWA (3) reported several studies where there was little or no change in speeds from changes in speed limits. However, U.S. and foreign studies generally show an increase in speeds when speeds are raised on freeways. Crash incidence or crash severity generally declines when limits are lowered and rises when limits are raised, especially on freeways.

FHWA (44) analyzed speed and crash data collected from 22 States at 100 sites (rural, small urban, and urban) before and after speed limits were changed. Limits were lowered at 59 sites and raised at 41 sites. Data from 83 sites where speed limits were not altered were collected for comparison purposes. Results showed that neither raising nor lowering the speed limit had much effect on vehicle speeds. Mean and $85^{\text {th }}$ percentile speeds did not change more than 1 or 2 mph. The percent compliance improved when the speed limits were raised and decreased when they were lowered.

The Center for Livable Communities (15) noted that in many States the lowest speed that can be posted on a public street is 25 or $30 \mathrm{mph}$. In this regard, New York State law (19) has recently been changed to permit cities with populations larger than 1,000,000 to set speed limits as low as $15 \mathrm{mph}$ on selected streets for the specific purpose of implementing physical traffic calming measures (not traffic signs only).

The Insurance Institute for Highway Safety (42) reported that London has a speed limit system on its M25 beltway that varies with traffic and speed conditions. Electronic loops detect traffic volumes and speeds and roadside processors analyze the data to detect where traffic is slowing. Speed limits ranging from 20 to $60 \mathrm{mph}$ are posted on electronic signs. Enforcement is handled by cameras. There were 28 percent fewer crashes involving occupant injuries during 
the first year of the program, and vehicle-damage-only crashes went down 25 percent. Injury crashes on a comparison road without the new traffic control system increased 2 percent during the same time period.

A study (38) was conducted to determine a method of setting speed limits by considering pedestrians first. Pedestrian risk factors such as visibility, vehicle stopping distances, consequences of collisions, and their vulnerability by age groups were analyzed. Criteria for street-by-street analysis were developed consisting of land-use density, motor vehicle traffic volumes, presence of sidewalks and boulevards, and width of pavement. Organized into flow charts, the criteria provide target speeds for individual streets.

ITE (2) stated that most studies show little or no speed reductions mid-block with stop signs. There are problems with compliance.

Athens-Clarke County, Georgia, (14) compared speeds of two streets - one with all-way stop signs and one with speed humps. There was a very limited area of influence around stop signs before drivers increased speeds to a rate faster than before the stops were installed. Speeds decreased with speed humps.

ITE (2) stated that turn restrictions are popular with neighborhoods in Phoenix. They appear to be most effective at peak hours. Violations run around 50 percent without enforcement.

ITE (2) reported that no before and after data are available on the use of one-way streets as traffic calming measures. In a survey (28) of agencies using traffic calming measures, no safety or legal consequences were reported.

Boulder, Colorado, (50) tested a "rest on red" device at one intersection. This device remains red until it detects a vehicle traveling within the speed limit when it turns green to permit the vehicle to pass. "Speed Sensitive Signal" signs were posted to alert drivers that speeding would influence signal operation. Photo radar enforcement was used. Colorado did not report the data but indicated that vehicle speeds were not changed significantly. A possible explanation was that the combined volumes on the intersecting streets were too high for most of the day for the speed sensitive programming to influence signal operation. A test of "rest on green" signals was planned but not implemented because of limitations in the traffic signal controller software. Replacement software was reported to be under development.

The Virginia DOT (4) reported that the State has enacted a code that permits counties to install "Watch for Children" and "Additional \$200 Fine" signs.

Hampton, Virginia, (10) implemented "invisible" traffic calming methods to reduce speeding and cut-through traffic. The methods included elimination of a left/through overlap causing delay for through vehicles, reduction of maximum green time for selected lights, prohibition of right turns on red, and changes in left turns from protective/permissive to protected only. Volumes and speeds dropped.

\section{Pedestrian Crash Estimation}


Vehicle speed report: The NHTSA vehicle speed report did not cover this topic. follows.

Supplementary Information: Information obtained about pedestrian crash estimation

Two papers were located that provided models for estimating pedestrian crash data. One paper (40) created a model to determine the probability of a pedestrian-vehicle collision since such collisions are rare on local streets. Both parametric and nonparametric methods are described, including an example in which estimates of the collision probability and the probability distribution of vehicle collision speeds are used to identify promising sites for traffic calming. The other paper (41) was used to evaluate the effect of roadway and area type features on injury severity of pedestrian crashes in rural Connecticut. Crashes were limited to those in which the pedestrian was trying to cross an uncontrolled two-lane highway. Variables that significantly influenced pedestrian severity were clear roadway (excludes on-street parking space), vehicle type, driver alcohol involvement, pedestrian age 65 or older, and pedestrian alcohol involvement. Speed limit was found to be a poor predictor as was average annual daily traffic, darkness, illumination, and weather.

\section{Summary}

The supplementary literature review revealed very little new information over that reported in NHTSA's vehicle speed report. Most of the information obtained served to confirm or amplify information contained in the NHTSA report. The points that may be of interest to the current speed study are listed below.

- The most effective traffic calming methods involve vertical shifts in the roadway. Humps have been proven to be very effective. The public finds them effective in reducing speeding.

- Traffic circles as designed in Seattle have been proven to be very safe.

- There is a rubber hump that can be used as a temporary traffic calming measure. Other measures can be created for temporary use (e.g., permitting parking on opposite sides of the street for each block to create a chicane, using planters as bulbouts).

- Although some professional groups and jurisdictions have proposed standards, there are no national standards for design and use of traffic calming measures.

- Data on the effectiveness of roadway perceptual devices are inconclusive. Although street narrowing decreases speeding, there are data that show that it increases crashes. Some data show that streets need to be 20 feet or less in width before speed reductions are noted.

- No studies were found in which education alone was used as a traffic calming measure. Typically, education programs consist of citizen watches combined with enforcement. Success in reducing speeding has been reported. 
- Enforcement is impractical on low volume streets. Compliance is greatest in the vicinity of the police vehicle. This is also true of speed display boards. The public finds enforcement effective in reducing speeding.

- Photo radar has been used very successfully in Europe. It has had some success in the United States but still has problems with political acceptability. The public finds photo radar to be effective.

- A study was identified on a method for analyzing pedestrian risk factors and developing criteria that lead to target speeds for individual streets.

- Two studies were identified that provided a means of estimating crashes in low-crash areas.

- There are no commonalities for taking before and after measurements and frequently the time factors aren't stated.

- Measures are typically $85^{\text {th }}$ percentile speed, average speed, percent exceeding posted speed, percent $x$ mph above posted speed, and volume. Crashes are included sometimes. Only one study was located that used driver or pedestrian measures - it used number of drivers yielding to pedestrians.

- "Rest on red" traffic lights were investigated with negative results - possibly due to the volume of traffic at the intersection. No study was located that investigated "rest on green" traffic lights.

- Some jurisdictions use "hidden" measures for traffic calming (e.g., changes in traffic lights, prohibiting turns, making a "maze-like" path by creating a series of one-way streets).

\section{Documents Reviewed}

1. Literature Review on Vehicle Travel Speeds and Pedestrian Injuries (Leaf and Preusser). NHTSA Report No. HS 809 021, October 1999.

2. Traffic Calming: State of the Practice (Ewing). Institute of Transportation Engineers, Publication No. FHWA-RD-99-135, August 1999.

3. Synthesis of Safety Research Related to Speed and Speed Management (Stuster, Coffman, and Warren). Publication No. FHWA-RD-98-154, July 1998.

4. VDOT's Residential Traffic Management Program (Arnold and Cottrell). Paper presented at the Institute of Transportation annual meeting, August 2000.

$5 \quad$ Arterial Traffic Calming - Is It an Oxymoron? (West). Paper presented at the Institute of Transportation annual meeting, August 2000.

6. Balancing Mobility Needs and Community Issues Using Traffic Calming Techniques (Solarz, Jehanian, and Davis). Paper presented at the Institute of Transportation annual meeting, August 2000. 
7. Cambridge's Traffic Calming Program: Pedestrians are the Focus (Watkins). Paper presented at the Institute of Transportation annual meeting, August 2000.

8. Collector Street Traffic Calming: A Comprehensive Before - After (Buchholz, Baskett and Anderson). Paper presented at the Institute of Transportation annual meeting, August 2000.

9. $\quad$ Creating Walkable Communities: The Michigan Example (Sisiopiku). Paper presented at the Institute of Transportation annual meeting, August 2000.

10. Invisible Traffic Calming - Low Cost Solution Yielding Significant Benefits (Allsbrook). Paper presented at the Institute of Transportation annual meeting, August 2000.

11. The Legal Aspects of Traffic Calming - Negligence (Williams). Paper presented at the Institute of Transportation annual meeting, August 2000.

12. Lessons Learned to "Calm" a Traffic Calming Program (Zoumalan and Yalda). Paper presented at the Institute of Transportation annual meeting, August 2000.

13. Traffic Engineer Beware Traffic Calming Can Be Dangerous to Your Professional Health (Khorshid and Yalda). Paper presented at the Institute of Transportation annual meeting, August 2000.

14. All-Way Stops Versus Speed Humps: Which is More Effective at Slowing Traffic Speeds? (Clark). Paper presented at the Institute of Transportation annual meeting, August 2000.

15. Street Design Guidelines for Healthy Neighborhoods (Burden, Wallwork, Sides, Trias, and Rue). Center for Livable Communities, Sacramento, California, January 1999.

16. Streets and Sidewalks, People and Cars: The Citizen's Guide to Traffic Calming (Burden). Center for Livable Communities, Sacramento, California, April 2000.

17. Civilizing Traffic: The Manual - Neighborhood Traffic Calming in Honolulu (Burden). Walkable Communities, High Springs, Florida, May 1999.

18. Personal communication with Michael Cynecki, Phoenix, Arizona.

19. New York State Vehicle Code $§ 1642$ (a)26.

20. National Survey of Speeding and Other Unsafe Driving Actions: Volume I-Methodology, Volume II-Driver Attitudes and Behavior, Volume III-Countermeasures (Boyle, Dienstfrey, and Sothoron) NHTSA report Nos. DOT HS 808 748, 749, and 750, September 1998.

21. Effects of Police Presence in an Increased Speed Zone (Patel, Sisiopiku, and Taylor). ITE Journal, Vol. 68, No. 3, March 1998, p.12. (Abstract review only)

22. Speed Hump Effectiveness and Public Acceptance (Ballard). ITE Journal, Vol. 68, No. 2, February 1998, p.70. (Abstract review only)

23. Traffic Calming Benefits, Costs and Equity Impacts (Litman). Victoria Transport Policy Institute, December 1999.

24. City of Portland Speed Bump Peer Review (Robinson, Wempler, and Colyar). October 1998. (http://www.trans.ci.portland.or.us/traffic_management/trafficcalming/reports/ reports.htm)

25. Automated Enforcement of Traffic Laws (Retting). TR News, Issue 201, March 1999, pp. 15-18, 29.

26. Growing Pains or Growing Calmer? Lessons Learned from a Pilot Traffic Calming Program avis and Lum). Paper presented at the Institute of Transportation International Conference, 1998.

27. Does Traffic Calming Make Streets Safer? (Beaubien). Paper presented at the Institute of Transportation International Conference, 1998. 
28. Liabilities/Safety Issues with Traffic Calming Devices (Dabkowski). Paper presented at the Institute of Transportation International Conference, 1998.

29. Recruiting Private Help for a Public Demonstration Project: Taking the "Hump" out of Traffic Calming (Aspelin). Paper presented at the Institute of Transportation International Conference, 1998.

30. Designing Speed Controlled Subdivisions Without Road Humps (Szplett and Butzier). Paper presented at the Institute of Transportation International Conference, 1999.

31. Traffic Calming - Beware of the Backlash (Cline and Dabkowski). Paper presented at the Institute of Transportation International Conference, 1999.

32. A Traffic Calming Toolbox - A Technical Resource Developed for the South Western Region of Connecticut (Ford, Court, and Prosi). Paper presented at the Institute of Transportation International Conference, 1999.

33. The Effectiveness of a Community Traffic Safety Program (Blume, Noyce, and Sicinski). Paper presented at the Institute of Transportation: Transportation Operations Moving into the $21^{\text {st }}$ Century Conference, 2000.

34. Overview of Automated Enforcement in Transportation (Turner and Polk). ITE Journal, Vol. 68, No. 6, June 1998, pp 20-29.

35. Traffic issues for smaller communities (Edwards). ITE Journal, Vol. 68, No. 8, August 1998, pp.30-33.

36. Signs of things to come. Roads and Bridges, Vol. 38, No. 3, March 2000, pp. 60-65.

37. Towards a North American Geometric Design Standard for Speed Humps (Weber and Braaksma). ITE Journal, Vol 70, No. 1, January 2000, pp. 30-33.

38. Target Speeds for Speed Zoning and Traffic Calming in Residential Areas. Paper prepared for presentation at the Transportation Research Board's $80^{\text {th }}$ Annual Meeting, January 2001.

39. Making Walking and Cycling Safer: Lessons from Europe (Pucher and Dijkstra). Transportation Quarterly, Vol. 54, No. 3, Summer 2000.

40. Method for Estimating Effect of Traffic Calming Volume and Speed on Pedestrian Safety for Residential Streets (Davis). Transportation Research Record, Issue 1636, 1998, pp. 110-115.

41. Factors Influencing Injury Severity of Motor Vehicle-Crossing Pedestrian Crashes in Rural Connecticut (Zajac and Ivan). Paper prepared for presentation at the Transportation Research Board's 80 ${ }^{\text {th }}$ Annual Meeting, January 2001.

42. Who Cares About a Camera If You Are Not Speeding? (Insurance Institute for Highway Safety) Status Report, Vol. 34, No. 6, June 19, 1999, pp.1-3.

43. Guidelines for Developing a Municipal Speed Enforcement Program (NHTSA) Undated. (http://www.nhtsa.dot.gov/people/injury/enforce/program.htm)

44. Effects of Raising and Lowering Speed Limits on Selected Roadway Sections (FHWA). November 1998. (http://www.tfhrc.gov/humanfac/rd97002.htm)

45. Rubber Speed Bumps (Portland, Oregon) (http://www.trans.ci.portland.or.us/ traffic_management/trafficcalming/devices/)

46. Split Speed Bump (Mulder). January 1998 (http://www.trans.ci.portland.or.us/ traffic_management/trafficcalming/reports/split.htm)

47. Speed Alert Program (Wakefield). June 15, 1999 (http://www.tempe.gov/traffic/ speed.htm)

48. Tampa (FL) Neighborhood Speed Watch Program (http://www.ci,tampa,fl.us/ dept_public_works/transportation.htm) 
49. Strategic Analysis Report on Traffic Calming (http://www.ci.sf.ca.us/sfta/final.htm)

50. Boulder (CO) Neighborhood Traffic Mitigation Program (http://www.ci.boulder.co.us/ publicworks/depts/tr7.html)

51. Personal communication with Michael Blume, University of Massachusetts.

52. Speeders See the Light (Gilbert). Traffic Safety, January/February 1999, pp. 8-9.

53. An Economic Evaluation of Incremental Resources to Road Safety Programmes in New Zealand (Guria). Accident Analysis \& Prevention, Vol 31, 1999, pp. 91-99.

54. Traffic Calming Primer (Pat Noyes \& Associates). Boulder, Colorado, 1998.

55. Effective Traffic Calming Applications and Implementation (Saffel). Minnesota Local Road Research Board, Minnesota Department of Transportation, Office of Research Services, St. Paul, Minnesota, October 1998.

56. Practitioner's Forum: Video Technology in Traffic Engineering and Transportation Planning (Shuldiner). Journal of Transportation Engineering, May/June 1999, pp.169175.

57. Managing Speed: Review of Current Practice for Setting and Enforcing Speed Limits. Transportation Research Board, National Research Council, Special Report No. 254, 1998.

58. Emergency Response: Healthy Streets and Traffic Calming (Burden). Local Government Commission Center for Livable Communities, Sacramento, California, planned publication date: November 2000.

59. Delaware State Department of Transportation Traffic Calming Design Manual. State of Delaware, Department of Transportation, Dover, Deleware, August 2000.

60. Rural Traffic Calming: Returning to Basics (Suzman). International Municipal Signal Association Journal, Volume 37, Issue 4, p.28. 


\section{This Page Intentionally Left Blank}




\section{APPENDIX B WORKSHOP REPORT}

This letter report was prepared early in the study and is discussed in Section 2 of the report. 


\section{Letter Report \\ Pilot Test of Novel Speed Reducing Program \\ Contract No. DTNH22-99-D-05099, Task Order 2 \\ July 3, 2001}

\section{THE SPEED WORKSHOP: FEASIBLE COUNTERMEASURES}

A panel of 14 experts was assembled for a speed workshop. The panel included individuals from areas with and without innovative speed reduction activities. It also included individuals who were specialists in research on speed countermeasures, research on pedestrian safety, state-of-the-practice of traffic calming, enforcement, and education. The workshop was held on May 10 and May 11, 2001, at the Federal Highway Administration Learning Center in Arlington, Virginia. The panel members are listed in Appendix A.

The NHTSA Task Order Manager explained that the purpose of the study was to develop a behavior-based supplement to engineering approaches to reduce speeding in neighborhoods. The program will be tested to determine if education and enforcement techniques produce an added benefit when added to traffic calming.

The study principal investigator explained that workshop participants will be challenged to identify candidate test conditions, evaluation paradigms and possible test locations. The aim was to identify a reasonable (in terms of cost and time) and sufficiently general test or tests that will shed light on the problem at hand.

\section{Countermeasures}

The program was initiated by having workshop participants identify speed-reducing techniques in the three E's-engineering, enforcement, and education. They identified engineering techniques first, followed by enforcement techniques and education techniques. Participants were asked to consider new as well as existing techniques and were told that they could identify temporary as well as permanent techniques. The focus was to be on reducing speed, and all ideas were to be considered acceptable (that is, there were no bad ideas). When they ran out of ideas, participants were asked to identify anything in the roadway that had made them slow down recently. Over 250 different ideas were documented. They are appended to this letter report (Appendices B, C, and D). The ideas in the appendices are listed in the section (engineering, enforcement, education) in which they were identified regardless of whether or not they were appropriate to that section.

The various countermeasures in each set were noted on index cards and random selections were made from each set. Constraints and positive aspects were then noted for each. These data are summarized in Table 1. The table shows the following principles and considerations that emerged from this activity that would be applicable to the project: 
Table 1

\section{Randomly Selected Triples}

\begin{tabular}{|c|c|c|c|c|}
\hline Engineering & Enforcement & Education & Constraints & Positives \\
\hline Construction zone & Peer trial & $\begin{array}{l}\text { Manually operated } \\
\text { pedestrian walking } \\
\text { sign }\end{array}$ & $\begin{array}{l}\text { Deceit; ugliness; don't devalue } \\
\text { neighborhood; unwillingness to } \\
\text { be bad guy; no teeth in sanctions }\end{array}$ & OK to trick senses \\
\hline $\begin{array}{l}\text { Irregular shaped } \\
\text { sidewalks }\end{array}$ & $\begin{array}{l}\text { Red light running } \\
\text { cameras }\end{array}$ & $\begin{array}{l}\text { Windshield wiper } \\
\text { flyers }\end{array}$ & $\begin{array}{l}\text { Few red lights in residential areas; } \\
\text { litter; nuisance; annoyance; } \\
\text { Engineering may not need any } \\
\text { education }\end{array}$ & Targets neighborhood offenders \\
\hline In-car cameras & $\begin{array}{l}\text { Positive reinforcement } \\
\text { for speed compliance }\end{array}$ & Utility pole posters & $\begin{array}{l}\text { Utility pole posters are illegal; } \\
\text { tough to target cameras; high } \\
\text { cost; privacy; don't want to feel } \\
\text { watched }\end{array}$ & $\begin{array}{l}\text { Generalized/group } \\
\text { reinforcement would be OK }\end{array}$ \\
\hline Adequate lighting & $\begin{array}{l}\text { Educating police about } \\
\text { the importance of } \\
\text { speed control }\end{array}$ & $\begin{array}{l}\text { Having elementary } \\
\text { school children take } \\
\text { things home }\end{array}$ & Cost; dark sky issues & $\begin{array}{l}\text { Reduces crime; sets good model } \\
\text { for kids }\end{array}$ \\
\hline Medians & $\begin{array}{l}\text { Neighborhood speed } \\
\text { watch program }\end{array}$ & Use of GIS tools & $\begin{array}{l}\text { Can be ugly; street has to be } \\
\text { sufficiently wide; limits access; } \\
\text { must fasten things to roadway; } \\
\text { GIS is probably only good for } \\
\text { crash not speed data }\end{array}$ & $\begin{array}{l}\text { Can be good looking; builds } \\
\text { social capital; can use short } \\
\text { medians or flower pots; GIS } \\
\text { good for locating other facilities } \\
\text { (e.g., churches, schools); } \\
\text { demographics; may be able to } \\
\text { use crash data base for speed } \\
\text { info; gives concerned neighbors } \\
\text { something to do }\end{array}$ \\
\hline
\end{tabular}


- The countermeasure can trick the senses, but it can't be deceitful (e.g., an artificial construction zone).

- The countermeasure can't be ugly or devalue the neighborhood (e.g., an artificial construction zone, a poorly designed median).

- The countermeasure should improve the neighborhood (e.g., a well-designed median).

- Neighbors might not like to be the bad guy (e.g., participate in a trial by peers).

- There should be teeth in the sanctions (a trial by peers may not have teeth).

- There must be places in the area to mount the countermeasure (e.g., there are few red lights in residential areas).

- The countermeasure must not contribute to neighborhood litter (e.g., windshield wiper flyers).

- The countermeasure must not be annoying (e.g., windshield wiper flyers).

- The countermeasure must be legal (e.g., mounting flyers on utility poles is illegal).

- The countermeasure must be easily targeted (in-car cameras are tough to target).

- The cost must be reasonable (cameras are expensive).

- There should be no privacy issue (people don't want to feel watched).

- Providing a good model for children is desirable (e.g., sending materials home from school).

- Crime reduction can be an added benefit (e.g., assuring adequate lighting).

- Sufficient space must be available (e.g., a street wide enough to install a median).

- It is preferable that a residential countermeasure not limit access to homes and driveways (as would a median; however, short medians could be installed).

- Temporary engineering measures, if used, must be attached to the roadway.

- Appropriate data must be available or collectible (GIS data may be good for locating facilities, providing crash data as a surrogate for speed data).

- Neighborhood involvement is advisable (as in a neighborhood speed watch program).

- Good engineering may not need education. 
As an assignment, participants were asked to identify one or more of each type of countermeasure that they would recommend for the study. The countermeasures could be selected from the lists developed by workshop participants or could be ones not previously identified. In effect, the participants were asked to select the engineering, enforcement, and education countermeasures that they would recommend for the NHTSA program. Participants were advised that they did not necessarily need to choose the most widespread traffic calming implementations. They were advised that the project needs an engineering technique that has been shown to produce some speed reduction without education or enforcement. Twelve participants responded. Their recommended programs are shown in Table 2.

Participants were then asked to vote for their preferred program but were not allowed to vote for the ones they recommended. There was no consensus among participants. Two programs (numbers 2 and 8 in Table 2) received two votes each. All others received one vote or no votes.

With regard to types of countermeasures, engineering activities included primarily standard interventions (e.g., speed humps, roundabouts, diverters, bulbouts, curb extensions, medians). Some participants did not feel that speed humps represent good current practice. Enforcement activities included police patrols, radar trailers, and neighborhood watches. One participant recommended judicial support. Participants noted that highlighting police presence can be impractical in small neighborhoods. Education activities were localized and included door hangers, signs, brochures/flyers brought home by school children, community meetings, street parties, newspaper articles, and printing of violators.

\section{Evaluation/Measurement Considerations}

With regard to temporary versus permanent engineering measures, participants were unanimous in recommending that the project work with permanent installations. The following principles were noted:

Temporary installations devalue treatment; there is no ownership; they convey the wrong message ("we're not sure" or "we want to see if you like it").

- Installations must have public acceptance.

- It is hard to generalize from temporary to permanent installations.

- Temporaries provide no permanent change. 
Table 2

\section{Participant-Selected Triples}

\begin{tabular}{|c|c|c|c|c|}
\hline \# & Engineering & Enforcement & Education & How To Do It \\
\hline 1 & Neighborhood entrance choker point & $\begin{array}{l}\text { Routine police patrol-go } \\
\text { there and work it. Regular } \\
\text { but not increased. }\end{array}$ & $\begin{array}{l}\text { Door-to-door delivery of a door hanger-before, during } \\
\text { building, after. }\end{array}$ & $\begin{array}{l}\text { Neighborhood meeting. Good } \\
\text { for transition streets where } \\
\text { speed lowers but people don't } \\
\text { slow down. }\end{array}$ \\
\hline 2 & $\begin{array}{l}\text { Roundabouts; diverters as appropriate; } \\
\text { encourage on-street parking }\end{array}$ & $\begin{array}{l}\text { Not much beyond normal } \\
\text { patrol. Some heightened } \\
\text { emphasis on worst street. } \\
\text { Speeding cameras. }\end{array}$ & $\begin{array}{l}\text { Signs at entrances to calmed neighborhood. School info } \\
\text { for kids. Newspapers/media coverage. }\end{array}$ & $\begin{array}{l}\text { Grid layout with cut-through } \\
\text { and speeding problems. } \\
\text { Determine community's view of } \\
\text { the problem and what they } \\
\text { would accept. }\end{array}$ \\
\hline 3 & $\begin{array}{l}\text { Median on a curve (with good visibility) } \\
\text { on a school route. Landscaping, trees, } \\
\text { planter strips, and post-mounted } \\
\text { delineators. }\end{array}$ & $\begin{array}{l}\text { Radar trailer. Police auto } \\
\text { dial to get the word out. }\end{array}$ & $\begin{array}{l}\text { Signs, kids as spokespersons, brochures, and door } \\
\text { hangers in the neighborhood (speed versus pedestrian } \\
\text { fatality graph); school take-home materials. }\end{array}$ & $\begin{array}{l}\text { Find a good curve and put } \\
\text { median on it and take before } \\
\text { and after measurements. }\end{array}$ \\
\hline 4 & Roundabouts, bulbouts/curb extensions & $\begin{array}{l}\text { Routine. Neighborhood } \\
\text { watch. }\end{array}$ & $\begin{array}{l}\text { Homeowners' associations, signs, and community } \\
\text { meetings. }\end{array}$ & $\begin{array}{l}\text { Block with roundabouts and } \\
\text { bulbouts at both ends. }\end{array}$ \\
\hline 5 & $\begin{array}{l}\text { Speed humps and medians (standard } \\
\text { recognized interventions rather than new } \\
\text { ideas) }\end{array}$ & $\begin{array}{l}\text { Police officers in the } \\
\text { neighborhood on an } \\
\text { intermittent basis. }\end{array}$ & $\begin{array}{l}\text { Neighborhood door-to-door campaign with petitions; } \\
\text { flyers and appropriate signage. }\end{array}$ & $\begin{array}{l}\text { Neighborhood people would } \\
\text { educate; get locals involved. }\end{array}$ \\
\hline 6 & Engineer street for max speed of $25 \mathrm{mph}$ & $\begin{array}{l}\text { Change philosophy with } \\
\text { respect to traffic. Make it } \\
\text { a crucial component of the } \\
\text { policing function. }\end{array}$ & Door hangers, flyers, utility bills, telephone bills. & $\begin{array}{l}\text { Make it work-cooperative } \\
\text { effort. }\end{array}$ \\
\hline 7 & $\begin{array}{l}\text { Roundabout with bench and bronze } \\
\text { person in center of area. Put name of } \\
\text { neighborhood or safety message on } \\
\text { truck apron of roundabout. Playground } \\
\text { on vacant lot. Define a gateway. }\end{array}$ & $\begin{array}{l}\text { Periodic enforcement with } \\
\text { letters to violators. }\end{array}$ & $\begin{array}{l}\text { Speed signs showing enforcement speed with feedback } \\
\text { of actual speed. Known spokesperson who will do } \\
\text { messages on risk of speed and fatalities (race drivers?). } \\
\text { Include drivers, pedestrians, and pets. TV, print, cable. } \\
\text { Follow-up with kids in the neighborhood. }\end{array}$ & $\begin{array}{l}\text { NIICE-neighborhoods } \\
\text { interested in community } \\
\text { environments; give it an identity } \\
\text { and a buy-in. }\end{array}$ \\
\hline
\end{tabular}


Table 2 (continued)

\begin{tabular}{|c|c|c|c|c|}
\hline \# & Engineering & Enforcement & Education & How To Do It \\
\hline 8 & $\begin{array}{l}\text { Residents select the } \\
\text { engineering technique } \\
\text { reviewed by engineers } \\
\text { for safety and feasibility }\end{array}$ & $\begin{array}{l}\text { Judicial support-heavy-handed } \\
\text { fines. }\end{array}$ & Street party. & $\begin{array}{l}\text { Must involve people in the neighborhood. It must } \\
\text { select itself. It has to apply for help }(50 \%+\text { of } \\
\text { residents). Make sure they have a selection of tools } \\
\text { both provided and paid for by them. Require a } \\
\text { commitment from them. Then they select the } \\
\text { engineering technique reviewed by engineers for } \\
\text { safety and feasibility. }\end{array}$ \\
\hline 9 & $\begin{array}{l}1 \text { lane flat top speed } \\
\text { table with curb } \\
\text { extensions to act as a } \\
\text { choker ( } 300-2500 \\
\text { average daily vehicle } \\
\text { travel) }\end{array}$ & $\begin{array}{l}\text { 24-hour speed box (nothing in it). } \\
\text { Yellow box painted in the street. } \\
\text { Apparent lens and strobe unit. }\end{array}$ & $\begin{array}{l}\text { Neighborhood street festival to gain } \\
\text { signatures for petition to gain support for } \\
\text { the treatment }\end{array}$ & \\
\hline 10 & $\begin{array}{l}\text { Two-lane arterial with } \\
\text { high speeds. Install bike } \\
\text { lane to effectively } \\
\text { narrow }\end{array}$ & Some spot speed enforcement. & $\begin{array}{l}\text { Pre-installation activity to understand } \\
\text { why this is being done. Community } \\
\text { paper to explain. }\end{array}$ & $\begin{array}{l}\text { Measure speed; major emphasis on education to } \\
\text { lower resistance and gain acceptance. Rockville, } \\
\text { Maryland }\end{array}$ \\
\hline 11 & Speed humps & $\begin{array}{l}\text { Increase enforcement and police } \\
\text { presence-display boards and cars in } \\
\text { neighborhood. Positive police } \\
\text { presence at street parties, } \\
\text { homeowners meetings, and } \\
\text { community meetings. }\end{array}$ & $\begin{array}{l}\text { Identify community resources and build } \\
\text { program on those. Publish newspaper } \\
\text { articles and include violation counts. } \\
\text { Door hangers. Mount a sign at the } \\
\text { gateway "entering speed zone." Slow } \\
\text { signs between the humps. }\end{array}$ & \\
\hline 12 & Speed humps & $\begin{array}{l}\text { Radar trailer rotated in one day a } \\
\text { week at random. }\end{array}$ & $\begin{array}{l}\text { Signs that say "Speed Kills Pedestrians" } \\
\text { and slow down signs between the } \\
\text { humps. }\end{array}$ & \\
\hline
\end{tabular}


With regard to process, it was considered desirable that the project start from the beginning and look at transition from a non-calmed to a calmed neighborhood. The time to reach a steady state would be examined. Police play a role in the transition. The process is critical. Perceptions of prevailing speeds should be measured before the neighborhood is selected. On the other hand, it was acknowledged that this might not be possible under the constraints of the study. Using an already calmed location with available "before" data was considered viable.

In a discussion of meaningful speed and volume reductions, the following measures of effectiveness were noted:

- Impact on pedestrian traffic

- Volume

- Cut-throughs

- Speed (speed tube technology, stopwatch distance approaches)

With regard to speed, it was agreed that 85th percentile and average aren't good measures of what people are concerned about. People want the excessive speeders eliminated. The ratio of speed above and below the speed limit can provide a threshold. Police could give a ticket if the speed is seven miles per above the posted speed. For a neighborhood speed of $25 \mathrm{mph}$, one can provide:

- A ratio of $32+$ to $<32$

- A ratio of $32+$ to $25-$

- A speed drop of 85 th to 95 th percentile distribution

It was agreed that the project should focus on overall comfort level and unacceptably high speeds. The aim is to eliminate the bizarre speeds-the outliers. Thus the project should focus on both the high tail, the threshold ratio, and the mean. This focus requires accurate speed data on each vehicle not class interval or "bin" data that are produced by some traffic counters.

The project needs to collect raw speed data. Data should show speed at the intervention as well as through the neighborhood. Thus, there must be multiple measurement points.

Other ideas that were posed for evaluation include:

- Obtain pre- and post-project community opinions-Is the community better? Was the inconvenience worth it?

- Conduct a realtor survey to determine relative value of people's properties-What is the perceived value of homes? How many days do homes stay on the market before selling?

- Survey neighborhood associations and friends. What are the number and types of contacts with neighbors (direct and indirect) in the last week?

- Determine neighbor speed perceptions? Is the rate too fast, not too fast? 
- Increase the number at or below the speed limit by x percent $(50 \%)$.

- Measure speed uniformity/variability.

- What is the travel time through the neighborhood?

\section{Possible Test Sites}

The communities listed below were recommended as possible test sites. They include sites where pre- and post-studies have not shown optimum results, places with good process and treatments pending, and those with both areas where installations have not had optimum results and where good process and treatments are pending.

- Pre- and post- studies that have not had optimum results:

Sacramento, California

Kensington, Maryland

Salt Lake City, Utah

Phoenix, Arizona

Gainesville, Florida

Boca Raton, Florida

- Places with good process and treatments pending:

Clearwater, Florida

Long Island, New York

Asheville, North Carolina

Hillsborough, Florida

Pinellas County, Florida

- Both:

St. Petersburg, Florida

Cambridge, Massachusetts

Fort Lauderdale, Florida

Orlando, Florida

Seattle, Washington

Bellevue, Washington

\section{Future Plans}

At a brief meeting between project personnel and the Task Order Manager following the workshop, it was agreed that a working session should be scheduled with the Task Order Manager to process the data from the workshop and make a final choice requiring countermeasure selection. 


\section{Appendix A}

\section{Workshop Participants}

Richard D. Blomberg

Dunlap and Associates, Inc.

110 Lenox Avenue

Stamford, CT 06906-2300

203-323-8464 (tel)

203-964-0799 (fax)

Rdblomberg@aol.com

Dan Burden

Walkable Communities

320 South Main Street

High Springs, FL 32643

904-454-3304 (tel)

904-454-3306 (fax)

Dburden@aol.com

Arlene M. Cleven

Dunlap and Associates, Inc.

110 Lenox Avenue

Stamford, CT 06906-2300

203-323-8464 (tel)

203-964-0799 (fax)

Arlenecleven@aol.com

Earl Hardy

U.S. Department of Transportation

National Highway Traffic Safety

Administration

Code NTS-13

400 Seventh Street SW.

Washington, DC 20590

202-366-4292 (tel)

202-366-7721 (fax)

ehardy@nhtsa.dot.gov

Richard L. Knoblauch

Center for Applied Research, Inc.

9661 Fringe Tree Road

Great Falls, VA 22066-1901

703-759-2880 (tel)

703-759-2992 (fax)

rlknoblauch@erols.com

William Leaf

Preusser Research Group

7100 Main Street

Trumbull, CT 06611

203-459-8700 (tel)

203-459-8310 (fax)

preusser@worldnet.att.net
Marvin Levy

U.S. Department of Transportation

National Highway Traffic Safety

Administration

Code NTS-31

400 Seventh Street SW.

Washington, DC 20590

202-366-5597 (tel)

202-366-7096 (fax)

mlevy@nhtsa.dot.gov

Leigh Matusick

Florida Department of Transportation

719 South Woodland Boulevard

MS 3-564

Deland, FL 32720

904-943-5600 (tel)

Lmatusick@aol.com

Angela Mickalide

National SAFE KIDS Campaign

1301 Pennsylvania Avenue NW.

Suite 1000

Washington, DC 20004

202-662-0603 (tel)

202-393-2072 (fax)

amickalide@safekids.org

John M. Moffat

Traffic Safety Commission

1000 S. Cherry

P.O. Box 40944

Olympia, WA 98504-0944

360-753-4018 (tel)

360-586-6489 (fax)

jmoffat@wtsc.wa.gov

Keith Moore

U.S. Department of Transportation

Federal Highway Administration

Code HEPH-30

400 Seventh Street SW.

Washington, DC 20590

202-366-0524 (tel)

202-366-3409 (fax)

keith.moore@fhwa.dot.gov
Sue Newberry

Community Partners, LLC

1407 Patrick Avenue

Reno, NV 89509

775-322-5839 (tel)

775-332-5838 (fax)

SueNewb@nvbell.net

Ken Sides

City of Clearwater PWA

100 S. Myrtle Avenue, MSB220

Clearwater, FL 33756-5520

727-562-4792 (tel)

727-562-4755 (fax)

ksides@clearwater-fl.com

Davey Warren

U.S. Department of Transportation

Federal Highway Administration

Code HRDS-05

6300 Georgetown Pike

McLean, VA 22101-2296

202-493-3318 (tel)

202-493-3417 (fax)

Davey.Warren@fhwa.dot.gov 
Appendix B

\section{Engineering Techniques}

- Medians

- Speed bumps

- Speed humps

- Speed tables

- Chicanes

- Roundabouts

- Landscaping

- Curb extensions

- Bike lanes

- Sidewalks

- Parking management

- Angle parking

- Horizontal diversions

- Angle slow points

- Pot holes

- Delineators

- Street closures

- One-way streets

- Two-ways from one-ways

- Traffic management

- Narrowing lanes

- Adequate lighting

- Signage

- Stop signs

- Four-way stops

- Differential paving color

- Differential paving textures

- System network

- Rumble strips

- Visual narrowing

- Vista termination

- Post-mounted delineators

- RPMs

- Bollards

- Planter strips

- Trees

- Ambiance

- Pedestrians

- Striping to achieve narrowing

- Crosswalks

- Traffic signals 
- Flashing lights/beacons

- Speed-sensitive traffic signals

- Staggerings/chokers

- Gateways

- Smart speed feedback display trailers

- Driveway link

- Toys in the road

- Chalk outline of a body

- Crosses for fatals

- Roadside ditches

- Roadway governors/electronic imposed

- Adaptive speed bump-the faster you go the higher it gets

- Posted vs. actual speed display

- Variable speed limits

- Encourage on street parking

- Pedestrian malls near schools

- Street closures

- Woonerfs

- Informal playgrounds/play streets

- Picnic tables, petting zoos in street

- Mural painted in intersection

- District gateway

- Car with speed chip to remind of speeding

- Painted potholes

- Dips

- Swingarms/toll barriers

- Red light that only turns green if you're below speed limit

- 200 "toot" car design limit

- On-board warning transmitter to car

- Unusual speed limits (e.g., $23 \mathrm{mph}$ )

- Tiger teeth that appear if you're speeding

- Portable tiger teeth

- Zigzags before crosswalks

- Mud baths

- Footprint crosswalks

- Make intersection look like room as on Orange Blossom Trail in Orlando (monotubes)

- Embedded pavement lights in crosswalks

- Centerline lights that flash to speeders

- Speed pillows

- Countdown timers/time to wait/time to cross

- Laser closure

- On street alert-louder as you get faster

- Alternate streets convert to left-hand drive

- Pinball gate-flips you to next street if going too fast

- Inflatable speed bumps

- Cobblestones 
- Lights get brighter as you go faster

- Hold red until crosswalk clear

- Hologram pedestrians and police officers

- Grass streets

- Longitudinal treatment to effectively narrow streets

- Tractor beam

- Electronic school pass with so many school trips allowed

- EZ Pass debit/credit system based on speed

- Neighborhood speeder, "good guy" list based on EZPass

- Weather sensitive speed activities

- Countermeasures for aggressive driving stimulators

- Car reporting automatically to police department

- Teenage monitor cameras, GPS

- Visual pacifiers/calming devices

- Irregular shaped sidewalks

- Limit on teenage passengers

- Deteriorating pavement (made driver slow down)

- Dead deer/pets (made driver slow down)

- Mud on road (made driver slow down)

- Tailgater (made driver slow down)

- Feedback signs (made driver slow down)

- Construction zones (made driver slow down)

- Funeral processions (made driver slow down)

- Negative superelevations as in roundabouts

- Rebrick streets

- Manually operated pedestrian present sign

- Put old tires in the street as planters 
Appendix C

\section{Enforcement Techniques}

- Red light running cameras

- Hide cameras in trees

- Neighborhood changeable message signs

- Tickets

- Highly visible enforcement folks-frequent reminders-be seen a lot

- Lots of sirens

- Bright yellow police cars

- Affordable neighborhood cops-can write tickets, speed enforcement specialists

- Fine on the spot

- Automated enforcement

- Neighborhood crime/speed watch

- Publish names of offenders

- Special patrols in school grounds-double fines in school zones

- Radar speed feedback trailer

- Feedback trailer that would also display license plate

- Post license number of speeders

- School police involved in traffic

- Loss of parking privileges at school/on street if you speed

- Positive reinforcement for speed compliance

- Park police cars in neighborhoods

- More local doughnut shops

- Police service aids

- Citizen reporting of violations and police follow-up letters

- Drone radars to set off radar speed detectors

- Train citizens on how to estimate speed with stopwatches and chalk lines

- Autodial every phone in neighborhood and deliver a recorded message

- Publicize a blitz enforcement on particular streets

- Enlist all enforcement agencies to be involved (e.g., Sheriff, Highway Patrol)

- Warnings

- Speed watch neighborhood adopted by residents-double fines/graduated fines; speed trailers, more enforcement

- Alternative sentencing-with speed culprit scarlet letter

- Make violators get out of car to make them more visible

- Violator bumper stickers/zebra tags

- Residents mark cars so cops know that car was driven by a violator

- Automatic speeding lights installed on cars that only police can turn off

- Patrol area community policing kiosks to expand presence

- Bike cops

- Motorcycle/motor scooter cops

- Feedback from citizens-neighborhood intelligence gathering

- Adopt-a-cop

- Educating the police about the importance of speed control 
- Crossing guards feedback paddles

- Recognition for individual police officer effort

- Direct financial rewards for enforcement

- Decoy officers/decoy offenders

- Political permission/mandate to enforce the laws

- Enforce all laws equally-driver/pedestrian/bicycle

- Judicial support

- Peer courts-community tries you

- Variation in speed tolerance as a function of speed limit

- Block parties with police invited-increase police contact in the neighborhood

- Direct police/citizen contact with violators

- Specialist speed officers remove the stigma of traffic "trophies"

- Ticket cars parked on sidewalk to get them to move to the street and slow traffic

- Neighborhood speed audit-trained officer conducts speed audit-publish result-get residents to do things to control speeds like parking in the street

- Set speed limits by consensus of residents

- Follow-up letters to speeding tickets from police and community association

- Neighborhood speeding school instead of fine for ticket

- Officers deploy speed attenuation signs/cones, scene tape to control speeds

- Pedestrian presence reduced speed limit

- Take home police cars allowed for personal use

- Better graduation of penalties for speeding so that threshold does come up all of a sudden

- Community service fines 


\section{Appendix D}

\section{Education Techniques}

- Premium for people driving slow

- Pace car

- Pop-up policeman-speed sensitive

- Automatic ticket machine

- Burma Shave signs

- High visibility materials on pedestrians

- More graphic PSAs as in Australia

- Public media support for police mission

- Educate developers in design for speed control

- Involve children as spokespersons

- Elementary school education and take home

- Use education to change the culture that car is king

- Reward car nonuse around schools-walkers first

- Target drivers rather than pedestrians

- Involve seniors in campaigns since they are most vulnerable

- Traffic calming does not take away your mobility-it's responsible use

- Drivers handbooks

- TV

- Radio

- Newspapers

- Internet ads

- Training programs

- Billboards

- Utility pole signs-homemade

- Mix safety education with regular curriculum

- Positive messages thanking people for driving responsibly

- Stencils

- Special signs-“A traffic calmed neighborhood"

- Two-sided paddle signs held by people in the neighborhood

- Churches

- Homeowners' associations

- Scouts

- Local businesses

- Signs

- Tailored brochures on speeding

- Tailored brochures signed by neighbors

- Walk our Children to School Day

- Neighborhood gateway entry sign showing number of people/pets killed or injured-days since a close call or injury

- Sign which shows percentage of people following the speed limit and the all-time high percentage

- Sign with neighborhood census showing the real population characteristics 
- Convincer demos with dummies

- Publicize increased risk of dying as speed goes up for drivers as well as peds

- Neighborhood speed regulation made part of remedial traffic offender schools

- Link between excess speed and community livability

- Use GIS tools to target residential neighborhoods based on crashes

- Find a spokesperson who was involved in a speeding-related crash

- Cut down speed depiction in movies/TV

- Doorhangers

- Personal interviews

- Homeowners'associations newsletters

- Message under windshield wipers

- Banner over street

- PTA/PTO

- Street party

- Senior centers/community centers

- Painting murals in the street

- Neighborhood petition

- Neighborhood flags

- "We live here"

- "No bump" sign

- Neighborhood pace car program

- MTV to target young adults

- Cable

- Consequences - insurance, wrecking a car

- Focus on teenage driver and lifelong disability

- Need to identify the speeders

- Special identification of streets

- Name street after kids or families to personify it

- Intersection painting program

- People waving to cars

- Benches in front yards at curb

- Camera boxes to watch motorists like the school bus camera

- "Speed box" ahead

- Ribbons for anti-speeding program

- Watch for "ground hogs"

- "We have no sidewalks - we depend on you for pedestrian safety"

- Neighborhood ownership

- Knock on doors

- Neighborhood services department

- Autodial "outgoing 911"

- Retroreflective giveaway

- Real estate agent newsletters

- Educate realtors to indicate when house is in calmed area

- Flags distributed (American flag) saying we don't speed 
- School contests focused on speeding

- Come up with name for individuals who exhibit the behavior we're trying to discourage (e.g., jaywalker, scofflaw)

- Come up with better phrase than "traffic calming" 


\section{APPENDIX C \\ PROGRAM COUNTERMEASURE MATERIALS}

This appendix contains copies of program countermeasures and supporting materials provided to each city in electronic form. City representatives adapted the materials as necessary for distribution to their neighborhoods or used them as resource material. Included are the following:

- Heed the Speed - an 8-1/2 x 11 flyer for residents reproduced in English and Spanish

- A message for parents - an 8-1/2 x 11 flyer for parents reproduced in English and Spanish

- Now that you're a driver - a flyer for high school students reproduced in English and Spanish - divided into two 4-1/4 x 5-1/2 flyers and printed on both sides

- Speed is lethal - an 8-1/2 x 11 flyer for drivers - reproduced on the reverse side of both the Phoenix and Peoria facsimile traffic tickets

- Speed is lethal - a 4 x 9-3/8 version of the above flyer for drivers

- A message for car dealers - an 8-1/2 x 11 flyer for car dealerships in/near the neighborhoods

- A two-page press release announcing the program

- A set of traffic safety facts that might be used in preparing program publicity materials

- Three sets of articles prepared for inclusion in neighborhood newsletters:

- $\quad$ Engineering versus education/enforcement

- Distance to stop

- Driver fatality likelihood

- Descriptions of problems that can be affected by speeding - prepared as a resource for the newsletter and other articles for the Heed the Speed program

- Radio spots:

- $\quad$ Heed the Speed - The consequences - 30 seconds

- Heed the Speed - In a hurry - 15 seconds

- Heed the Speed - Station ID - Live promo

- Heed the Speed - Want to be a good neighbor? - 15 seconds

- Heed the Speed - The bumps - 15 seconds

- Topics for newspaper articles 


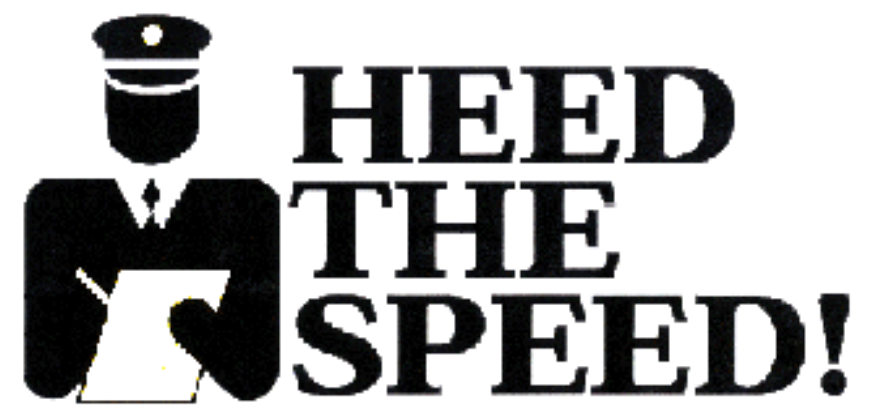

Many individuals in Phoenix and Peoria have expressed concern about the speeds that vehicles travel in their neighborhoods. Heed the Speed is a program that uses education and enforcement to reduce those speeds. The Heed the Speed program is a collaborative effort of the traffic and police departments of the cities of Phoenix and Peoria with support from the National Highway Traffic Safety Administration of the U.S. Department of Transportation.

Heed the Speed in your neighborhood could include:

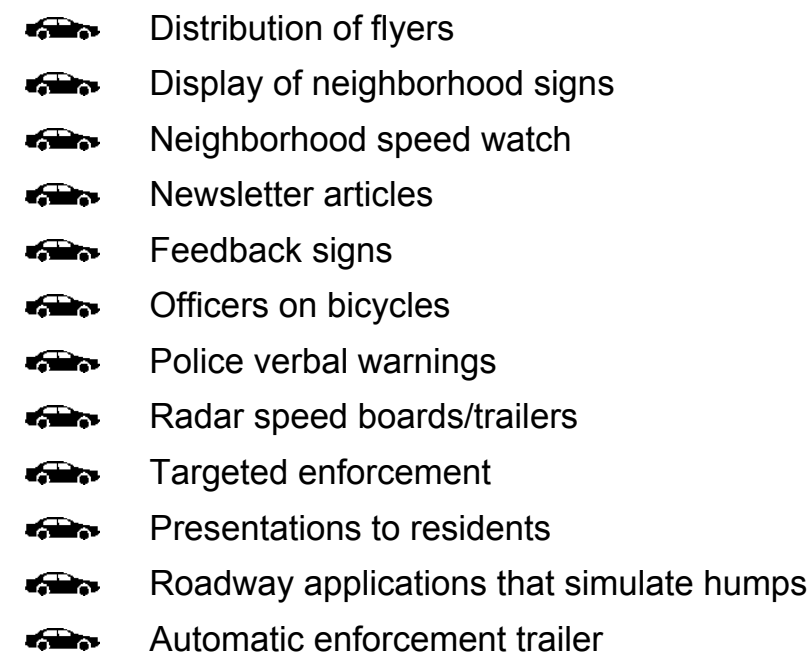

\section{You can make Heed the Speed a success by:}

\section{Putting up signs Driving slower \\ Supporting the police Asking others to slow down}

For further information about Heed the Speed, please contact:

(6) Phoenix: Michael Cynecki, Phoenix Street Transportation Department, 602-262-7217

Peoria: $\quad$ Kelly LaRosa, Peoria Traffic Division, 623-773-7652 


\section{A MESSAGE FOR PARENTS}

When cars speed in residential neighborhoods, it is your children who are at greatest risk. Children act impulsively and frequently run into the street without searching carefully for cars. This problem is compounded when cars speed. If struck by a car going $40 \mathrm{mph}$, a child is 17 times more likely to die than when hit by a car going $20 \mathrm{mph}$. It's important for parents to teach their children to be safe pedestrians by stopping and looking left-right-left before entering the street.

Many parents in Phoenix and Peoria have expressed concern about the speeds that cars travel in their neighborhoods. Heed the Speed is a program that uses education and enforcement to reduce those speeds.

Heed the Speed in your neighborhood could include:

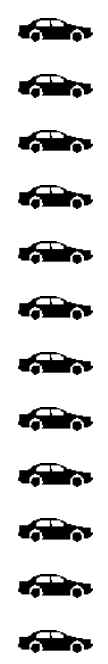

Distribution of flyers Display of neighborhood signs Neighborhood speed watch Newsletter articles Feedback signs

Officers on bicycles Police verbal warnings Radar speed boards/trailers

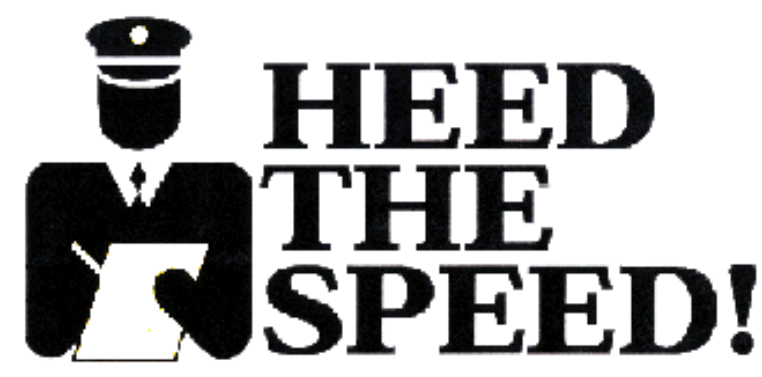
Targeted enforcement Presentations to residents Roadway applications that simulate humps Automatic enforcement trailer

You can make Heed the Speed a success by:

Putting up signs
Supporting the police
And teaching your children to search left-right-left before entering the
street

For further information about Heed the Speed, please contact:

Phoenix:

Michael Cynecki, Phoenix Street Transportation Department, 602-262-7217

Peoria: Kelly LaRosa, Peoria Traffic Division, 623-773-7652 


\section{SPEED CAN BE DEADLY!}

\section{Now that}

\section{You're a Driver ...}

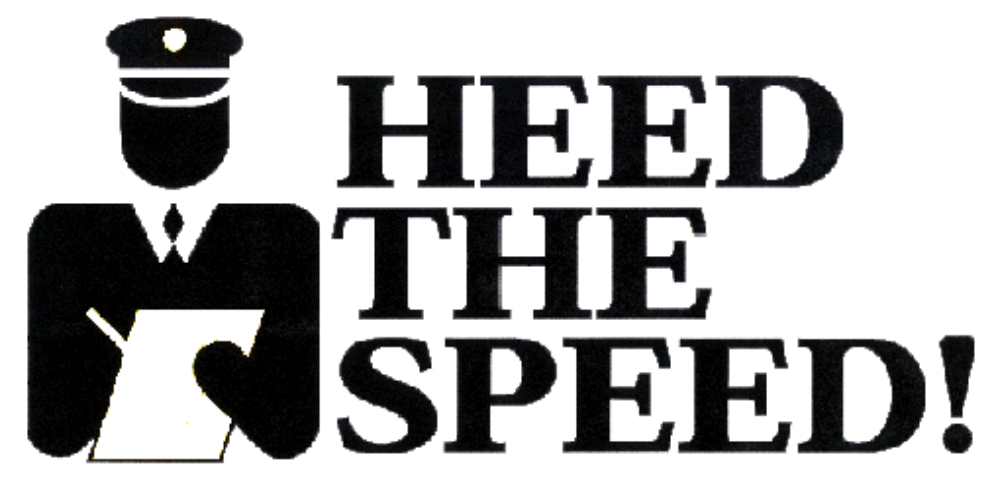

And turn this over

\section{If you hit a pedestrian}

- At $20 \mathrm{mph}, 5 \%$ will die

- At $30 \mathrm{mph}, 45 \%$ will die

- At $40 \mathrm{mph}, 85 \%$ will die

- At $50 \mathrm{mph}$, almost all will die

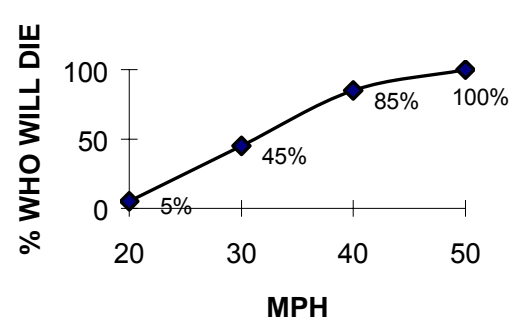

You need time and space to stop

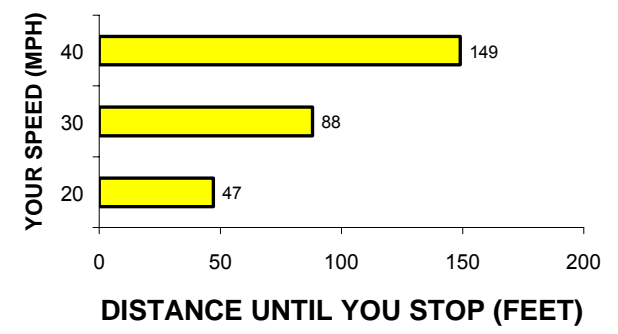

- At $20 \mathrm{mph}$, it will take 47 feet to stop

- At $30 \mathrm{mph}, 88$ feet

- At 40 mph, 149 feet

If you get a ticket for speeding, you'll also get

- A fine of over $\$ 100$

- An insurance increase of hundreds of dollars

- 3 points on your license

So ...

- Drive carefully

- Watch out for pedestrians

- And Heed the Speed

City of Phoenix

City of Peoria

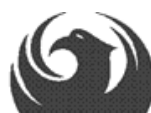




\section{SPEED IS LETHAL!}

When you hit a pedestrian

- At $20 \mathrm{mph} 5 \%$ will die

- At $30 \mathrm{mph} 45 \%$ will die

- At $40 \mathrm{mph} 85 \%$ will die

- At $50 \mathrm{mph}$ almost all will die

You need time and space to stop
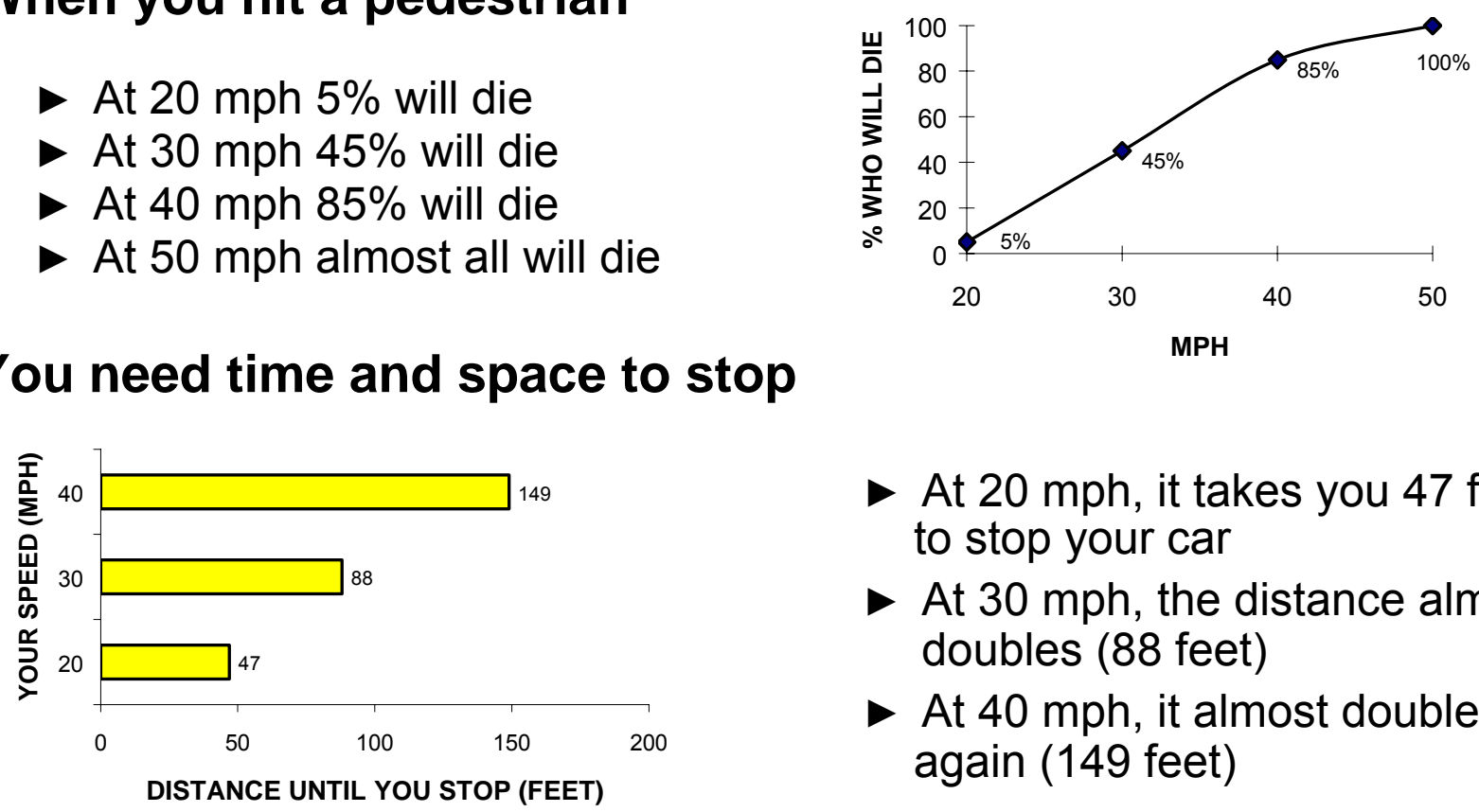

- At $20 \mathrm{mph}$, it takes you 47 feet to stop your car

- At $30 \mathrm{mph}$, the distance almost doubles (88 feet)

- At $40 \mathrm{mph}$, it almost doubles again (149 feet)

For a speeding ticket, you'll get

- A fine of over $\$ 100$

- An insurance increase of hundreds of dollars

- 3 points on your license

\section{Slow down and make your neighborhood safer}

City of Phoenix
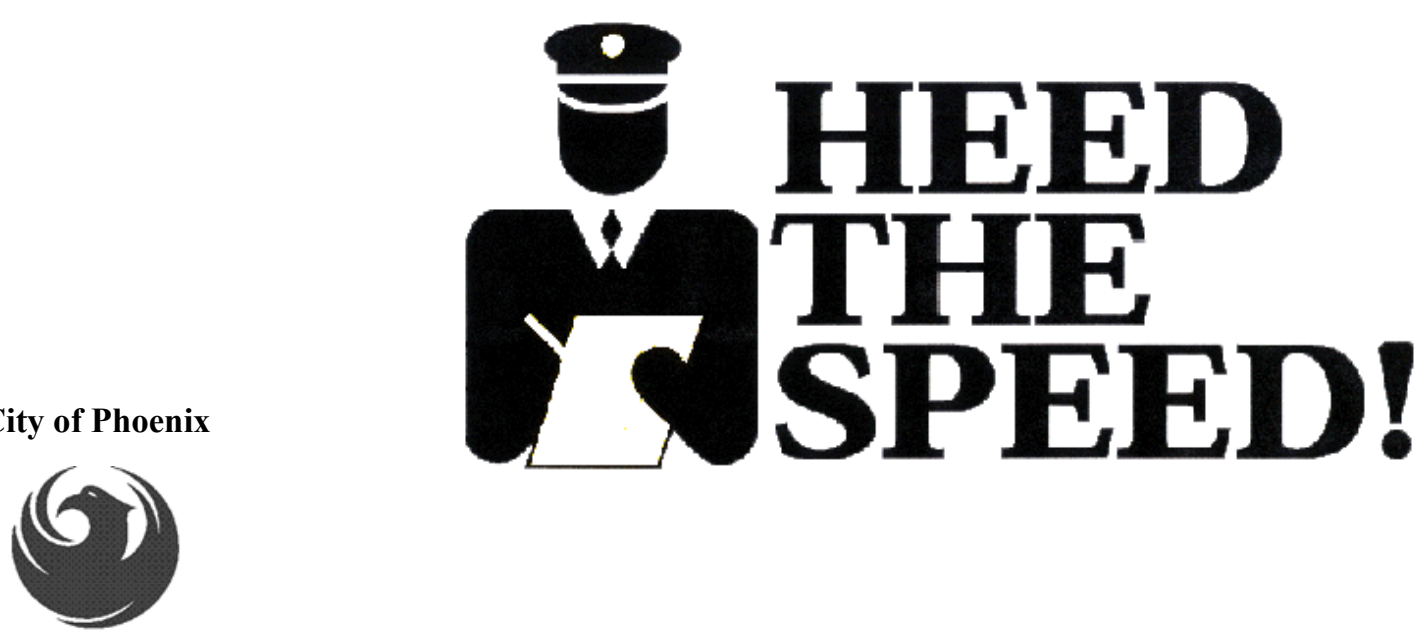

Sources: Arizona Driver License Manual; Transportation Research Board Special Report No. 254: Managing Speed. 


\section{SPEED IS LETHAL!}

\section{If you hit a pedestrian}

- At $20 \mathrm{mph}, 5 \%$ will die

- At $30 \mathrm{mph}, 45 \%$ will die

- At $40 \mathrm{mph}, 85 \%$ will die

- At $50 \mathrm{mph}$, almost all will die

\section{You need time and space to stop}

- At 20 mph it takes you 47 feet to stop your car

- At $30 \mathrm{mph}$, the distance almost doubles (88 feet)

- At 40 mph, it almost doubles again (149 feet)

For a speeding ticket, you'll get

- A fine of over $\$ 100$

- An insurance increase of hundreds of dollars

- 3 points on your license

\section{Slow down and make your neighborhood safer}

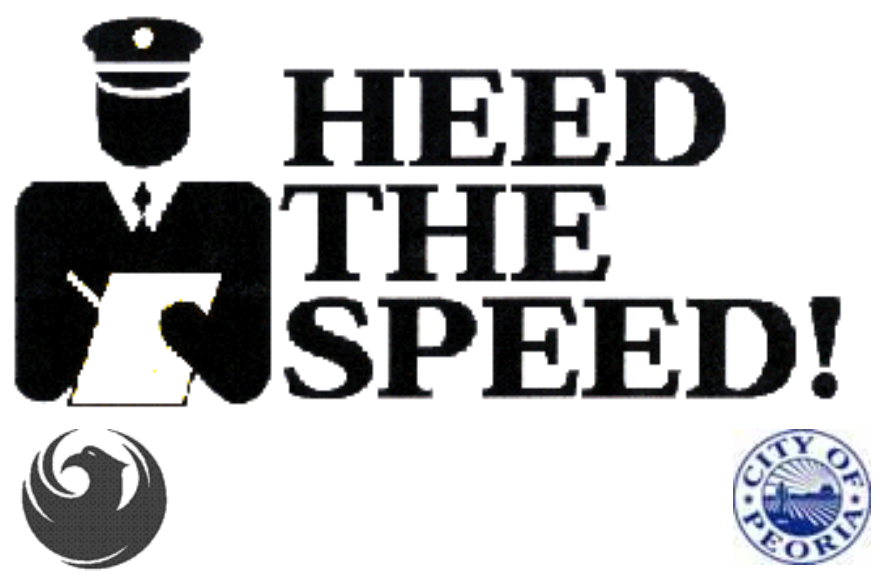

City of Phoenix

City of Peoria

Sources: Arizona Driver License Manual; Transportation Research Board Special Report No. 254: Managing Speed. 


\section{A MESSAGE FOR CAR DEALERS}

When cars speed in residential neighborhoods, both drivers and pedestrians are at risk. If struck by a car going $40 \mathrm{mph}$, a person is 17 times more likely to die than when hit by a car going 20 $\mathrm{mph}$. When conducting test drives, people frequently drive too fast. To be safe, it's important that test drives be made at reasonable speeds and that they avoid neighborhood streets when possible.

Many people in Phoenix and Peoria have expressed concern about the speeds that vehicles travel in their neighborhoods. Heed the Speed is a program that uses education and enforcement to reduce those speeds. It is a collaborative effort of the traffic and police departments of the cities of Phoenix and Peoria with support from the National Highway Traffic Safety Administration of the U.S. Department of Transportation.

You can help make Heed the Speed a success by:

Asking customers to slow down

Driving slower yourself

Avoiding test drives on neighborhood streets

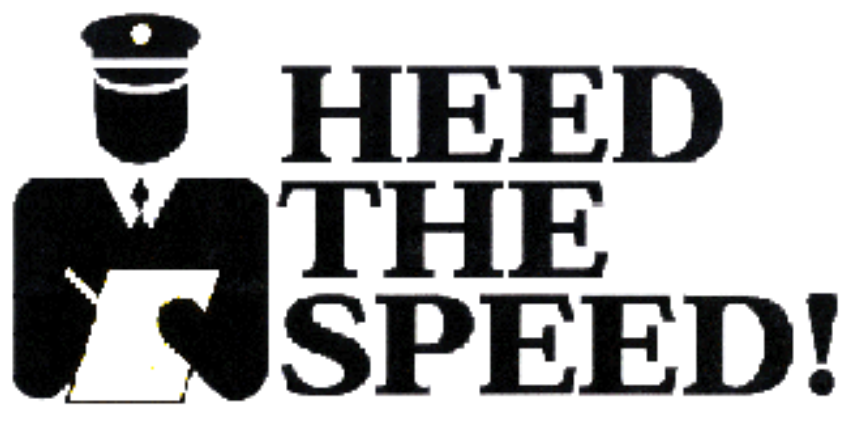

For further information about Heed the Speed, please contact:

(6) Phoenix: Michael Cynecki, Phoenix Street Transportation Department, 602-262-7217

Peoria: Kelly LaRosa, Peoria Traffic Engineering Division, 623-773-7652 


\section{FOR IMMEDIATE RELEASE}

Date

\section{PHOENIX AND PEORIA ANNOUNCE PROGRAM TO REDUCE SPEEDING IN NEIGHBORHOODS}

Many residents of Phoenix and Peoria have expressed concern about the speeds at which vehicles travel in their neighborhoods. Because of these concerns, the two cities have agreed to serve as test sites for a model program to reduce those speeds. Known as Heed the Speed, the program uses a variety of education and enforcement activities to encourage motorists to drive at or below the speed limit.

Heed the Speed is a collaborative effort of the traffic and police departments of the cities of Phoenix and Peoria with support from the National Highway Traffic Safety Administration (NHTSA) of the U.S. Department of Transportation. It is an expanded version of a program of the same name that was previously implemented in the Arcadia section of Phoenix. Lt. Stan Hoover of the Phoenix Police Department said, "We were pleased with the results we obtained with Heed the Speed in Arcadia and are happy to see the program expanded."

There is abundant evidence that higher speeds are associated with a higher likelihood of a pedestrian crash and with more severe pedestrian injuries and death. There has been significant work on engineering approaches to reduce traffic speeds. There have, however, been few attempts to combine public information and enforcement techniques with engineering changes as a means of achieving greater speed reductions. Mike Cynecki of the Phoenix Street Transportation Department commented that "We can't use engineering techniques to reduce speeds on all streets because of special needs. For example, some streets are routes for emergency vehicles and therefore aren't candidates for treatments such as speed humps. We hope an enhanced education and enforcement program will be an effective way to reduce speeds on those streets."

In serving as test sites, the two cities have agreed to implement a variety of education and enforcement activities that will be evaluated over a three-month period. Among others, Heed the Speed activities will include the distribution of flyers, display of neighborhood signs, conduct of a neighborhood speed watch, feedback signs, newsletter articles, police verbal warnings, radar speed boards/trailers, targeted enforcement, presentations to residents, and roadway applications that simulate humps. "We're extremely pleased to be part of this innovative activity and to work with NHTSA and our colleagues in Phoenix" said Scott Nodes, Peoria's Traffic Engineer.

The Phoenix neighborhoods that will participate in Heed the Speed include sections of the following roads: Sweetwater, Moon Valley and Clarendon. In Peoria, sections of the following roads will participate: $95^{\text {th }}$ Avenue, Desert Harbor and Bell Park. The residents of the selected neighborhoods had all previously expressed concerns about excessive vehicle speeds. 
Heed the Speed will include an evaluation component to determine the effectiveness of the program in reducing speeds. If effective, it can serve as a model for other communities that wish to reduce speeding in their neighborhoods. The evaluation is being performed by Dunlap and Associates, Inc., a research-consulting firm from Stamford, CT. Richard Blomberg, the president of Dunlap, said "We're pleased to be doing another study in the Phoenix area because of the sincere interest in traffic safety of all the agencies we've worked with here."

\section{Contacts:}

(6) Phoenix: Michael Cynecki, Phoenix Street Transportation Department, 602-262-7217

Peoria: $\quad$ Kelly LaRosa, Peoria Traffic Division, 623-773-7652 


\section{TRAFFIC SAFETY FACTS}

\section{Managing Speed (TRB SR 254)}

In 1996, NHTSA reported that speed is a contributing factor in 30 percent of all fatal crashes on U.S. highways. (TRB-NRC, p. 39)

The higher the speed, the greater the fatalities, injuries, and property damage in a crash. (From Solomon in TRB, p. 63-64)

When struck by a vehicle traveling at $20 \mathrm{mph}, 5$ percent of pedestrians die; at $30 \mathrm{mph}, 45$ percent of pedestrians die; at $40 \mathrm{mph}, 85$ percent of pedestrians die; and at $50 \mathrm{mph}$, almost all die. (TRB, p. 66)

\section{Literature Review on Vehicle Travel Speeds and Pedestrian Injuries (DOT HS 809021 )}

Fatalities rose from under 2 percent of struck pedestrians when speed limits were below $25 \mathrm{mph}$ to over 22 percent when speed limits were $50 \mathrm{mph}$ or more. (Leaf, p. iv)

\section{Synthesis of Safety Research Related to Speed and Speed Management (FHWA-RD- 98-154, p.10)}

When the national speed rate changed from 55 to $65 \mathrm{mph}$, fatalities increased by 21 percent. (NHTSA source)

\section{Arizona Driver License Manual}

How far a car travels before the driver responds and the vehicle stops. Average stopping distance (feet) of cars on dry, level pavement:

$$
\begin{array}{lcl}
20 \mathrm{mph}= & & 47(22+25) \\
30 \mathrm{mph}= & 88(33+55) \\
40 \mathrm{mph}= & 149(44+105) \\
50 \mathrm{mph}= & 243(55+188) \\
60 \mathrm{mph}= & 366(66+300) \\
70 \mathrm{mph}= & 529(74+455)
\end{array}
$$

Braking distance is directly related to:

Driver perception time

Driver reaction time

Type and condition of the pavement

Type and condition of the tires

Vehicle design and condition of the shock absorbers

Vehicle weight when loaded or owing

Type and condition of the brakes

Speed of the vehicle

When the driver behind you wants to pass, reducing your speed will allow that driver to pass more quickly. The added distance will make it easier for the passing motorist to pull back into the lane. 


\section{Deadly Crossings: American Intersections (Discovery Channel Program)}

It is estimated that more than seven million people will be injured in traffic accidents worldwide this year

- one third of them at intersections.

In the U.S. alone, one million people will be injured crossing an intersection - 7,000 will die.

Traffic claims 40,000 lives each year.

One in four Americans knows someone who was killed or seriously injured in an intersection crash.

One hundred years ago, there were 8,000 cars on the road.

Side impacts account for 80,000 deaths and injuries each year in the U.S.

Every 24 hours in the U.S., 10 people are killed at stop sign intersections. Another 300 are injured. The vast majority are side-impact collisions.

Speed is the single most lethal element in any intersection crash and is a contributing factor in 30 percent of all fatal crashes.

Signals are synchronized to move traffic.

For every $10 \mathrm{mph}$ increase in impact speed, the chance of death doubles for the driver so that the driver who crashes at $40 \mathrm{mph}$ has twice the chance of getting killed as the driver who crashes at $30 \mathrm{mph}$.

The ramifications of that speed are even more terrifying when applied to pedestrians.

Forty thousand pedestrians in the U.S. are killed or injured crossing intersections each year. The difference between those who live and those who die is the speed of the car.

Pedestrians hit at $20 \mathrm{mph}$ have a 95-percent chance of surviving the collision. At $40 \mathrm{mph}$, the chance of survival drops to 13 percent.

Red light running has increased by 20 percent since 1996.

A driver runs a red light approximately every six minutes in the U.S.

In only two seconds, a driver going $40 \mathrm{mph}$ travels 100 feet.

Red light camera results in 40-percent reduction in red light running and a 50-percent reduction in the "halo" effect (reductions in red light running at nearby intersections). 


\section{Neighborhood 1 - Engineering versus Education/Enforcement}

There is abundant evidence that higher speeds are associated with more pedestrian injuries and deaths. In fact, if struck by a car going $40 \mathrm{mph}$, a pedestrian is 17 times more likely to die than when hit by a car going $20 \mathrm{mph}$.

Many residents of the cities of Phoenix and Peoria have expressed concern about the speeds that vehicles travel through their neighborhoods and have requested help in reducing those speeds. In many instances, road humps or other engineering measures have been installed to force cars to slow down. However, as Mike Cynecki of the Phoenix Street Transportation Department has said, "We can't use engineering techniques to reduce speeds on all streets because of special needs. For example, some streets are routes for emergency vehicles and therefore aren't candidates for treatments such as speed humps. We hope an enhanced education and enforcement program will be an effective way to reduce speeds on those streets."

To help solve the speeding problem, the traffic departments of both Phoenix and Peoria are embarking on a program called Heed the Speed. It uses a variety of education and enforcement activities with engineering changes to encourage drivers to go slower. It is adapted from a program by the same name that was previously implemented in the Arcadia section of Phoenix. Lt. Stan Hoover of the Phoenix Police Department said, "We were pleased with the results we obtained with Heed the Speed in Arcadia and are happy to see the program expanded."

Phoenix and Peoria have selected neighborhoods to participate in the program from those whose residents have requested help with their speeding problem. For Phoenix, the program will be implemented on sections of the following roads: Sweetwater, Moon Valley and Clarendon. In Peoria, sections of the following roads will participate: $95^{\text {th }}$ Avenue, Desert Harbor, and Bell Park.

Among others, Heed the Speed activities will include the distribution of flyers, display of neighborhood signs, conduct of a neighborhood speed watch, feedback signs, newsletter articles, police verbal warnings, radar speed boards/trailers, targeted enforcement, presentations to residents, and roadway applications that simulate humps.

The program is being evaluated by Dunlap and Associates, Inc., of Stamford, Connecticut, under a contract with the National Highway Traffic Safety Administration of the U.S. Department of Transportation. If effective, Heed the Speed can serve as a model to reduce speeds in other residential sections of the two cities and in other communities. 


\section{Neighborhood 2 - Distance to Stop}

There is abundant evidence that higher speeds are associated with more pedestrian injuries and deaths. In fact, if struck by a car going $40 \mathrm{mph}$, a pedestrian is 17 times more likely to die than when hit by a car going $20 \mathrm{mph}$.

Many residents of the cities of Phoenix and Peoria have expressed concern about the speeds that vehicles travel through their neighborhoods and have requested help in reducing those speeds. They note that children sometimes run into the street without first searching leftright-left for cars. And sometimes pedestrians simply aren't seen by motorists because trees, shrubs, and other roadway articles block their views of each other until the pedestrian steps into the street. Kelly La Rosa, Peoria's Assistant Traffic Engineer, noted, "in general, it takes three times as much space to stop a car going $40 \mathrm{mph}$ than one going $20 \mathrm{mph}$. Thus, if vehicles travel at slower speeds, the motorist has more time to react if a pedestrian suddenly appears in the roadway."

To help solve the speeding problem, the traffic departments of both Phoenix and Peoria are embarking on a program called Heed the Speed. It uses a variety of education and enforcement activities with engineering changes to encourage drivers to go slower. It is adapted from a program by the same name that was previously implemented in the Arcadia section of Phoenix. Lt. Stan Hoover of the Phoenix Police Department said, "We were pleased with the results we obtained with Heed the Speed in Arcadia and are happy to see the program expanded."

Phoenix and Peoria have selected neighborhoods to participate in the program from those whose residents have requested help with their speeding problem. For Phoenix, the program will be implemented on sections of the following roads: Sweetwater, Moon Valley, and Clarendon. In Peoria, sections of the following roads will participate: $95^{\text {th }}$ Avenue, Desert Harbor, and Bell Park.

Among others, Heed the Speed activities will include the distribution of flyers, display of neighborhood signs, conduct of a neighborhood speed watch, feedback signs, newsletter articles, police verbal warnings, radar speed boards/trailers, targeted enforcement, presentations to residents, and roadway applications that simulate humps.

The program is being evaluated by Dunlap and Associates, Inc., of Stamford, Connecticut, under a contract with the National Highway Traffic Safety Administration of the U.S. Department of Transportation. If effective, Heed the Speed can serve as a model to reduce speeds in other residential sections of the two cities and in other communities. 


\section{Neighborhood 3 - Driver Fatality Likelihood}

There is abundant evidence that higher speeds are associated with more pedestrian injuries and deaths. In fact, if struck by a car going $40 \mathrm{mph}$, a pedestrian is 17 times more likely to die than when hit by a car going $20 \mathrm{mph}$.

Many residents of the cities of Phoenix and Peoria have expressed concern about the speeds that vehicles travel through their neighborhoods and have requested help in reducing those speeds. Not only are these high speeds dangerous to pedestrians, but drivers themselves have an increased chance of fatality when speeds are increased. Peoria Traffic Engineer Scott Nodes noted, "For every $10 \mathrm{mph}$ increase in vehicle speed, the driver's chance of death doubles. Thus a driver who crashes at $30 \mathrm{mph}$ has twice the chance of getting killed as a driver who crashes at 20 mph."

To help solve the speeding problem, the traffic departments of both Phoenix and Peoria are embarking on a program called Heed the Speed. It uses a variety of education and enforcement activities with engineering changes to encourage drivers to go slower. It is adapted from a program by the same name that was previously implemented in the Arcadia section of Phoenix. Lt. Stan Hoover of the Phoenix Police Department said, "We were pleased with the results we obtained with Heed the Speed in Arcadia and are happy to see the program expanded."

Phoenix and Peoria have selected neighborhoods to participate in the program from those whose residents have requested help with their speeding problem. For Phoenix, the program will be implemented on sections of the following roads: Sweetwater, Moon Valley, and Clarendon. In Peoria, sections of the following roads will participate: $95^{\text {th }}$ Avenue, Desert Harbor, and Bell Park.

Among others, Heed the Speed activities will include the distribution of flyers, display of neighborhood signs, conduct of a neighborhood speed watch, feedback signs, newsletter articles, police verbal warnings, radar speed boards/trailers, targeted enforcement, presentations to residents, and roadway applications that simulate humps.

The program is being evaluated by Dunlap and Associates, Inc., of Stamford, Connecticut, under a contract with the National Highway Traffic Safety Administration of the U.S. Department of Transportation. If effective, Heed the Speed can serve as a model to reduce speeds in other residential sections of the two cities and in other communities. 


\title{
DESCRIPTIONS OF PROBLEMS THAT CAN BE AFFECTED BY SPEEDING
}

\author{
(Prepared as a resource for the preparation \\ of newsletter and other articles for the Heed the Speed program)
}

Briefly described in the following paragraphs are several problem areas in which the safety of pedestrians in residential communities can be affected by the driver's speed. They include errors made by the driver and pedestrian, conditions of both driver and pedestrian, location of the crash, roadway design factors, and the types of individuals involved. The problem areas are grouped into the following categories: pedestrian errors, motorist errors, impairment, visibility/conspicuity, special locations, geometrics/operations, high injury severity, and target group.

The information has been assembled as a resource for preparing newsletter and other articles for the Heed the Speed program. If there is excessive driver speed, each problem will be compounded, the likelihood of a crash will increase and the severity of the crash will increase.

\section{Pedestrian Errors}

1. Mid-block Dart-out/Dash. The pedestrian enters the street suddenly from a driveway, sidewalk, or curb and presents a short-time exposure to the motorist. The pedestrian typically goes into the roadway without stopping and searching adequately for motor vehicles and may be running. The pedestrian often enters the roadway between parked cars and is not seen by the motorist until it is too late for the motorist to stop. The motorist typically assumes that any entering traffic (including pedestrians) will yield and therefore also fails to search adequately. If the vehicle is speeding, the motorist may not be able to stop in time to avoid a crash. Most of these crashes occur to children under 15 years of age. The problem occurs frequently on residential roadways where small children are playing, but it can occur on any roadway.

2. Intersection Dash. The pedestrian enters the roadway suddenly at an intersection and presents a short-time exposure to the motorist. As with the mid-block dart-out, the pedestrian typically enters the roadway without stopping and searching adequately for vehicles and may be running. The motorist typically assumes that any entering traffic (including pedestrians) will yield and therefore also fails to search adequately. If the vehicle is speeding, the motorist may not be able to stop in time to avoid a crash. These crashes occur frequently to children under 15 years of age.

3. Intersection Negotiation. The pedestrian fails to negotiate an intersection safely. The pedestrian may fail to obey a traffic signal and be struck by a vehicle moving with the green light. The pedestrian may fail to clear the intersection before the light turns green for opposing traffic and therefore be trapped in the intersection. The pedestrian may misjudge the traffic gap and walk in front of a vehicle or walk into a vehicle. One or more motorists may stop to let the pedestrian pass and the pedestrian is struck by a following motorist whose view of the pedestrian is blocked by the vehicles that have stopped to yield to the pedestrian. If the vehicle is speeding, the motorist may not be able to stop in time to avoid a crash. 
4. Walking in Roadway. The pedestrian walks in the roadway either on the shoulder or in a traffic lane usually because an adequate sidewalk does not exist. The pedestrian may be walking to or from a disabled vehicle. Frequently, the pedestrian walks with (rather than facing) traffic. The pedestrian therefore does not have a view of traffic on the side of the road on which the pedestrian is traveling and is not able to see and react in time to avoid an impending danger. If the vehicle is speeding, the motorist may not be able to stop in time to avoid a crash. This problem occurs most frequently on rural and residential roads. Conspicuity can be a problem the pedestrian may be difficult to see, particularly at night.

5. Failure to Search. The pedestrian simply fails to search adequately for vehicles before entering the roadway. This is a particular problem when something screens the pedestrian and motorist from seeing each other. For example, when crossing in front of a hedge, the pedestrian might search but forget to search around the hedge. This pedestrian error occurs with many crash types. First, it occurs with intersection and mid-block darts and dashes when the pedestrian typically runs into the street and does not search at all. It occurs when pedestrians step into the roadway behind a vehicle and pay no attention to cues that the vehicle is backing. It occurs when pedestrians enter and exit parked or stopped vehicles and are struck by passing vehicles. It occurs when a pedestrian enters a traffic lane in front of a vehicle that has stopped to let the pedestrian pass and then is hit by a vehicle in the next lane whose driver cannot see the pedestrian because of the screening effect of the stopped vehicle (the multiple-threat crash). If the vehicle is speeding, the motorist may not be able to stop in time to avoid a crash. The problem occurs with pedestrians of all ages.

6. Unsafe In-Street Activities. This problem occurs when the pedestrian is playing or standing in the street and disregarding traffic or when the pedestrian is playing games with traffic. Small children sometimes play in the street unsupervised and pay no attention to traffic. Older children and young adults stand in the street or lean against cars without regard to traffic in adjacent travel lanes. Some teens and young adults jump on and off or in and out of vehicles without regard to other traffic. In addition, some persons (usually impaired by alcohol) actually lie down and sleep in the street. If the vehicle is speeding, the motorist may not be able to stop in time to avoid a crash.

\section{Motorist Errors}

7. Improper Turns. The motorist strikes a pedestrian while making a turn at an intersection or mid-block. At an intersection, the turn can be left or right, including a right turn on red. The motorist may run a stop sign or signal at an intersection while making the turn. The motorist can also be making a turn mid-block to enter or exit a driveway or alley and strike a pedestrian on the sidewalk or in the driveway. The critical element is that the motorist's workload is heightened by the turning maneuver and the motorist does not make a last check for pedestrians before starting the turn. In addition, if the vehicle is speeding, the motorist may not be able to stop in time to avoid a crash.

8. Right Turn on Red. The motorist stops at a controlled intersection, searches for traffic approaching from the left and proceeds to make a right turn on a red signal without searching to the right. The motorist then strikes a pedestrian who is attempting to cross the street in front of the stopped motorist. By not searching to the right before moving, the motorist may also strike a 
pedestrian who is attempting to cross the street that the motorist is entering. In addition, if the vehicle is speeding, the motorist may not be able to stop in time to avoid a crash.

9. Failure to Search. The motorist simply fails to search adequately for other roadway users, and that is the major cause of the crash problem. This motorist error is commonly associated with several crash types. It occurs when the motorist is proceeding straight ahead or is turning into or out of an intersection, driveway or alley. The turn can be left or right, including right turn on red. The motorist may cut the corner when making a turn and strike a pedestrian at the curb or on the sidewalk. The motorist frequently fails to search adequately, particularly for pedestrians, when entering or exiting on-street parking, when backing, and when in a nonroadway location (for example, a parking lot). The motorist may run a sign or signal without searching or, alternatively, the motorist may obey the sign or signal but fail to yield to a pedestrian because the pedestrian is not recognized. The motorist may fail to stop and search for pedestrians when a vehicle in the next lane has stopped (the multiple-threat crash). In addition, if the vehicle is speeding, the motorist may not be able to stop in time to avoid a crash.

10. Excessive Speed. The motorist is driving too fast to respond quickly enough to avoid hitting a pedestrian in or entering the roadway. The pedestrian may be walking in the roadway or may appear suddenly in the roadway. In the latter case, the pedestrian typically runs out from a driveway, alley, or sidewalk mid-block, often on a play vehicle. The motorist may be overtaking the pedestrian and simply may not have sufficient time to see the pedestrian. The motorist may lose control of the vehicle due to the excessive speed.

11. Overtaking, Failure to See. The motorist is overtaking a pedestrian walking or running in the roadway and fails to see the pedestrian until it is too late to take evasive action. Although the problem is more frequent during darkness, it also occurs during daylight. Poor pedestrian conspicuity (for example, due to dark clothing) can be a contributing factor as can excess speed and alcohol use on the part of the motorist. In addition, if the vehicle is speeding, the motorist may not be able to stop in time to avoid a crash.

\section{Impairment}

12. Pedestrian Alcohol/Drugs. The pedestrian is impaired by alcohol or drugs and is struck by a motor vehicle. The pedestrian frequently acts in an unexpected manner. For example, the pedestrian may enter the roadway suddenly from the sidewalk or median or may cross in front of a stopped vehicle and then suddenly turn and walk in front of the vehicle in the reverse direction. The pedestrian may be lying in the roadway. In addition, if the vehicle is speeding, the motorist may not be able to stop in time to avoid a crash.

13. Motorist Alcohol/Drugs. The motorist is impaired by alcohol or drugs and hits a pedestrian. The motorist may be overtaking the pedestrian and may not detect the pedestrian or may misjudge the space required to pass safely. The motorist may make a left or right turn in front of a pedestrian. The motorist may lose control of the vehicle. In addition, if the vehicle is speeding, the motorist may not be able to stop in time to avoid a crash. 


\section{Visibility/Conspicuity}

14. Visual Screens. A visual screen is an object that blocks the pedestrian and motorist views of each other. Examples include parked cars, cars in adjacent lanes, sidewalk furniture, fences, vegetation, signs, and street clutter. Visual screen problems occur both in roadway and non-roadway situations (for example, parking lots). The views from residential and commercial driveways and alleys and at mid-block crossings are frequently blocked by visual screens. Therefore, pedestrians who enter the street from driveways and alleys without searching around visual screens are frequently struck by motorists who simply don't know that they are there. Young pedestrians on play vehicles ("big wheels") are one component of this problem since they are small, low to the ground and easily screened. Pedestrians entering the street from sidewalks are often not seen by motorists because they are screened by parked cars or a variety of other objects. Views at intersections can also be blocked. In addition, if the vehicle is speeding, the motorist may not be able to stop in time to avoid a crash.

15. Daytime Conspicuity. The pedestrian simply isn't conspicuous enough in the daytime, that is, the pedestrian doesn't stand out enough from the background. As a result, the pedestrian is not noticed by the motorist in time to avoid a crash. These pedestrians are certainly above the visual threshold, but still fail to prompt detection and recognition from motor vehicle drivers. Motorists often fail to see pedestrians who are riding on play vehicles, probably because they are small, low to the ground, and fast-moving. The motorist can fail to see a pedestrian when executing turns because the pedestrian is camouflaged against vegetation or hidden in shadows. Daytime conspicuity problems can occur when motorists drive out of driveways or alleys. Motorists also frequently fail to detect pedestrians that they are overtaking. In addition, if the vehicle is speeding, the motorist may not be able to stop in time to avoid a crash.

16. Nighttime Conspicuity. The pedestrian is not conspicuous at night often because the pedestrian is near or below the visual threshold for detection. Sometimes, parts of the pedestrian, particularly one wearing retroreflective garments, are visible but do not stand out from among similar competing signals. The motorist can fail to see a pedestrian when the motorist is turning in front of a pedestrian. Nighttime conspicuity can be a problem when the motorist is backing, driving out from a driveway or alley, running a sign or signal at an intersection, and overtaking a pedestrian. In addition, if the vehicle is speeding, the motorist may not be able to stop in time to avoid a crash.

\section{Special Locations}

17. High-Risk Locations. Some pedestrian/motor vehicle problems occur because the location is inherently risky for a pedestrian. The types of high-risk locations vary by community. Generic locations that are typically high risk include busy intersections, high-speed roads, and residential and commercial driveways. Particular high risk locations can be generated by ongoing road construction, poor road conditions, poor lighting, flawed access management or faulty roadway design. Residential mail box locations in rural and suburban areas can be high risk if the pedestrian is forced to cross to and from the mailbox. Expressways are especially high risk locations for pedestrians. In addition, if the vehicle is speeding, the motorist may not be able to stop in time to avoid a crash with a pedestrian. 
18. Residential Driveways. Residential driveways are dangerous places, particularly for young pedestrians. Crashes that occur largely involve young children who run into the street from the driveway or sidewalk area without first looking for traffic. Sometimes the children are riding on play vehicles. A visual screen such as a parked car is often involved in these crashes. Backing vehicles in driveways are a particular danger to small children. Also included are crashes where a vehicle makes a turn into the driveway and strikes a pedestrian who is not seen in time for the driver to take evasive action. In addition, if the vehicle is speeding, the motorist may not be able to stop in time to avoid a crash with a pedestrian.

19. Sidewalks. Pedestrians sometimes walk or run into the street directly from the sidewalk without first searching for traffic. This can be a particular problem for young children. Sidewalks are out of the normal search pattern for many motorists, and the pedestrian frequently isn't seen until it is too late. Visual screens are often a contributing factor to this problem area. Turning vehicles can cut the corner and strike pedestrians on the sidewalk. Backing vehicles can strike pedestrians on the sidewalk. Out-of-control vehicles can mount the sidewalk and strike pedestrians. In addition, if the vehicle is speeding, the motorist may not be able to stop in time to avoid a crash with a pedestrian.

20. Bus Stops. At commercial bus stops, pedestrians frequently exit a bus and then try to cross the street in front of the bus without first searching for traffic. They are screened by the bus from other traffic and are struck when they emerge into traffic. Pedestrians also run from the other side of the street to catch a bus without first looking for traffic. Similar problems exist for young children when crossing the street to and from the school bus. Drivers fail to recognize the significance of the stopped bus and don't perform an adequate search for pedestrians. In addition, if the vehicle is speeding, the motorist may not be able to stop in time to avoid a crash with a pedestrian. Commercial bus stops located on the near sides of intersections are particularly dangerous because they encourage crossings in front of the bus.

21. Roadway Work Sites. Construction workers are present in or near the roadway as part of their work responsibilities. Very few are trying to cross the road. Rather, they are directing traffic or performing other assigned duties in the roadway. These pedestrians are victims of motorists who are traveling too fast to take evasive action. In addition, motorists frequently misjudge the passing distance required to avoid striking a pedestrian in the roadway. Conspicuity can also be a problem.

22. Schools. Schools can be particularly dangerous places for pedestrians. Child drop-off and pick-up locations can consist of a maze of cars and buses pulling in and out at school start and closing times. Children are excited about both arriving at and leaving school and fail to pay attention to traffic. Proper design and control of drop-off locations is required to avoid pedestrian crashes. Although posted speeds are usually reduced in school zones, many motorists fail to obey them. Some schools are located on busy roads, and children need assistance in crossing the street. Safe routes to school are often not identified.

\section{Geometrics/Operations}

23. Geometrics/Roadway Design. Increases in traffic volume and speed elevate the danger of a pedestrian/motor vehicle crash. Street design elements impact driver speeds and volume. Increased speeds influence the driver's perception/reaction time and vehicle stopping times. 
Crosswalk details such as high-visibility markings and stop bar placement influence driver behavior. Bulb outs and refuge islands shorten pedestrian crossing distance and improve visibility between drivers and pedestrians. The provision of a sidewalk or shoulder determines whether a pedestrian must walk in the roadway. Grade separated tunnels or bridges that remove pedestrians from the vehicle path may be practical in some situations. Subtle elements of roadway geometrics, such as corner radii, have far reaching implications for pedestrians as well as vehicles. Every roadway feature should be evaluated for its impact on both motorized and nonmotorized users.

24. Operations/Maintenance. Characteristics of the roadway such as signal timing, traffic speed and gaps, marking and striping, push button location, surface type and condition, and ramp angle and location influence the safety and behavior of pedestrians. Factors such as signals that do not allow adequate time for pedestrians to cross at the intersection will influence the crossing points selected by pedestrians. Operational changes, such as a change in signal timing, can provide effective, low-cost strategies to reduce pedestrian conflicts in some environments.

\section{High Injury Severity}

25. Fatal Crashes. Fatal crashes typically generate a significant public outcry and demands for change. Many fatal pedestrian crashes involve motorists who do not detect the pedestrian walking or running in the roadway. Crashes involving elderly pedestrians are often fatal. Fatal crashes include mid-block and intersection darts and dashes where the pedestrian presents only a short-term exposure to the motorist, vehicle turns at intersections and mid-block, driver violations at intersections, and other intersection and mid-block crashes. In addition, if the vehicle is speeding, the motorist may not be able to stop in time to avoid a crash with a pedestrian.

26. Nighttime Crashes. Nighttime crashes often become a focal point because of the obvious mismatch between a pedestrian and a motor vehicle. In many nighttime crashes, the motorist fails to detect a pedestrian walking or running in the roadway. The night detection problem is most critical on higher speed roadways. Alcohol use by the pedestrian and/or motorist is often a factor. In addition, if the vehicle is speeding, the motorist may not be able to stop in time to avoid a crash with a pedestrian.

\section{Target Group}

27. Pre-School Pedestrian. A pre-school child is typically involved in crashes near home. These children often play in driveways or on sidewalks in front of their homes. When not supervised, they run into the street without stopping and looking for traffic. If a vehicle is going too fast, the driver may not be able to respond in time to avoid a crash. Pre-school children are often on play vehicles. They can be the focus of safety efforts in a pre-school setting.

28. Elementary School Pedestrian. Elementary school children are often the focus of safety efforts because they are easy to reach in a school setting. The elementary school pedestrian is typically involved in crashes close to home, at nearby intersections and in nearby non-roadway locations (for example, parking lots). These crashes can involve the pedestrian running out from a residential or commercial driveway or sidewalk. The motorist may be 
backing. In addition, if the vehicle is traveling too fast, the motorist may not be able to stop in time to avoid a crash.

29. Middle/High School Pedestrian. As with elementary school students, middle and high school pupils can be addressed with school-based programs. Since middle and high school pedestrians travel farther from home than their younger counterparts, they are exposed to both neighborhood and commercial district threats as well as to threats that occur in non-roadway locations (for example, parking lots). They therefore can be involved in almost any crash type including both those common to children and those common to adults. These include mid-block dashes from driveways and sidewalks and crashes involving overtaking motorists, motorist turns and merges, motorist failure to yield to the pedestrian and backing motorists. The pedestrian can be trapped in an intersection when the light changes or can proceed past a stopped vehicle and then be hit by a vehicle in the next lane. In addition, if the vehicle is traveling too fast, the motorist may not be able to stop in time to avoid a crash.

30. Parent. Young children don't appreciate roadway dangers, and they make common errors. They run into the roadway without stopping and searching for traffic, and traffic may be moving too quickly for motorists to make safe responses and avoid a crash. Lack of parental supervision exacerbates the problem.

31. Adult. Most adults are pedestrians at some time during their day. Some walk to and from work. Some simply walk to and from buses/trains or to and from parked cars, parking lots and garages. As such, adults walk at all times of day including peak traffic hours. They are involved in all types of pedestrian crashes including those in which the motorist is speeding.

32. Recreational/Exercise Walker/Jogger. Many adults walk or jog for recreation or exercise. In order to maintain their exercise rhythm, many stop and jog in place in the street while waiting for traffic to pass. Many also walk or run in the street, frequently with traffic. Some do not wear conspicuous clothing, particularly at nighttime. They can be particularly vulnerable when a vehicle is going too fast for the motorist to respond in time to avoid a crash.

33. Older Adult. Senior pedestrians (aged 65+) are involved in fewer pedestrian crashes $(7.7 \%)$ than would be expected by their numbers $(12.5 \%)$ in the population. However, they account for almost one-quarter of all pedestrian fatalities. Older pedestrians typically cross at intersections and are therefore involved in many intersection crashes, including those with turning vehicles. Because they are likely to move slowly, they are particularly vulnerable to cars that are traveling too fast. Older adults tend to wear conservative clothing that does not stand out from the environment. They are also often involved in parking lot crashes where they are hit by backing vehicles. Their crashes tend to occur in the daytime.

34. People With Disabilities. Many persons with disabilities use walking for exercise as well as for purposeful activities. Those with impaired mobility may have difficulty crossing the street even on a green light. Some may not be able to increase their speed without the danger of falling. Some are confined to wheelchairs and therefore more easily screened from the motorist's view by parked cars, vegetation, street furniture, and other objects. Some may find it difficult to negotiate curbs unless ramps are provided. Persons with visual impairments may have difficulty interpreting signs and signals unless auditory cues are provided. Individuals with mental impairments may act like small children and enter a traffic lane suddenly and unexpectedly. In 
addition, if a vehicle is traveling too fast, the motorist may not be able to stop in time to avoid a crash.

35. Skaters/Scooter Riders. This target group includes persons on skateboards, roller skates, inline skates, and scooters. Included are both children and adults who operate in the street, on the sidewalk, and on bicycle/pedestrian paths. Skill levels range from beginner to advanced. Most of these pedestrians do not wear protective equipment. They may appear in the street suddenly, and the motorist may have insufficient time to react to their appearance. In addition, if the vehicle is traveling too fast, the motorist may not be able to stop in time to avoid a crash. Individuals in this target group may attempt to attach themselves to moving vehicles in the roadway. On the sidewalk, they can cause dangers to pedestrians on foot. Inexperienced persons may fall.

36. Teenage Motorist. Teenage motorists lack roadway experience and often overestimate their abilities. Many young drivers operate their vehicles too fast in critical areas, especially around schools and residential neighborhoods where many young unpredictable children are present. Teenage motorists are involved in crashes in which the pedestrian darts or dashes into the roadway at an intersection or mid-block. They make violations at intersections. They are involved in crashes in which pedestrians are working or playing in the roadway. Teenage motorists cause problems when they are backing. 


\section{Heed the Speed - The Consequences}

\section{Announcer:}

Ever get a speeding ticket? It's no fun. The fine is at least a hundred, and the insurance increases can be a lot more. Plus, you get three points on your license. If all you got was the ticket, you were lucky. If you had hit a pedestrian when you were speeding, you would have done a lot of damage. Almost all pedestrians struck at 40 miles per hour will die. But at 20 miles per hour, almost all will live. Please slow down, Heed the Speed and let your neighbors live.

Many individuals in Phoenix and Peoria have expressed concern about the speeds that vehicles travel in their neighborhoods. Heed the Speed is a program that uses education and enforcement along with traffic engineering changes to reduce those speeds. The Heed the Speed program is a collaborative effort of the traffic and police departments of the cities of Phoenix and Peoria with support from the National Highway Traffic Safety Administration of the U.S. Department of Transportation.

For further information about Heed the Speed, please contact:

(6) Phoenix: Michael Cynecki, Phoenix Street Transportation Department, 602-262-7217

Peoria: $\quad$ Kelly LaRosa, Peoria Traffic Engineering Division, 623-773-7652 


\section{Heed the Speed - In a Hurry}

\section{Announcer:}

In a hurry? Running late? Driving a little too fast? Did you know that you're 17 times more likely to kill a pedestrian at 40 miles per hour than at 20? Please slow down, Heed the Speed and let your neighbors live.

Many individuals in Phoenix and Peoria have expressed concern about the speeds that vehicles travel in their neighborhoods. Heed the Speed is a program that uses education and enforcement along with traffic engineering changes to reduce those speeds. The Heed the Speed program is a collaborative effort of the traffic and police departments of the cities of Phoenix and Peoria with support from the National Highway Traffic Safety Administration of the U.S. Department of Transportation.

For further information about Heed the Speed, please contact:

(6) Phoenix: Michael Cynecki, Phoenix Street Transportation Department, 602-262-7217

Peoria: $\quad$ Kelly LaRosa, Peoria Traffic Engineering Division, 623-773-7652 
Radio Live Promo

\section{Heed the Speed - Station ID}

\section{Announcer:}

[Station call letters and name] reminds you to please slow down, Heed the Speed and let your neighbors live.

Many individuals in Phoenix and Peoria have expressed concern about the speeds that vehicles travel in their neighborhoods. Heed the Speed is a program that uses education and enforcement along with traffic engineering changes to reduce those speeds. The Heed the Speed program is a collaborative effort of the traffic and police departments of the cities of Phoenix and Peoria with support from the National Highway Traffic Safety Administration of the U.S. Department of Transportation.

For further information about Heed the Speed, please contact:

(6) Phoenix: Michael Cynecki, Phoenix Street Transportation Department, 602-262-7217

Peoria: $\quad$ Kelly LaRosa, Peoria Traffic Engineering Division, 623-773-7652 


\section{Heed the Speed - Want to Be a Good Neighbor?}

\section{Announcer:}

Want to be a good neighbor? It's easy. Slow down and you'll make life better in your neighborhood for everyone. [This station]

[Station call letters][Station name] asks you to please slow down, Heed the Speed and let your neighbors live.

Many individuals in Phoenix and Peoria have expressed concern about the speeds that vehicles travel in their neighborhoods. Heed the Speed is a program that uses education and enforcement along with traffic engineering changes to reduce those speeds. The Heed the Speed program is a collaborative effort of the traffic and police departments of the cities of Phoenix and Peoria with support from the National Highway Traffic Safety Administration of the U.S. Department of Transportation.

For further information about Heed the Speed, please contact:

(6) Phoenix: Michael Cynecki, Phoenix Street Transportation Department, 602-262-7217

Peoria: $\quad$ Kelly LaRosa, Peoria Traffic Engineering Division, 623-773-7652 


\section{Heed the Speed - The Bumps}

\section{Announcer:}

Ever hit a speed bump too fast? Well, what if that bump were a pedestrian? The faster you're going, the more likely you are to kill a pedestrian if you hit one. Seventeen times more likely at 40 than at 20. Please slow down, Heed the Speed and let your neighbors live.

Many individuals in Phoenix and Peoria have expressed concern about the speeds that vehicles travel in their neighborhoods. Heed the Speed is a program that uses education and enforcement along with traffic engineering changes to reduce those speeds. The Heed the Speed program is a collaborative effort of the traffic and police departments of the cities of Phoenix and Peoria with support from the National Highway Traffic Safety Administration of the U.S. Department of Transportation.

For further information about Heed the Speed, please contact:

(6) Phoenix: Michael Cynecki, Phoenix Street Transportation Department, 602-262-7217

Peoria: $\quad$ Kelly LaRosa, Peoria Traffic Engineering Division, 623-773-7652 


\section{Topics for Newspaper Articles}

1. Speeding-related crashes in U.S. and Arizona. In 2000, speeding was a contributing factor in 29 percent of all fatal crashes in the United States, and 12,350 lives were lost in speeding-related crashes. In 2000, there were 1,036 traffic fatalities in Arizona; 354 (34\%) of them were speeding-related.

2. Speeding on interstates - Fifty-three of the 254 speeding-related fatalities in Arizona occurred on interstate highways; the remainder on non-interstates. In the U.S., 85 percent of speeding-related fatalities occurred on roads that were not interstate highways

3. Age and speeding - For drivers involved in fatal crashes, young males are the most likely to be speeding. The relative proportion of speeding-related crashes to all crashes decreases with increasing age. In 2000, 34 percent of the male drivers 15 to 20 years old who were involved in fatal crashes were speeding at the time of the crash.

4. Speeding and alcohol - In 2000, 23 percent of the speeding drivers under 21 years old who were involved in fatal crashes were also intoxicated, with a blood alcohol concentration (BAC) of .10 g/dL (grams per deciliter) or greater. Only 10 percent of non-speeding drivers were intoxicated. In 2000, 40 percent of intoxicated drivers were speeding. Between midnight and 3 a.m., 77 percent of speeding drivers involved in fatal crashes had been drinking.

5. Speeding and safety belts - Among drivers in fatal crashes in 2000, those who were not speeding were nearly twice as likely to be wearing safety belts as those who were speeding at the time of the crash.

6. Speeding and driver's licenses - In 2000, 20 percent of speeding drivers involved in fatal crashes had an invalid license at the time of the crash compared to 9 percent of non-speeding drivers.

7. National speed limit - When the national speed rate changed from 55 to $65 \mathrm{mph}$, fatalities increased by 21 percent. (NHTSA source)

8. Accidents worldwide - It is estimated that more than seven million people will be injured in traffic accidents worldwide this year - one third of them at intersections.

9. Pedestrian intersection crashes - In the U.S. alone, one million people will be injured crossing an intersection $-7,000$ will die.

10. Impact speed and driver death - For every 10 miles an hour increase in impact speed the chance of death doubles for the driver so that the driver who crashes at $40 \mathrm{mph}$ has twice the chance of getting killed as the driver who crashes at $30 \mathrm{mph}$. The ramifications of that speed are even more terrifying when applied to pedestrians. 
This Page Intentionally Left Blank 


\section{APPENDIX D \\ PROGRAM DATA COLLECTION FORMS}

This appendix contains copies of the materials used to collect data for the study. They were essentially the same for each city. They include the following:

- Letter accompanying the survey sponsored by the City of Peoria

- Peoria neighborhood survey form

- Peoria Heed the Speed motorist stop form

- Letter accompanying the survey sponsored by the City of Phoenix

- Phoenix neighborhood survey form

- Phoenix Heed the Speed motorist stop form 


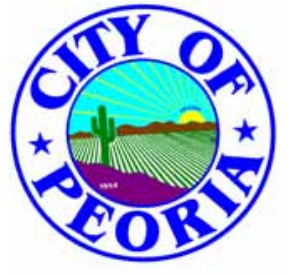

\section{ENGINEERING DEPARTMENT \\ Traffic Engineering Division \\ 8401 West Monroe Street, Peoria, Arizona 85345 \\ Phone: (623) 773-7210 \\ Fax: (623) 773-7211}

Dear Peoria Neighbor:

The City of Peoria's Traffic Engineering Division and Police Department are conducting a study on traffic safety in Peoria neighborhoods. The study is being done in collaboration with the City of Phoenix and the National Highway Traffic Safety Administration of the U.S. Department of Transportation.

The survey is designed to obtain your opinions and observations about traffic safety in your neighborhood. Since we are asking only a small number of people to complete the survey, it is extremely important that everyone respond. Please complete the form on the reverse side and return it in the postage paid envelope.

Thank you for your cooperation.

Regards,

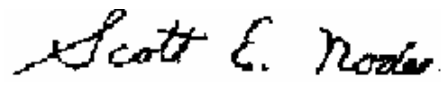

Scott E. Nodes, P.E., P.T.O.E.

City Traffic Engineer 


\section{PEORIA NEIGHBORHOOD SURVEY}

1. Are you aware of any recent activities to control speeds in your neighborhood?

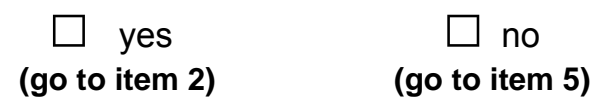

2. Did any of these activities include any publicity?

$\square$ yes

$\square$ no

don't know

If yes, what publicity?

3. Were the police involved in any of these activities?

yes

$\square$ no

$\square$ don't know

If yes, what activities?

4. Did any of these activities include any physical changes to the road or the physical environment?

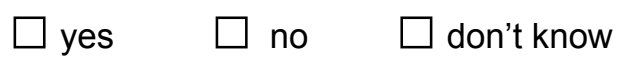

If yes, what changes?

5. Compared to 6 months ago, how would you rate the speeds in your neighborhood?
$\square$ much slower
$\square$ a bit slower
the same
$\square$ a bit faster
$\square$ much faster

6. How long have you lived in your current neighborhood?

$\square$ less than 1 year

$\square 1$ to 5 years

more than 5 years

7. What is your age? years

8. What is your gender? $\square$ male $\square$ female 
Date:

Time:

\section{PEORIA Heed the Speed MOTORIST STOP FORM}

\section{Location of Stop:}

1. Peoria neighborhood: $\square 95^{\text {th }}$ Avenue $\quad \square$ Desert Harbor $\quad \square$ Bell Park

2. Street:

\section{Driver:}

3. Proximity of driver address to neighborhood:

$\square$ in neighborhood $\square$ near neighborhood ( $\leq 1 \mathrm{mi}) \quad \square$ outside neighborhood (>1 mi)

4. Gender: $\square$ male $\square$ female

5. Date of birth (mmddyy):

6. Driver wearing seatbelt? $\square$ yes $\quad \square$ no

7. How often does driver travel on this road?
daily
weekly
monthly
never before
other:

\section{Occupants:}

8. Total number of people in vehicle (including driver):

Vehicle:

9. Vehicle type: $\square$ car $\square$ minivan $\quad \square$ sUV $\square$ pickup $\square$ other truck $\quad \square$ motorcycle other:

10. Model year:

\section{Officer's Action:}

11. What did you do? (Check all that apply) $\square$ gave ticket $\square$ gave literature 


\section{(a) \\ City of Phoenix \\ Street Transportation Department}

Dear Phoenix Resident:

The City of Phoenix Police and Street Transportation Departments are conducting a study on traffic safety in your neighborhood. The study is being done in collaboration with the National Highway Traffic Safety Administration of the U.S. Department of Transportation.

The survey is designed to obtain your opinions and observations about traffic safety in your neighborhood. Since we are asking only a small number of people to complete the survey, it is extremely important that everyone respond. Please complete the form on the reverse side and return it in the postage-paid envelope.

If you have any questions, please call Mike Cynecki at 602-262-7217.

Thank you for your cooperation.

Sincerely,

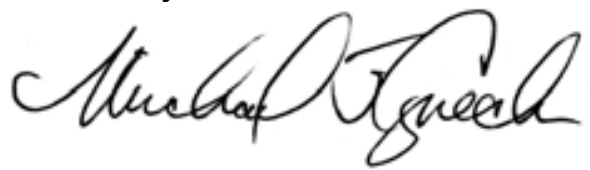

Michael J. Cynecki, P.E.

Traffic Engineering Supervisor

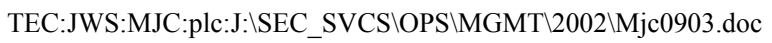




\section{PHOENIX NEIGHBORHOOD SURVEY}

1. Are you aware of any recent activities to control speeds in your neighborhood?

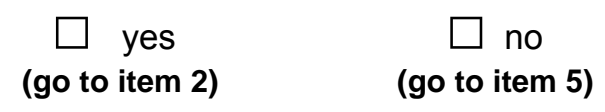

2. Did any of these activities include any publicity?

yes

$\square$ no

don't know

If yes, what publicity?

3. Were the police involved in any of these activities?

yes

$\square$ no

$\square$ don't know

If yes, what activities?

4. Did any of these activities include any physical changes to the road or the physical environment?

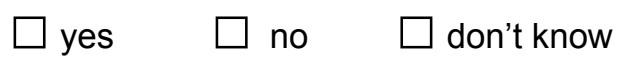

If yes, what changes?

5. Compared to 6 months ago, how would you rate the speeds in your neighborhood?

$\square$ much slower $\square$ a bit slower $\square$ the same $\square$ a bit faster $\square$ much faster

6. How long have you lived in your current neighborhood?

$\square$ less than 1 year $\quad \square 1$ to 5 years $\quad \square$ more than 5 years

7. What is your age? _ years

8. What is your gender? $\square$ male $\square$ female 
Date:

Time:

\section{PHOENIX Heed the Speed MOTORIST STOP FORM}

\section{Location of Stop:}

1. Phoenix neighborhood:

Sweetwater

Moon Valley

Clarendon

2. Street:

\section{Driver:}

3. Proximity of driver address to neighborhood:
in neighborhood
near neighborhood $(\leq 1 \mathrm{mi})$
outside neighborhood (>1 mi)

4. Gender: $\square$ male $\square$ female

5. Date of birth (mmddyy):

6. Driver wearing seatbelt? $\square$ yes $\square$ no

7. How often does driver travel on this road?
daily
weekly
$\square$ monthly
never before
other:

\section{Occupants:}

8. Total number of people in vehicle (including driver):

Vehicle:

9. Vehicle type: $\square$ car $\square$ minivan $\quad \square$ SUV $\square$ pickup $\square$ other truck $\square$ motorcycle other:

10. Model year:

\section{Officer's Action:}

11. What did you do? (Check all that apply)

gave ticket

gave literature

Return completed form to Sgt. Rich Maiocco at the Desert Horizon Precinct

1. Fold form in half

2. Tape or staple closed

3. Drop in inter-office mail 
This Page Intentionally Left Blank 


\section{APPENDIX E \\ MAPS OF PHOENIX AND PEORIA STUDY AREAS}

Phoenix

Clarendon Avenue

Sweetwater Avenue

Moon Valley/Coral Gables

Moon Valley Drive

Coral Gables Drive

North-south segment

East-west segment

Peoria

Bell Park $/ 84^{\text {th }}$ Avenue and $85^{\text {th }}$ Lane

Desert Harbor/91 ${ }^{\text {st }}$ Avenue

$95^{\text {th }}$ Avenue 


\section{CLARENDON AVE STUDY LOCATION MAP}

(I) - SPEED HUMP LOCATIONS

$\bigcap$ - count locations

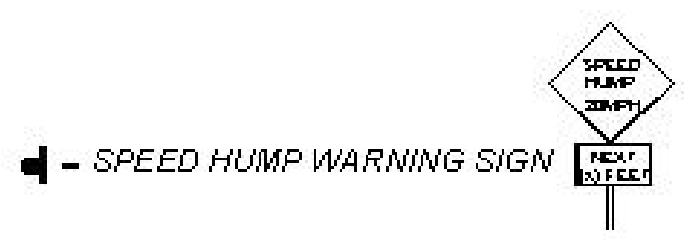

Indianola Ave

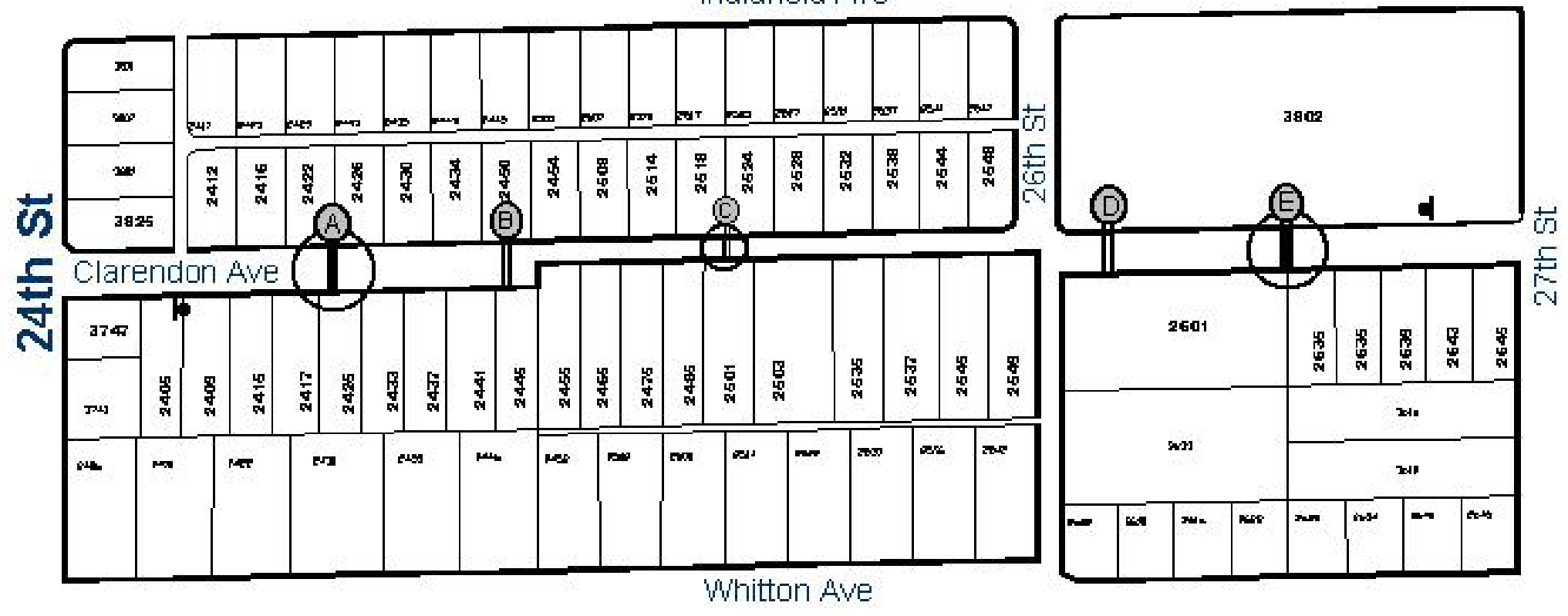




\section{SWEETWATER AVE STUDY LOCATION MAP}

$\mid$ - TYREGRIPLOCATIONS

P- COUNT LOCATIONS

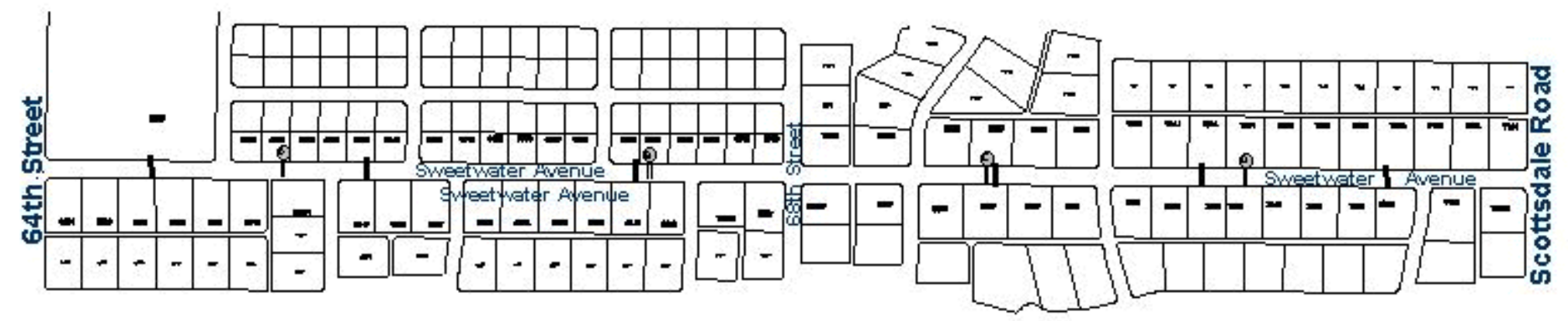




\section{MOON VALLEY DR STUDY LOCATION MAP}

(1)- SREEOHUP LOCATONS

- COUNT LOCATIONS

- - SPEED HUMP WARNING SIGN

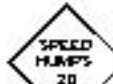

aresucic

$$
\text { COUNT LOCATIONS }
$$

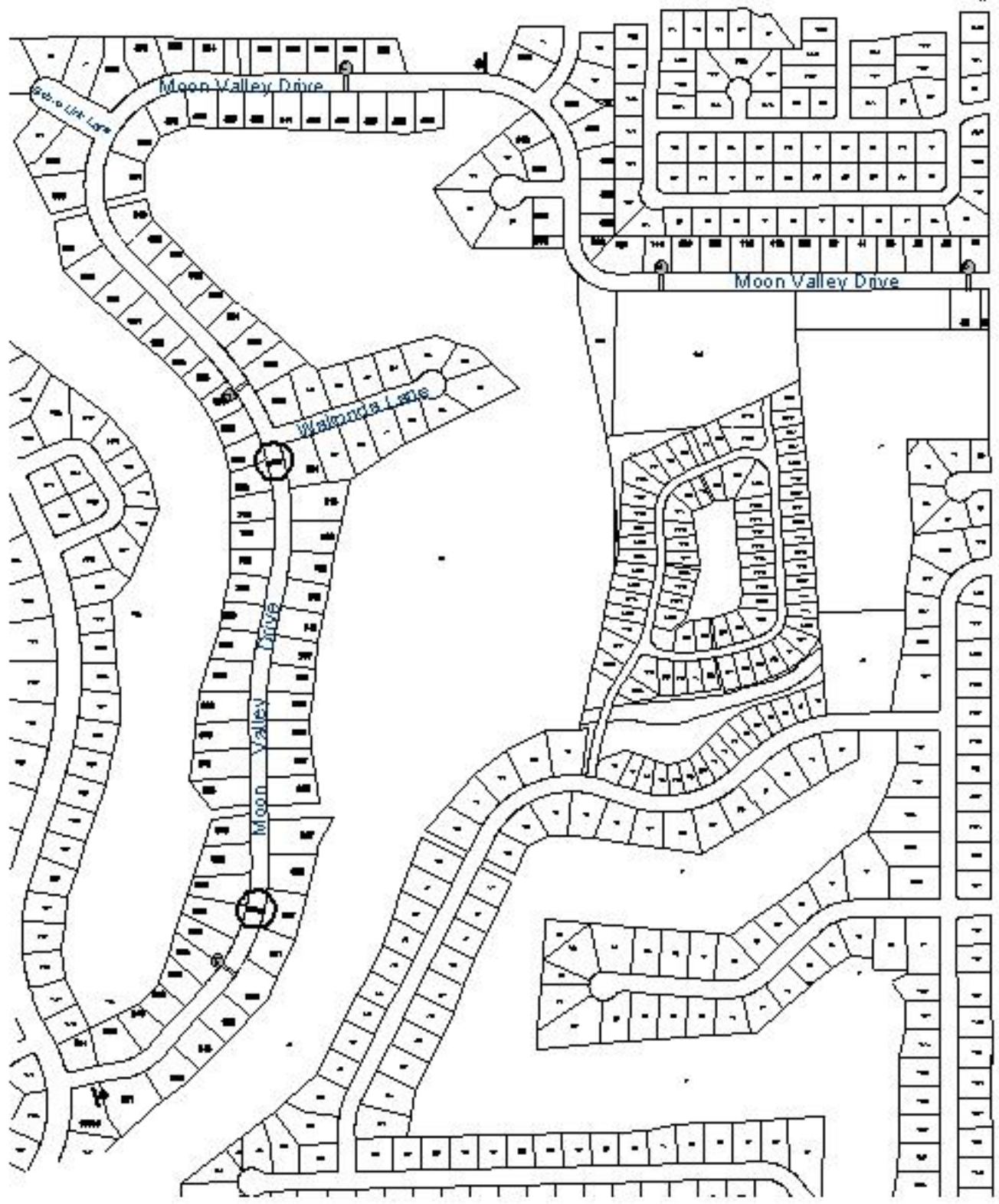

STREET TRANSPORTGTION DEPMRTMENT CITY OF PHOENIX TRAFFIC OPERATIONS DIVISION an 


\section{CORAL GABLES DR STUDY LOCATION MAP \\ I - tYregriplocations
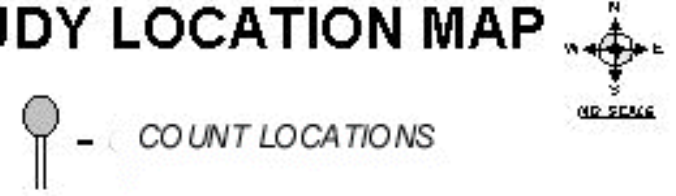

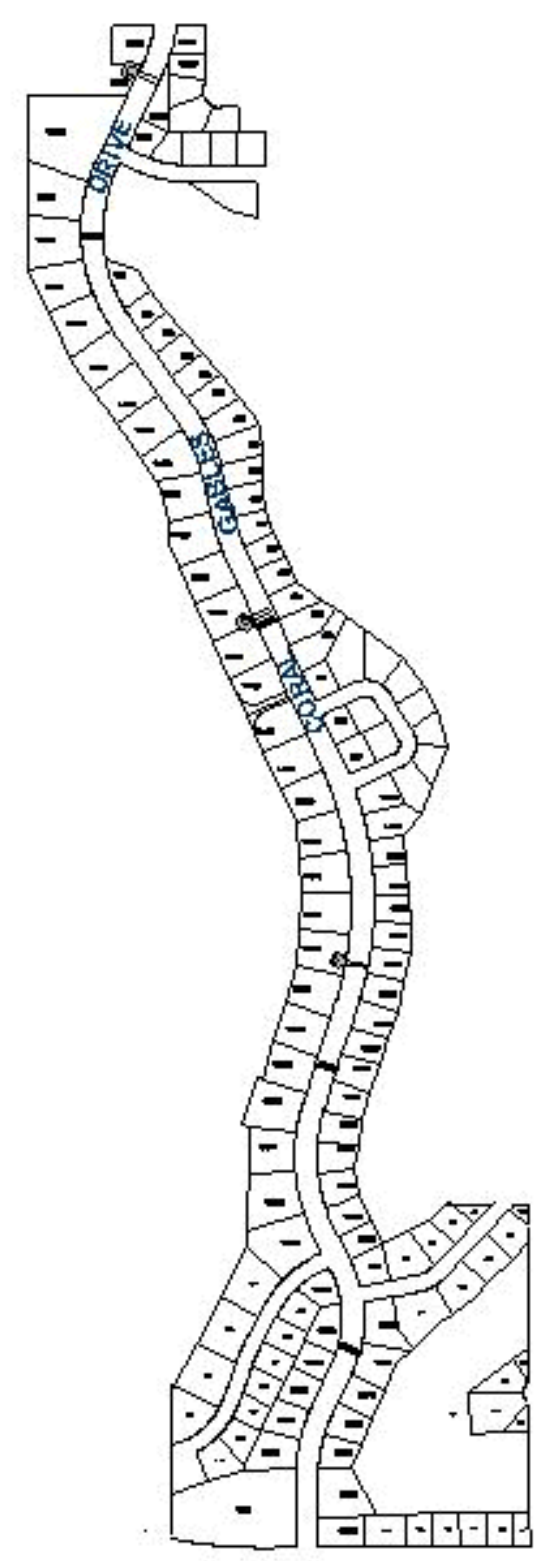

STREET TRANSPORTATION DEPARTMENT CITY OF PHOENIX TRAGFIC OPERÁTIONS DIVISION 


\section{CORAL GABLES DR STUDY LOCATION MAP}

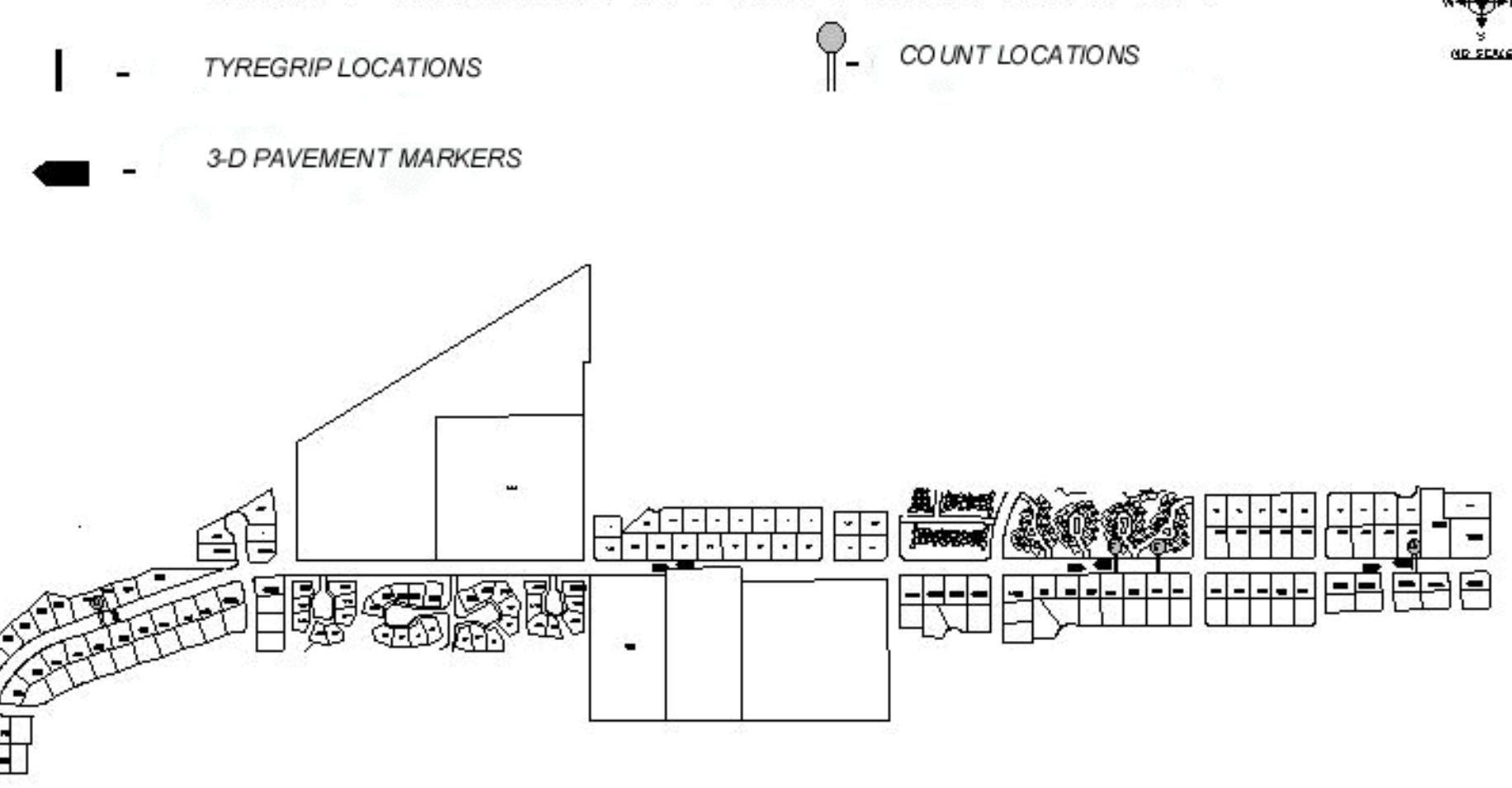




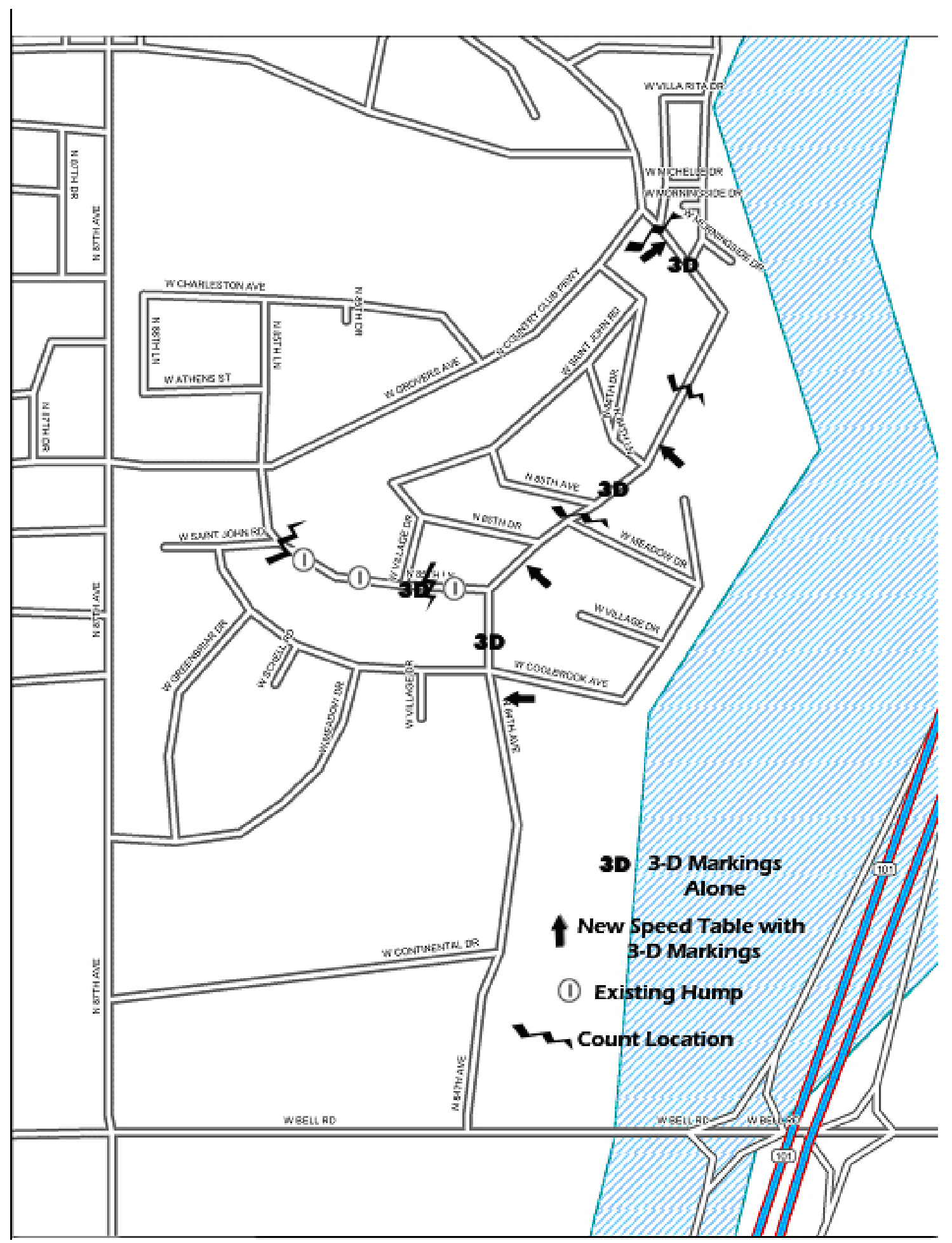

Peoria - Bell Park $/ 84^{\text {th }}$ Avenue and $85^{\text {th }}$ Lane 


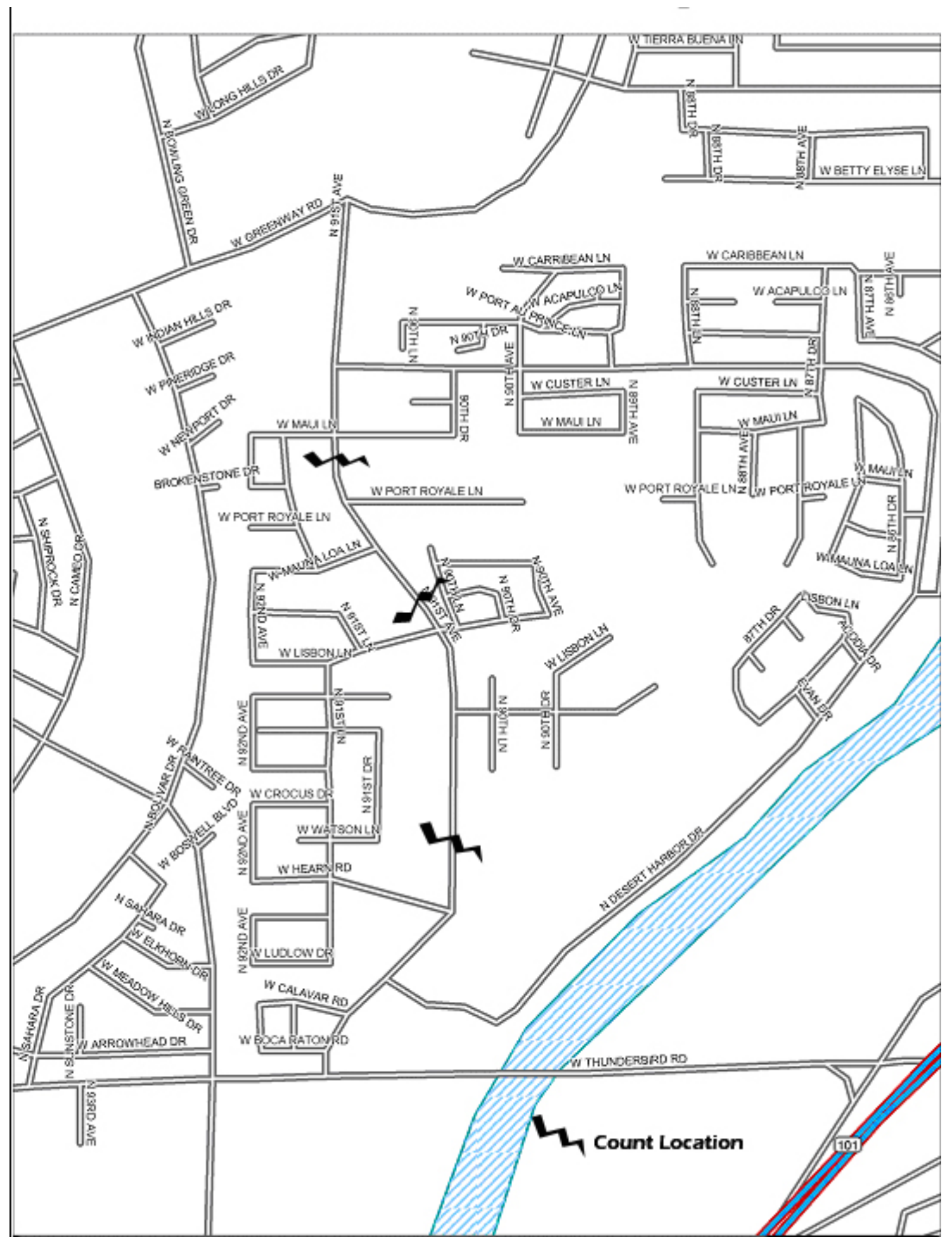

Peoria - Desert Harbor $/ 91^{\text {st }}$ Avenue 


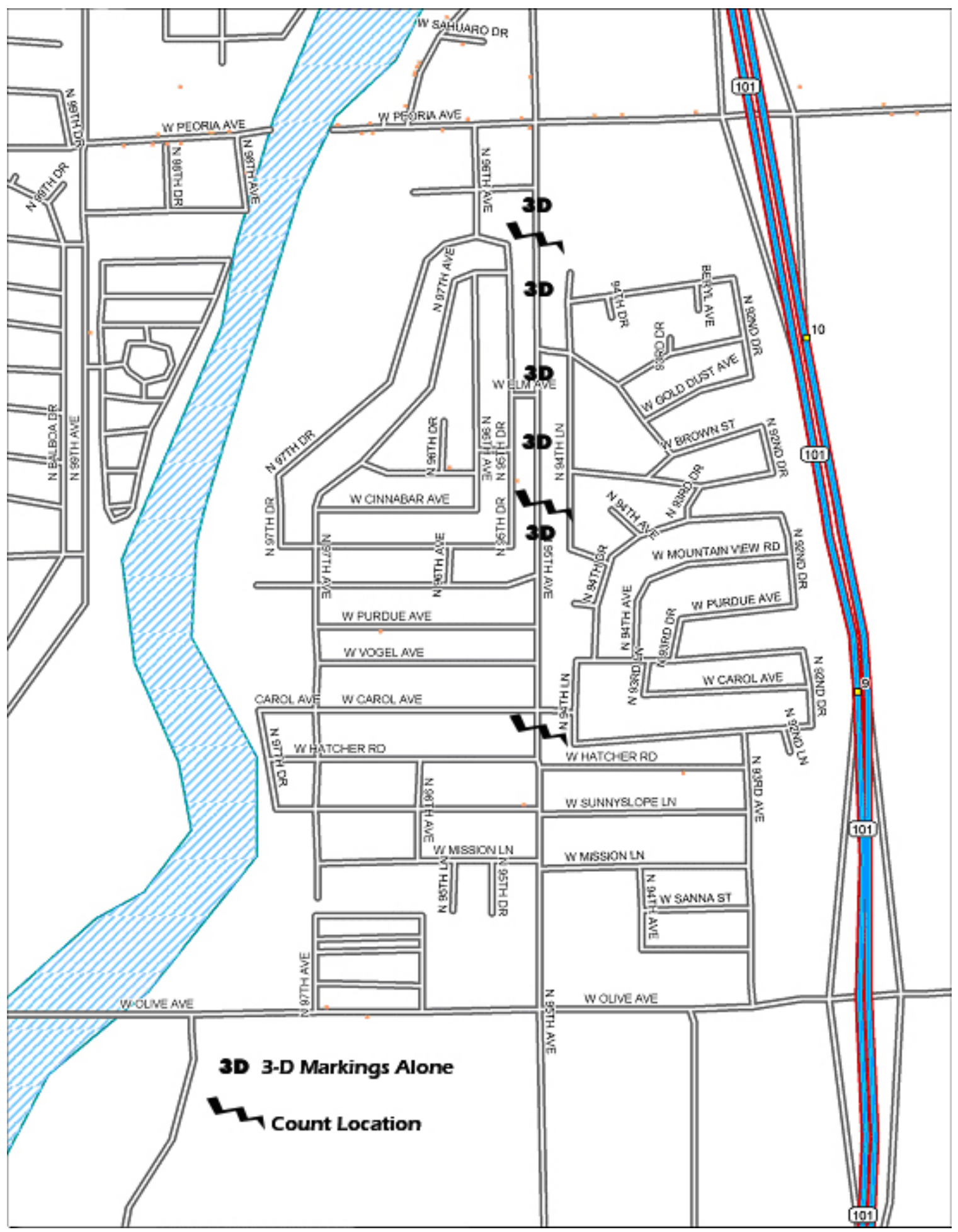

Peoria $-95^{\text {th }}$ Avenue 


\section{This Page Intentionally Left Blank}




\section{APPENDIX F \\ HEED THE SPEED GUIDE}

This Appendix contains a draft of a Guide that can be used by communities to develop their own Heed the Speed program based on the principles researched during the present study. As discussed in Section 6, for best results the information in this Guide must be tailored to the local situation. 


\section{This Page Intentionally Left Blank}




\title{
DEVELOPING A PROGRAM
}

\author{
TO
}

\author{
HEED THE SPEED
}

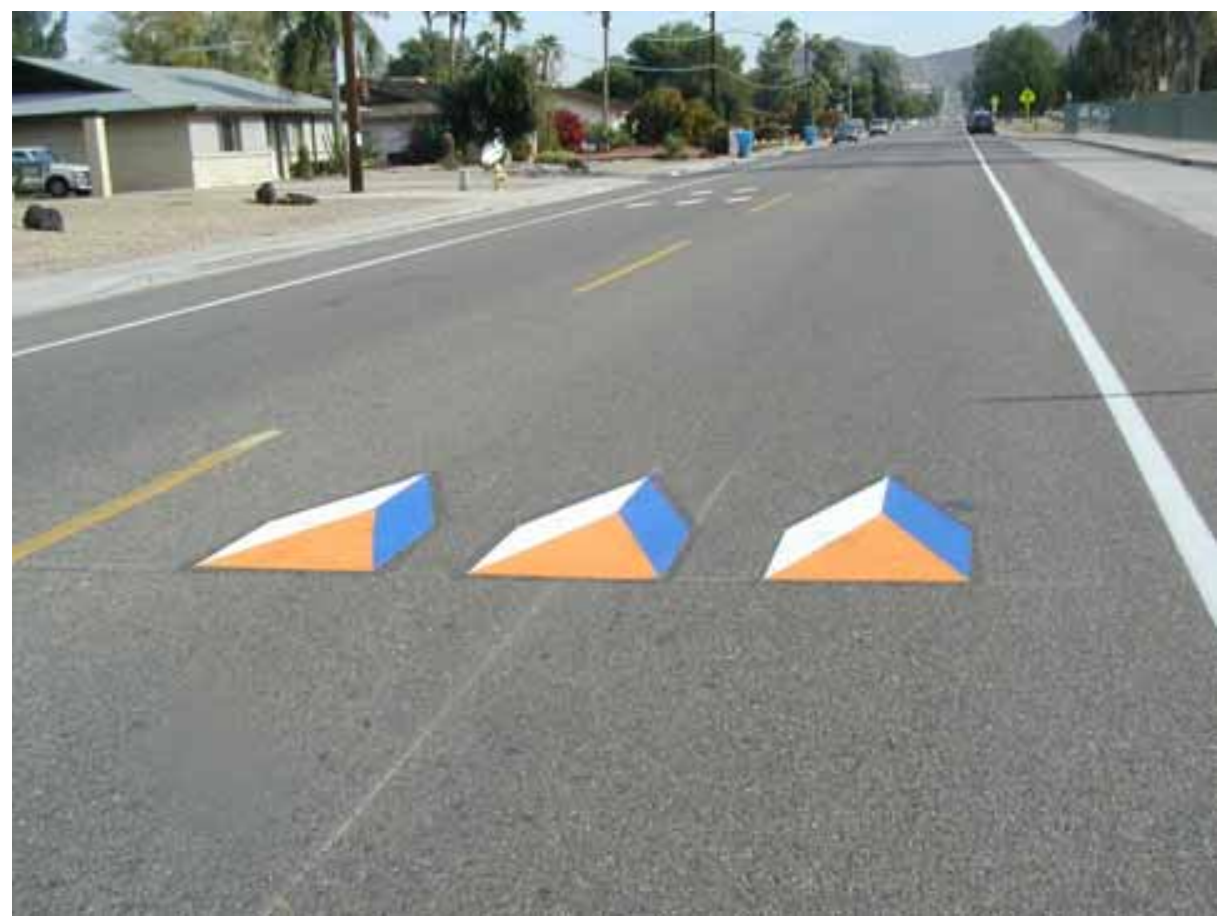

U. S. Department of Transportation

National Highway Traffic Safety Administration 
Prepared by Dunlap and Associates, Inc. under Task Order 2 of Contract DTNH22-99-D-05099 


\section{INTRODUCTION}

This Guide is designed to provide information to local communities that want to mount programs to decrease speeds in residential neighborhoods in order to reduce traffic crashes, particularly to pedestrians. The advice is based on research that successfully combined enforcement, engineering and education into action programs called Heed the Speed tailored to specific communities and road segments. The basic premise of Heed the Speed is that physical traffic calming - things such as vertical treatments (speed tables, speed humps, etc.) and roundabouts - cannot always be installed. Even when traffic calming is planned, it can take years to be implemented. By using enforcement, education and innovative approaches, Heed the Speed can improve the effects of traffic calming when it is installed and provide some of traffic calming's speed reduction benefits when circumstances prevent it from being used.

\section{The Speeding Problem}

There is much evidence to support the fact that higher speeds are associated with more severe pedestrian injuries and death. Studies have reported that 5 percent of pedestrians will die if they are struck by a vehicle traveling at 20 miles per hour; 45 percent will die if the vehicle is traveling at 30 miles per hour; 85 percent will die if the vehicle is traveling at 40 miles per hour; and almost all will die if the vehicle is traveling at 50 miles per hour.

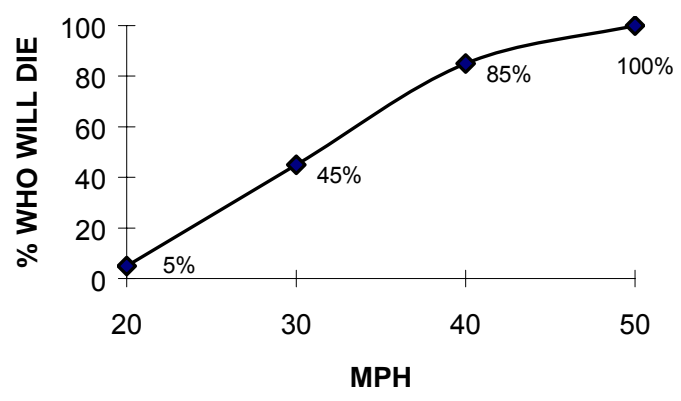

A motor vehicle needs time and space to stop. A vehicle traveling at 20 miles per hour will need 47 feet to stop. At 30 miles per hour, the distance almost doubles ( 88 feet), and at 40 miles per hour, it almost doubles again (149 feet). Thus, excess speed can be related both to an increase in crash likelihood and to a greatly elevated injury severity when a crash does occur.

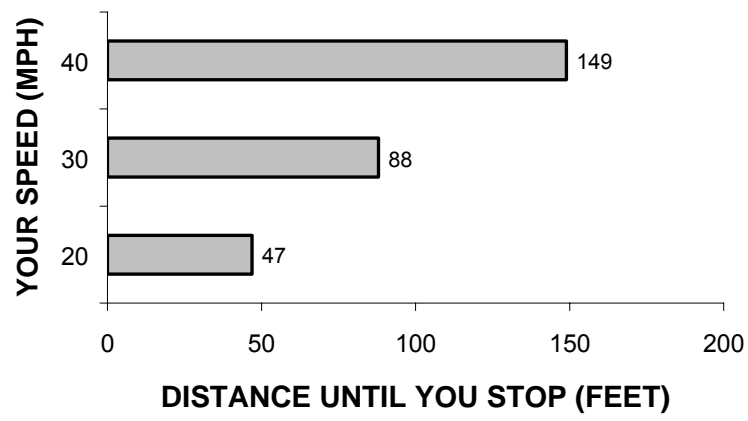

The problems of speeding have been of concern to community residents as well as to government officials at all levels for many years. These concerns have resulted in the implementation of a variety of measures to reduce speeds. Past programs have typically focused on one of the primary ways to change speeding behavior - engineering (traffic calming), enforcement or education. Few programs combined all three "E's" to try for maximum impact. 
This guide describes how a community can use a multi-pronged approach to reduce motorist speeds in residential areas by adding education and enforcement to engineering in a Heed the Speed program. It contains the following steps:

- Cataloging local resources/recruiting support

- Establishing a working committee

- Reviewing the local problem

- Selecting study neighborhoods

- Designing the program

- Implementing the program

- Assessing program success

Examples are taken from the experience of the Heed the Speed implementations in Phoenix and Peoria, Arizona that were part of a NHTSA-funded research program.

\section{Cataloging Local Resources}

Many local safety programs begin with a lead group or agency that responds to an explicit or implicit need in the community. Others are catalyzed by a directive from a governmental body or city executive in response to citizen complaints or a tragic crash. Regardless of the underlying motivation for beginning an effort such as Heed the Speed, there will probably be an originating group or individual with the responsibility of putting together a program. It is important for that individual or group to begin the entire process with a catalog of local resources. While the ideal is for every relevant discipline to join willingly in Heed the Speed efforts, the reality is that local conditions will vary widely. As long as some involved group - enforcement, engineering, safety education, or active citizens - is eager to proceed, a successful Heed the Speed program is possible. Soliciting the help of all of the other participants, however, is clearly desirable, adds to the chances of program success and should be attempted. Once all of the players are identified and fully committed, the remaining steps in this Guide can be viewed in the proper context and adapted appropriately.

\section{Establishing a Working Group}

From the outset, a group, committee, or task force is needed to plan and manage a local Heed the Speed program. Tasks for this group include conducting an assessment of the speeding problem, identifying the specific neighborhood or neighborhoods that will participate in the program, planning the program to be conducted in each neighborhood, overseeing program activities to ensure that they are proceeding as planned, and collecting and analyzing any data needed to assess program success.

At a minimum the committee should try to have representation from the following groups:

- Traffic engineering - to select and oversee the installation of appropriate roadway treatments, signs, signals, and markings 
- Police - to select and oversee the implementation of enforcement and related education activities above and beyond routine patrols

- Public information - to design and arrange for production and distribution of program education materials and local media publicity

- Local safety groups - to provide volunteer support

It is recognized, however, that it may not be possible to recruit actively involved members from each of these disciplines. When that happens, the working group must realistically acknowledge its own strengths and weaknesses and plan a Heed the Speed program accordingly.

Once the neighborhoods that will participate in the program have been identified, a representative from each neighborhood may be added to the committee. These individuals can assist in identifying specific problems that are encountered at the neighborhood level, in evaluating the acceptability of specific countermeasures to the neighborhood, in identifying neighborhood individuals or groups that need to be addressed, and in pulling together neighborhood resources that can be used to enhance the program. Having locals on board can help to ensure that the program runs smoothly at the neighborhood level. It also can spark a useful dialogue across neighborhoods to generate new ideas.

One committee member needs to be selected as the lead for the program. That person will assure that meetings of the committee are held on a regular basis throughout the program's tenure, that agendas are prepared for each meeting and that minutes of each meeting are prepared and distributed to coalition members. Meetings that are scheduled on a routine basis (such as once a month) can serve to keep all committee members apprised of program activities and progress and give them an opportunity to solve problems as they occur.

The choice of the frequency of meetings is important to the success of a Heed the Speed effort. If they are too close together, the time demands may become too great and participation will drop off. If they are too far apart the committee may not be able to react quickly enough to changes, and Heed the Speed can lose importance. A monthly timetable has worked well in some sites, but each committee should define a schedule based on the needs of its own members.

\section{Reviewing the Local Problem}

A Heed the Speed program should start with an assessment of the local speeding problem in order to identify neighborhoods to include. Although Heed the Speed programs are typically started at the city or county level, the focus is on speed reduction in individual neighborhoods that have a problem. Identifying neighborhoods is done with information generally available to local police and traffic engineering personnel. Citizen complaints about speeders, citizen requests for traffic calming, records of citations issued, crashes involving speeding and general police department/traffic engineering knowledge of the speeding problem in various areas of the community are all relevant. Actual speed data may be available for some neighborhoods from routine traffic counts. If necessary, special traffic counts/speed measurements can be taken. The result of this effort will be the development of a candidate set of neighborhoods that could benefit from a speed reduction effort. 


\section{Selecting Study Neighborhoods}

One or more neighborhoods can be selected for Heed the Speed implementations depending on the resources that are available for the program and the degree of local interest. The primary aim, of course, will be to have as large an impact as possible on the community speed problem. In most locales, there will be no shortage of neighborhoods desiring a reduction in vehicle speeds to improve safety and the quality of life, but there may be insufficient resources to give Heed the Speed to every neighborhood that wants it.

The first effort will be to develop a rank order for the neighborhoods that have been identified as candidate sites. The primary criteria will be twofold:

- The strength of the expressed desire on the part of neighborhood residents to participate in a speed reduction program as evidenced by their prior requests for traffic calming devices or requests of support from the police in dealing with speeders. Grass roots involvement in the affected neighborhoods, although not absolutely essential to a successful Heed the Speed program, is highly beneficial. It provides the eyes, ears, hands, and legs for the program on a day-to-day basis. Committed and involved local residents can help adapt and distribute educational materials and provide feedback on program progress.

- There is an actual speeding problem based on speed measurements or on police reports if no measured speed data are available. Sometimes people will perceive a speeding problem when it does not, in fact, exist. A Heed the Speed program can't afford to allocate resources to areas where speeding is not really a problem.

It is also important to identify any constraints or opportunities that might affect neighborhood selection. These might include:

- Is this a one-time effort where one or more neighborhoods will be selected for the program? Or, is the selection the first of a program that will continue indefinitely with other neighborhoods added or substituted from time to time?

- What is the program time frame? Will a neighborhood selection be restricted by a limited time frame and will it be reasonable

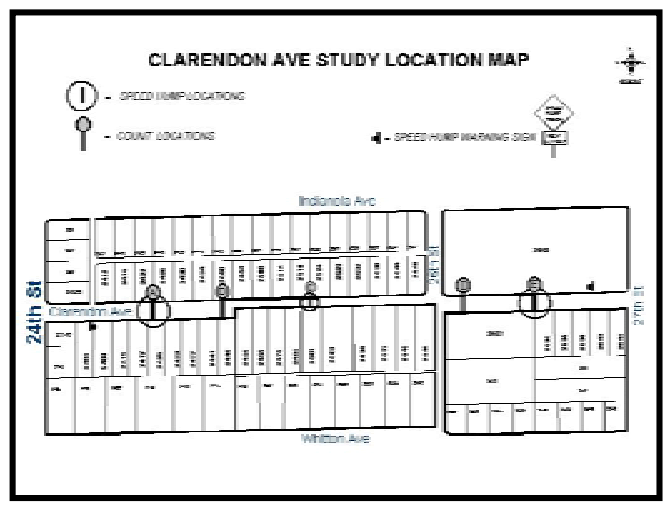
to apply all proposed countermeasures in that time period? For example, is there time to ensure that any planned roadway treatments or proposed legislation will be in place at the start of the program or shortly after program start?

- What types of streets are in the area - neighborhood, collector, arterial? What roadway treatments, if any, could be used for each?

- What is the size of the area? Can it all be accommodated in the speed reduction program? 
- What efforts are already planned for or actually in place in the area? For example, is traffic calming planned? Are new sidewalks going in? Are periodic traffic counts scheduled?

- What resources are located in or near the area that can affect traffic positively or negatively (e.g., schools, churches, businesses)? Will the program need special countermeasures addressed to these groups? For example, in one Heed the Speed city nearby car dealerships used adjacent neighborhoods for test drives and were therefore the subject of a special education piece requesting them to minimize such drives and to drive more slowly.

- Are there organized groups in or near the neighborhoods that can serve as resources for the distribution of program materials? For example, schools can act as distribution points for flyers directed to parents.

- Is there an established homeowner's association? If not, can one or more residents of the area be identified to serve as contact points for the community? If there is no homeowner's association and no contact can be identified, special attention must be paid to ensuring that the neighborhood residents receive program materials. Distribution by means of door hangers can be used as well as distributions by mail.

- Are there specific racial or ethnic groups in the community that need to be addressed? For example, are there large numbers of Hispanics that will need Spanish translations of education materials?

The final selection of neighborhoods must be based on the resources that the community and the neighborhood together can apply and the practicality of combining those resources into a coherent and ongoing Heed the Speed effort.

\section{Designing the Program}

A Heed the Speed program should try to include the three E's - education, enforcement, and engineering. It can also include changes in legislation if needed, but these changes can take time.

Education: Education as part of Heed the Speed should be focused on materials and activities to inform the public about the dangers of speeding, the existence of a problem, the increased risk of getting a ticket and the need to slow down. Examples of Heed the Speed education materials that have been used successfully include:

- Program logo

- Street traffic signs displaying the slogan and logo

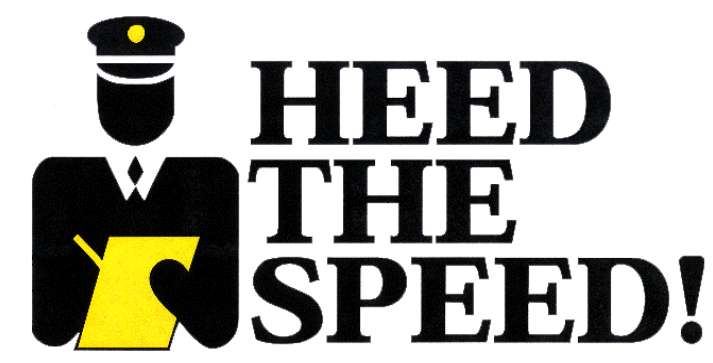


- Lawn signs displaying the slogan and logo printed on bright yellow weatherproof material

- Homeowner's association meetings in which presentations were made by traffic engineering and police personnel to discuss the problem and the program

- Flyers for residents, parents, and high school drivers - reproduced in both English and Spanish

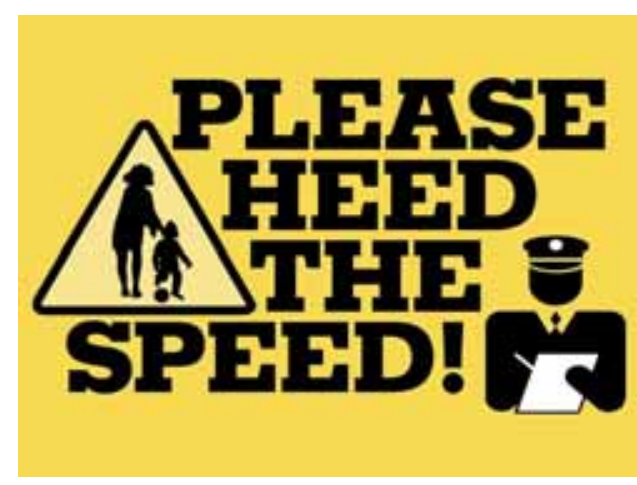

- Flyers for drivers with a traffic ticket facsimile on the reverse side

- A slim version of the above flyer minus the traffic ticket

- Flyers for car dealerships which encouraged them not to do test drives on neighborhood streets and to drive responsibly

- Press release announcing the program

- Live copy radio spots.

One strategy that has worked well is to distribute sample items done with desktop publishing on a CD-ROM. These can then be adapted as necessary for individual neighborhoods by the local participants. Heed the Speed education materials don't necessarily have to be "slick." They do have to be accurate and relevant to the local problem. They also have to be in a form that can be easily distributed. By providing examples that can be tailored or localized, factual information is provided, and local participants can apply their unique knowledge to making sure the information is relevant and receives widespread distribution.

Additional education items that have been successful include articles for insertion in neighborhood newsletters, outlines for television interviews, news releases to local newspapers, and radio spots.

Enforcement: Nothing gets the attention of speed violators better than enforcement. Police involvement does not, however, have to be limited to writing tickets. Presentations to homeowner's organizations and other local groups, training of local residents to conduct speed watches and deployment of speed trailers and other speed-related equipment are also potentially effective enforcement efforts. It is not surprising, however that the police effort noticed most and appreciated most by residents in Heed the Speed neighborhoods was added enforcement - both ticketing and warning stops.

Engineering: Engineering can make physical changes to the roadway to reduce speeds. These traditionally encompass virtually any traffic

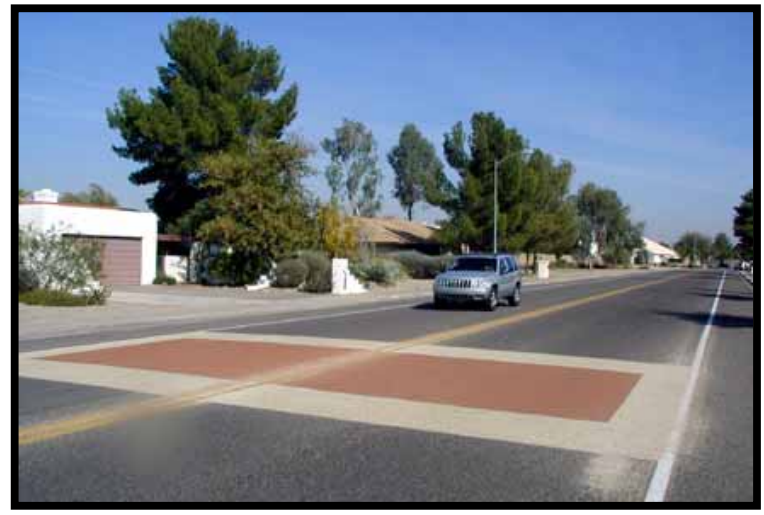


calming technique used in the community, such as vertical treatments (speed humps and speed tables) and traffic circles, as well as new or changed traffic signs, signals and marking. Some innovative roadway markings have also been tried as part of Heed the Speed. A material that simulates speed tables and one that provides the appearance of a three-dimensional object in the roadway were tested in several neighborhoods. These pavement applications produced an immediate and quite significant reduction in speeds that seemed to remain for some time. It is not known what will happen over a long period of time when drivers become accustomed to them. It is hoped that they will continue to serve as a reminder of the Heed the Speed program because of their compelling appearance.

Legislation: Changes to existing laws and ordinances or the enactment of new ones can help to solve the speeding problem. For example, posted speeds can be reduced or fines can be doubled for speeding in selected high-speed areas. As with roadway alterations, legislative changes take time to effect and need to be planned long before program start. The debate over a legislative change or the fact that a new law has been passed can serve as a motivation to start a Heed the Speed activity and also provide good publicity.

\section{Implementing the Program}

Once activities and materials planned for the program are defined, the next step is to plan a program timeline. This will define when each activity must start and orders for materials must be placed. For example, changes to the roadway should preferably be in place when the program starts or at least in place within the first month of program activity. If they will not be available early, it may be better to delay the start of the program than to proceed without them if they are an integral part of the effort. The same holds true for any legislative changes that are included in the Heed the Speed program.

Issuing a news release announcing the program is often a good idea. In addition, it can help to have the mayor or other city official announce the start of the program with a press conference. This is an easy and often effective way to generate media coverage.

In addition to roadway treatments and legislative enactments, education materials and schedules for their release need to be available at program start. Schedules should also be available for all planned police activities.

It is advisable to have education and enforcement activities conducted throughout the life of the program. For education, this means creating a variety of materials/activities that can be distributed/conducted at different times throughout the program. Police activities should also be initiated at program start and continue throughout the life of the program. In addition, the public information member of the working committee should arrange for as much media attention throughout the program as possible.

Heed the Speed does not have to be a "one shot deal." Research has shown that bad behavior such as speeding tends to return after programs such as Heed the Speed end. Reality, however, dictates that intense, focused efforts cannot be sustained forever. There simply are not enough resources in most communities. The best plan provides for an intensive Heed the Speed effort at the start that lasts as long as possible followed by as much continuing activity as 
possible. Periodic enforcement visits and renewed educational distributions can revive or sustain a Heed the Speed program so that its results are not totally dissipated.

\section{Assessing Program Success}

Knowledge of results is an important and often overlooked step in taking action. It has two major benefits - providing feedback for program improvement and satisfying sponsors that their support produced results. There are two levels of evaluation that are of importance program outcome and process.

Program outcome evaluation determines how the program changed speeds. This requires, as a minimum, a measurement of speeds before program start and after program completion. It's even better to take periodic measures as things go along. This will provide a more detailed look at how activities are influencing motorist behavior. Speed measurements can be made in several ways. For maximum precision, traffic counters can be placed on streets to record counts and speeds of all vehicles as they pass. If a simpler approach is needed, citizens can volunteer to use police-provided radar equipment or even stop watches to measure speeds of a sample of cars at selected locations and times in their neighborhoods. If no measurement of actual speeds is possible, neighborhood residents can be asked to give their opinions on whether or not speeds have been reduced, but this requires some type of survey data collection.

Process evaluation assesses how the program did its work. It generally examines actual achievements compared to plans for activities such as media distribution or police patrol hours. In addition to comparing actual versus planned expenditures of resources, a process evaluation can include a survey or focus groups directed at determining perceptions of effectiveness and recall of Heed the Speed activities. Both members of the working committee and local citizens can participate in this evaluation by answering such questions as the following:

- For each planned countermeasure, did it work? If yes, what made it work? If no, why didn't it work? Would you use the countermeasure again? How would you change it?

- Were there sufficient countermeasures available? Were they available on time? What others should have been included?

- How were publicity materials distributed? Did they reach their intended audience?

- Were the neighborhoods selected for the program appropriate for the countermeasures that were implemented? Was there something attributable to the neighborhood that ensured or prevented successful completion of the program?

- If you were to start over again, what changes would you make in the program?

Phoenix and Peoria used both outcome and process measures to evaluate their programs. Analysis of traffic counter measurements made before, during and after the program showed that speeds were reduced and provided insight on the relative effectiveness of different remedial approaches. A neighborhood survey provided information on whether or not residents felt that speeds had gone down and the extent to which they had been exposed to Heed the Speed 
activities. In addition, focus groups were conducted with both the working committee and with representatives from the neighborhoods to obtain opinions on the program schedule and countermeasures.

\section{For More Information Contact:}

Office of Behavioral Safety Research, NTI-130

National Highway Traffic Safety Administration

400 Seventh Street SW.

Washington, DC 20590 
DOT HS 810648

August 2006

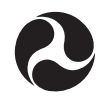

U.S. Department of Transportation

National Highway

Traffic Safety

Administration

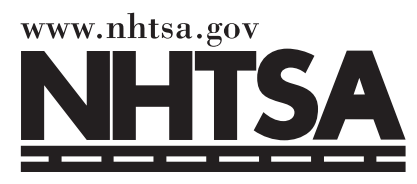

